\title{
MORPHOLOGICAL, FUNCTIONAL AND IMMUNOMODULATORY EFFECTS OF ROSUVASTATIN AND ASPIRIN IN CULTURED MICROGLIAL CELLS
}

\author{
Diána Kata \\ Theoretical Medicine Doctoral School \\ Department of Cell Biology and Molecular Medicine \\ Faculty of Medicine and Faculty of Science and Informatics \\ University of Szeged
}

Ph.D. Thesis

Szeged, 2017 
PUBLICATIONS RELATED TO THE THESIS:

I. Kata D, Földesi I, Feher LZ, Hackler L Jr, Puskas LG, Gulya K (2016) Rosuvastatin enhances anti-inflammatory and inhibits pro-inflammatory functions in cultured microglial cells. Neuroscience $314: 47-63$. (IF: 3.231)

II. Kata D, Földesi I, Feher LZ, Hackler L Jr, Puskas LG, Gulya K (2017) A novel pleiotropic effect of aspirin: beneficial regulation of pro-and anti-inflammatory mechanisms in microglial cells. Brain Research Bulletin Accepted for publication, DOI: 10.1016/j.brainresbull.2017.05.009 (IF:2.572)

\section{POSTERS RELATED TO THE THESIS:}

I. Kata D, Gulya K (2014) Aspirin regulates the inflammatory responses of activated microglia. $9^{\text {th }}$ FENS Forum of Neuroscience, Milan, Italy, FENS0477; C112

II. Kata D, Földesi I, Feher LZ, Hackler L Jr, Puskas LG, Gulya K (2015) A rosuvastatin gyulladásgátló hatása bakteriális lipopoliszacharid által aktivált tiszta mikroglia kultúrában. MÉT 79. Vándorgyülése és a MMVBT 2015. évi konferenciája, Szeged, Magyarország, P2.7 


\section{TABLE OF CONTENTS}

Abbreviations 3

SUMMARY 4

1. INTRODUCTION 6

1.1. Roles of microglial cells in the central nervous system $\quad 6$

1.2. Mechanisms and effects of statins $\quad 8$

1.3. Mechanisms and effects of aspirin 11

2. SPECIFIC AIMS $\quad 13$

3. MATERIALS AND METHODS 14

3.1. Animals 14

3.2. Antibodies 14

3.3. Preparation and maintenance of cell cultures 14

3.4. Cell culture treatments 15

3.5. Immunocytochemistry 16

3.6. Western blot analysis 16

3.7. Quantitative determination of in vitro phagocytosis 17

3.8. Quantitative determination of IL-1 $\beta$, IL-10 and TNF- $\alpha \quad 18$

3.9. Determination of cell adhesion and proliferation 18

3.10. RNA isolation 18

3.11. RNA expression 19

3.12. Digital processing and image analysis 20

3.13. Statistical analysis $\quad 21$

4. RESULTS 22

4.1. Morphological effects of rosuvastatin and aspirin treatments 22

4.2. Rosuvastatin inhibits proliferation and cell adhesion 29

4.3. Rosuvastatin and aspirin reduce the phagocytic activity in activated 30 microglia

4.4. Both rosuvastatin and aspirin decrease pro-inflammatory and increase anti- 33 inflammatory cytokine levels

4.5. The effects of rosuvastatin and aspirin on the expression of inflammation- 36 related genes

5. DISCUSSION 47

6. CONCLUSION

7. ACKNOWLEDGMENTS

8. REFERENCES 56

9. APPENDIX $\quad 69$ 


\section{Abbreviations}

AA: arachidonic acid; A $\beta$ : amyloid beta; AD: Alzheimer's disease; APP: amyloid precursor protein; BBB: blood-brain barrier; BDNF: brain derived neurotrophic factor; $\mathrm{Cd}$ : cluster of differentiation; Cdc42: cell division control protein 42 homolog; CNS: central nervous system COX: cyclooxygenase (prostaglandin-endoperoxide synthase; EC 1.14.99.1); DIV: days in vitro; DMEM: Dulbecco's Modified Eagle's Medium; E18: embryonic day 18; ELISA: enzyme-linked immunosorbent assay; ERK: extracellular signal-regulated kinase; FBS: fetal bovine serum; FPP: farnesyl-pyrophosphate; GAPDH: glyceraldehyde 3-phosphate dehydrogenase (EC 1.2.1.12); GGPP: geranylgeranylpyrophosphate; HDL: high density lipoprotein; HMG-CoA: 3-hydroxy-3-methyl glutaryl coenzyme A; Iba1: ionized calcium-binding adaptor molecule 1; IL: interleukin; IкB: inhibitor of kappa B; LDL: low-density lipoprotein ; LPS: bacterial lipopolysaccharide; MAPK: mitogen activated protein kinase; MHC: major histocompatibility complex; MIP: macrophage inflammatory protein; MS: multiple sclerosis; NF- $\kappa \mathrm{B}$ : nuclear transcription factor kappa B; NO: nitrogen oxide; NOS: nitrogen oxide synthase (EC 1.14.13.39); NSAID: non-steroidal anti-inflammatory drug; OATP: organic anion transporting polypeptide; PCR: polymerase chain reaction; PD: Parkinson's disease; PG: prostaglandin; PBS: phosphate-buffered saline; RT: room temperature; RhoA: Ras homolog family member A; ROS: reactive oxygen species; S.D.: standard deviation; SDS: sodium dodecyl sulfate; subDIV: subcloned days in vitro; TBS: Tris-buffered saline; TI: transformation index; TLR: toll-like receptor; TNF- $\alpha$ : tumor necrosis factor $\alpha$. 


\section{SUMMARY}

Microglia is the principal immune cell in the central nervous system. Under pathophysiological conditions (injury, infection or neurodegeneration) microglia become activated and proliferate, phagocytose and release pro- and anti-inflammatory cytokines, growth factors or reactive species; this leads to profound morphological, functional and gene expression changes that affect the inflammatory mechanism of these cells. Statins are commonly used in the treatment of high blood cholesterol level. Although statins also have beneficial effects on inflammation, they have not been thorougly investigated for their ability to affect microglial function. Rosuvastatin inhibits cholesterol biosynthesis most efficiently, and it is one of the most commonly prescribed drugs in cardiovascular therapy. Aspirin, one of the most widely used non-steroidal anti-inflammatory drugs, also has extensively studied effects on the cardiovascular system.

To reveal further pleiotropic, beneficial effects of rosuvastatin and aspirin on a number of pro- and anti-inflammatory microglial mechanisms, we performed morphometric and functional studies relating to cell adhesion and proliferation, phagocytosis, pro- and anti-inflammatory cytokine production (IL-1 $\beta$, tumor necrosis factor- $\alpha$ (TNF- $\alpha$ ) and IL-10, respectively), and analyzed the expression of a number of inflammation-related genes, including those related to the above functions, in pure microglial cells. We examined the effects of rosuvastatin $(1 \mu \mathrm{M})$ and aspirin $(0.1 \mathrm{mM}$ and $1 \mathrm{mM}$ ) in unchallenged (control) and bacterial lipopolysaccharide (LPS)-challenged secondary pure microglial cultures.

We found that microglia could be an important therapeutic target of rosuvastatin. In unchallenged (control) microglia, rosuvastatin inhibited proliferation and cell adhesion, but promoted microspike formation and elevated the expression of certain antiinflammatory genes ( $\mathrm{Cxcl1}, \mathrm{Ccl} 5, \mathrm{Mbl2})$, while phagocytosis or pro- and antiinflammatory cytokine production were unaffected. Moreover, rosuvastatin markedly inhibited microglial activation in LPS-challenged cells by affecting both their morphology and functions as it inhibited LPS-elicited phagocytosis and inhibited proinflammatory cytokine (IL-1 $\beta, \mathrm{TNF}-\alpha$ ) production, concomitantly increasing the level of IL-10, an anti-inflammatory cytokine. Finally, rosuvastatin beneficially and differentially affected the expression of a number of inflammation-related genes in LPS-challenged cells by inhibiting numerous pro-inflammatory and stimulating several anti-inflammatory genes. In an overall similar fashion, aspirin affected microglial morphology and functions 
in a dose-dependent manner as it inhibited LPS-elicited microglial activation by promoting ramification and the inhibition of phagocytosis in both concentrations. Aspirin strongly reduced the pro-inflammatory IL- $1 \beta$ and TNF- $\alpha$ production, while it increased the anti-inflammatory IL-10 level in LPS-challenged cells. Moreover, aspirin differentially regulated the expression of a number of inflammation-related genes as it downregulated such pro-inflammatory genes as Nos2, Kng1, IL-1, Ptgs 2 or Ccr1, while it upregulated some anti-inflammatory genes such as $I L-10, C s f 2, C x c l 1, C c l 5$ or Tgfbl.

Since microglial cells could elicit pro-inflammatory responses leading to neurodegeneration, it is important to attenuate such mechanisms and promote antiinflammatory properties, and develop prophylactic therapies. Thus, based on our studies, the use of rosuvastatin and aspirin could be beneficial in the medication of certain neurodegenerative disorders. 


\section{INTRODUCTION}

\subsection{Roles of microglial cells in the central nervous system}

Microglial cells are the resident immune cells in the central nervous system (CNS) and contribute to $10-12 \%$ of its total cell population. They are from the monocyte/macrophage lineage and belong to the group of mononuclear phagocytes (Ginhoux et al., 2010; Prinz and Priller, 2014). Microglial cells are the most remarkable sensors that contribute to the homeostatis of the CNS (Franco and Fernandez-Suarez, 2015). They play important roles in both physiological and pathophysiologycal conditions such as traumatic injury, stroke, ischemia or neurodegenerative diseases (Kreutzberg, 1996). Microglial cells enter the brain during the early embryonic development. From the middle of the first trimester to the early part of the second trimester blood monocytes invade the CNS and give rise to the microglia population (Kettenmann et al., 2011). In the healthy intact brain microglial cells exist in a stable population. After damage to the blood brain barrier (BBB) blood monocytes are able to enter the brain and transform into microglial cells.

Microglial cells are well known for their functions related to morphological features. In the healty brain micoglial cells have a ramified morphology. These cells have small soma with branching cellular processes. This appearance is associated with the "resting" state (Block and Hong, 2005; Kettenmann et al, 2011). Upon challenges such as infection, ischemia, trauma, neurodegenerative diseases or altered brain homeostasis microglia transforms from resting to activated state. The activation leads to rapid and profound changes in microglial morphology, functions and gene expression. During the activation microglia reduce their cellular complexity by retracting their processes and turn into an amoeboid phenotype (Block and Hong, 2005; Kettenmann et al., 2011). In connection with the morphological features of these cells in vivo, it must be noted that microglial cells in vitro generally do not show this typical ramified morphology. Under in vivo conditions, they usually have heterogeneous shapes such as bushy, rod-shaped or bi and tripolar spindle-shaped forms with short, thick processes and lamellopodias (Kettenmann et al., 2011). The morphological changes and reorganization by the activation can still be imposed and remain noticeable in vitro.

Activated microglial cells are also capable of releasing different types of soluble factors with inflammatory and immunoregulatory effects. They are able to release chemoattractive factors which can guide immune cells to the CNS. Further, surface molecules for cell-cell and cell-matrix interactions such as complement receptors and 
major histocompatibility complex (MHC) molecules are also upregulated. Activated microglial cells also have increased proliferative and phagocytic activity (Block and Hong, 2005; Kettenmann et al., 2011). Similarly to macrophage cells activated microglial cells can be divided to subtypes (Franco and Fernandez-Suarez, 2015). M1 type cells are cytotoxic and exhibit proinflammatory markers and factors such as reactive oxygen and nitrogen intermediates, proinflammatory cytokines (e.g. IL-1 $\beta$, IL-12, IL-23, TNF- $\alpha$ ), proteolytic enzymes and arachidonic acid metabolites. M2 type cells contribute to repair and regeneration by expressing anti-inflammatory cytokines such as IL-10, immunoregulatory molecules and trophic factors such as brain-derived neurotrophic factor (BDNF) (Stollg and Jander, 1999; Block and Hong, 2005; Franco and FernandezSuarez, 2015). M2 cells also show increased phagocytic capability (Prinz and Priller, 2014). Although such anti-inflammatory mechanisms are essential in protecting the CNS, activated microglial cells can also be harmful to neurons by eliciting neuroinflammation that could lead to neurodegeneration (Banati et al., 1993; Gehrmann et al., 1995; Gonzalez-Scarano and Baltuch, 1999; Streit, 2002; Graeber, 2010; Gresa-Arribas et al., 2012; Ghosh et al., 2013).

Unregulated and maladapted responses or chronic over-activation could lead to neurotoxic consequences. Accumulating evidences indicate that microglial cells and inflammatory responses play crucial role in connection with multiple neurodegenerative diseases (Long-Smith et al, 2009; Prokop et al., 2013). For example, previous studies revealed that in Alzheimer's disease (AD) brain microglial cells could be located in the centre of senile plaques (Stollg and Jander, 1999). The activated and proliferating microglial cells present around the amyloid deposits activate inflammatory processes (Arends et al., 2000). Amyloid-beta (A $\beta$ ) activates the production of proinflammatory cytokines and mediators such as IL-1 $\beta$, IL-6, IL-8, TNF- $\alpha$, the macrophage inflammatory protein (MIP) - 1 $\alpha$, nitric oxide (NO), inducible nitric oxide sythase (iNOS) and glutamate in microglial cells (McGeer and McGeer, 1995, 2003; Arends et al., 2000; Benveniste et al., 2001). The proinflammatory cytokine IL-1 that promotes the synthesis of amyloid precursor protein (APP) is overexpressed in the AD brain and therefore triggers further amyloid production (McGeer and McGeer, 1995, 2003; Akiyama et al., 2000). Parkinson's disease (PD) can also be characterized by overactive immune response of the brain (Phani et al., 2011). Previous studies suggested that many proinflammatory cytokines are upregulated in PD such as IL-1 $\beta$, IL-2, IL-6, TNF- $\alpha$ (Orr et al., 2004). IL-1 increases the expression of $\alpha$-synuclein, the main component of the Lewy-body protein 
aggregates; $\alpha$-synuclein is able to activate further microglial cells to produce superoxide and increase the concentration of reactive oxigen species (ROS) and reactive nitrogen species that are the main sources of the oxidative stress responsible for dopaminergic cell death (McGeer and McGeer, 2004; Block and Hong, 2005; Phani et al., 2011). Microglial cells also play crucial role in multiple sclerosis (MS). MS is a well-known inflammationmediated demyelinating disease (Block and Hong, 2005). During MS an increased microglial activity can be observed. Microglial cells proliferate and increase lysosomal activity around the site of demyelinization (Block and Hong, 2005). At the site of the lesion microglia display increased COX-2 and iNOS expression which in turn promote the production of neurotoxic prostaglandin E2 $\left(\mathrm{PGE}_{2}\right)$ and NO. Activated microglial cells also secrete proteases and TNF- $\alpha$ (Minagar et al., 2002, Muzio et al., 2007). NO and TNF- $\alpha$ damage oligodendrocytes and the myelin sheet, and contribute to demyelination (Block and Hong, 2005). Microglial cells are also capable of engulfing myelin (Minagar et al., 2002). Perivascular microglial cells excert antigen presenting cell function to myelin-specific T-cells infiltrating the CNS which initiates the progression of MS (Block and Hong, 2005; Muzio et al., 2007). Pharmacological regulation of microglial functions may therefore play an important role in the prevention and during the progression of several neurodegenerative diseases.

\subsection{Mechanisms and effects of statins}

The 3-hydroxy-3-methyl glutaryl coenzyme A (HMG-CoA) reductase inhibitors (HMGCRIs), commonly known as statins, are the agents of first choice for the treatment of high blood cholesterol levels (Wierzbicki et al., 2003; Taylor et al., 2013). They were discovered in 1975 as natural products of some moulds. These inhibitors can be divided in two groups: the natural compounds derived from fungal fermentation, and the fully synthetic compounds (Zipp et al., 2007). Their main biochemical effect is the reduction of the amount of low-density lipoprotein (LDL) cholesterol, but they can also increase the amount of high density lipoprotein (HDL) cholesterol and reduce triglyceride concentration (Wierzbicki et al., 2003). Statins act by blocking the cholesterol synthesis through inhibition of the enzyme necessary for the production of L-mevalonate. Statins can bind competitively to the HMGCR displacing its natural substrate HMG-CoA (Zipp et al., 2007). Inhibition of the first step of cholesterol synthesis also decreases the pools of intermediate metabolites in the pathway that have crucial metabolic functions (Wierzbicki 
et al., 2003; Cordle et al., 2005). The pathway of cholesterol synthesis produces farnesylpyrophosphate (FPP) which can be used for the production of geranylgeranylpyrophosphate (GGPP). Both FPP and GGPP are isoprenoids that are involved in the post-translational protein modification process called prenylation. Isoprenylated proteins include nuclear lamins, protein kinases and G-proteins. Prenylation is required for the assembly of G-protein heterotrimers. Through their effect of isoprenylated G-proteinmediated signalling, statins regulate a wide range of cellular functions.

The small monomer G-proteins, such as Rho, are also regulated by prenylation. Small G-proteins are part of many cellular functions including cell growth, transcriptional regulation, intracellular trafficking, cell motility, phagocytosis and cytoskeleton rearrangement (Takai et al., 2001; Cordle et al., 2005). The Rho subfamily of small Gproteins regulates the actin-based cytoskeleton. Activation of RhoA, Rac and Cdc42 leads to the formation of stress fibres, lamellopodia, filopodia (Corde et al., 2015). GTPases are also involved in events leading to inflammation (Zipp et al., 2007). RhoA is involved in inflammatory signal transduction cascades that lead to the synthesis of cytokines and chemokines (Corde et al., 2015). HMGCRIs are interfering with the process of antigen presentation. They reduce the MHC II class molecules and promote the differentation of T-cells towards the $T_{h} 2$ phenotype. They decrease the secretion of pro-inflammatory $T_{h} 1$ cytokines and increase the anti-inflammatory $\mathrm{T}_{\mathrm{h}} 2$ cytokines. Statins are also target the Rac-stress kinase pathway and the Rab-dependent pathway of receptor-induced endocytosis.

Apart from their therapeutic use in cardiovascular diseases, statins may also have beneficial effects in the CNS (Zipp et al., 2007; van der Most et al., 2009; Famer et al., 2010). Animal studies have demonstrated that statins attenuate neuroinflammation (Zelcer et al., 2007) and reduce senile plaques and inflammatory responses (Kurata et al., 2012). Experiments revealed that statin treatment after brain damage increases neurogenesis and synaptogenesis (van der Most et al., 2009). Statins induce neuroprotection by promoting the expression of neurotrophic factors such as BDNF (van der Most et al., 2009). Statins protect cells and tissues from oxidative damage by reducing the production of ROS (van der Most et al., 2009). They can induce the beneficial NO production by eNOS while reducing the NO overexpression by reducing iNOS (van der Most et al., 2009). The eNOS generation is essential for promoting cerebral blood flow to ischemic regions of the brain (Zipp et al., 2007). 
Several epidemiological studies suggested that statins reduced the risk of developing $\mathrm{AD}$ by as much as $70 \%$ (Jick et al, 2000; Wolozin et al, 2000). The A $\beta$ stimulated phagocytosis is dependent on Rac to drive actin polimerization and phagosome formation (Corde et al., 2015). A $\beta$ production is increased by high levels of cholesterol. Lipid rafts are known to be the site of $A \beta$ production. Raft depletion is suggested to reduce neuronal A $\beta$ production in vitro (van der Most et al., 2009). The APP is found both in and outside of lipid rafts, while the enzyme that converts it into $A \beta$ only occurs in rafts. Cholesterol depletion reduces the $\mathrm{A} \beta$ production. Animal models show that statins reduce leukocyte migration and infiltration to the inflamed tissue by inhibiting the $\beta 2$ integrin leukocyte function antigene (LFA-1) (van der Most et al., 2009). LFA-1 plays important role in leukocyte recirculation and tissue infiltration, as well as in the activation of T-cells by antigen presenting cells. These functions suggest that statins may have an inportant role in the treatment of MS (van der Most et al., 2009).

Of all the commercially available statins rosuvastatin exhibits the greatest inhibitory effect on cholesterol biosynthesis. Rosuvastatin is part of the fully synthetic class of HMGCRIs, relatively hydrophylic compared to other statins, and is anionic in neutral $\mathrm{pH}$ (Kitamura et al., 2008). Uptake studies revealed that organic anion transporting polypeptides (OATPs) accept rosuvastatin as a substrate (Kitamura et al., 2008). OATPs are polyspecific anion transporters expressed on the endothelial cell of BBB, the choroid plexus and other organs (e.g. liver) (Stieger and Gao, 2015). They belong to the superfamily of solute carriers (Stieger and Gao, 2015). Rosuvastatin is able to transport through OATP1A2, OATP1B1, OATP1B3 and OATP2B1 transporters (Ho et al., 2006; Kitamura et al., 2008). While the OATP1B1 and OATP1B3 tranporters show liverspecific expression, OATP1A2 and OATP2B1 are found at the BBB (Kitamura et al., 2008; Stieger and Gao, 2015). OATP1A2 is strongly expressed in brain capillary endothelial cells and has emerged as an important BBB uptake transporter for drugs (Liu et al., 2015). It transports amphipathic substrates, including bile salts, steroid conjugates, thyroid hormones, organic dyes and anionic oligopeptides (Liu et al., 2015). Experiments on MDCKII-WT monolayer cells revealed that OATP1A2 contributes to the transcellular permeability of rosuvastatin (Liu et al., 2015).

The effective anti-inflammatory and immunomodulatory effets of statins indicate that these drugs may have beneficial regulatory effects on microglial cells and may be able to modulate the strong neuroinflammatory processes orchestrated by microglial cells. 


\subsection{Mechanisms and effects of aspirin}

Aspirin is one of the most widely used medicines worldwide. Aspirin belongs to the nonsteroidal anti-inflammatory drugs (NSAIDs) and exerts analgesic, anti-inflammatory and antipyretic effets. It is extensively studied in the cardiovascular system. Its main action is the ireversible inhibition of cyclooxygenase (COX) enzyme activity by selective acetylation of the serine residue (Ser530) (Amman and Peskar, 2002; Vane and Botting, 2003). COX is the key enzyme in the conversion of arachidonic acid (AA) to prostaglandins (PGs) and other lipid mediators that are involved in several physiological and pathological processes including inflammation (Choi et al, 2009). During the initial phase of the inflammation prostaglandins play crucial role as local mediators in the development of inflammatory conditions and promote the activation of proinflammatory cytokines (Berk et al., 2013). COX-mediated production of inflammatory cytokines and prostanoids such as prostaglandins (e.g. $\mathrm{PGE}_{2}, \mathrm{PGI}_{2}$ ) and thromboxanes (e.g. $\mathrm{TXA}_{2}$ ) play a critical tole in modulating the immune response (Hussain et al, 2012). Aspirin, a COX inhibitor, modulates the prostanoid-mediated immune regulation (Hussain et al., 2012) and suppresses the NF- $\mathrm{kB}$-mediated proinflammatory signalling by inhibiting the binding of NF- $\mathrm{KB}$ to TNF- $\alpha$ promoter leading to the downregulation of TNF- $\alpha$ (Marchini et al., 2005; Hussain et al., 2012; Pettit et al., 2013). Aspirin is able to downregulate other proinflammatory cytokines released by macrophages such as IL-1 $\beta$, IL-6, IL-12, IFN- $\gamma$ (Hussain et al., 2012; Berk et al., 2013). Aspirin modulates the phagocytic capacity and antigen presenting function in macrophages, and inhibits the MHC I and MHC II associated antigen presentation in dencritic cells (Hussain et al., 2012). There are two main isoforms of the COX enzyme. COX-1 considered to be the constitutive isoform that support beneficial homeostatic function wherease COX-2 can be induced by variety of inflammatory stimuli and is the main isoform responsible for the PG biosynthesis in inflammed tissue (Amman and Peskar, 2002; Vane and Botting, 2003).

Previous studies revealed that COX-2 acetylation by aspirin resulting in a modulated enzymatic activity initiates the generation of new substrates that can interact with lipoxygenase to genetare aspirin-triggered lipoxins (Amann and Peskar, 2002; Schrör and Rauch, 2015). Aspirin-triggered lipoxins are anti-inflammatory mediators that inhibit proinflammatory cytokine release by activation of the supressor of cytokine signalling-2 (SOCS-2) expression (Hussain et al., 2012). 
In the brain both COX-1 and COX-2 are constitutively expressed (Aid and Bosetti, 2011). Under physiological conditions COX-1 is mainly expressed in microglial cells and COX-2 is found in excitatory terminals and post-synaptic dendrites (Aid and Bosetti, 2011). COX-1 is an important player in several inflammatory actions in the CNS and upregulated in numerous models of neuroinflammation (Aid and Bosetti, 2011). In AD brain an increased level of COX-1, COX-2 and $\mathrm{PGE}_{2}$ can be observed (Phillis et al., 2006). COX-1 expressing microglial cells surrounding amyloid plaques in AD (Choi et al., 2009; Aid and Bosetti, 2011). COX-1 and COX-2 maintain A $\beta$ generation through the interaction between $\mathrm{PGE}_{2}$ synthesis and $\gamma$-secretase activity that modulate $\mathrm{A} \beta$ deposition and induce neuroinflammation (Phillis et al., 2006). Prevoius studies suggested that COX1 inhibitors can reduce the level of amyloid plaques in transgenic models of $\mathrm{AD}$ brain (Sung et al., 2004). COX-1 expressing microglial cells are located in the developing necrotic core after focal ischemia (Schwab et al., 2000) and COX-1 inhibition reduces the oxidative stress and neuronal injury after global ischemia (Candelario-Jalil et al., 2003).

These observations suggest that COX-expressing microglial cells play crucial roles under pathological situations and COX inhibition by aspirin might be beneficial during the therapy. 


\section{SPECIFIC AIMS}

Inflammation has a critical role in the progression of neurodegeneration. Microglial activation results in profound morphological, functional and gene expression changes that activate both pro- and anti-inflammatory mechanisms that, in turn, not only protect the nervous tissue but could elicit chronic inflammation leading to the development of neuropathological conditions. Drugs that are able to alter the excessive microglial activation might therefore be useful for the prevention and treatment of several neurodegenerative diseases. Statins are used for the primary treatment of hypercholesterolemia albeit their anti-inflammatory effects are also noted. Although a few previous studies examined the effets of statins on the CNS, these experiments only used lipophilic statins such as simvastatin or atorvastatin. Rosuvastatin exhibits the greatest inhibitory effect on cholesterol biosynthesis but its effect on the CNS was not examined perhaps because of its presumed hydrophylic feature. Since rosuvastatin was able to enter the brain through specific transporters we decided to investigate its effect on microglial cells. Aspirin is one of the most commonly used non-steroidal antiinflammatory drugs. It also has widespread effects on immune cell functions, but it has not been extensively studied in microglial cells so we decided to clarify its effects on CNS immune functions. Therefore, we investigated the pleiotropic effects of rosuvastatin and aspirin on secondary microglial cultures derived from mixed primary cultures of 18day-old embryonic (E18) rat forebrains under control (unchallenged) and bacterial lipopolysaccharide (LPS)-challenged conditions.

Our specific aims were:

1. To characterize the effects of rosuvastatin and aspirin on the morphological, including cytoskeletal and immunocytochemical, features of microglial cells;

2. To characterize the effect of rosuvastatin on cell adhesion and proliferation of microglial cells;

3. To determine if rosuvastatin and aspirin alter microglial phagocytic properties;

4. To determine the effects of rosuvastatin and aspirin on microglial release of both proinflammatory (IL-1 $\beta$, TNF- $\alpha$ ) and anti-inflammatory (IL-10) cytokines;

5. To characterize the effects of rosuvastatin and aspirin on the expression patterns of inflammation related genes in pure microglial cells. 


\section{MATERIALS AND METHODS}

\subsection{Animals}

All animal experiments were carried out in strict compliance with the European Council Directive (86/609/EEC) and EC regulations (O.J. of EC No. L 358/1, 18/12/1986) regarding the care and use of laboratory animals for experimental procedures, and followed the relevant Hungarian and local legislation requirements. The experimental protocols were approved by the Institutional Animal Welfare Committee of the University of Szeged (I-74II/2009/MÁB). The pregnant Sprague-Dawley rats (170-190 g) were kept under standard housing conditions and fed ad libitum.

\subsection{Antibodies}

For a thorough characterization of different microglial phenotypes developed in vitro, an antibody against Iba1, an intracellular actin- and $\mathrm{Ca}^{2+}$-binding protein expressed in the CNS specifically in macrophages and microglia (Ahmed et al., 2007), was used in our immunocytochemical and Western blot analyses. The anti-glyceraldehyde 3-phosphate dehydrogenase (GAPDH) antibody was used as an internal control in Western blot experiments ( $\mathrm{Wu}$ et al, 2012). Dilutions of primary and secondary antibodies, and also incubation times and blocking conditions for each antibody used were carefully tested for both immunocytochemistry and Western blot analysis. To detect the specificities of the secondary antisera, omission control experiments (staining without the primary antibody) were performed. In such cases, no fluorescent or Western blot signals were detected.

\subsection{Preparation and maintenance of cell cultures}

Pure microglial cells were isolated from mixed primary cortical cell cultures of rat embryos of either sex by the method we described earlier (Szabó and Gulya, 2013; Kata et al., 2016). Sibling embryos obtained from the same pregnancy were processed for culturing together; each pregnancy was considered as an independent experiment. Briefly, 10-12 fetal rats (E18) under anesthesia were decapitated and the frontal lobe of the cerebral cortex was removed, minced with scissors, incubated in $9 \mathrm{ml}$ Dulbecco's Modified Eagle's Medium (DMEM; Invitrogen, Carlsbad, USA) containing 1 g/l D-glucose, 110 mg/l Na-pyruvate, 4 mM L-glutamine, $3.7 \mathrm{~g} / 1 \mathrm{NaHCO}_{3}, 10,000 \mathrm{U} / \mathrm{ml}$ penicillin $\mathrm{G}, 10 \mathrm{mg} / \mathrm{ml}$ streptomycin sulfate, $25 \mu \mathrm{g} / \mathrm{ml}$ amphotericin $\mathrm{B}$ and $0.25 \%$ trypsin for $10 \mathrm{~min}$ at $37{ }^{\circ} \mathrm{C}$, and then 
centrifuged at $1,000 \mathrm{~g}$ for $10 \mathrm{~min}$ at room temperature (RT). The pellet was resuspended and washed twice in $5 \mathrm{ml}$ DMEM containing $10 \%$ heat-inactivated fetal bovine serum (FBS; Invitrogen) and centrifuged for $10 \mathrm{~min}$ at $1,000 \mathrm{~g}$ at RT. The final pellet was resuspended in $2 \mathrm{ml} \mathrm{DMEM} / 10 \% \mathrm{FBS}$, after which the cells were plated in the same medium on a poly-Llysine-coated culture flask $\left(75 \mathrm{~cm}^{2}, 12 \times 10^{6}\right.$ cell/flask) and cultured for a number of days in vitro (DIV) at $37{ }^{\circ} \mathrm{C}$ in a humidified air atmosphere supplemented with $5 \% \mathrm{CO}_{2}$ for the subsequent generation of pure microglial cell cultures.

Secondary microglial cells were subcloned from mixed primary cultures (DIV7) maintained in a poly-L-lysine-coated culture flask $\left(75 \mathrm{~cm}^{2}, 12 \times 10^{6}\right.$ cells/flask $)$ by shaking the cultures at $100 \mathrm{rpm}$ in a platform shaker for $30 \mathrm{~min}$ at $37{ }^{\circ} \mathrm{C}$. Microglia from the supernatant were collected by centrifugation at 3,000 $\mathrm{g}$ for $8 \mathrm{~min}$ at RT and resuspended in 2 $\mathrm{ml}$ DMEM/10\% FBS. The cells were seeded 1) in poly-L-lysine-coated Petri dishes $(60 \mathrm{~mm}$ x $15 \mathrm{~mm} ; 4$ x $10^{5}$ cells/dish) for Western blot and enzyme-linked immunosorbent assays (ELISA); 2) in poly-L-lysine-coated coverslips (15 x $15 \mathrm{~mm} ; 2$ x $10^{5}$ cells/coverslip) for immunocytochemistry, proliferation or phagocytosis assays; or 3) in poly-L-lysine-coated Petri dishes (60 mm x $15 \mathrm{~mm} ; 1 \times 10^{6}$ cells/dish) for RNA expression and cultured in DMEM in a humidified atmosphere supplemented with $5 \% \mathrm{CO}_{2}$ at $37{ }^{\circ} \mathrm{C}$. The medium was changed on the first day after seeding (subDIV1).

\subsection{Cell culture treatments}

On the fourth day of subcloning (subDIV4), DMEM was replaced and the expanded pure microglial cells were treated with either bacterial lipopolysaccharide (LPS; $20 \mathrm{ng} / \mathrm{ml}$ final conc., dissolved in DMEM; Sigma, St. Louis, MO, USA), rosuvastatin (1 $\mu \mathrm{M}$ final conc., dissolved in sterile, distilled water; Santa Cruz Biotechnology, Inc., Dallas, TX, USA) or aspirin $(0.1 \mathrm{mM}$ (low) and $1 \mathrm{mM}$ (high) final conc., from $\geq 99 \%$ acetylsalicylic acid dissolved in sterile, distilled water; Sigma) alone, or with a combination of LPS + rosuvastatin, or LPS + aspirin, and the effects were compared in a variety of morphological and functional tests. LPS treatment served as an immunochallenge.

Eight types of treatment regimens were used: 1) control (unchallenged and untreated) cultures; 2) LPS-challenged cultures received $20 \mathrm{ng} / \mathrm{ml}$ LPS; 3) rosuvastatin treated cultures received $1 \mu \mathrm{M}$ rosuvastatin; 4) LPS-challenged + rosuvastatin treated cultures received $20 \mathrm{ng} / \mathrm{ml}$ LPS and $1 \mu \mathrm{M}$ rosuvastatin; 5) aspirin-treated cultures received $0.1 \mathrm{mM}$ aspirin; 6) aspirin-treated cultures received $1 \mathrm{mM}$ aspirin; 7) LPS-challenged + 
aspirin-treated cultures were challenged with $20 \mathrm{ng} / \mathrm{ml}$ LPS and treated with $0.1 \mathrm{mM}$ aspirin; 8) LPS-challenged + aspirin-treated cultures received $20 \mathrm{ng} / \mathrm{ml} \mathrm{LPS} \mathrm{and} 1 \mathrm{mM}$ aspirin. Depending on the experiments, the treatments lasted for 6,24 , or $72 \mathrm{~h}$ at $37^{\circ} \mathrm{C}$.

\subsection{Immunocytochemistry}

Pure secondary microglial cultures treated with different treatment regimens were fixed on coverslips with $4 \%$ formaldehyde for $5 \mathrm{~min}$ and rinsed with $0.05 \mathrm{M}$ phosphate-buffered saline (PBS) for $2 \times 5$ min. After permeabilization and blocking of the nonspecific sites in 0.05 M PBS solution containing 5\% normal goat serum (Sigma), 1\% heat-inactivated bovine serum albumin (Sigma) and $0.05 \%$ Triton $\mathrm{X}-100$ for $30 \mathrm{~min}$ at $37^{\circ} \mathrm{C}$, the cells on the coverslips were incubated overnight in a humidified chamber at $4{ }^{\circ} \mathrm{C}$ with rabbit antiIba1 polyclonal antibody (1:500 final dilution; Wako, Japan) in the above solution (Szabó and Gulya, 2013). The cultured cells were washed for 4 x 10 min at RT in 0.05 M PBS, and then incubated with the Alexa Fluor 568 fluorochrome-conjugated goat anti-rabbit antibody (1:1,000 final dilution; Invitrogen) in the dark for $3 \mathrm{~h}$ at RT. The cells on the coverslip were washed for $4 \times 10 \mathrm{~min}$ in $0.05 \mathrm{M}$ PBS at RT, and the nuclei were stained in $0.05 \mathrm{M}$ PBS solution containing $1 \mathrm{mg} / \mathrm{ml}$ polyvinylpyrrolidone and $0.5 \mu \mathrm{l} / \mathrm{ml}$ Hoechst 33258 dye (Sigma). The coverslips were rinsed in distilled water for $5 \mathrm{~min}$, air-dried and mounted on microscope slides in Vectashield mounting medium (Vector Laboratories, Burlingame, CA, USA). Cells were viewed on a Nikon Microphot-FXA epifluorescent microscope (Nikon Corp., Tokyo, Japan) and photographed with a Spot RT Color CCD camera (SPOT RT/ke, Diagnostic Instruments, Inc., Sterling Heights, MI, USA).

\subsection{Western blot analysis}

Cultured microglial cells (subDIV4) were collected through use of a rubber policeman, homogenized in $50 \mathrm{mM}$ Tris- $\mathrm{HCl}(\mathrm{pH} 7.5)$ containing $150 \mathrm{mM} \mathrm{NaCl}, 0.1 \%$ Nonidet $\mathrm{P} 40$, $0.1 \%$ cholic acid, $2 \mu \mathrm{g} / \mathrm{ml}$ leupeptin, $1 \mu \mathrm{g} / \mathrm{ml}$ pepstatin, $2 \mathrm{mM}$ phenylmethylsulfonyl fluoride and $2 \mathrm{mM}$ EDTA, and centrifuged at 10,000 $\mathrm{g}$ for $10 \mathrm{~min}$. The pellet was discarded and the protein concentration of the supernatant was determined (Lowry et al., 1951). For the Western blot analyses, 5-10 $\mu \mathrm{g}$ of protein was separated on a sodium dodecyl sulfate/polyacrylamide gel (4\%/10\% stacking gel/resolving gel), transferred onto HybondECL nitrocellulose membrane (Amersham Biosciences, Little Chalfont, Buckinghamshire, 
England), blocked for $1 \mathrm{~h}$ in 5\% nonfat dry milk in Tris-buffered saline (TBS) containing $0.1 \%$ Tween 20 , and incubated overnight with either a rabbit anti-Iba1 polyclonal antibody (1:1,000 final dilution; Wako) or a mouse anti-GAPDH monoclonal antibody (clone GAPDH-71.1; 1:20,000 final dilution; Sigma). After 5 rinses in 0.1\% TBS-Tween 20, the membranes were incubated for $1 \mathrm{~h}$ with the peroxidase-conjugated goat anti-rabbit secondary antibody (1:2,000 final dilution; Invitrogen) for Iba1 or with the peroxidaseconjugated rabbit anti-mouse secondary antibody (1:2,000 final dilution; Sigma) for GAPDH Western blots, and washed 5 times as before. The enhanced chemiluminescence method (ECL Plus Western blotting detection reagents; Amersham Biosciences) was used to reveal immunoreactive bands according to the manufacturer's protocol.

\subsection{Quantitative determination of in vitro phagocytosis}

The fluid-phase phagocytic capabilities of the control and variously treated pure microglial cell cultures were determined via the uptake of fluorescent microspheres (carboxylatemodified polystyrene beads, fluorescent yellow-green $(\lambda \mathrm{ex} \sim 470 \mathrm{~nm} ; \lambda \mathrm{em} \sim 505 \mathrm{~nm})$, aqueous suspension, $2.0 \mu \mathrm{m}$ mean particle size; L4530, Sigma) as described previously (Szabó and Gulya, 2013). Unchallenged (control) and LPS-challenged pure microglial cell cultures (subDIV4) with or without rosuvastatin or aspirin treatments were tested for $24 \mathrm{~h}$. At the end of the treatment period, $1 \mu \mathrm{l}$ of a $2.5 \%$ aqueous suspension of fluorescent microspheres per $\mathrm{ml}$ was added to the culture, which was then incubated for $60 \mathrm{~min}$ at 37 ${ }^{\circ} \mathrm{C}$. The cells were next washed 5 times with $2 \mathrm{ml}$ of PBS to remove dish- or cell surfacebound residual fluorescent microspheres, and fixed with $4 \%$ formaldehyde in PBS. In another setup, we also determined the number of microglial cell membrane-associated but not phagocytosed beads. Such negative controls were treated as above with the exception that microglial cultures with beads were incubated for $60 \mathrm{~min}$ at $4{ }^{\circ} \mathrm{C}$. At this temperature, the number of beads associated with cell surface averaged less than 1 bead per 100 Iba1labeled cells, thus the phagocytosis was not considered significant. For measurement of the phagocytic activity, cells labelled with phagocytosed microbeads and processed for Iba1 immunocytochemistry were counted in 20 random fields in each treatment group (mean \pm S.D.) under a $20 \mathrm{x}$ or $40 \mathrm{x}$ objectives. Statistically significant differences were determined by two-way ANOVA. 


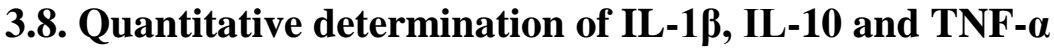

For ELISA assays, the supernatants were collected from each treatment and stored at -20 ${ }^{\circ} \mathrm{C}$. Concentrations of IL-1 $\beta$, IL-10 and TNF- $\alpha$ were measured with rat-specific ELISA kits (eBioscience, Vienna, Austria). The sensitivity of IL-1 $\beta$ (Cat\# BMS630), IL-10 (Cat\# BMS629) and TNF- $\alpha$ (Cat\#BMS622) assays was $4 \mathrm{pg} / \mathrm{ml}, 1.5 \mathrm{pg} / \mathrm{ml}$ and $11 \mathrm{pg} / \mathrm{ml}$, respectively. As stated by the manufacturer, the overall intra- and interassay coefficients of variation were $<10 \%$ in both cases for IL- $1 \beta$ and TNF- $\alpha$, and $<5 \%$ in both cases for IL-10.

\subsection{Determination of cell adhesion and proliferation}

To measure changes in cell adhesion, proliferation and cell viability, the ACEA Real-Time Cell Analysis (RTCA) system and 16-well E-Plates (Acea Biosciences, Inc., San Diego, CA, USA) were used. This system measured the electrical impedance of the cells expressed as cell index in real-time. Briefly, 4 x 10 5 pure microglial cells in poly-L-lysine-coated Petri dishes were plated as described above. On the fourth day of culturing, the cells were trypsinized, centrifuged as above and seeded into gelatin-coated 16-well E-Plates at a density of 6,000 cells per well. Test doses of LPS and rosuvastatin, either alone or in combination, were added to the wells before plating. After equilibration at RT for $10 \mathrm{~min}$, the E-plate was loaded into the RTCA machine and the cell index was measured continuously for $60 \mathrm{~h}$ using the xCELLigence real-time cell analysis system (RTCA DP; Acea Biosciences) as published earlier (Ozsvári et al., 2010). Cell indices at $24 \mathrm{~h}$ were analyzed for comparison with cell proliferation data. Data analysis was carried out with the system's dedicated software (RTCA Software 1.2; Acea Biosciences) and Excel (Microsoft Corp., Redmond, WA, USA). To estimate the number of surviving/proliferating microglial cells after treatments, the cells were washed twice with $2 \mathrm{ml}$ PBS to remove cell debris, treated with $0.25 \%$ trypsin solution for $10 \mathrm{~min}$ at $37{ }^{\circ} \mathrm{C}$, collected and counted in a Burker chamber. The number of viable cells was presented as mean \pm S.D.

\subsection{RNA isolation}

Total RNA from control and treated pure microglial cells was purified as described previously (Fabian et al., 2011); columns and wash buffer were from Bioneer (Viral RNA extraction kit; Daejon, South Korea). Briefly, cells were washed with PBS, incubated in lysis buffer (RA1; Macherey-Nagel, Düren, Germany), then collected and mixed with 70\% 
ethanol in RNase-free water (Bioneer). The mixture was transferred through columns (Bioneer) and washed with $350 \mu 180 \%$ ethanol in diethylpyrocarbonate-treated water, and then with $600 \mu 1$ and $300 \mu \mathrm{lW} 2$ wash buffer (Bioneer). Total RNA was eluted in $50 \mu 1$ RNase free-water. One $\mu 1$ RNase inhibitor (Applied Biosystems, Foster City, CA, USA) was added to the samples. The quality and quantity of the isolated RNA was measured with NanoDrop1000 Version 3.8.1. (Thermo Scientific, Budapest, Hungary).

\subsection{RNA expression}

Reverse transcription from $3 \mu \mathrm{g}$ total RNA in $30 \mu \mathrm{l}$ was performed with the High Capacity cDNA Archive Kit (Applied Biosystems) according to the manufacturer's protocol. cDNA was diluted to $80 \mu \mathrm{l}$ with nuclease-free water. The instrumentation included the Bravo automatic liquid handling system (Agilent Technologies, Inc., Santa Clara, CA, USA) for polymerase chain reaction (PCR) assay preparation and a LightCycler 1536 System (Roche Diagnostics Corp., Indianapolis, IN, USA) or a Light Cycler Nano Instrument (Roche) for cycling (Woudstra et al., 2013). The expression of 116 inflammation-related genes, together with that of 6 control genes (see below), was measured with Universal Probe Library (UPL) assays using intron-spanning gene-specific primers (Rat Immune Panel; Avidin Ltd., Szeged, Hungary, www.avidinbiotech.com/services/gene-expression) and the LightCycler 1536 DNA Probe Master kit (Roche). Moreover, the expression of certain phagocytosis-related genes such as the integrin associated protein or cluster of differentiation 47 (Cd47, NM_019195_2), the engulfment or cell motility protein (Elmo1, NM_001108415.1), the scavenger receptor class B member 1 (Scarb1, NM_031541_1), the plasminogen activator inhibitor1 (Serpine1, NM_012620_1), the signal-regulatory protein $\alpha$ (Sirpa, NM_013016_2) and the vesicle-associated membrane protein 7 (Vamp7, NM_053531_1) were also analyzed by the Light Cycler Nano Instrument. For the 1536 System, each $2 \mu$ PCR reaction contained $8 \mathrm{ng}$ cDNA, $0.4 \mu \mathrm{l}$ LightCycler DNA Probes Master (5x), the corresponding primer set and UPL probe and the Setup Control. The PCR cycling protocol was as follows: enzyme activation at $95{ }^{\circ} \mathrm{C}$ for $60 \mathrm{sec}, 50$ cycles of denaturation at $95{ }^{\circ} \mathrm{C}$ for 0 sec, and annealing and extension at $60^{\circ} \mathrm{C}$ for $30 \mathrm{sec}$. For the Nano Instrument, each $20 \mu \mathrm{l}$ PCR reaction contained $20 \mathrm{ng}$ cDNA, $10 \mu \mathrm{l}$ Lightcycler DNA Probes Master (5x), the corresponding primer set and UPL probe and the Setup Control. The PCR protocol was as follows: enzyme activation at $95^{\circ} \mathrm{C}$ for $10 \mathrm{~min}, 50$ cycles of denaturation at $95^{\circ} \mathrm{C}$ for 15 
sec, and annealing and extension at $60{ }^{\circ} \mathrm{C}$ for $30 \mathrm{sec}$. Gene expression was normalized to the average values of clathrin, heavy chain (Cltc, NM_019299.1), Gapdh (M17701.1), glucuronidase, beta (Gusb, NM_017015.2), hypoxanthine phosphoribosyl transferase 1 (Hprt1, NM_012583.2), phosphoglycerate kinase 1(Pgk1, NM_053291.3) and tubulin, beta 5 class I (Tubb5, NM_173102.2) expression as endogenous controls and expressed relative to the unchallenged controls by using the $2^{-\Delta \Delta \mathrm{Ct}}$ method.

A total of 122 gene-specific assays were run on 3 independent samples from each condition. Gene expression was analyzed by GraphPad Prism 6 (GraphPad Software, Inc., La Jolla, CA, USA). For hierarchical cluster analysis and visualization, the Hierarchical Clustering Explorer (v3.0) software was used (Human-Computer Interaction Lab., University of Maryland, MD, USA; publicly available at http://www.cs.umd.edu/hcil/multi-cluster/hce3.html). The complete linkage clustering method was applied with Euclidean distance metric.

\subsection{Digital processing and image analysis}

Digital images were captured by a Nikon Microphot-FXA epifluorescent microscope (Nikon Corp., Tokyo, Japan), using a Spot RT Color CCD camera and the Spot RT software (Spot RT/ke Diagnostic Instruments, Sterling Heights, MI, USA). For the determination of microglial cell purity, Hoechst 33258-labelled cell nuclei that belonged to Iba1-immunopositive cells were counted on coverslip-cultured samples. For each culture, 50-100 randomly selected microscope fields were analyzed. In every case, the cultures had, on average, at least 99 Iba1-positive somata for 100 Hoechst 33258-labelled cell nuclei (> 99\% purity for microglial cells). Phagocytosed microspheres on 20 randomly sampled microscope fields from 3 coverslips for each treatment regimen were counted with the use of the computer program ImageJ (version 1.47; http://rsb.info.nih.gov/ij). For the measurement of area $\left(\mu \mathrm{m}^{2}\right)$, perimeter $(\mu \mathrm{m})$ and transformation index $(\mathrm{TI})$, Ibalimmunoreactive microglial cell images were converted into binary replicas by using thresholding procedures implemented by ImageJ and Adobe Photoshop CS5.1 software (Adobe Systems, Inc., San Jose, CA, USA) as we published earlier (Szabó and Gulya, 2013; Szabó et al., 2016). Microglial cell silhouettes were acquired by transforming the raw digital files of Iba1-immunoreactive cells recorded under fluorescent microscope light to binary files. The color cell images were transformed into their binary replicas (silhouettes) by using automatic thresholding procedures (Szabó and Gulya, 2013; Szabó et al., 2016). 
After the values of cell perimeter $(\mu \mathrm{m})$ and cell area $\left(\mu \mathrm{m}^{2}\right)$ had been determined, the TI reflecting the degree of process extension was determined according to the following formula: [perimeter of cell $(\mu \mathrm{m})]^{2} / 4 \pi$ [cell area $\left.\left(\mu \mathrm{m}^{2}\right)\right]$ (Fujita et al., 1996). Color correction and cropping of the light microscopic images were performed when photomicrographs were made for publication and assembled for a panel. Gray-scale digital images of the immunoblots were acquired by scanning the autoradiographic films with a desktop scanner (Epson Perfection V750 PRO; Seiko Epson Corp., Japan). The images were scanned and processed at identical settings to allow comparisons of the Western blots from different samples. The bands were analyzed through the use of ImageJ. The immunoreactive densities of equally loaded lanes were quantified, and all samples were normalized to the internal GAPDH load controls.

\subsection{Statistical analysis}

All statistical comparisons were made by using R 3.1.0 for Windows (The R Foundation for Statistical Computing; Vienna University of Economics and Business, Vienna, Austria). Results were analyzed with two-way ANOVA, and the Bonferroni correction was used to establish significance between groups. Values were presented as means $\pm \mathrm{SD} ; \mathrm{p}<0.05$ was considered significant; *,** and $* * *$ denote $\mathrm{p}<0.05, \mathrm{p}<0.01$ and $\mathrm{p}<0.001$, respectively. 


\section{RESULTS}

All experiments were performed on pure microglial cultures 4 days after seeding (subDIV4). Immunocytochemistry routinely performed on these secondary cultures consistently detected a $>99 \%$ incidence of the Iba1 immunopositive microglial cells for the Hoechst 33258 dye-labeled cell nuclei (Fig. 1).

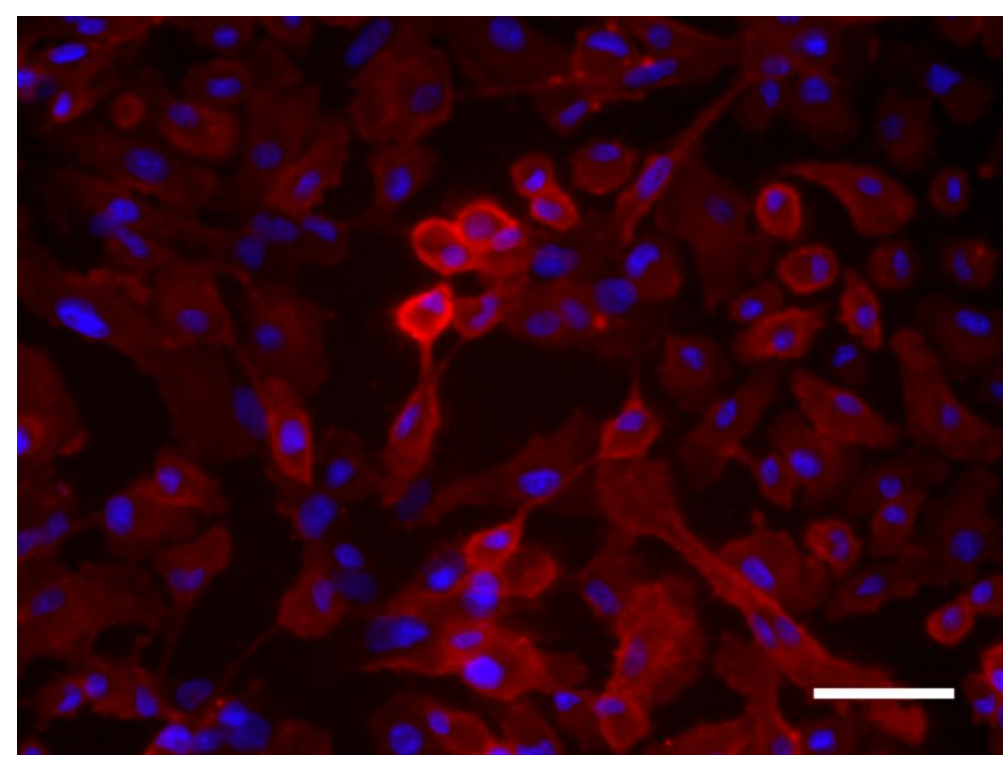

Fig. 1. Localization of Iba1 immunoreactive microglial cells in a pure secondary microglial culture (subDIV4). The typical purity of the culture is $>99 \%$; in this representative photomicrograph of a field of view the purity is $100 \%$ since every Hoechst 33258 -labeled cell nuclei (blue) is surrounded by Iba1 immunopositive cytoplasm (red). Scale bar: $50 \mu \mathrm{m}$.

\subsection{Morphological effects of rosuvastatin and aspirin treatments}

The morphological changes elicited by rosuvastatin and aspirin in unchallenged (control) and LPS-challenged pure microglia cultures were documented through the use of Iba1 immunocytochemistry (Fig. $2 A-D$ and Fig. $4 A-F$ ) and quantitatively analyzed on binary silhouettes of individual microglial cells (Fig. 3A-G and Fig. 5A-F). Iba1 protein expression was also monitored during treatments (Fig. $2 E$ and Fig. $4 G$ ).

Our experiments with rosuvastatin demonstrated that most of the unchallenged and untreated (control) microglia displayed ameboid morphology with TI <3; they had predominantly ameboid shape, occasionally with small pseudopodia (Fig. 2A, Fig. 3A). When administered alone for $24 \mathrm{~h}$, rosuvastatin induced the formation of numerous microspikes (Fig. 2B, Fig. 3B); these slender cytoplasmic projections (filopodia) resulted in significantly increased perimeter and TI values of these cells (Fig. $3 F, G$ ). 

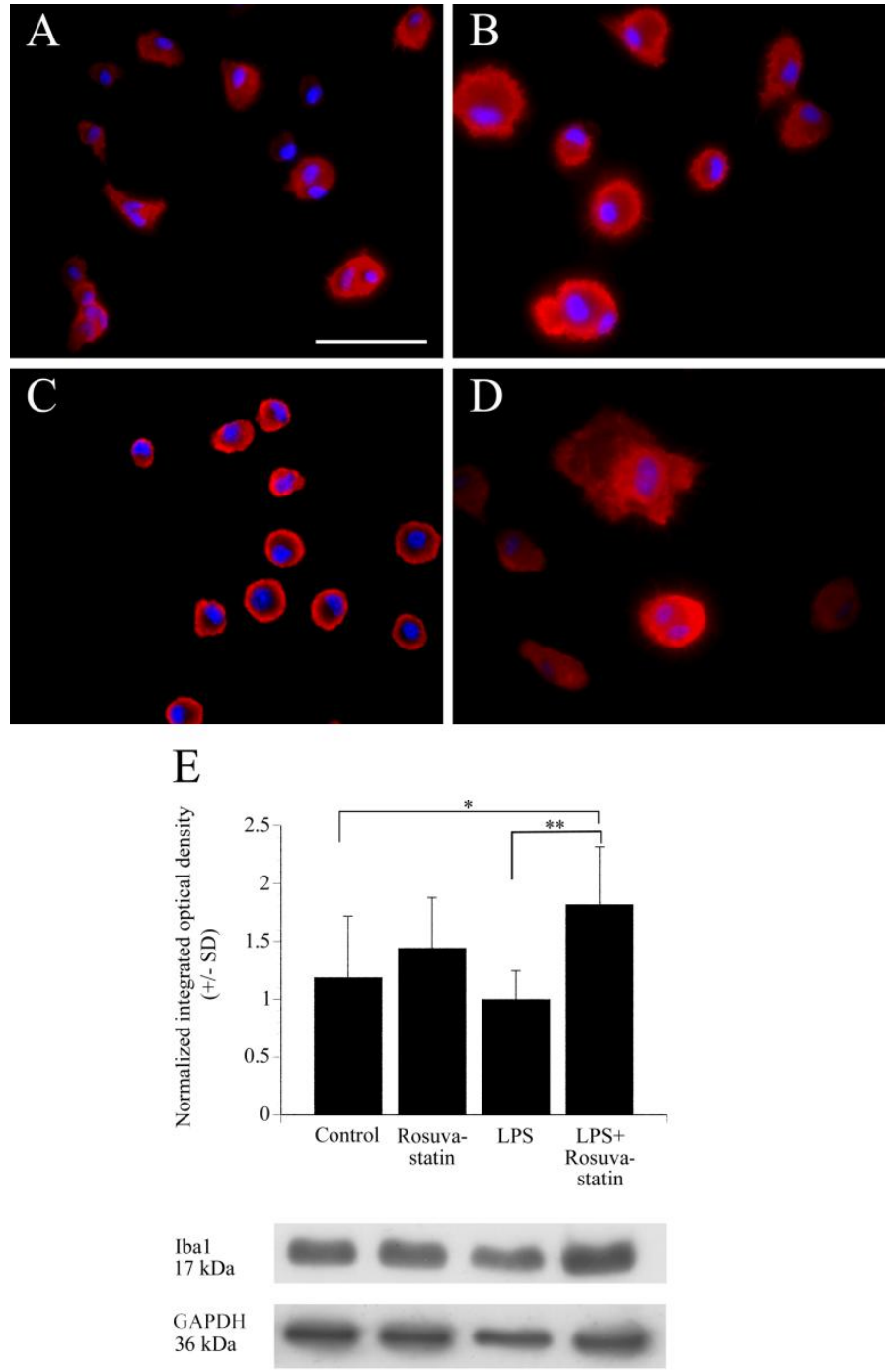

Fig. 2. Rosuvastatin affects microglial cell morphology and Iba1 immunoreactivity in pure microglial cells after various treatments. Representative fluorescent immunocytochemical pictures demonstrate the typical cellular distribution of Iba1 immunoreactivity (red) in (A) control (unchallenged and untreated), (B) rosuvastatin-treated, (C) LPS-challenged and (D) LSP-challenged + rosuvastatin-treated microglial cells. The effects of rosuvastatin in unchallenged and LSP-challenged microglia were the most marked. Hoechst 33258labeled cell nuclei are shown in blue. Scale bar in A (for all pictures): $50 \mu \mathrm{m}$. (E), Quantitative Western blot analysis of Iba1 and GAPDH immunoreactivities in pure microglial cell cultures. Protein samples from the cultures were separated by gel electrophoresis, transferred to nitrocellulose membranes and probed with either the Iba1 or the GAPDH antibody. Gray scale digital images of the immunoblots were acquired by scanning the autoradiographic films with a desktop scanner. The images were scanned and processed at identical settings to allow comparisons between the Western blots from different samples. Error bars indicate integrated optical density values (means \pm SD) normalized to the internal standard GAPDH. Representative Western blot pictures are shown below the graphs. Data were analyzed with two-way ANOVA. *p $<0.05$, **p $<0.01$. 
A Control

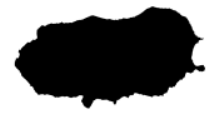

A: 693.48

P: 145.57

TI:2.43

B

Rosuvastatin

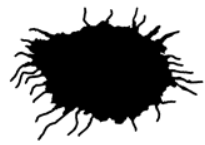

A:595.39

P: 388.23

TI: 20.25

$\mathrm{C}_{\text {LPS }}$

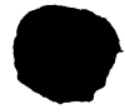

A: 415.15

P: 83.78

TI: 1.35

D ${ }_{\text {LPS }+}$

Rosuvastatin

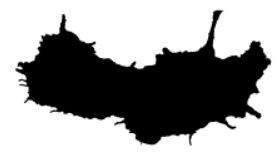

A: 1188.99

P: 329.15

TI: 7.25

E

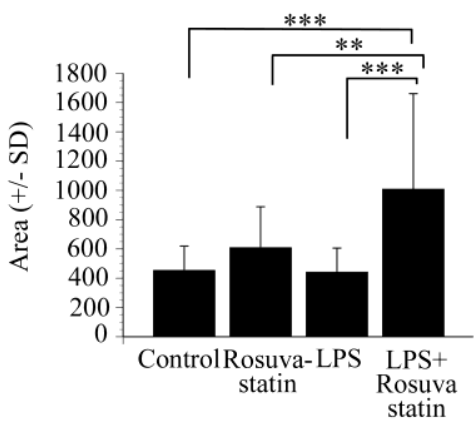

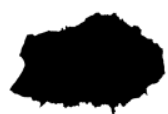

A: 550.58

P: 132.01

TI: 2.52

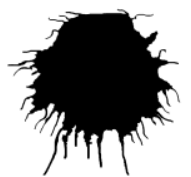

A: 710.48

P: 434.64

TI: 21.46

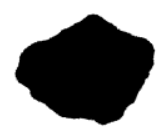

A: 522.02

P: 109.44

TI: 1.82

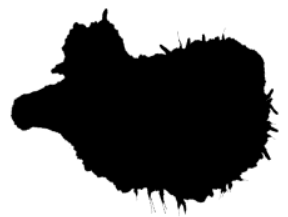

A: 2449.77

P: 490.51

TI: 7.81

F

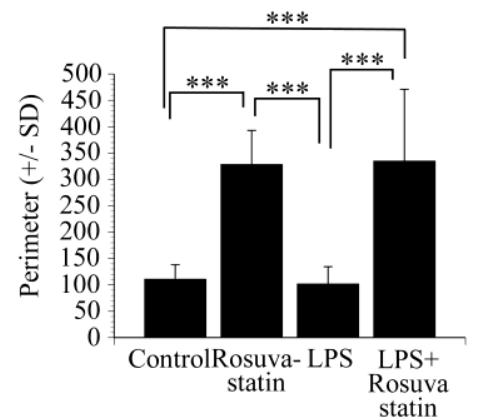

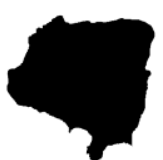

A: 685.19

P: 142.53

TI: 2.36

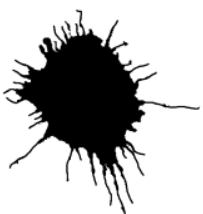

A: 608.74

P: 388.23

TI: 19.70

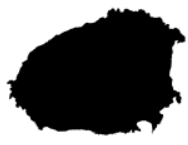

A: 800.69

P: 178.85

TI: 3.11

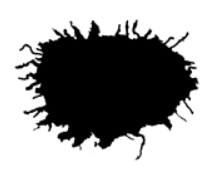

A: 757.04

P: 482.70

TI: 24.29

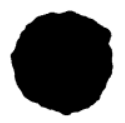
A: 420.32
P: 80.61
A: 155.40
P: 49.14
TI: 1.23
TI: 1.24
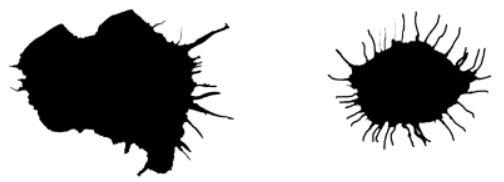

A: 1346.65
P: 391.95
TI: 9.08

A: 508.89

P: 219.43

TI: 5.540

G

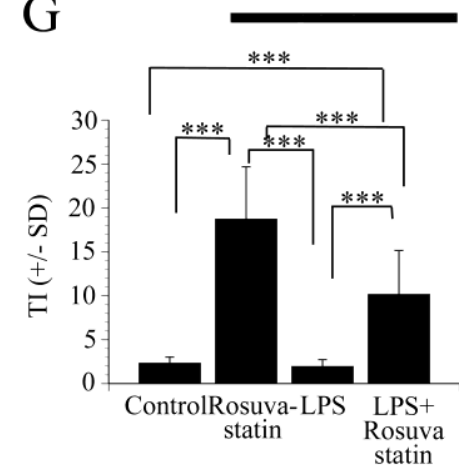

Fig.3. Quantitative analysis of microglial morphology in pure microglial cell cultures after various treatments I. Iba1-positive microglial cells from pure microglial cultures (subDIV4) were photographed, the pictures were digitized, and the morphological characteristics were quantitatively analyzed on binary silhouettes of unchallenged (A), rosuvastatin-treated (B), LPS-challenged (C) and LPS-challenged + rosuvastatin-treated (D) microglia. Four representative binary silhouettes are shown for each culturing protocol. Scale bar for all silhouettes: $50 \mu \mathrm{m}$. Area (E) in $\mu^{2}{ }^{2}$, perimeter (F) in $\mu \mathrm{m}$, and TI values (G), calculated as [perimeter of cell $(\mu \mathrm{m})]^{2} / 4 \pi\left[\right.$ cell area $\left.\left(\mu \mathrm{m}^{2}\right)\right]$, are indicated for each digitized cell. Unchallenged and untreated (control) cells, similarly to LPS-challenged cells, displayed a typical ameboid morpology with low TI values. Rosuvastatin affected the morphology of both the control and the LPS-challenged microglia (B, 
D). In unchallenged cultures, it promoted microspike formation with a concurrent slight ramification of the cells (B). In the LPS-challenged + rosuvastatin-treated cultures (D), the microglia became larger and, while retaining microspikes, also developed thicker processes. Both the rosuvastatin treatment alone and the combined treatment with LPS resulted in larger perimeter (F) and higher TI values (G) as compared with both the unchallenged and the LPS-challenged cultures. (E) Average area (in $\mu \mathrm{m}^{2} \pm$ S.D.) measurements for cultured pure microglial cells. (F) Average perimeter (in $\mu \mathrm{m} \pm$ S.D.) measurements for cultured pure microglial cells. (G) Average TI values ( \pm S.D.) for cultured pure microglial cells. LPS: $20 \mathrm{ng} / \mathrm{ml}$; rosuvastatin: $1 \mu \mathrm{M}$. For $(\mathbf{E}-\mathbf{G})$, error bars indicate means \pm SD of six replicate measurements from three independent culturings. Data were analyzed with two-way analysis of variance (ANOVA). **p $<0.01, * * * p<$ 0.001 .

For example, the average $\mathrm{TI}$ in this group increased about 10-fold, to above 19, as compared with the controls (Fig. 3G). The LPS challenge did not result in any significant morphometric change (Fig. 2C, Fig. 3C, E-G). However, rosuvastatin treatment in LPSchallenged cells resulted in a significantly enlarged and more ramified cell form (TI> 7) with a much larger perimeter value as compared with their respective control values (Fig. $2 D$, Fig. $3 D, E-G)$, indicating that rosuvastatin profoundly antagonized the morphological changes characteristic of LPS-induced microglial activation. In relation to the substantially increased size of the LPS-challenged and rosuvastatin-treated microglia (Fig. 2D, Fig. 3D, $E$ ), their Iba1 immunoreactivity was also significantly increased (Fig. 2E, Fig. 3E).

The amount of Iba1 immunoreactivity was significantly increased in the aspirintreated (low: $2.09 \pm 0.49$; high: $2.22 \pm 0.75$ ) and the LPS-challenged + aspirin-treated groups (low: $2.30 \pm 0.79$; high: $2.49 \pm 0.92$ ) as compared to LPS-challenged values (1.35 \pm 0.34; Fig. 4G). 

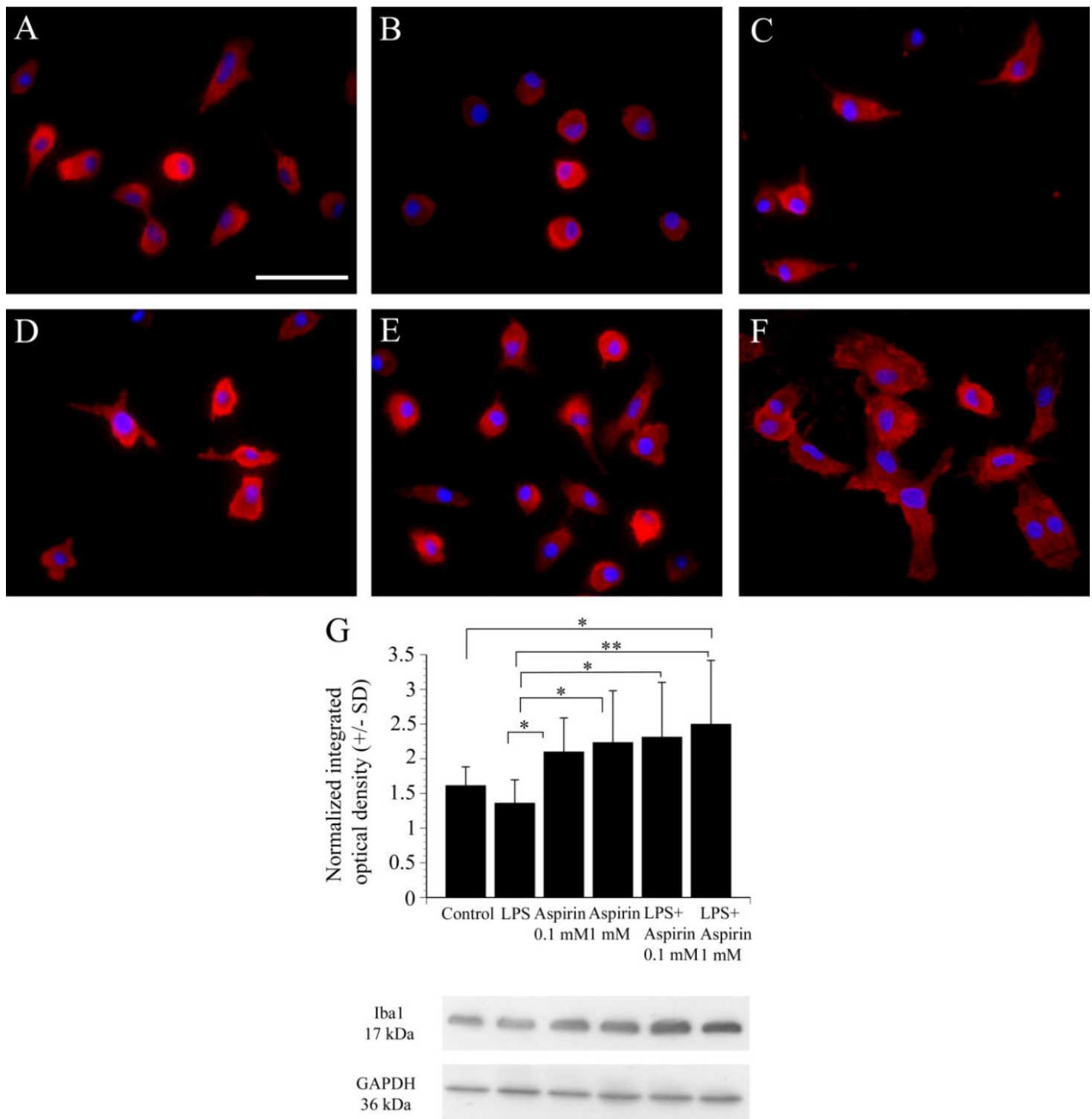

Fig. 4. Aspirin affects microglial morphology and Iba1 immunoreactivity in pure microglial cells. Representative fluorescent immunocytochemical pictures demonstrate the typical cellular distribution of Iba1 immunoreactivity (red) in (A) control (unchallenged and untreated), (B) LPS-challenged, (C) $0.1 \mathrm{mM}$ aspirin-treated, (D) $1 \mathrm{mM}$ aspirin-treated, (E) LPS-challenged $+0.1 \mathrm{mM}$ aspirin-treated and (F) LPSchallenged $+1 \mathrm{mM}$ aspirin-treated microglial cells. Hoechst 33258-labeled cell nuclei are shown in blue. Scale bar in A (for all pictures): $50 \mu \mathrm{m}$. G, Quantitative Western blot analysis of Iba1 and GAPDH immunoreactivities in pure microglial cell cultures. Protein samples from the cultures were separated by gel electrophoresis, transferred to nitrocellulose membranes and probed with either the Iba1 or the GAPDH antibody. Gray scale digital images of the immunoblots were acquired by scanning the autoradiographic films with a desktop scanner. The images were scanned and processed at identical settings to allow comparisons between the Western blots from different samples. Error bars indicate integrated optical density values (means \pm SD) normalized to the internal standard GAPDH. Representative Western blot pictures are shown beside the graph. Data were analyzed with two-way analysis of variance (ANOVA). *p $<0.05, * * \mathrm{p}<0.01$. 
A

Control

$\begin{array}{ll} & \text { A: } 546.26 \\ \text { B } & \text { P: } 221.57 \\ \text { TI: } 7.15\end{array}$

LPS

C

Aspirin

$0.1 \mathrm{mM}$

D

Aspirin

E

LPS+

Aspirin

$0.1 \mathrm{mM}$
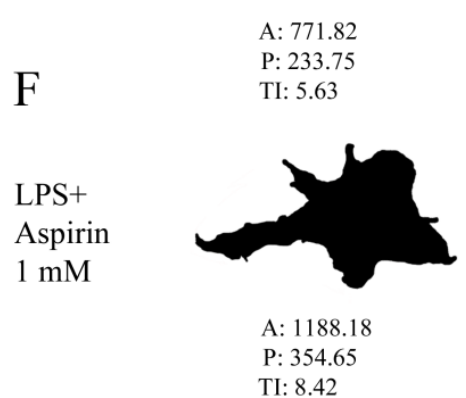

P: 354.65
TI: 8.42

G

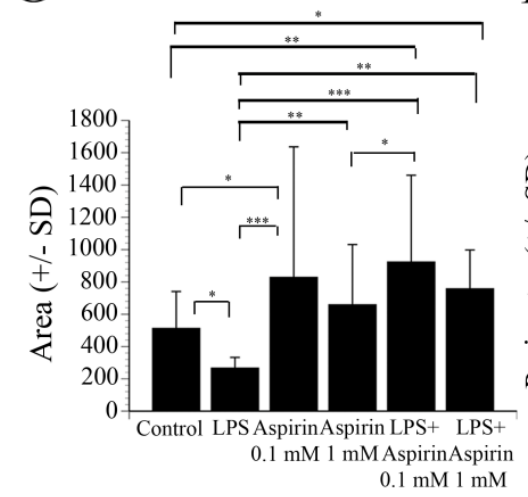

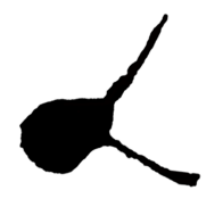

A: 796.12

P: 280.22

TI: 7.85

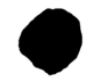

A: 228.37

P: 62.08

TI: 1.34

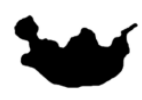

A: 352.52

P: 120.96

TI: 3.30

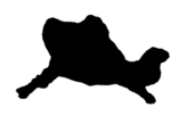

A: 482.57

P: 147.30

TI: 3.58

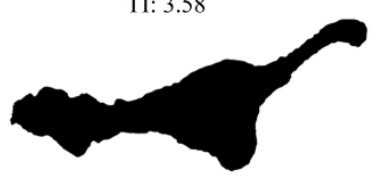

A: 1305.92

P: 273.17

TI: 4.55

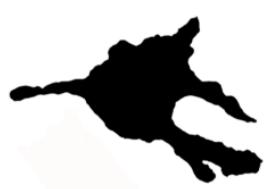

A: 1022.96

P: 292.92

TI: 6.67

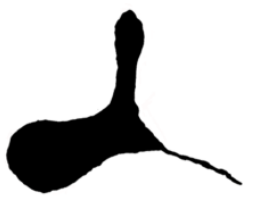

A: 381.97

P: 183.81

TI: 7.04

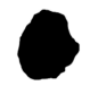

A: 234.69

P: 60.98

TI: 1.26

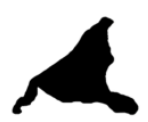

A: 352.21

P: 124.95

TI: 3.52

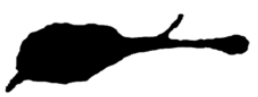

A: 531.26

P: 185.25

TI: 5.14

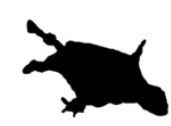

A: 466.76

P: 171.57

TI: 5.02

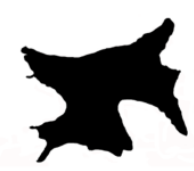

A: 884.66

P: 270.35

TI: 6.57

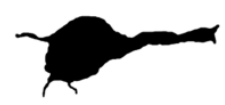

A: 585.08

P: 179.55

TI: 4.39

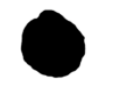

A: 241.23

P: 62.24

TI: 1.28

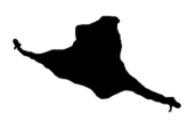

A: 377.66

P: 150.72

TI: 4.79

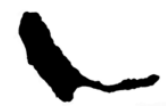

A: 265.40

P: 118.59

TI: 4.22

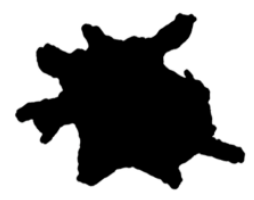

A: 1596.80

P: 285.93

TI: 4.07

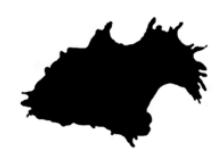

A:948.96

P: 283.64

TI: 6.74

$\mathrm{H}$

I
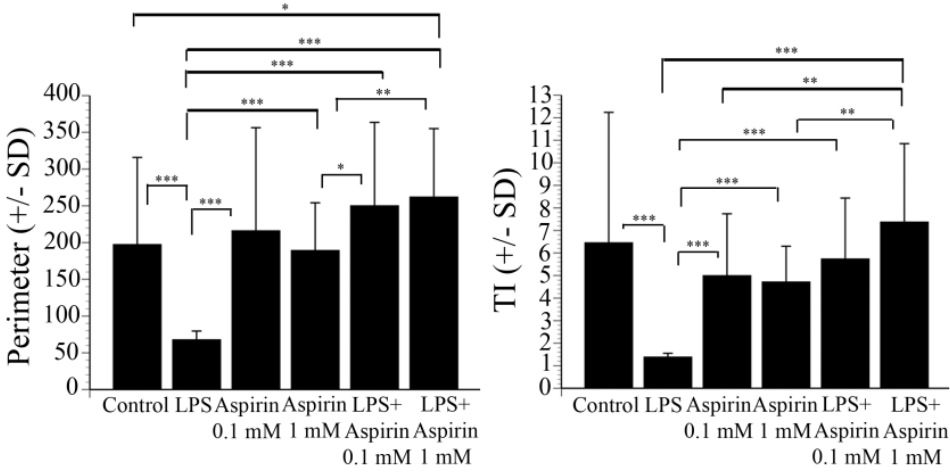

Fig. 5. Quantitative analysis of microglial morphology in pure microglial cell cultures after different treatments II. (A-F) Iba1-positive microglial cells from pure microglial cultures (subDIV4) were photographed, the pictures were digitized and the morphological characteristics were quantitatively 
analyzed on binary silhouettes of unchallenged (A), LPS-challenged (B), $0.1 \mathrm{mM}$ aspirin-treated (C), $1 \mathrm{mM}$ aspirin treated (D), LPS-challenged $+0.1 \mathrm{mM}$ aspirin-treated (E) and LPS-challenged $+1 \mathrm{mM}$ aspirintreated (F) microglia. Four representative binary silhouettes are shown for each culturing protocol. Scale bar for all silhouettes: $50 \mu \mathrm{m}$. Area $(\mathbf{G})$ in $\mu \mathrm{m}^{2}$, perimeter $(\mathbf{H})$ in $\mu \mathrm{m}$, and TI values (I), calculated as [perimeter of cell $(\mu \mathrm{m})]^{2} / 4 \pi\left[\right.$ cell area $\left.\left(\mu \mathrm{m}^{2}\right)\right]$, are indicated for each digitized cell. Unchallenged and untreated (control) microglia displayed slightly amoeboid/ramified morphology, and neither of the aspirin treatments changed the control values significantly. LPS challenge resulted in amoeboid morphology with the accompanying significant morphometric changes. Both aspirin treatments in LPS-challenged cells resulted in an enlarged and more ramified cell form with a much larger area, perimeter, and TI value as compared with the LPS results $(\mathbf{B}, \mathbf{E}, \mathbf{F}, \mathbf{G}, \mathbf{H}, \mathbf{I})$. In the control and the aspirin-treated cultures, cells displayed short processes or small pseudopodia with a concurrent slight ramification (A, C, D). In the LPSchallenged cultures (B), the microglia became smaller and showed amoeboid morphology. Aspirin treatments in these cells $(\mathbf{E}, \mathbf{F})$ resulted in a much larger area $(\mathbf{G})$ but similar perimeter $(\mathbf{H})$ and TI values (I) as compared the control cultures. (G) Average area (in $\mu \mathrm{m}^{2} \pm$ S.D.) measurements for cultured pure microglial cells. (H) Average perimeter (in $\mu \mathrm{m} \pm$ S.D.) measurements for cultured pure microglial cells. (I) Average TI values ( \pm S.D.) for cultured pure microglial cells. For (G-I), error bars indicate means \pm SD of six replicate measurements from three independent culturing. Data were analyzed with two-way analysis of variance (ANOVA). $* \mathrm{p}<0.05, * * \mathrm{p}<0.01, * * * \mathrm{p}<0.001$.

Most of the unchallenged and untreated (control) microglia displayed slightly amoeboid/ramified morphology with TI $=6.44 \pm 5.79$; they typically had only a few short processes (Fig. 4A, Fig. 5A). LPS challenge resulted in a significant change in morphology (Fig. $4 B$, Fig. 5B, $G-I$ ) as amoeboid morphologies with low TI values $(1.37 \pm 0.17)$ were more typical; LPS challenge decreased area, perimeter and TI values (by 48\%, 65\% and $78 \%$, respectively) as compared to the controls. When LPS-challenged cells were treated with aspirin, significantly enlarged and more ramified cells were seen as compared to the values of the LPS-challenged cells (Fig. $4 B, E, F$, Fig. 5B, E-I) indicating that aspirin was able to reverse the morphological changes induced by LPS-challenge. Both aspirin doses increased the TI values to the control level (low: $5.73 \pm 2.70$; high: $7.36 \pm 3.48$ ) and induced ramified morphology with thick processes and microspikes (Fig. 4E, F; Fig. 5E, F). 


\subsection{Rosuvastatin inhibits proliferation and cell adhesion}

Rosuvastatin significantly inhibited cell proliferation in both unchallenged and LPSchallenged cultures, by $47.8 \%$ and $68.9 \%$, respectively, after a $24 \mathrm{~h}$ treatment period (Fig. $6 A)$. We used a 16-well E-Plate-based real-time analysis to determine whether rosuvastatin affects cell adhesion. Rosuvastatin inhibited cell adhesion in both unchallenged (control) and LPS-challenged microglia (Fig. 6B). The differences in the levels of inhibition of cell adhesion between cultures with or without rosuvastatin (unchallenged and LPS-challenged microglia vs. rosuvastatin-treated and LPS-challenged + rosuvastatin-treated microglia) were significant by $20 \mathrm{~h}$ of culturing and thereafter. This was probably due to the significantly larger cell populations in the control and LSP-challenged microglial cultures as compared with those in the rosuvastatin or LPS + rosuvastatin-treated cultures (Fig. 6B), and to the ability of rosuvastatin to stimulate the formation of microspikes (Fig. $3 B, D$ ), i.e. the actin-based filamentous protrusions implicated in the cell motility, and consequently in the decreased adhesion of these cells.

A

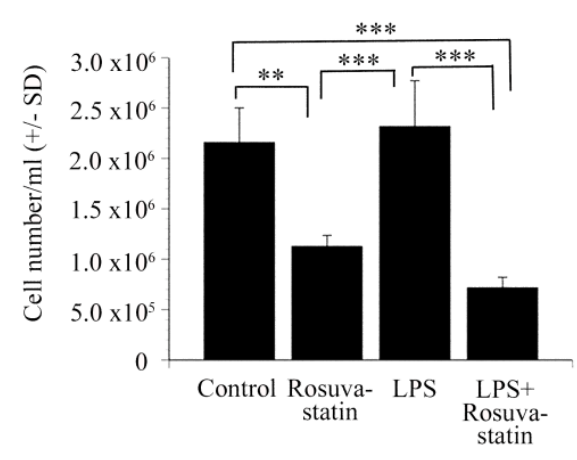

B
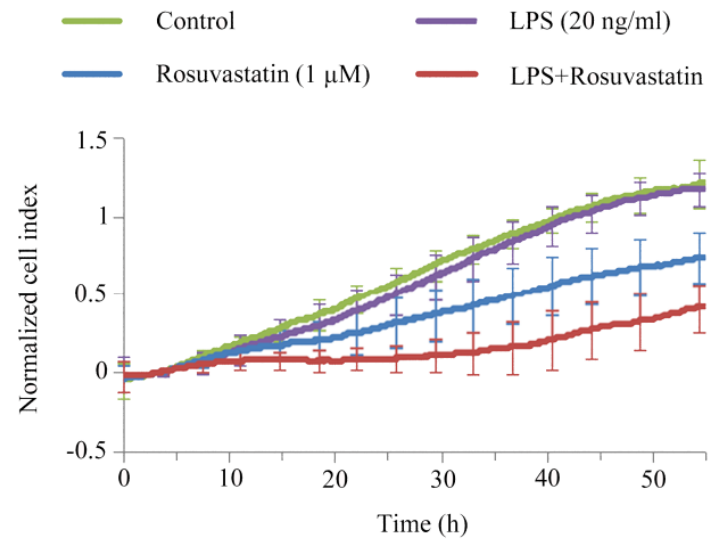

Fig. 6. Rosuvastatin inhibits cell proliferation and decreases cell adhesion. (A) After culturing, the cells were collected and the number of surviving microglia was determined with a Bürker chamber. Rosuvastatin, in both unchallenged and LPS-challenged cultures, inhibited cell proliferation and displayed some anti-mitotic characteristic. LPS treatment did not affect cell proliferation. (B) Real-time monitoring of microglial cell adhesion after different treatment regimens. The ACEA Real-Time Cell Analysis (RTCA) system and 16-well E-Plates were used to determine cell indices as described in the Materials and methods section. Normalized cell index values are plotted as a function of time. In both unchallenged and LPS-challenged cells, rosuvastatin decreased cell adhesion (blue and red lines, respectively). Error bars indicate means \pm SD of six replicate measurements from three independent culturings. Data were analyzed with two-way analysis of variance (ANOVA). $* * p<0.01, * * * p<0.001$. 


\subsection{Rosuvastatin and aspirin reduce the phagocytic activity in activated microglia}

The microglial function is inherently related to its phagocytic activity. In pure microglial cultures (subDIV4), the control (unchallenged and untreated) microglia exhibited a low level of fluid-phase phagocytosis (Fig. 7A, E), engulfing only $2.62 \pm 1.7$ beads per cell $(\mathrm{n}=$ 91) during rosuvastatin treatment, and only $3.63 \pm 1.6$ beads per cell $(\mathrm{n}=60$; Fig. $8 A, G)$ during aspirin treatment. Rosuvastatin did not affect phagocytosis appreciably (Fig. 7B, E) as the number of phagocytosed microbeads remained low $(2.70 \pm 1.7 ; n=50)$.
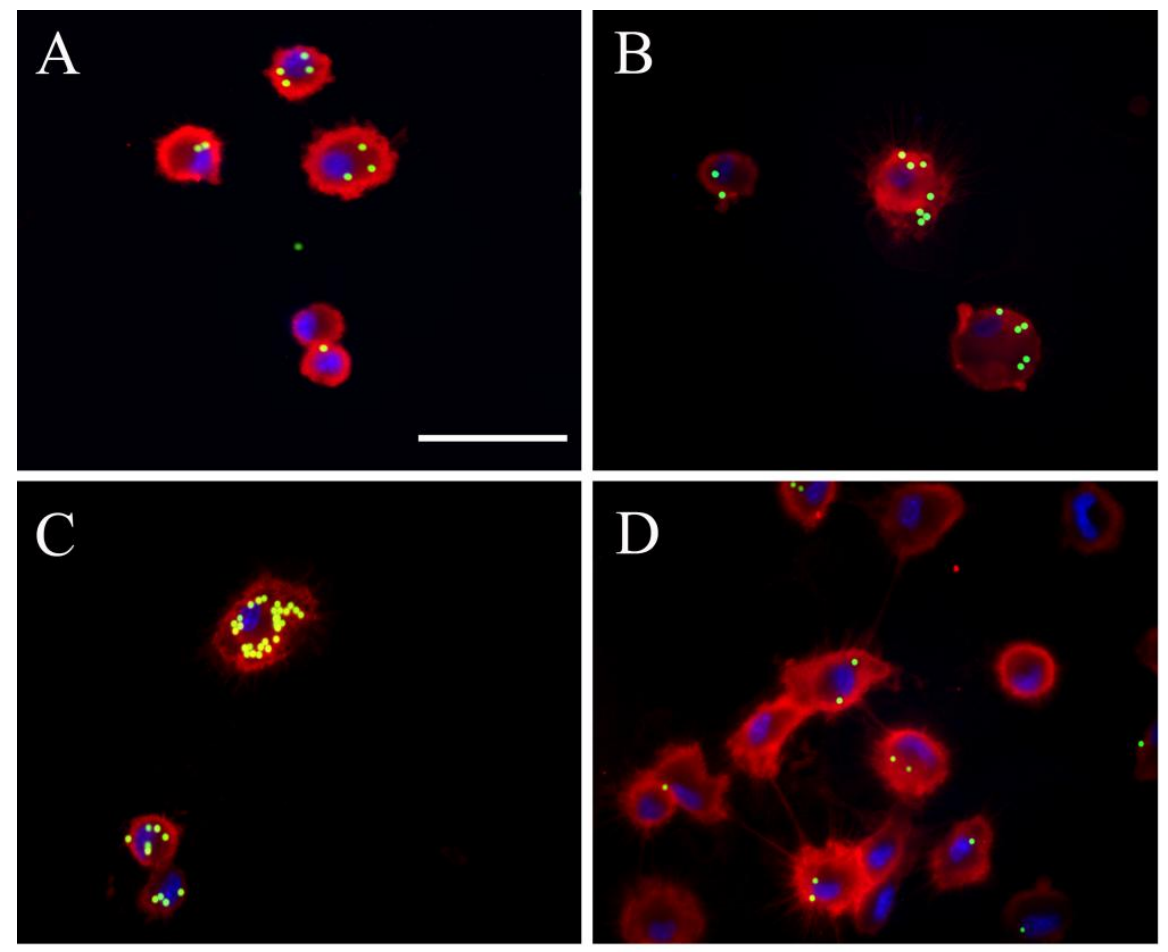

$\mathrm{E}$

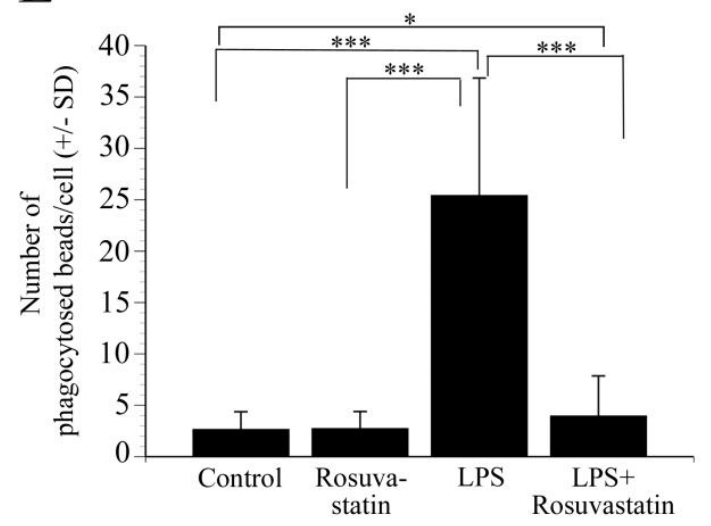

Fig. 7. Rosuvastatin is a potent inhibitor of phagocytosis. Pure microglial cultures (subDIV4) were maintained and treated with fluorescent microbeads ( $2 \mu \mathrm{m}$ in diameter) as described in the Materials and methods 3.7 section (A-D). Iba1-specific fluorescent immunocytochemistry (red: microglia; blue: nucleus; green: microspheres) on unchallenged (A), rosuvastatin-treated unchallenged cells (B), LPS-challenged cells 
(C) and LPS-challenged + rosuvastatin-treated microglial cells (D) revealed that rosuvastatin inhibited phagocytosis in both naive, unchallenged (B) and LPS-challenged cells (D). Scale bar in A (for all pictures) = $50 \mu \mathrm{m}$. (E) Quantitative analysis of the number of phagocytosed microbeads revealed that LPS dramatically activated phagocytosis, while rosuvastatin, when present, significantly decreased this microglial function. Error bars indicate means \pm SD of six replicate measurements from three independent culturings. Data were analyzed with two-way ANOVA. *p $<0.05, * * \mathrm{p}<0.01, * * * \mathrm{p}<0.001$.

As expected, the LPS challenge increased the phagocytic activity of the microglial cells significantly (Fig.7C, E). On average, the LPS-challenged cells accumulated $25.39 \pm$ 11.4 beads per cell $(n=70)$, and some of the cells engulfed as many as 40 microbeads. In the LPS-challenged microglia, however, rosuvastatin inhibited phagocytosis drastically, by nearly $80 \%$ (Fig.7D, E), as the fluid-phase phagocytotic activity was returned close to the level of the control cells ( $4.67 \pm 3.9$ microbeads per cell; $n=88$ ).

During aspirin treatments, microglial activation was associated with a robust phagocytic activity as LPS challenge increased phagocytosis significantly to about $350 \%$ of the control level $(12.87 \pm 4.86 ; \mathrm{n}=58$; Fig. $8 A, B, G)$. Aspirin alone did not affect the phagocytosis appreciably (Fig. $8 C, D, G$ ), as the number of phagocytosed microbeads remained low in both cases (low: $2.72 \pm 1.47$, high: $3.30 \pm 1.64 ; n=60$ ). However, aspirin inhibited phagocytosis significantly in LPS-challenged microglia (Fig. 8E, F, G). Aspirin $(0.1 \mathrm{mM}$ or $1 \mathrm{mM})$ decreased phagocytosis dose-dependently by about $30 \%(9.20 \pm 4.25 ; \mathrm{n}$ $=55$; Fig. $8 E, G)$ and $70 \%(3.86 \pm 1.85$ microbeads per cell; $\mathrm{n}=67$; Fig. $8 F, G)$, respectively, as compared to LPS treatment. As activated microglial cells often damage neuronal tissue; such a strong inhibition of a proinflammatory action by rosuvastatin and aspirin could be beneficial in preventing or ameliorating neurodegeneration. 

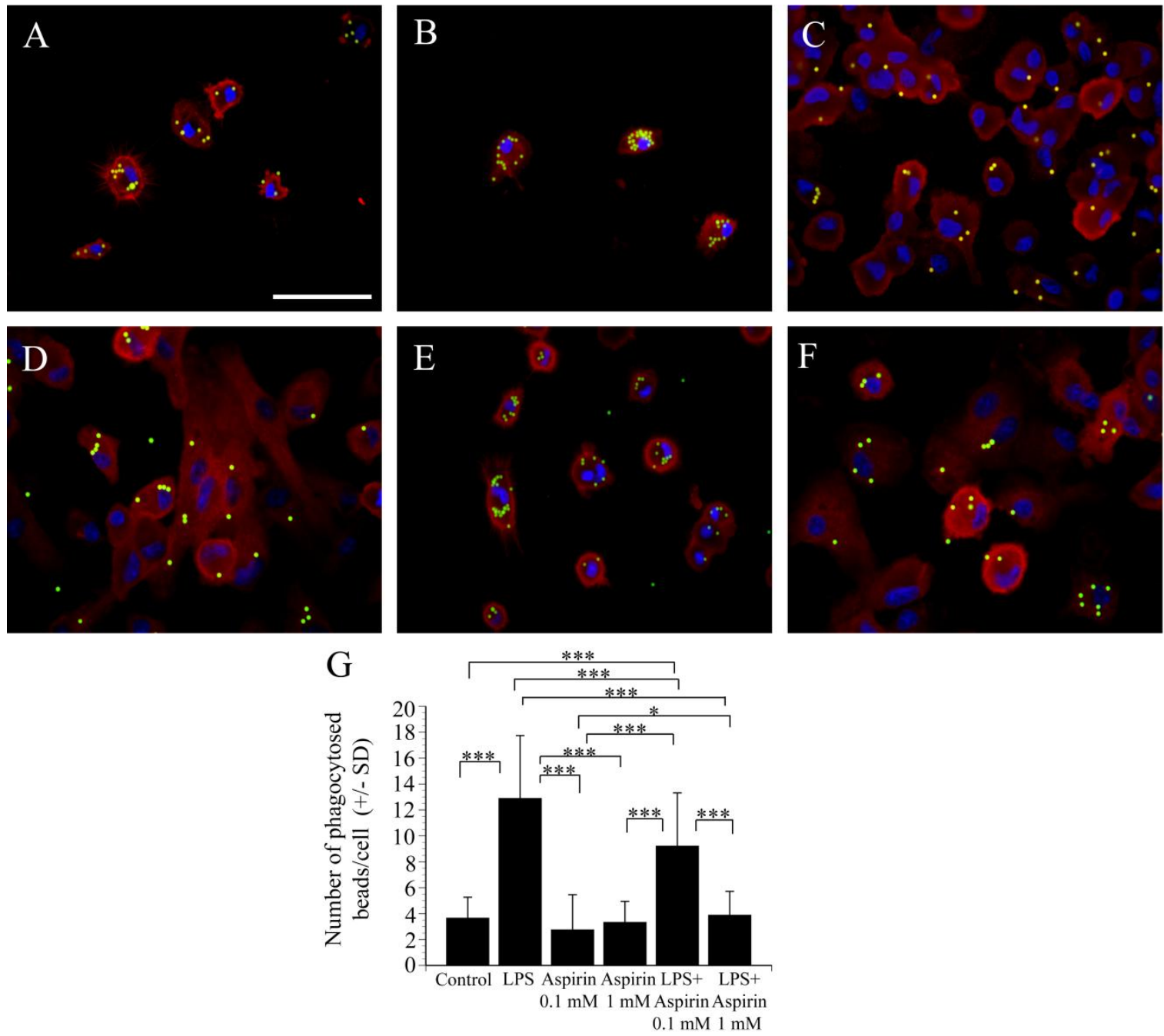

Fig. 8. Aspirin strongly inhibits phagocytosis. Pure microglial cultures (subDIV4) were maintained and treated with fluorescent microbeads ( $2 \mu \mathrm{m}$ in diameter) as described in the Materials and methods 3.7 section (A-F). Iba1-specific fluorescent immunocytochemistry (red: microglia; blue: nucleus; green: microspheres) on unchallenged (A), LPS-challenged (B), $0.1 \mathrm{mM}$ aspirin-treated (C), $1 \mathrm{mM}$ aspirin-treated (D), LPS-challenged $+0.1 \mathrm{mM}$ aspirin-treated (E), and LPS-challenged $+1 \mathrm{mM}$ aspirin-treated $(\mathbf{F})$ microglia. Scale bar in A (for all pictures) $=50 \mu \mathrm{m}$. (G) Quantitative analysis of the number of phagocytosed microbeads revealed that LPS dramatically activated phagocytosis, while aspirin significantly decreased this microglial function. Error bars indicate means $\pm \mathrm{SD}$ of six replicate measurements from three independent culturing. Data were analyzed with two-way ANOVA. *p $<0.05, * * * p<0.001$. 


\subsection{Both rosuvastatin and aspirin decrease proinflammatory and increase anti- inflammatory cytokine levels}

Activated microglia are known to express several pro- and anti-inflammatory cytokines. As previous studies indicated that statins were able to reduce the inflammatory effect in the vicinity of atherosclerotic plaques, we presumed that rosuvastatin regulates the amount of cytokines released by the microglia. Indeed, when the basal levels of the proinflammatory cytokines IL-1 $\beta$ and TNF- $\alpha$ and the anti-inflammatory cytokine IL-10 in unchallenged microglia were compared with the levels from rosuvastatin-treated LPS-challenged or unchallenged cells, a unique regulatory pattern emerged (Fig. 9A-C). The basal level for IL$1 \beta$ in unchallenged (control) microglia was $15.00 \pm 5.6 \mathrm{pg} / \mathrm{ml}$ (Fig.9A). Rosuvastatin did not change this level significantly $(9.56 \pm 13.1 \mathrm{pg} / \mathrm{ml})$. As expected, a 24 h-long LPS challenge significantly elevated the IL-1 $\beta$ level in the activated microglia, to $156.05 \pm 63.0$ $\mathrm{pg} / \mathrm{ml}$. However, when added together with LPS, rosuvastatin significantly inhibited the development of this elevated IL-1 $\beta$ level, by about $45 \%$, to $86.25 \pm 49.3 \mathrm{pg} / \mathrm{ml}$.

A similarly strong effect of rosuvastatin was demonstrated on the level of TNF- $\alpha$, another proinflammatory cytokine, in LPS-challenged microglial cells (Fig.9B). Two different treatment times $(6 \mathrm{~h}$ and $24 \mathrm{~h})$ were used as the TNF- $\alpha$ production responded quickly to the LPS challenge. The level of TNF- $\alpha$ in the unchallenged (control) and the rosuvastatin-treated microglia could not be detected, but its level quickly rose, to $906.80 \pm$ $281.7 \mathrm{pg} / \mathrm{ml}$ in the LPS-challenged cells after $6 \mathrm{~h}$, and the level was still robust after $24 \mathrm{~h}$ $(188.19 \pm 38.6 \mathrm{pg} / \mathrm{ml})$. When rosuvastatin was co-administered to LPS-challenged cells for either $6 \mathrm{~h}$ or $24 \mathrm{~h}$, it significantly inhibited the overproduction of TNF- $\alpha$, by $39 \%$ and 40\%, respectively (Fig. 9B).

More importantly, however, rosuvastatin affected the production of IL-10, an antiinflammatory cytokine (Fig.9C). The basal and rosuvastatin-treated levels of IL-10 in the unchallenged microglia were not significantly different $(37.01 \pm 18.4 \mathrm{pg} / \mathrm{ml}$ vs. $75.32 \pm$ $35.4 \mathrm{pg} / \mathrm{ml}$ ), although elevated IL-10 production was noted after rosuvastatin treatment. Interestingly, LPS increased the IL-10 protein expression significantly to about $340 \%$ of the level of the unchallenged microglia $(125.3 \pm 25.3 \mathrm{pg} / \mathrm{ml} \mathrm{pg} / \mathrm{ml})$. When rosuvastatin was coadministered with LPS, it boosted the IL-10 protein expression even higher, to about $750 \%$ of the basal level $(276.84 \pm 85.6 \mathrm{pg} / \mathrm{ml})$, indicating the very strong anti-inflammatory action of rosuvastatin. 

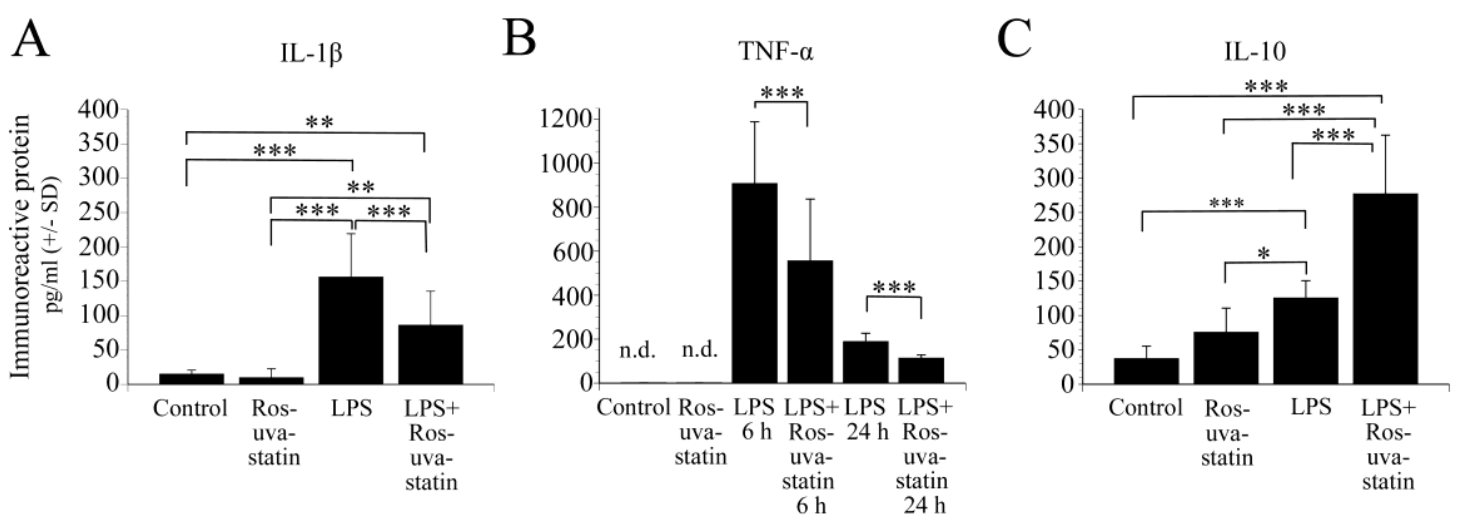

Fig.9. Rosuvastatin reduces the pro-inflammatory cytokine IL-1 $\beta$ and TNF- $\alpha$ levels and increases the anti-inflammatory IL-10 production. After treatments for 6 or $24 \mathrm{~h}$, immunoreactive protein levels $(\mathrm{pg} / \mathrm{ml} \pm$ SD) for IL-1 $\beta$ (A), TNF- $\alpha$ (B) and IL-10 (C) were detected by ELISA. TNF- $\alpha$ production was measured after $6 \mathrm{~h}$ and $24 \mathrm{~h}$ (B). As expected, pro-inflammatory cytokine production was significantly increased in the LPSchallenged cells $(\mathbf{A}, \mathbf{B})$. Rosuvastatin was a potent inhibitor of this effect for both IL-1 $\beta$ (A) and TNF- $\alpha$ (B). The level of the anti-inflammatory cytokine IL-10 was measured after $24 \mathrm{~h}$ (C). Rosuvastatin increased the value of IL-10 both in unchallenged and in LPS-challenged microglia, to $750 \%$ of the control level in the latter case $(\mathbf{C})$. Error bars indicate means $\pm \mathrm{SD}$ of six replicate measurements from three independent culturings. Data were analyzed with two-way ANOVA. n.d. = not detected. $* \mathrm{p}<0.05 ; * * \mathrm{p}<0.01, * * * \mathrm{p}<0.001$.

When the basal levels of the proinflammatory cytokines IL-1 $\beta$ and TNF- $\alpha$ and the anti-inflammatory cytokine IL-10 in unchallenged microglia were compared with the levels from aspirin-treated LPS-challenged cells, a regulatory pattern similar to that seen after rosuvastatin treatments emerged (Fig. 10). In the case of IL-1 $\beta$ the basal level in unchallenged (control) microglia was $22.45 \pm 11.14 \mathrm{pg} / \mathrm{ml}$ (Fig. 10A). Both aspirin treatments were able to change this level (low: $10.26 \pm 6.9 \mathrm{pg} / \mathrm{ml}$; high: $10.19 \pm 6.7 \mathrm{pg} / \mathrm{ml}$ ). As expected, LPS challenge significantly elevated the IL-1 $\beta$ level to $336.15 \pm 206.91 \mathrm{pg} / \mathrm{ml}$. However, co-incubation of LPS and $1 \mathrm{mM}$ aspirin significantly inhibited IL-1 $\beta$ level by about $50 \%$, to $169.6 \pm 89.0 \mathrm{pg} / \mathrm{ml}$, while $0.1 \mathrm{mM}$ aspirin decreased it by about $16.5 \%$, to $280.05 \pm 100.0 \mathrm{pg} / \mathrm{ml}$ (Fig. 10A). A similarly strong effect of aspirin was demonstrated on the level of TNF- $\alpha$, another proinflammatory cytokine, in LPS-challenged microglial cells (Fig. 10C, D). Two different treatment periods $(6 \mathrm{~h}$ and $24 \mathrm{~h})$ were used as the TNF- $\alpha$ production responded quickly to the LPS challenge. The level of TNF- $\alpha$ in the control group could not be detected, but its level quickly rose, to $1135.88 \pm 276.30 \mathrm{pg} / \mathrm{ml}$ in the LPS-challenged cells after $6 \mathrm{~h}$, and the level was still elevated after $24 \mathrm{~h}(189.92 \pm 82.20$ $\mathrm{pg} / \mathrm{ml})$. Aspirin treatments $(0.1 \mathrm{mM}$ and $1 \mathrm{mM})$ resulted in small, detectable TNF- $\alpha$ levels 
for both doses $(27.69 \pm 6.47 \mathrm{pg} / \mathrm{ml}$ and $29.23 \pm 3.87 \mathrm{pg} / \mathrm{ml}$ after $6 \mathrm{~h}$, while $8.24 \pm 3.14$ $\mathrm{pg} / \mathrm{ml}$ and $9.09 \pm 1.03 \mathrm{pg} / \mathrm{ml}$ after $24 \mathrm{~h}$ ). When aspirin was co-administered to LPSchallenged cells for either $6 \mathrm{~h}$ or $24 \mathrm{~h}$, it inhibited the production of TNF- $\alpha$ significantly in both doses: $1 \mathrm{mM}$ aspirin decreased the TNF- $\alpha$ level by about $25 \%$ (to $863.42 \pm 157.40$ $\mathrm{pg} / \mathrm{ml}$ after $6 \mathrm{~h}$ ) and $50 \%(96.79 \pm 14.70 \mathrm{pg} / \mathrm{ml}$ after $24 \mathrm{~h})$, and $0.1 \mathrm{mM}$ aspirin inhibited its level only after $6 \mathrm{~h}$ by about $16 \%$ (to $946.95 \pm 84.74 \mathrm{pg} / \mathrm{ml}$ ) (Fig. 10C, D).
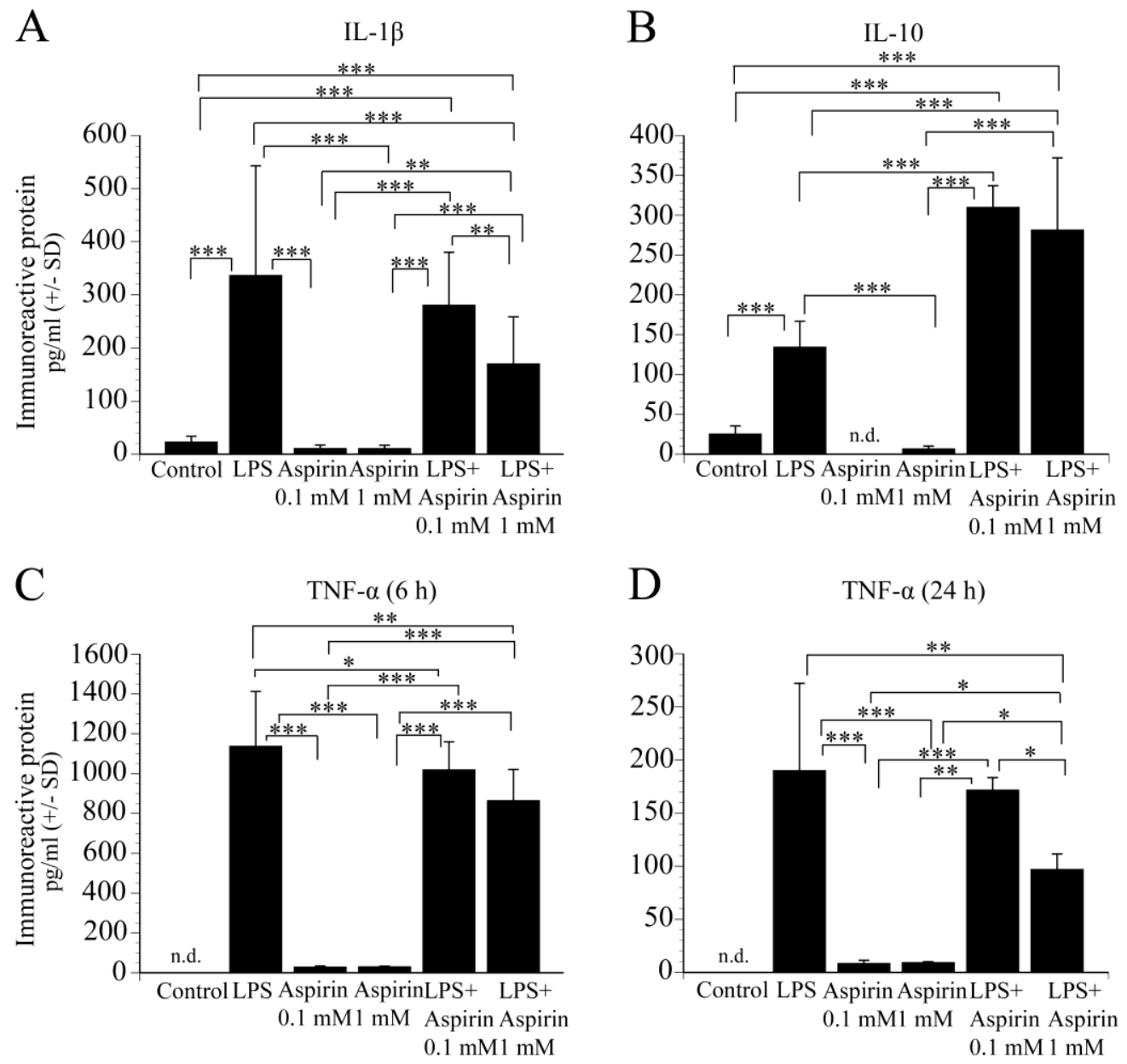

Fig.10. Aspirin reduces the pro-inflammatory cytokine IL-1 $\beta$ and TNF- $\alpha$ levels and increases the anti-inflammatory IL-10 production. After treatments for 6 or $24 \mathrm{~h}$, immunoreactive protein levels $(\mathrm{pg} / \mathrm{ml} \pm \mathrm{SD})$ for IL-1 $\beta$ (A), TNF- $\alpha(\mathbf{C}, \mathbf{D})$ and IL-10 (B) were detected by ELISA. TNF- $\alpha$ production was measured after $6 \mathrm{~h}$ and $24 \mathrm{~h}(\mathbf{C}, \mathbf{D})$. As expected, pro-inflammatory cytokine production was significantly increased in the LPS-challenged cells (A, C, D). Aspirin (1 mM) inhibited this effect for both IL-1 $\beta$ (A) and TNF- $\alpha$ (C, D). The level of the anti-inflammatory cytokine IL-10 was measured after $24 \mathrm{~h}$ (B). Aspirin (0.1 $\mathrm{mM}$ and $1 \mathrm{mM}$ ) did not increase the level of IL-10 in unchallenged cultures but strongly increased it in LPS-challenged cultures (to $115 \%$ and $130 \%$ of the control values, respectively) (B). Error bars indicate means $\pm \mathrm{SD}$ of six replicate measurements from three independent culturing. Data were analyzed with twoway ANOVA. n.d. = not detected. *p $<0.05 ; * * \mathrm{p}<0.01, * * * \mathrm{p}<0.001$. 
Aspirin also affected the production of IL-10, an anti-inflammatory cytokine (Fig. $10 B)$. When administered alone to unchallenged cells it decreased the IL-10 levels. However, LPS challenge increased the basal IL-10 level $(24.98 \pm 10.40 \mathrm{pg} / \mathrm{ml})$ significantly $(134.0 \pm 32.85 \mathrm{pg} / \mathrm{ml})$. When aspirin was co-administered with LPS, the IL-10 protein expression was further increased as compared to the LPS challenged value (low: $309.47 \pm$ $27.49 \mathrm{pg} / \mathrm{ml}$, high: $280.95 \pm 90.91 \mathrm{pg} / \mathrm{ml})$.

These data indicate that both rosuvastatin and aspirin have strong overall antiinflammatory effects, the result of a combination of a strong inhibition of pro-inflammatory cytokine production and a similarly strong activation of anti-inflammatory cytokine synthesis, in LPS-challenged (activated) microglia.

\subsection{The effects of rosuvastatin and aspirin on the expression of inflammation- related genes}

When the profound morphological and functional effects of rosuvastatin and aspirin on the pro- and anti-inflammatory capabilities of the microglia had become apparent, we set out to analyze the effects of these treatments on the expression of 116 inflammationrelated genes in unchallenged and LPS-challenged pure microglial cells. For the rosuvastatin experiments the hierarchical cluster analysis of 75 such genes is summarized in Fig. 11, and the genes with 47 of the the most noteworthy and significant expression changes in response to treatment are listed in Table 1. For the aspirin experiments the hierarchical cluster analysis of 46 such genes is summarized in Fig. 12, and those with the most noteworthy and significant expression changes in response to the treatments are summarized in Table 2.

Our analysis indicated that treatment with $1 \mu \mathrm{M}$ rosuvastatin in unchallenged and LPS-challenged microglia could induce either the upregulation or the downregulation of a number of genes. The levels of expression of selected inflammation-related genes (for example, Ccl24, Ccrl, IL-11, Cxcl1, Ccl4, Ccl5, Hspb1, TGFb-2 and Mbl2) are highlighted in Fig. 13. 


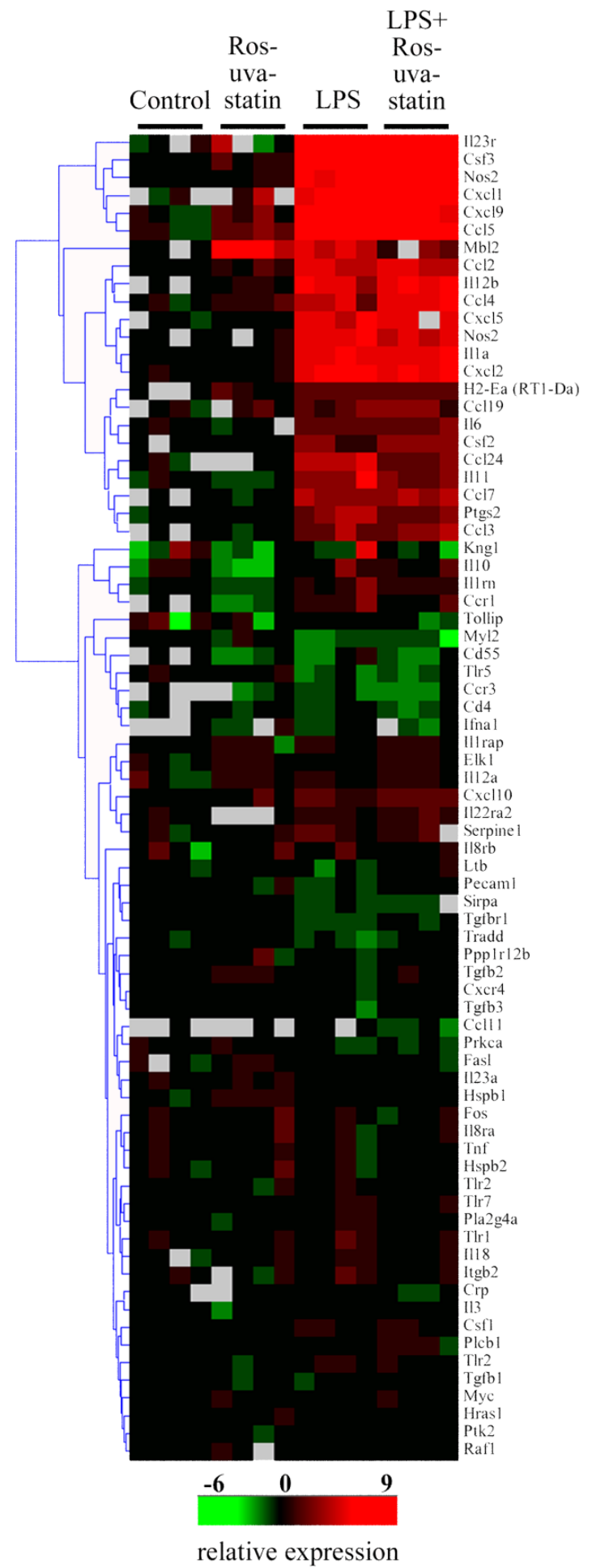

Fig. 11 Hierarchical cluster analysis of inflammation related genes I. Cells (subDIV4) were cultured with or without LPS for $24 \mathrm{~h}$ in the presence or absence of rosuvastatin. Rosuvastatin: $1 \mu \mathrm{M}$; LPS: 20 $\mathrm{ng} / \mathrm{ml}$; LPS + rosuvastatin: LPS $(20 \mathrm{ng} / \mathrm{ml})+$ rosuvastatin $(1 \mu \mathrm{M})$. For hierarchical cluster analysis and visualization, the Hierarchical Clustering Explorer (v3.0) software was used. The complete linkage clustering method was applied with Euclidean distance metric. The heat map depicts expression values relative to control samples on a $\log _{2}$ scale (overexpression: red, repression: green and no change: black). Missing values are indicated in gray. 


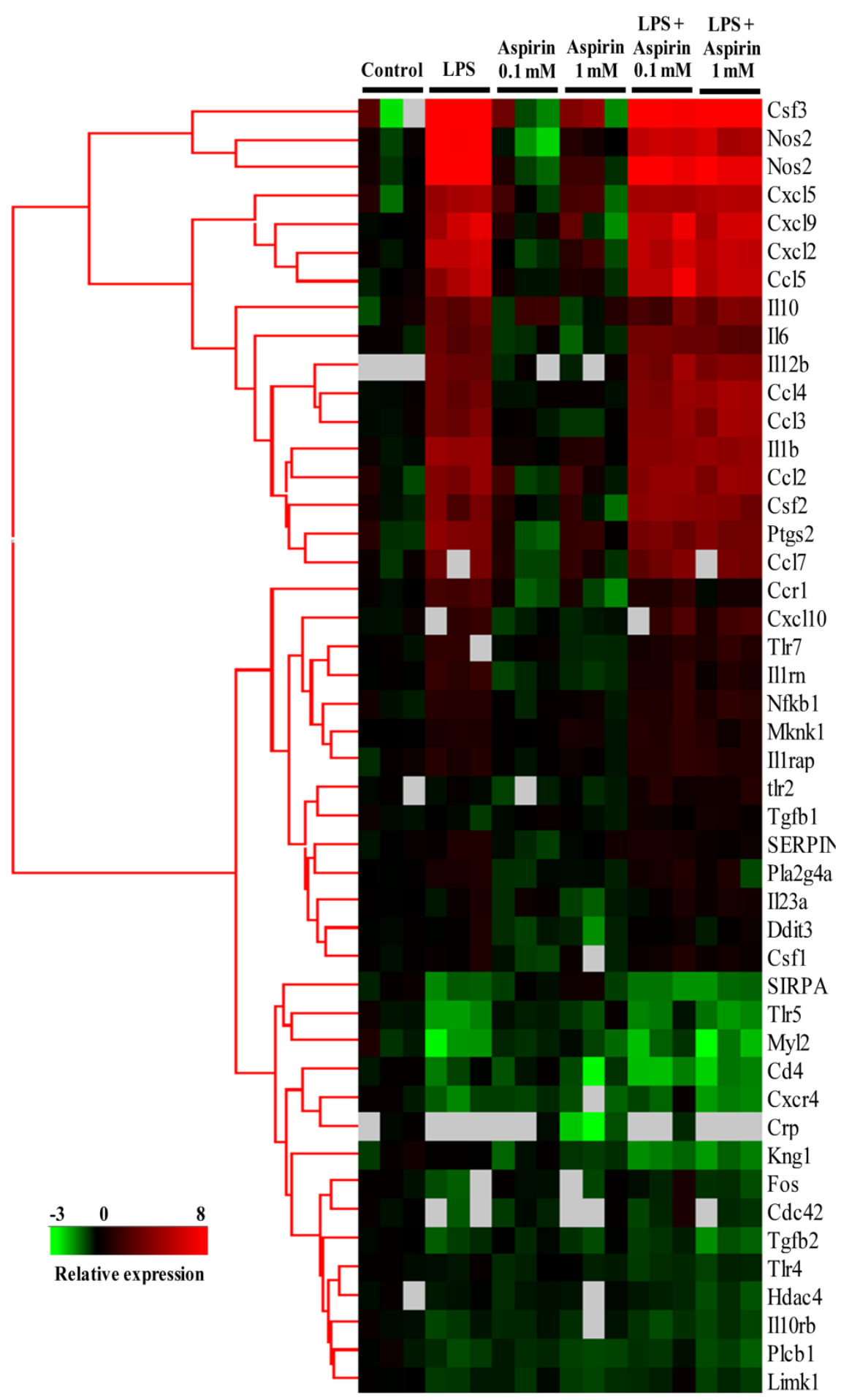

Fig. 12. Hierarchical cluster analysis of inflammation related genes II. Cells (subDIV4) were cultured with or without LPS for $24 \mathrm{~h}$ in the presence or absence of aspirin. Aspirin: $0.1 \mathrm{mM}$ or $1 \mathrm{mM}$; LPS: 20 $\mathrm{ng} / \mathrm{ml}$; LPS + aspirin: LPS $(20 \mathrm{ng} / \mathrm{ml})+$ aspirin $(0.1 \mathrm{mM}$ or $1 \mathrm{mM})$. For hierarchical cluster analysis and visualization, the Hierarchical Clustering Explorer (v3.0) software was used. The complete linkage clustering method was applied with Euclidean distance metric. The heat map depicts expression values relative to control samples on a $\log _{2}$ scale (overexpression: red, repression: green and no change: black). Missing values are indicated in grey. 
Some of these genes responded to rosuvastatin in unchallenged or challenged cells, or were affected by the LPS challenge. The genes upregulated by the LPS challenge included those coding for chemokine ligands 1, 2, 4, 5, 9, 19 and 24 (Cxcl1 = 111.6-fold, Ccl2 = 34.5-fold, Ccl4 = 17.6-fold, Ccl5 = 147.0-fold, Cxcl9 = 118.2-fold, Ccl19 = 5.2-fold and Ccl24 $=24.6$-fold $),$ IL-11 $(I l 11=19.3$-fold $)$, IL-23 receptor $(I l 23 r=246.6$-fold $)$ and mannose-binding lectin (protein C) 2 receptor $(M b l 2=33.2$-fold). Only a few genes were downregulated by the LPS challenge, the most affected one being that of the myosin regulatory light chain $2(M y l 2=-4.4$-fold $)$. Rosuvastatin treatment in unchallenged cells affected fewer, but similarly important microglial genes involved in pro- and antiinflammatory processes. The genes upregulated by rosuvastatin included Cxcll (7.0-fold; Fig. 13D), Ccl5 (6.6-fold; Fig. 13F), and, most importantly, Mbl2 (126.2-fold; Fig. 13I), a crucial factor in the development of innate immunity (Worthley et al., 2005). Rosuvastatin was in general a weak inhibitor of the expression of inflammatory genes as it downregulated only a few genes, notably the anti-inflammatory interleukin-10 $(I l 10=-4.0-$ fold) and the proinflammatory chemokine $(\mathrm{C}-\mathrm{C}$ motif $)$ receptor $1(\mathrm{Ccrl}=-2.9$-fold $)$. When rosuvastatin was applied to LPS-challenged cultures (Table 1, Figs. 11, 13), a more complex picture emerged. Some of the LPS-upregulated genes were inhibited by rosuvastatin, as seen in the case of $C c l 24$, where a substantial, $73.5 \%$ decrease in gene expression was observed, down from the 24.5-fold increase after LPS treatment to a 6.5fold increase (Fig. 13A), or in the case of Ccrl, where a $49.5 \%$ decrease in gene expression was detected (Fig. 13B). Interestingly, rosuvastatin alone did not exhibit a strong effect on these latter genes, but only in those cells activated by LPS (Fig. 13C, D). Other genes were regulated synergistically by rosuvastatin when applied to LPS-challenged microglia. For example, $\mathrm{Cxcll}$ and $\mathrm{Ccl} 4$ were both further upregulated by rosuvastatin in LPS-challenged cells (Fig. 13D, E). Some of the genes related to inflammation were not affected by the LPS challenge, but reacted weakly to rosuvastatin, as seen in $H s p b l$ gene expression (Fig. 13G, $H$ ), where a 2.8 -fold increase was detected. 

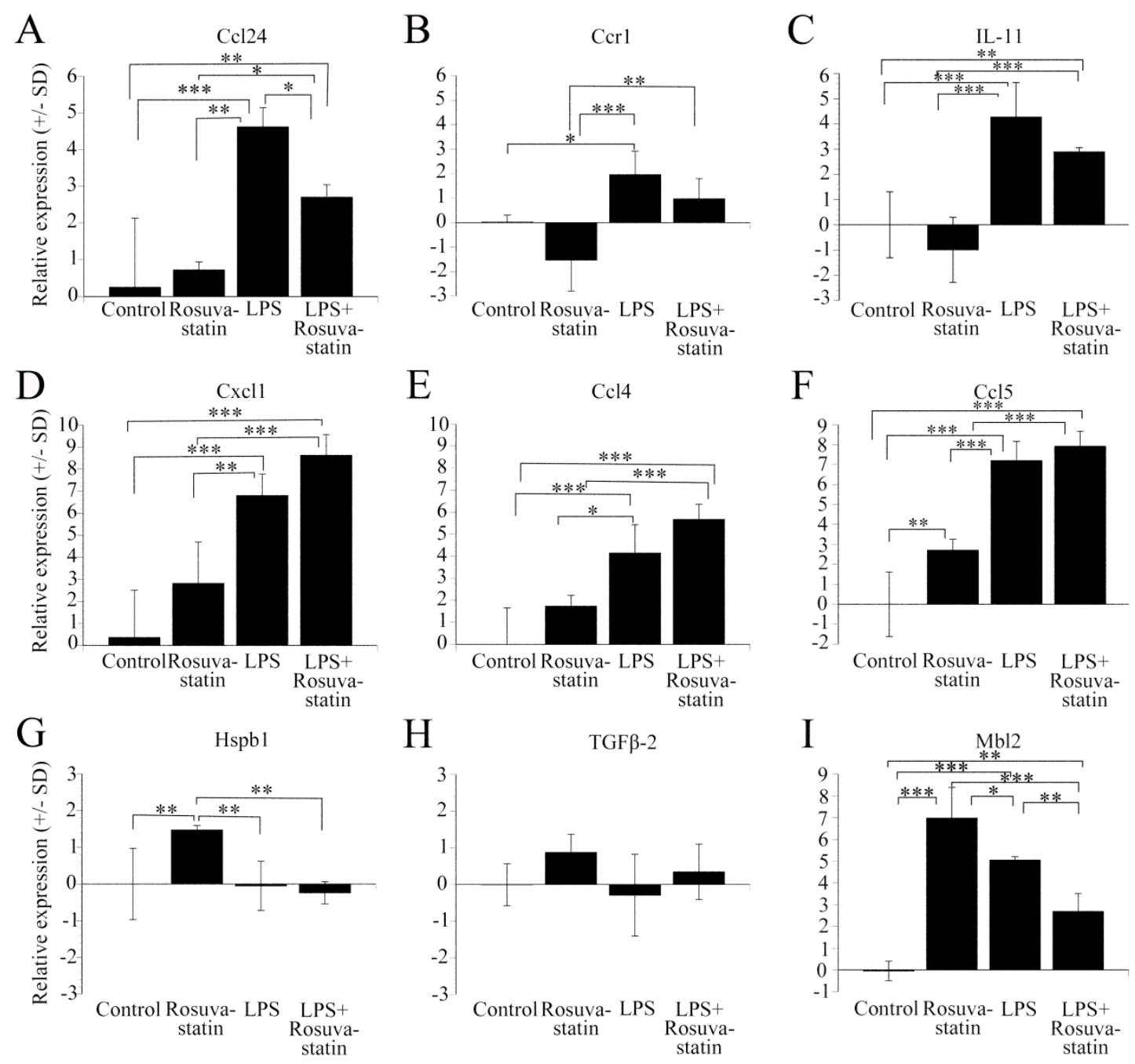

Fig. 13. Relative expression levels of various inflammation-related genes identified by real-time PCR in pure microglia cells treated with rosuvastatin. The cells (subDIV4) were cultured with or without LPS for $24 \mathrm{~h}$ in the presence or absence of rosuvastatin. The extraction of total RNA and the real-time PCR are described in the Materials and methods section. The transcription levels of the chemokine ligand 24 ( $C c l 24$, A), the chemokine receptor $1(C c r l, \mathbf{B}), I L-11(\mathbf{C})$, the chemokine (CXC motif) ligand 1 (or melanoma growth-stimulating activity, alpha), $(\mathrm{Cxcll}, \mathbf{D})$, the chemokine ligand $4(\mathrm{Ccl} 4, \mathbf{E})$, the chemokine ligand 5 $(C c l 5, \mathbf{F})$, the heat shock protein $1(H s p b 1, \mathbf{G})$, the transforming growth factor beta $(T G F \beta-2, \mathbf{H})$ and the mannose-binding lectin (protein C) 2 (Mbl2, I) are shown in unstimulated (control), LPS-challenged and LPSchallenged + rosuvsatatin-treated cells. For some pro-inflammatory genes, rosuvastatin inhibited their expression which was upregulated in LPS-challenged cells. In connection with $\mathrm{Cxcll}, \mathrm{Ccl} 4$ and $C c l 5$, the combined treatment revealed synergistic effects between rosuvastatin and LPS for Cxcl1, Ccl4 and Ccl5. Rosuvatatin increased the levels of expression of $H s p b 1, T G F-\beta$ and Mbl2. Relative expression levels (on a $\log _{2}$ scale) \pm SD from at least four separate experimentsare shown for each condition. Data were analyzed with two-way ANOVA. *p<0.05, **p $<0.01, * * * \mathrm{p}<0.001$ 
Table 1. Differentially expressed transcripts in rosuvastatin-treated pure microglial cells with or without LPS challenge

\begin{tabular}{|c|c|c|c|c|}
\hline Gene & $\begin{array}{l}\text { Name } \\
\text { NCBI Reference Sequence ID } \\
\text { RGD ID }\end{array}$ & $\begin{array}{l}\text { Rosuva- } \\
\text { statin }\end{array}$ & LPS & $\begin{array}{l}\text { LPS+ } \\
\text { Rosuva- } \\
\text { statin }\end{array}$ \\
\hline Cxcl1 & $\begin{array}{l}\text { Chemokine ligand } 1 \text { (melanoma growth- stimulating } \\
\text { activity, alpha) } \\
\text { NM_030845.1, RGD ID } 619869\end{array}$ & +7.05 & +111.55 & +394.01 \\
\hline Csf3 & $\begin{array}{l}\text { Colony stimulating factor } 3 \\
\text { NM_017104.1 (old), NM_017104.2, RGD ID2426 }\end{array}$ & +2.9 & +310.7 & +321.7 \\
\hline $\mathrm{II} 23 \mathrm{r}$ & $\begin{array}{l}\text { Interleukin } 23 \text { receptor } \\
\text { XM_001072576.2, RGD ID } 1586368\end{array}$ & +2.12 & +246.56 & +268.81 \\
\hline $\mathrm{Ccl5}$ & $\begin{array}{l}\text { Chemokine ligand 5 } \\
\text { NM_031116.3, RGD ID } 69069\end{array}$ & +6.56 & +146.97 & +241.56 \\
\hline Nos2 & $\begin{array}{l}\text { Nitric oxide synthase } \\
\text { U26686.1, RGD ID } 3185\end{array}$ & +1.82 & +169.95 & +135.48 \\
\hline Cxc19 & $\begin{array}{l}\text { Chemokine ligand } 9 \\
\text { NM_145672.4, RGD ID } 628798\end{array}$ & +3.82 & +118.20 & +100.95 \\
\hline $\mathrm{Il} 12 \mathrm{~b}$ & $\begin{array}{l}\text { Interleukin 12B } \\
\text { NM_022611.1, RGD ID628704 }\end{array}$ & +1.7 & +42.0 & +87.7 \\
\hline Cxcl2 & $\begin{array}{l}\text { Chemokine ligand } 2 \\
\text { NM_053647.1, RGD ID70069 }\end{array}$ & +1.2 & +75.4 & +67.3 \\
\hline Il1a & $\begin{array}{l}\text { Interleukin 1 alpha } \\
\text { NM_017019.1, RGD ID2890 }\end{array}$ & +1.1 & +45.3 & +57.0 \\
\hline $\mathrm{Ccl} 4$ & $\begin{array}{l}\text { Chemokine ligand } 4 \\
\text { NM_053858.1, RGD ID } 620441\end{array}$ & +3.33 & +17.65 & +51.0 \\
\hline Cxcl5 & $\begin{array}{l}\text { Chemokine ligand } 5 \text { (also known as Cxc16) } \\
\text { NM_022214.1, RGD ID708540 }\end{array}$ & +1.1 & +54.9 & +43.4 \\
\hline $\mathrm{Ccl} 2$ & $\begin{array}{l}\text { Chemokine ligand } 2 \\
\text { NM_031530.1, RGD ID } 3645\end{array}$ & +2.34 & +34.49 & +33.27 \\
\hline$\overline{\mathrm{Ccl} 7}$ & $\begin{array}{l}\text { Chemokine ligand } 7 \\
\text { NM_001007612.1, RGD ID1359152 }\end{array}$ & -1.4 & +12.4 & +14.4 \\
\hline $\mathrm{Ccl} 3$ & $\begin{array}{l}\text { Chemokine ligand } 3 \\
\text { NM_013025.2, RGD ID3647 }\end{array}$ & -1.3 & +9.1 & +11.4 \\
\hline Il6 & $\begin{array}{l}\text { Interleukin } 6 \\
\text { M26744.1, RGD ID2901 }\end{array}$ & -1.1 & +5.6 & +8.4 \\
\hline Il11 & $\begin{array}{l}\text { Interleukin 11 } \\
\text { NM_133519.4, RGD ID } 621475\end{array}$ & -1.99 & +19.28 & +7.40 \\
\hline Ptgs2 & $\begin{array}{l}\text { Prostaglandin endoperoxide synthase } 2 \\
\text { NM_017232.3, RGD ID620349 }\end{array}$ & -1.2 & +11.8 & +7.2 \\
\hline Ccl19 & $\begin{array}{l}\text { Chemokine ligand } 19 \\
\text { NM_001108661.1, RGD ID } 1310336\end{array}$ & +2.39 & +5.21 & +6.87 \\
\hline $\mathrm{Mbl2}$ & $\begin{array}{l}\text { Mannose-binding lectin } 2 \\
\text { NM_022704.2, RGD ID } 67380\end{array}$ & +126.17 & +33.22 & +6.46 \\
\hline Ccl24 & $\begin{array}{l}\text { Chemokine ligand 24 } \\
\text { NM_001013045.1, RGD ID } 1310245\end{array}$ & +1.65 & +24.55 & +6.51 \\
\hline Cxcl10 & $\begin{array}{l}\text { Chemokine ligand } 10 \\
\text { NM_139089.1, RGD ID620209 }\end{array}$ & +1.8 & +4.5 & +5.5 \\
\hline Il22ra2 & $\begin{array}{l}\text { Interleukin } 22 \text { receptor, alpha } 2 \\
\text { NM_001003404.1, RGD ID1303169 }\end{array}$ & +1.1 & +2.5 & +4.0 \\
\hline Il10 & $\begin{array}{l}\text { Interleukin } 10 \\
\text { NM_012854.2, RGD ID } 2886\end{array}$ & -3.97 & +3.08 & +2.69 \\
\hline Il1rn & $\begin{array}{l}\text { Interleukin } 1 \text { receptor antagonist } \\
\text { NM_022194.2, RGD ID } 621159\end{array}$ & -2.19 & +3.76 & +2.63 \\
\hline Tlr2 & $\begin{array}{l}\text { Toll-like receptor } 2 \\
\text { NM_198769.2, RGD ID735138 }\end{array}$ & -1.5 & +1.8 & +2.1 \\
\hline
\end{tabular}




\begin{tabular}{|c|c|c|c|c|}
\hline Ccr1 & $\begin{array}{l}\text { Chemokine receptor } 1 \\
\text { NM_020542.2, RGD ID } 708446\end{array}$ & -2.89 & +3.88 & +1.96 \\
\hline Traf2 & $\begin{array}{l}\text { Tnf receptor-associated factor } 2 \\
\text { NM_001107815.2, RGD ID1310457 }\end{array}$ & +1.6 & +1.9 & +1.6 \\
\hline Mknk1 & $\begin{array}{l}\text { MAP kinase-interacting serine/threonine kinase } 1 \\
\text { NM_001044267.1, RGD ID1559603 }\end{array}$ & +1.4 & +1.6 & +1.5 \\
\hline CD47 & $\begin{array}{l}\text { Cluster of differentiation } 47 \\
\text { NM_019195.2, RGD ID } 2308\end{array}$ & -1.1 & +1.3 & +1.4 \\
\hline Pla2g4a & $\begin{array}{l}\text { Phospholipase A2, group IVA (cytosolic, Ca-dependent) } \\
\text { NM_133551.2, RGD ID67366 }\end{array}$ & -1.7 & +1.7 & +1.3 \\
\hline Tlr7 & $\begin{array}{l}\text { Toll-like receptor } 7 \\
\text { EF032637.1, RGD ID1563357 }\end{array}$ & -1.2 & +1.8 & +1.3 \\
\hline Ddit3 & $\begin{array}{l}\text { DNA-damage-inducible transcript } 3 \\
\text { NM_001109986.1, RGD ID62391 }\end{array}$ & -1.3 & +1.7 & +1.3 \\
\hline Il18rap & $\begin{array}{l}\text { Interleukin } 18 \text { receptor accessory protein } \\
\text { XM_003750691.2, RGD ID727867 }\end{array}$ & +1.2 & +1.7 & +1.2 \\
\hline Hmgn1 & $\begin{array}{l}\text { High-mobility group nucleosome binding domain } 1 \\
\text { NM_001013184.1, RGD ID1307761 }\end{array}$ & +1.6 & +1.2 & +1.0 \\
\hline Scarb1 & $\begin{array}{l}\text { Scavenger receptor class B, member } 1 \\
\text { NM_031541.1, RGD ID2302 }\end{array}$ & +1.1 & -1.3 & +1.0 \\
\hline Jun & $\begin{array}{l}\text { Jun proto-oncogene } \\
\text { NM_021835.3, RGD ID2943 }\end{array}$ & +1.2 & -1.8 & -1.1 \\
\hline Hspb1 & $\begin{array}{l}\text { Heat shock protein } 1 \\
\text { NM_031970.3, RGD ID } 61306\end{array}$ & +2.79 & -1.04 & -1.19 \\
\hline $\mathrm{Hc}$ & $\begin{array}{l}\text { Clathrin, heavy chain } \\
\text { NM_019299.1, RGD ID2364 }\end{array}$ & +1.0 & +1.1 & -1.3 \\
\hline Tgfb3 & $\begin{array}{l}\text { Transforming growth factor, beta } 3 \\
\text { NM_013174.2, RGD ID } 3851\end{array}$ & +1.2 & -1.9 & -1.4 \\
\hline Elmo1 & $\begin{array}{l}\text { Engulfment and cell motility } 1 \\
\text { NM_001108415.1, RGD ID1308182 }\end{array}$ & -1.0 & -1.7 & -1.6 \\
\hline Prkca & $\begin{array}{l}\text { Protein kinase C, alpha } \\
\text { NM_001105713.1, RGD ID3395 }\end{array}$ & +1.3 & -2.1 & -1.7 \\
\hline Il10rb & $\begin{array}{l}\text { Interleukin } 10 \text { receptor, beta } \\
\text { NM_001107111.1, RGD ID1560373 }\end{array}$ & -1.4 & -1.1 & -1.9 \\
\hline Tgfbr1 & $\begin{array}{l}\text { Transforming growth factor, beta receptor } 1 \\
\text { NM_012775.2, RGD ID3852 }\end{array}$ & -1.2 & -2.5 & -2.0 \\
\hline Sirpa & $\begin{array}{l}\text { The signal-regulatory protein a } \\
\text { NM_013016.2, RGD ID3449 }\end{array}$ & -1.5 & -2.7 & -2.8 \\
\hline Tlr5 & $\begin{array}{l}\text { Toll-like receptor } 5 \\
\text { FJ750588.1, RGD ID631351 }\end{array}$ & -1.2 & -3.0 & -2.9 \\
\hline Ccl11 & $\begin{array}{l}\text { Chemokine ligand } 11 \\
\text { NM_019205.1, RGD ID3644 }\end{array}$ & -1.2 & -1.4 & -3.0 \\
\hline Myl2 & $\begin{array}{l}\text { Myosin, light polypeptide } 2 \\
\text { NM_001035252.1 (old), NM_001035252.2, } \\
\text { RGD ID1564245 }\end{array}$ & -1.3 & -4.4 & -5.2 \\
\hline
\end{tabular}

The National Center for Biotechnology Information (NCBI) Reference Sequence Database can be retrieved at http://www.ncbi.nlm.nih.gov/refseq/. A description of a gene function (RGD ID) can be found in The Rat Genome Database 2015 (Shimoyama et al., 2015) at http://rgd.mcw.edu/. Data are expressed as fold-change over the expression of unchallenged and untreated (control) microglial cells. Treatments had different effects on inflammation-related genes. LPS mostly induced the upregulation of genes as compared with the untreated control microglia. Rosuvastatin alone also had some effects on these genes. Combined treatment demonstrated that rosuvastatin had different effects on LPS-activated microglia cells: inhibited the effect of LPS on certain genes (e.g. Ccl24, Ccr1, Kngl, Nos2, Ill1), while it had a synergistic effect with LPS on others (e.g. Cxcll, Ccl4, Il23r). Note that in Fig. 13 relative expression levels in $\log _{2}$ scale are used. 
The analysis of experiments that involved aspirin indicated that treatments with 0.1 $\mathrm{mM}$ or $1 \mathrm{mM}$ aspirin in unchallenged and LPS-challenged microglia could induce either the upregulation or the downregulation of a number of inflammation-related genes. The genes upregulated by the LPS challenge included those coding for chemokine ligands 1, 2, 4, 5, 7, $9($ Cxcll $=84.30$-fold, $C c l 2=16.95$-fold, $C c l 4=9.80$-fold, $C c l 5=38.26$-fold, $C x c l 5=$ 33.19, Cxcl9 = 73.44-fold,) IL-1 $\beta$ (Il1 $\beta=24.70$-fold $)$, IL-6 receptor $($ Il6 $=7.57$-fold $)$ and nitric oxide synthase $(\operatorname{Nos} 2=369.22$-fold). Only a few genes were downregulated by the LPS challenge, including Tgfb2 (-1.73-fold), Sirpa (-2.42-fold), Tlr5 (-3.42-fold) and Myl2 (-4.46-fold).

The levels of expression of some inflammation-related genes strongly downregulated by aspirin are highlighted in Fig. 14. Aspirin treatment in unchallenged cells affected fewer, but similarly important microglial genes involved in pro- and anti-inflammatory processes. In unchallenged cells the genes downregulated by aspirin $(0.1 \mathrm{mM}$ or $1 \mathrm{mM})$ included the anti-inflammatory DNA damage inducible transcript 3 (Ddit $=-1.43$-fold, and -1.79 -fold), the interleukin 1 receptor antagonist (Ill rn = -1.37-fold; -1.44 -fold), the proinflammatory IL6 (Il6 = -1.23-fold; -1.55 -fold) and the proinflammatory chemokine (C-C motif) receptor $1($ C crl $=-1.42$-fold, -1.44 -fold $)$. When aspirin was co-administered to LPS-challenged cultures (Table 2), a more complex picture emerged. Some of the LPS-upregulated genes were inhibited by aspirin, as seen in the case of Ccrl (Fig. 14A), IL1-rn (Fig. 14B) or Nos2 (Fig. 14D). Kngl (Fig. 14C), a proinflammatory gene was downregulated by both aspirin treatments following LPS challenge. Other genes were further upregulated by aspirin when applied to LPS-challenged microglia such as the proinflammatory Ccl4 or the chemokine Ccl5 or Csf2 (Table 2). 
A

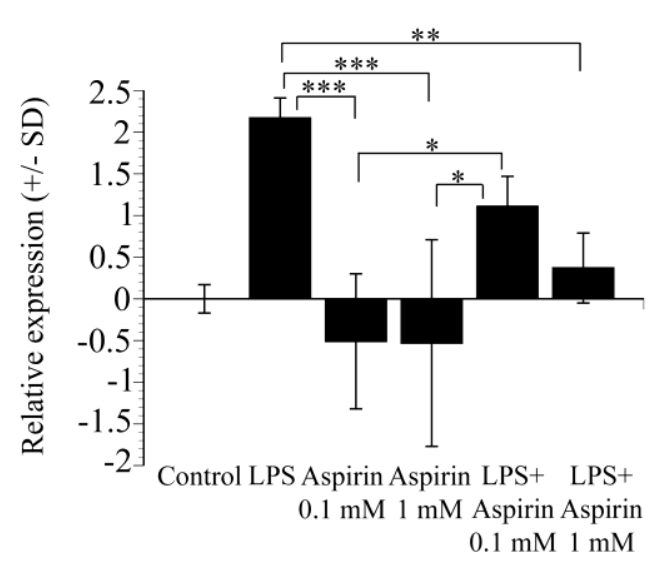

$\mathrm{C}$

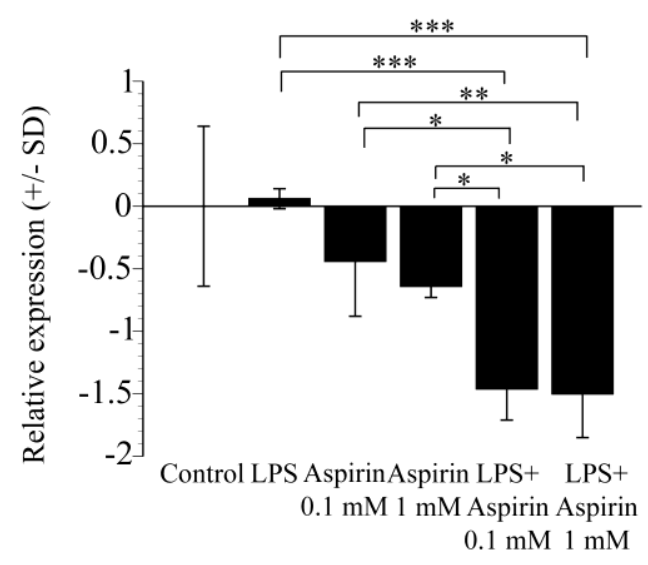

B IL-1rn

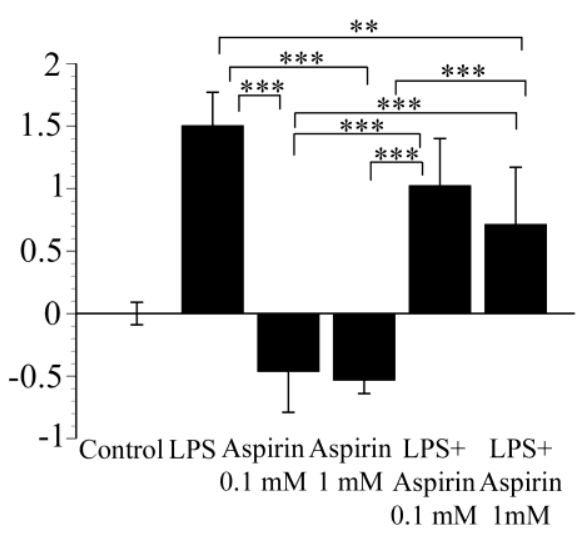

$\mathrm{D}$

Nos2

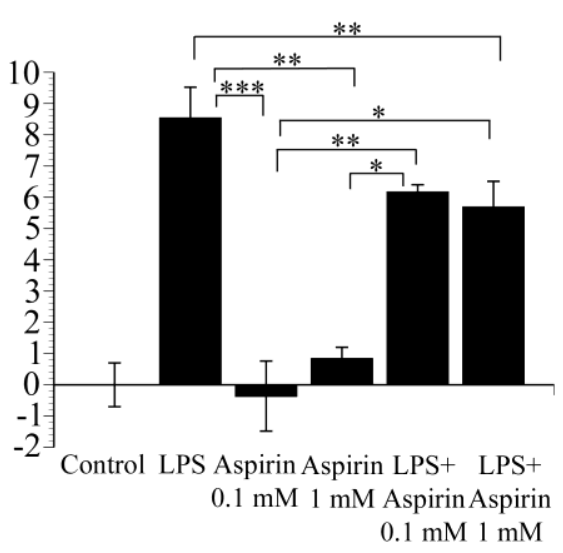

Fig. 14. Relative expression levels of various inflammation-related genes identified by real-time PCR in pure microglia cells treated with aspirin. The transcription levels of the chemokine receptor 1 ( $\mathrm{Ccrl}$, A), the interleukin 1 receptor antagonist $(I L-1 r n, \mathbf{B})$, the kininogen $1(K n g l, \mathbf{C})$ and the nitric oxide synthase (Nos2, D) genes are shown in unchallenged (control), LPS-challenged and LPS-challenged + aspirin-treated cells. Except for Kngl, these proinflammatory genes were upregulated in LPS-challenged cells but were all strongly inhibited by both doses of aspirin. Relative expression levels (on a $\log _{2}$ scale) \pm SD from at least 3 separate experiments are shown for each condition. Data were analyzed with two-way ANOVA. ${ }^{*} \mathrm{p}<0.05, * * \mathrm{p}<0.01, * * * \mathrm{p}<0.001$. 
Table 2. Differentially expressed transcripts in aspirin-treated pure microglial cells with or without LPS challenge

\begin{tabular}{|c|c|c|c|c|c|c|}
\hline Gene & $\begin{array}{l}\text { Name } \\
\text { NCBI Reference Sequence ID } \\
\text { RGD ID }\end{array}$ & LPS & $\begin{array}{l}\text { Aspirin } \\
0.1 \mathrm{mM}\end{array}$ & $\begin{array}{c}\text { Aspirin } \\
1 \mathrm{mM}\end{array}$ & $\begin{array}{c}\text { LPS+ } \\
\text { Aspirin } \\
0.1 \mathrm{mM}\end{array}$ & $\begin{array}{c}\text { LPS+ } \\
\text { Aspirin } \\
1 \text { mM }\end{array}$ \\
\hline $\mathrm{Ccl} 2$ & $\begin{array}{l}\text { Chemokine ligand } 2 \\
\text { NM_031530.1 } \\
\text { RGD ID } 3645\end{array}$ & +16.95 & +1.14 & +1.70 & +20.92 & +21.35 \\
\hline $\mathrm{Ccl} 3$ & $\begin{array}{l}\text { Chemokine ligand } 3 \\
\text { NM_013025.2 } \\
\text { RGD ID } 3647\end{array}$ & +11.33 & -1.01 & -1.31 & +18.41 & +24.79 \\
\hline$\overline{\mathrm{Ccl} 4}$ & $\begin{array}{l}\text { Chemokine ligand } 4 \\
\text { NM_053858.1 } \\
\text { RGD ID 620441 }\end{array}$ & +9.80 & -1.05 & +1.06 & +17.68 & +29.80 \\
\hline Cc15 & $\begin{array}{l}\text { Chemokine ligand } 5 \\
\text { NM_031116.3 } \\
\text { RGD ID } 69069\end{array}$ & +38.26 & +1.02 & +1.35 & +84.12 & +62.69 \\
\hline Ccl7 & $\begin{array}{l}\text { Chemokine ligand } 7 \\
\text { NM_001007612.1 } \\
\text { RGD ID 1359152 }\end{array}$ & +11.48 & -1.14 & +1.50 & +10.82 & +11.82 \\
\hline Ccr1 & $\begin{array}{l}\text { Chemokine receptor } 1 \\
\text { NM_020542.2 } \\
\text { RGD ID } 708446\end{array}$ & +4.51 & -1.42 & -1.44 & +2.16 & +1.29 \\
\hline Cxcl1 & $\begin{array}{l}\text { Chemokine ligand } 1 \text { (melanoma growth- } \\
\text { stimulating activity, alpha) } \\
\text { NM_030845.1 } \\
\text { RGD ID } 619869\end{array}$ & +84.30 & -1.51 & +4.11 & +43.46 & +246.78 \\
\hline Cxcl2 & $\begin{array}{l}\text { Chemokine ligand } 2 \\
\text { NM_053647.1 } \\
\text { RGD ID } 70069\end{array}$ & +69.02 & -1.37 & +1.73 & +63.70 & +60.07 \\
\hline Cxcl5 & $\begin{array}{l}\text { Chemokine ligand 5 (Cxc16) } \\
\text { NM_022214.1 } \\
\text { RGD ID } 708540\end{array}$ & +33.19 & +1.41 & +2.11 & +34.89 & +46.37 \\
\hline Cxc19 & $\begin{array}{l}\text { Chemokine ligand } 9 \\
\text { NM_145672.4 } \\
\text { RGD ID } 628798\end{array}$ & +73.44 & +1.40 & +1.22 & +86.22 & +68.51 \\
\hline Cxcl10 & $\begin{array}{l}\text { Chemokine ligand } 10 \\
\text { NM_139089.1 } \\
\text { RGD ID } 620209\end{array}$ & +2.83 & -1.30 & -1.24 & +3.93 & +3.21 \\
\hline Csf1 & $\begin{array}{l}\text { Colony stimulating factor-1 } \\
\text { AF515736.1 } \\
\text { RGD ID621063 }\end{array}$ & +1.31 & -1.49 & -1.03 & +1.48 & +1.30 \\
\hline Csf2 & $\begin{array}{l}\text { Colony stimulating factor-2 } \\
\text { XM_001074265.1(old) } \\
\text { NM_053852.1 } \\
\text { RGD ID621065 }\end{array}$ & +10.01 & +1.20 & -1.00 & +20.66 & +14.84 \\
\hline Csf3 & $\begin{array}{l}\text { Colony stimulating factor } 3 \\
\text { NM_017104.1 (old), NM_017104.2 } \\
\text { RGD ID } 2426\end{array}$ & +305.58 & +1.23 & +4.96 & +282.90 & +278.46 \\
\hline Ddit3 & $\begin{array}{l}\text { DNA-damage inducible transcript } 3 \\
\text { NM_001109986.1 } \\
\text { RGD ID } 62391\end{array}$ & +1.25 & -1.43 & -1.79 & +1.14 & +1.04 \\
\hline $\mathrm{II} 1 \beta$ & $\begin{array}{l}\text { Interleukin } 1 \text { beta } \\
\text { NM_031512.2 } \\
\text { RGD ID } 2891\end{array}$ & +24.70 & +1.18 & +1.62 & +19.88 & +22.98 \\
\hline Il1rap & $\begin{array}{l}\text { Interleukin } 1 \text { receptor accessory protein } \\
\text { NM_012968.1 } \\
\text { RGD ID2893 }\end{array}$ & +1.97 & -1.02 & +1.06 & +2.30 & +2.08 \\
\hline
\end{tabular}




\begin{tabular}{|c|c|c|c|c|c|c|}
\hline Il1rn & $\begin{array}{l}\text { Interleukin } 1 \text { receptor antagonist } \\
\text { NM_022194.2 } \\
\text { RGD ID } 621159\end{array}$ & +2.83 & -1.37 & -1.44 & +2.02 & +1.64 \\
\hline I16 & $\begin{array}{l}\text { Interleukin } 6 \\
\text { M26744.1 } \\
\text { RGD ID 2901 }\end{array}$ & +7.57 & -1.23 & -1.55 & +10.82 & +7.22 \\
\hline Il10 & $\begin{array}{l}\text { Interleukin } 10 \\
\text { NM_012854.2 } \\
\text { RGD ID } 2886\end{array}$ & +8.47 & +2.01 & +1.04 & +6.28 & +11.87 \\
\hline Il18 & $\begin{array}{l}\text { IFN-gamma-inducing factor (IL-18) } \\
\text { AY077842.1 } \\
\text { RGD ID } 2889\end{array}$ & +2.24 & +1.63 & -1.29 & +1.90 & +2.03 \\
\hline Kng1 & $\begin{array}{l}\text { Kininogen } 1 \\
\text { NM_012696.2 } \\
\text { RGD ID } 2980\end{array}$ & +1.04 & -1.36 & -1.55 & -2.75 & $\begin{array}{l}-2.82 \\
\end{array}$ \\
\hline Nos2 & $\begin{array}{l}\text { Nitric oxide synthase } \\
\text { U26686.1 } \\
\text { RGD ID } 3185\end{array}$ & +369.22 & -1.28 & +1.78 & +73.06 & +51.21 \\
\hline Pla2g4a & $\begin{array}{l}\text { Phospholipase A2, group IVA (cytosolic, } \\
\text { calcium-dependent) } \\
\text { NM_133551.2 } \\
\text { RGD ID } 67366\end{array}$ & +1.73 & $\begin{array}{l}-1.33 \\
\end{array}$ & -1.16 & +1.66 & +1.07 \\
\hline Ptgs2 & $\begin{array}{l}\text { Prostaglandin endoperoxide synthase } 2 \\
\text { NM_017232.3 } \\
\text { RGD ID } 620349\end{array}$ & +16.83 & -1.33 & +2.14 & +11.76 & +12.55 \\
\hline Sirpa & $\begin{array}{l}\text { The signal-regulatory protein a } \\
\text { NM_013016.2 } \\
\text { RGD ID } 3449\end{array}$ & -2.42 & -1.22 & +1.04 & -2.84 & -2.63 \\
\hline Tgfb1 & $\begin{array}{l}\text { Transforming growth factor, beta } 1 \\
\text { NM_021578.2 } \\
\text { RGD ID } 69051\end{array}$ & -1.21 & +1.05 & -1.10 & +1.25 & +1.34 \\
\hline Tgfb2 & $\begin{array}{l}\text { Transforming growth factor, beta } 2 \\
\text { NM_031131.1 } \\
\text { RGD ID } 70491\end{array}$ & -1.73 & -1.15 & -1.43 & -1.47 & -2.41 \\
\hline Tlr2 & $\begin{array}{l}\text { Toll-like receptor } 2 \\
\text { NM_198769.2 } \\
\text { RGD ID } 735138\end{array}$ & -1.03 & $\begin{array}{l}-1.49 \\
\end{array}$ & -1.22 & +1.63 & +1.63 \\
\hline Tlr7 & $\begin{array}{l}\text { Toll-like receptor } 7 \\
\text { EF032637.1 } \\
\text { RGD ID } 1563357\end{array}$ & +2.71 & +1.05 & -1.36 & +1.79 & +2.21 \\
\hline
\end{tabular}

The National Center for Biotechnology Information (NCBI) Reference Sequence Database can be retrieved at http://www.ncbi.nlm.nih.gov/refseq/. A description (Shimoyama et al., 2015) of a gene function (RGD ID) can be found in The Rat Genome Database 2015 at http://rgd.mcw.edu/. Data are expressed as fold-change over the expression of unchallenged and untreated (control) microglial cells. Treatments had different effects on inflammation-related genes. Most of the genes were upregulated by LPS challenge. Aspirin, either alone or in combination with LPS, had differential effects on the expression of certain genes. For example, aspirin treatment downregulated $T g f b 2, K n g 1$ or Ddit3, while upregulated other genes such as $C s f 3, I L-10$ and $C x C l 1$ in unchallenged cells. In LPS-challenged microglia, aspirin inhibited ILIrn, Ccr1, Kngl, Nos2, while it had a synergistic effect with LPS on others (e.g. Cxcl5, Ccl4, Csf2). Note that in Fig. 13 relative expression levels in $\log _{2}$ scale are used. 


\section{DISCUSSION}

We carried out a complex quantitative investigation of the morphological, functional and gene expression characteristics of pure microglial cells of embryonic origin after either rosuvastatin or aspirin treatment in unstimulated or LPS-challenged cultures, and highlighted the complex beneficial effects of both drugs that make them excellent candidates for preventive neuroinflammatory therapy with well-balanced properties of enhanced anti-inflammatory and subdued proinflammatory effects. Although microglial cells prepared from embryonic nervous tissue may differ from those of the adult brain in certain characteristics (Floden and Combs, 2006), they are nevertheless similarly responsive to immunological (LPS) challenge and suitable for morphological, functional and gene expression studies. When activated, the microglia display both pro- and anti-inflammatory properties as they can be polarized along a continuum toward a detrimental (M1) or a beneficial (M2) state in the injured CNS (Kroner et al., 2014). Inflammation that is mediated, and perhaps enhanced, by the microglia has been implicated in a number of neuropathological conditions, ranging from acute injuries (Loane and Byrnes, 2010) and chronic inflammatory conditions (Gay, 2007; Napoli and Neumann, 2010) to neurodegenerative diseases (Long-Smith et al., 2009; Prokop et al., 2013).

Statins are commonly used for the treatment of high blood cholesterol levels (Burg and Espenshade, 2011). They are classified on the basis of their lipid-lowering efficacy and their lipophilic/hydrophilic nature (Hamelin and Turgeon, 1998; Jones et al., 1998; Davidson, 2002; Schachter, 2005); while lipophilic statins penetrate the cell membrane, hydrophilic statins such as rosuvastatin (Crestor; AstraZeneca Pharmaceuticals, LP, Wilmington, DE, USA) are transported through the blood-brain barrier via multiple transporters, including the family of organic anion-transporting polypeptides (Kitamura et al., 2008; Abbott et al., 2010). Rosuvastatin exhibits the greatest inhibitory effect on cholesterol biosynthesis (McTaggart et al., 2001) and most favorably alters the high-density lipoprotein profile among statins (Asztalos et al., 2007); it was the fourth highest-selling prescription drug in the USA in 2013 (http://www.drugs.com/stats/top100/2013/sales). Although their main action is to block cholesterol synthesis, other effects of statins, including those on the regression of atherosclerotic coronary lesions, are also important (Wierzbicki et al., 2003). Expecting similarly beneficial effects on the microglia, we determined how rosuvastatin modulates both pro- and anti-inflammatory actions by affecting numerous morphological, functional and gene expression parameters in pure 
microglial cultures. These cultures provide a unique opportunity to study these functional and expression parameters without the significant influence of any contaminating cell types. Our microglial cultures were $>99 \%$ pure, a crucial factor when the levels of secreted proand anti-inflammatory peptides or gene expression levels are measured, as other cell types in the CNS are also capable of expressing such peptides (Gruol et al., 2014).

Our studies revealed the effects of rosuvastatin on various quantitative morphological properties of the microglia. Rosuvastatin affected the area, perimeter and TI profoundly in both unchallenged and LPS-challenged cells. It generally promoted microspike formation and increased the cell perimeter and TI through ramification. Concomitantly with the increase in cell area in both unchallenged and LPS-challenged cells, rosuvastatin affected the synthesis of Iba1, a protein that is implicated in actin cytoskeleton remodeling (Sasaki et al., 2001; Ohsawa et al., 2004). As expected, LPS treatment caused microglia activation that resulted in a low TI, but the combined treatment with LPS + rosuvastatin inhibited this activation through the development of microspikes and the cells becoming more ramified. Rosuvastatin strongly inhibited microglia proliferation and adhesion as it significantly decreased the number of cells in both naïve and LPS-challenged cultures. Although the precise mechanisms are not known, statins are able to inhibit mitosis through cell cycle arrest in G1 (Yang et al., 2008) and G2/M (Gao et al., 2012). As rosuvastatin displays some anti-mitogenic effect, its regular use may prove beneficial in lowering the risks of a number of cancer types (Simon et al., 2012). To quantify cell adhesion, we used the cell index value (Atienza et al., 2005; Jarvis et al., 2011). Our finding that rosuvastatin lowered cell adhesion in both unchallenged and LPS-challenged cells is in harmony with previous reports on the ability of statins to decrease the expression of cell adhesion molecules (Weber et al., 1997; Wierzbicki et al., 2003).

We also examined how rosuvastatin altered fluid-phase phagocytosis. Phagocytosis is crucial in both the normal and the pathologic CNS as it efficiently eliminates foreign materials, apoptotic cells and cell debris (Kettenmann et al., 2011), and alteration of this clearance function could be harmful (Hickman and El Khoury, 2014; Lue et al., 2014). For example, proinflammatory phenotypes are linked to the phagocytic activity, and the blocking of phagocytosis may prevent some forms of inflammatory neurodegeneration, and might therefore be beneficial during infection, trauma, ischemia, neurodegeneration and aging (Neher et al., 2011; He et al., 2014). LPS is a strong activator of microglial phagocytosis (Nakamura, 2002; Lund et al., 2006; Szabo and Gulya, 2013). In our study, rosuvastatin inhibited phagocytosis completely in the LPS-challenged microglia, while it 
was ineffective in inhibiting the basal-level phagocytosis in unchallenged cells, indicating that rosuvastatin is a potent inhibitor of this function only in proinflammatory situations.

Cytokines, important immunomodulators in the normal functioning of the CNS, can be released, among others, by the microglial cells. Cytokines can also be harmful: previous studies have shown that neurodegeneration originating through neuroinflammation is often elicited by activated microglia (McGeer and McGeer, 2003, 2010) through the release of different proinflammatory cytokines and chemokines (Hanisch, 2002). High levels of IL-1 $\beta$ could be observed, for instance, in the vicinity of amyloid plaques of AD patients (McGeer et al., 1993; Lindberg et al., 2005; Ghosh et al., 2013), where activated microglia accumulate (Rodriguez et al., 2014). Previous studies also suggested that statins reduce the levels of some of the proinflammatory cytokines (Lindberg et al., 2005; Nakamichi et al., 2006; Veillard et al., 2006) and increase the anti-inflammatory cytokine IL-10 (Schönbeck and Libby, 2004). As expected, both pro- (IL-1 $\beta$, TNF- $\alpha$ ) and anti-inflammatory cytokines (IL-10) were increased in LPS-challenged cells as compared with the unchallenged (control) group. Rosuvastatin did not significantly affect the basal cytokine levels in unchallenged microglia, but strongly inhibited the levels of the proinflammatory cytokines IL-1 $\beta$ and TNF- $\alpha$ when tested in LPS-challenged cells. Besides the inhibition of these proinflammatory agents, rosuvastatin exerted a direct anti-inflammatory effect by elevating the level of IL-10 in both unchallenged and LPS-challenged cells. Effects of rosuvastatin on such diverse immune mechanisms of microglia as phagocytosis and cytokine production indicated a strong likelihood of its involvement in many other immune system-wide functions and possible effects on inflammation-related genes.

We demonstrated that rosuvastatin, LPS and their combination had differential effects on the expression of inflammation-related genes. Several genes were upregulated after LPS challenge, confirming its strong proinflammatory effects on the microglia. Rosuvastatin itself, and in combination with LPS, displayed different effects on gene expression. Although rosuvastatin was not able to decrease all the LPS-upregulated genes, it suppressed the pro-inflammatory effects of LPS on some genes such as Ccl24 or Ccrl. Ccl24 is a chemokine that can readily be upregulated by proinflammatory cytokines or microbial stimulus such as LPS (Watanabe et al., 2002). Ccrl is implicated in MS and experimental autoimmune encephalomyelitis (EAE). Previous studies suggested that $C c r 1$ could be upregulated in EAE (Rottman et al., 2000), and the microglia expressed Ccr1 around the demyelinating plaques, making Ccr1 antagonists or inhibitors possible targets for the development of an effective therapy for MS (Hesselgesser et al., 1998; Eltayeb et al., 2007). 
Rosuvastatin additionally increased the expression of certain other genes. Its general effects on the microglia were predominantly anti-inflammatory. The gene most upregulated by rosuvastatin was $M b l 2$, which is important in innate immunity (Worthley et al., 2005; Ip et al., 2009) and involved in the stimulation of phagocytosis (Stuart et al., 2005). Hspbl was also upregulated by rosuvastatin. Hspb1 is a heat-shock protein with strong anti-apoptotic potential that regulates the cytoskeleton dynamics through F-actin stabilization (Concannon et al., 2003). Cxcl1 has been reported to be an anti-inflammatory protein with a neuroprotective role (Omari et al., 2009). Additional chemokine genes such as Ccl2 (El Khoury et al., 2007; El Khoury and Luster, 2008), Cxcl1 (Bosivert et al., 2006) and Ccl5 were all upregulated in our studies and implicated in microglia recruitment to areas of inflammation. Although $\mathrm{Ccl5}$ has been demonstrated to induce proinflammatory mechanisms (Skuljec et al., 2011), it has also been shown to ameliorate AD-like pathology by recruiting microglia to $\beta$-amyloid deposits (Lee et al., 2012) and to protect against neuronal injury (Campbell et al., 2013; Lim and Mochetti, 2015).

We also examined if aspirin was able to exert similar effects on microgial cells. As being one of the most commonly used drugs, it is noted for its strong anti-inflammatory actions. It acetylates the active site of the enzyme COX, and irreversibly blocks the conversion of arachidonic acid to prostanoid (Vane and Botting, 2003). Apart from its classical beneficial role in cardiovascular diseases, however, aspirin may also be beneficial in neuroinflammation-related disorders given that appropriate target cells, the microglia, are present in the nervous tissue.

Aspirin reversed the morphological effects of LPS-induced microglia activation through the increase of the area, perimeter and TI values; the combined treatment with LPS also inhibited this activation through the development of microspikes and inducing the cells to become more ramified. Aspirin also affected the synthesis of Iba1 protein (Oshawa et al., 2004; Szabo et al., 2016). Similarly to rosuvastatin, aspirin inhibited phagocytosis in the LPS-challenged microglia only, while it did not affect the basal phagocytotic activity in unchallenged cells, a physiological microglial function crucial for maintaining a healthy CNS.

LPS is the main ligand for Toll-like receptor 4 (TLR4). TLR4-induced signalling activates the NF- $\mathrm{KB}$ and MAPK pathways leading to the production of proinflammatory cytokines (Fuentes et al., 2016; Korneev et al., 2017). Aspirin inhibits the production of proinflammatory cytokines through the suppression of LPS-induced NF- $\mathrm{B}$ and MAPK pathways in microglial cells (Cianciulli et al., 2016; Sun et al., 2017; Yang et al., 2014). 
$\mathrm{NF}-\kappa \mathrm{B}$ activity is suppressed in the cytoplasm with an inhibitory I $\mathrm{B}$ protein. The phosphorylation and degradation of I $\kappa \mathrm{B}$ activates NF- $\kappa \mathrm{B}$ and allows to the NF- $\kappa \mathrm{B}$ dimer to translocate to the nucleus and activate target genes such as $I L-1 \beta$ and $T N F-\alpha$ (Sun et al, 2017; Yang et al, 2014). LPS-stimulated degradation of IкB could be strongly inhibited by aspirin (Yang et al, 2014). The anti-inflammatory property is mediated by inhibition of several members of MAPK family, e.g. p38 MAPK and ERK1/2 (Jung et.al, 2009; Li et al., 2017); according to recent data, aspirin enhances the inhibition of p38 MAPK and ERK phosphorylation in BV2 microglial cells (Yang et al., 2014).

Previous studies demonstrated a strong relationship between cytokines and neurodegenerative diseases through the activation of microglia (McGeer and McGeer, 2010). Microglial cells activated by $\beta$-amyloid deposits produce toxic mediators and proinflammatory cytokines such as IL-1 $\beta$, IL-6, TNF- $\alpha$ and enzymes such as iNos that could result in chronic inflammation (Benveniste et al, 2001). High level of IL-1 $\beta$ could be observed in the vicinity of amyloid plaques of AD patients (McGeer et al., 1993) that could also be responsible for plaque accumulation (Akiyama et al., 2000). COX-2 is also increased in AD patients (Akiyama et al., 2000). Similarly to the findings for AD, previous studies also suggested that activated microglia was associated with neuronal loss during PD due to the activation of cytokines, COX-2 and iNos expression (Orr et al., 2002; Phani et al., 2012). Increased levels of TNF- $\alpha$ and NO could cause demyelination in MS (Minagar et al., 2002). As expected, both pro- (IL-1 $\beta$, TNF- $\alpha$ ) and anti-inflammatory (IL-10) cytokines were increased in LPS-challenged microglia as compared with the unchallenged cells. Aspirin did not significantly affect the basal cytokine levels in unchallenged cells, but effectively reduced the levels of the proinflammatory cytokines IL-1 $\beta$ and TNF- $\alpha$ when tested in LPS-challenged microglia. Besides the inhibition of these proinflammatory agents, aspirin was also able to elevate the anti-inflammatory IL-10 in LPS-challenged cells. Thus, aspirin is remarkably beneficial as it concomitantly decreased proinflammation- but increased anti-inflammation-related mechanisms in immunochallenged cells.

We also demonstrated that aspirin, LPS and their combination had differential effects on the expression of several inflammation-related genes in pure microglial cells. Some of these genes encode markers that can be related to different microglia subtypes proposed as M1 or M2 phenotypes (Moehle and West, 2015; Orihuela et al., 2016). In this context, for example, the proinflammatory $I L-1 \beta, I L-6, I L-18, C x c l 9, T N F-\alpha, C x c l 10$, and the chemokine $C c l 5$, genes encode M1 markers, while the anti-inflammatory $I L-10$ and the proinflammatory Tgfb2 genes are M2 markers (Franco and Fernández-Suárez, 2015). In an 
LPS-based animal model for PD, a Rho kinase inhibitor reversed the inflammatory M1 to anti-inflammatory M2 microglia, decreased NF-кB activation, and inhibited IL-12 and TNF- $\alpha$ generation (He et al., 2016), demonstrating a protective effect against LPS-mediated dopamine degeneration. It must be noted, however, that the concept of M1/M2 polarization of microglia cells is not universally accepted and needs reassessment (Martinez and Gordon, 2014; Ransohoff, 2016). Our study demonstrated that several genes were upregulated after LPS challenge, confirming its strong proinflammatory effects on microglia. Aspirin, both alone and in combination with LPS, displayed different effects on microglial gene expression. It suppressed the proinflammatory effects of LPS on some genes such as $C c r l$ and $N o s 2$. It may be of importance that $C c r l$ was previously associated with both MS and EAE (Rottman et al., 2000) and Ccr1 protein was localized around the demyelinating plaques (Eltayeb et al., 2007). In our experiment (Fig. 14A) both aspirin doses decreased $C c r 1$ expression. Multiple studies concluded that Nos2 has a central role in inflammatory reactions and pathogenesis of certain neurodegenerative diseases (Galea and Feinstein, 1999; Akiyama et al., 2000; Block and Hong, 2005). Thus, downregulating Nos2 expression could be crucial for possible future therapies. We demonstrated that aspirin inhibited Nos2 expression significantly in LPS-challenged microglia. Kininogen (Kng1) is well known for its proinflammatory properties (Stewart et al., 1997; Sharma and Yusof, 1998) as it increases the release of inflammatory cytokines and affects the formation of inflammatory exudate and pain (Ueno and Ohishi, 2003). Aspirin also increased the expression of genes that were predominantly anti-inflammatory e.g. $I L-10, T g f b 1$ or $C c l 5$. For example, IL-10 is a well known anti-inflammatory cytokine that limits the production of proinflammatory cytokines including IL- $1 \alpha$ and $-\beta$, IL-6, IL-12, IL-18, and TNF- $\alpha$ (Couper et al., 2008). Previous studies showed that Tgfb1 had a protective effect against excitotoxicity and the loss of this protein resulted in neurodegeneration (Brionne et al., 2003). Ccl5 was also upregulated due to aspirin treatment similarly to that of rosuvastatin,. Upregulation of such anti-inflammatory genes in the prevention or amelioration of neurodegenerative disorders could prove beneficial.

In summary, both rosuvastatin and aspirin elicit strong responses to microglial functions in vitro. They inhibit the harmful proinflammatory signals and significantly enhance the beneficial anti-inflammatory actions after LPS challenge in pure microglial cells. Their pleiotropic beneficial effects include the robust inhibition of phagocytosis and the synthesis of proinflammatory cytokines combined with a very strong stimulation of anti- 
inflammatory cytokine production, and a beneficial differential expression of a number of inflammation-related genes. In connection with rosuvastatin we also observed some antimitogenic effect. As activated microglia often damage neuronal tissues or cause chronic inflammation by excessive cytokine production combined with high level of phagocytosis, effective inhibition of proinflammatory actions by these drugs could be an important prophylactic therapy in preventing or ameliorating neuroinflammation and thus neurodegeneration. Our data indicate that both rosuvastatin and aspirin beneficially regulate microglia, cells that could be a target in treating or preventing neurodegenerative disorders. Given the large population who receives aspirin for pain medication and prevention of a number of pathologic conditions or rosuvastatin for lipid-lowering treatment, to study the interactions of theses drugs with the nervous system is even more important. Early observations revealed that NSAIDs could reduce the risk of AD (McGeer et al., 1996; Stewart et al., 1997), a notion that has not been proven in randomised controlled trials assessing the efficacies of aspirin, steroidal and non-steroidal anti-inflammatory drugs in AD (Jaturapatporn et al., 2012). Previous studies also suggested that statins may reduce the risk of dementia (Jick et al., 2000). As the effects of aspirin on selected morphological, functional and gene expression characteristics of microglia are very similar to that of rosuvastatin, and these drugs are frequently prescribed together for a number of cardiovascular illnesses, their extended use may have contributed to the lower than expected incidence of AD (Schrijvers et al., 2012). Thus, the individual and combined effects of aspirin and rosuvastatin on microglial functions should be further analyzed for a prophylactic therapeutic approach in neurodegenerative disorders. Microglial cells could therefore be a novel, specific therapeutic targets in fighting neurodegenerative disorders. 


\section{CONCLUSION}

We characterized the morphological, functional and immunomodulatory effects of rosuvastatin and aspirin in pure secondary microglial cells derived from mixed primary cortical cultures of embryonic (E18) rat forebrains.

Analyzing Iba1 immunoreactivity and binary silhouettes of microglia we determined the morphological changes of microglial cells by measuring their TI values. LPS-induced activation resulted in low TI $(\mathrm{TI}<2)$ but both rosuvastatin and aspirin were able to inhibit this effect and increased the cell size, filopodia and microspike development of microglial cells $(\mathrm{TI}>6)$.

The quantitative analysis of the engulfed fluorescent microspheres revaled that both rosuvastatin and aspirin inhibited the LPS-induced phagocytosis by more than $50 \%$.

We used enzyme-linked immunosorbent assay to determine the amount of proinflammatory and anti-inflammatory cytokine level released by microglia. Although LPS treatment elevated the proinflammatory IL-1 $\beta$ (over $150 \mathrm{pg} / \mathrm{ml}$ ) and TNF- $\alpha$ (over 900 $\mathrm{pg} / \mathrm{ml}$ ) levels, both drugs significantly reduced the levels of these cytokines by about 20$50 \%$. Rosuvastatin and aspirin were also able to increase the anti-inflammatory IL-10 production in LPS-activated cells from $25-40 \mathrm{pg} / \mathrm{ml}$ to $280-310 \mathrm{pg} / \mathrm{ml}$ as compared to unchallenged (control) cells.

Rosuvastatin and aspirin also affected the expression patterns of certain genes. We analyzed the effects of these treatments on 116 inflammation related genes in the unchallenged and LPS-induced pure microglial cells. Both drugs induced either the upregulation or the downregulation of a number of genes. Rosuvastatin was able to supress the proinflammatory effects of LPS on some genes such as $C c l 24$ or $C c r l$, and upregulated anti-inflammatory genes such as Cxcll or Hspbl, while aspirin downregulated proinflammatory genes such as $I L-6, C c r l$ or Nos 2 and upregulated the anti-inflammatory $\mathrm{Ccl} 5$.

In summary the main findings of this study are:

1. TI values revealed that both rosuvastatin and aspirin promoted ramified microglial morphology with TI $>6$, and both drugs were able to antagonize the morphological changes characteristic of LPS-induced microglial activation $(\mathrm{TI}<2)$;

2. Rosuvastatin inhibited the cell proliferation by $40-60 \%$ and decreased the adhesion of microglial cells; 
3. Both rosuvastatin and aspirin were able to reduce the LPS-induced robust phagocytic activity but they did not affect to the basal (physiological) phagocytosis;

4. Rosuvastatin and aspirin had strong overall anti-inflammatory effect as they inhibited the proinflammatory cytokines (IL-1 $\beta, \mathrm{TNF}-\alpha$ ) and stimulated the anti-inflammatory IL-10 in activated microglial cells;

5. Analysis of the gene expression patterns revealed that both rosuvastatin and aspirin had various effects on a large number of inflammation-related genes in pure microglial cells. Out of the 116 inflammation related genes rosuvastatin significantly changed the expression pattern of 47 genes, while aspirin altered significantly the expression level of 30 genes. They inhibited several proinflammatory genes such as Ccrl, Ccl24, IL-6 or Nos2, while they upregulated other genes such as the anti-inflammatory Cxcll, Ccl5 or $I L-10$.

\section{ACKNOWLEDGMENTS}

I would like to thank to my supervisor Professor Karoly Gulya for his help. I am also grateful to Zsuzsa Ambrus and Olga Darányi for the technical support. This work was supported by the program project grants to the University of Szeged from the Ministry of Resources (TÁMOP-4.2.1.B-09/1/KONV-2010-0005 and TÁMOP-4.2.2.A-11/1/KONV2012-0052) through the European Union Cohesion Fund and from the National Development Agency of Hungary (KMR_12_1_2012_0072). I dedicate this work to my family for their help and support. 


\section{REFERENCES}

Abbott NJ, Patabendige AA, Dolman DE, Yusof SR, Begley DJ (2010) Structure and function of the blood-brain barrier. Neurobiol Dis 37:13-25.

Ahmed Z, Shaw G, Sharma VP, Yang C, McGowan E, Dickson DW (2007) Actin-binding proteins coronin-1a and IBA-1 are effective microglial markers for immunohistochemistry. J Histochem Cytochem 55:687-700.

Aïd S, Bosetti F (2011) Targeting cyclooxygenases-1 and -2 in neuroinflammation: Therapeutic implications. Biochimie 93(1):46-51.

Akiyama H, Barger S, Barnum S, Bradt B, Bauer J, Cole GM, Cooper NR, Eikelenboom P, Emmerling M, Fiebich BL, Finch CE, Frautschy S, Griffin WS, Hampel H, Hull M, Landreth G, Lue L, Mrak R, Mackenzie IR, McGeer PL, O'Banion MK, Pachter J, Pasinetti G, Plata-Salaman C, Rogers J, Rydel R, Shen Y, Streit W, Strohmeyer R, Tooyoma I, Van Muiswinkel FL, Veerhuis R, Walker D, Webster S, Wegrzyniak B, Wenk G, Wyss-Coray T (2000) Inflammation and Alzheimer's disease. Neurobiol Aging 21:383-421.

Amann R, Peskar BA (2002) Anti-inflammatory effects of aspirin and sodium salicylate. Eur J Pharmacol 447:1-9.

Arends YM, Duyckaerts C, Rozemuller JM, Eikelenboom P, Hauw JJ (2000) Microglia, amyloid and dementia in alzheimer disease. A correlative study. Neurobiol Aging 21(1):39-47.

Asztalos BF, Le Maulf F, Dallal GE, Stein E, Jones PH, Horvath KV, McTaggart F, Schaefer EJ (2007) Comparison of the effects of high doses of rosuvastatin versus atorvastatin on the subpopulations of high-density lipoproteins. Am J Cardiol 99:681685.

Atienza JM, Zhu J, Wang X, Xu X, Abassi Y (2005) Dynamic monitoring of cell adhesion and spreading on microelectronic sensor arrays. J Biomol Screen 10:795.

Banati RB, Gehrmann J, Schubert P, Kreutzberg GW (1993) Cytotoxicity of microglia. Glia 7:111-118.

Benveniste EN, Nguyen VT, O'Keefe GM (2001) Immunological aspects of microglia: relevance to Alzheimer's disease. Neurochem Int 39:381-391. 
Berk M, Dean O, Drexhage H, McNeil JJ, Moylan S, O'Neil A, Davey CG, Sanna L, Maes M (2013) Aspirin: a review of its neurobiological properties and therapeutic potential for mental illness. BMC Med 11:74.

Block ML, Hong JS (2005) Microglia and inflammation-mediated neurodegeneration: multiple triggers with a common mechanism. Prog Neurobiol 76:77-98.

Brionne TC, Tesseur I, Masliah E, Wyss-Coray T (2003) Loss of TGF-beta 1 leads to increased neuronal cell death and microgliosis in mouse brain. Neuron 40:1133-1145.

Boisvert WA, Rose DM, Johnson KA, Fuentes ME, Lira SA, Curtiss LK, Terkeltaub RA (2006) Up-regulated expression of the CXCR2 ligand KC/GRO-alpha in atherosclerotic lesions plays a central role in macrophage accumulation and lesion progression. Am J Pathol 168:1385-1395.

Burg JS, Espenshade PJ (2011) Regulation of HMG-CoA reductase in mammals and yeast. Progr Lipid Research 50:403-410.

Campbell LA, Avdoshina V, Rozzi S, Mocchetti I (2013) CCL5 and cytokine expression in the rat brain: differential modulation by chronic morphine and morphine withdrawal. Brain Behav Immun 34:130-140.

Candelario-Jalil E, González-Falcón A, García-Cabrera M, Alvarez D, Al-Dalain S, Martínez G, León OS, Springer JE (2003) Assessment of the relative contribution of COX-1 and COX-2 isoforms to ischemia-induced oxidative damage and neurodegeneration following transient global cerebral ischemia. $J$ Neurochem 86(3):545-55.

Cianciulli A, Calvello R, Porro C, Trotta T, Salvatore R, Panaro MA (2016) PI3k/Akt signalling pathway plays a crucial role in the anti-inflammatory effects of curcumin in LPS-activated microglia. Int Immunopharmacol 36:282-290.

Choi SH, Aid S, Bosetti F (2009) The distinct roles of cyclooxygenase-1 and -2 in neuroinflammation: implications for translational research. Trends Pharmacol Sci 30(4):174-81.

Concannon CG, Gorman AM, Samali A (2003) On the role of Hsp27 in regulating apoptosis. Apoptosis 8:61-70.

Couper KN, Blount DG, Riley EM (2008) IL-10: the master regulator of immunity to infection. J Immunol 180:5771-5777. 
Cordle A, Landreth G (2005) 3-Hydroxy-3-methylglutaryl-coenzyme A reductase inhibitors attenuate $\beta$-amyloid-induced microglial inflammatory responses. J Neurosci 25:299307.

Davidson MH (2002) Rosuvastatin: a highly efficacious statin for the treatment of dyslipidaemia. Exp Opin Invest Drugs 11:125-141.

El Khoury J, Toft M, Hickman SE, Means TK, Terada K, Geula C, Luster AD (2007) Ccr2 deficiency impairs microglial accumulation and accelerates progression of Alzheimerlike disease. Nat Med 13:432-438.

El Khoury J, Luster AD (2008) Mechanisms of microglia accumulation in Alzheimer's disease: therapeutic implications. Trends Pharmacol Sci 29:626-632.

Eltayeb S, Berg AL, Lassmann H, Wallström E, Nilsson M, Olsson T, Ericsson-Dahlstrand A, Sunnemark D (2007) Temporal expression and cellular origin of CC chemokine receptors CCR1, CCR2 and CCR5 in the central nervous system: insight into mechanism of MOG-induced EAE. J Neuroinflamm 4:14.

Fabian G, Farago N, Feher LZ, Nagy LI, Kulin S, Kitajka K, Bito T, Tubak V, Katona RL, Tiszlavicz L, Puskas LG (2011) High-density real-time PCR-based in vivo toxicogenomic screen to predict organ-specific toxicity. Int J Mol Sci 12:6116-6134.

Famer D, Wahlund LO, Crisby M (2010) Rosuvastatin reduces microglia in the brain of wild type and ApoE knockout mice on a high cholesterol diet; implications for prevention of stroke and AD. Biochem Biophys Res Commun 402:367-372.

Floden AM, Combs CK (2006) Beta-amyloid stimulates murine postnatal and adult microglia cultures in a unique manner. J Neurosci 26(17):4644-8.

Franco R, Fernández-Suárez D (2015) Alternatively activated microglia and macrophages in the central nervous system. Prog Neurobiol 131:65-86.

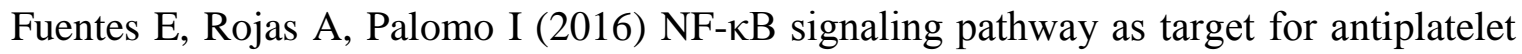
activity. Blood Rev 30:309-315.

Fujita H, Tanaka J, Toku K, Tateishi N, Suzuki Y, Matsuda S, Sakanaka M, Maeda N (1996) Effects of GM-CSF and ordinary supplements on the ramification of microglia in culture: A morphometrical study. Glia 18:269-281. 
Galea E, Feinstein DL (1999) Regulation of the expression of the inflammatory nitric oxide synthase (NOS2) by cyclic AMP FASEB J 13:2125-2137.

Gao B, Vavricka SR, Meier PJ, Stieger B (2015) Differential cellular expression of organic anion transporting peptides OATP1A2 and OATP2B1 in the human retina and brain: implications for carrier-mediated transport of neuropeptides and neurosteriods in the CNS. Pflugers Arch 467(7):1481-1493.

Gao Y, Lu XC, Yang HY, Liu XF, Cao J, Fan L (2012) The molecular mechanism of the anticancer effect of atorvastatin: DNA microarray and bioinformatic analyses. Int J Mol Med 30:765-774.

Gay F (2007) Activated microglia in primary MS lesions: defenders or aggressors? Int MS J MS Forum 14:78-83.

Gehrmann J, Matsumo Y, Kreutzberg G (1995) Microglia: intrinsic immunoeffector cell of the brain. Brain Res Rev 20:269-287.

Ghosh S, Wu MD, Shaftel SS, Kyrkanides S, LaFerla FM, Olschowka JA, O'Banion MK (2013) Sustained interleukin-1 $\beta$ overexpression exacerbates tau pathology despite reduced amyloid burden in an Alzheimer's mouse model. J Neurosci 33:5053-5064.

Ginhoux F, Greter M, Leboeuf M, Nandi S, See P, Gokhan S, Mehler MF, Conway SJ, Ng LG, Stanley ER, Samokhvalov IM, Merad M (2010) Fate mapping analysis reveals that adult microglia derive from primitive macrophages. Science 330:841-845.

Graeber MB (2010) Changing face of microglia. Science 330:783-788.

Gresa-Arribas N, Vieitez C, Dentesano G, Serratosa J, Saura J, Sola C (2012) Modelling neuroinflammation in vitro: A tool to test the potential neuroprotective effect of antiinflammatory agents. Plos One 7:9.

Gruol DL, Vo K, Bray JG (2014) Increased astrocyte expression of IL-6 or CCL2 in transgenic mice alters levels of hippocampal and cerebellar proteins. Front Cell Neurosci 8:234.

Gonzalez-Scarano F, Baltuch G (1999) Microglia as mediators of inflammatory and degenerative diseases. Annu Rev Neurosci 22:219-240. 
Hamelin BA, Turgeon J (1998) Hydrophilicity/lipophilicity: relevance for the pharmacology and clinical effects of HMG-CoA reductase inhibitors. Trends Pharmacol Sci 19:26-37.

Hanisch UK (2002) Microglia as a source and target of cytokines. Glia 40:140-155.

He GL, Liu Y, Li M, Chen CH, Gao P, Yu ZP, Yang XS (2014) The amelioration of phagocytic ability in microglial cells by curcumin through the inhibition of EMFinduced pro-inflammatory responses. J Neuroinflamm 11:49.

He Q, Li YH, Guo SS, Wang Y, Lin W, Zhang Q, Wang J, Ma CG, Xiao BG (2016) Inhibition of Rho-kinase by Fasudil protects dopamine neurons and attenuates inflammatory response in an intranasal lipopolysaccharide-mediated Parkinson's model. Eur J Neurosci 43:41-52.

Hesselgesser J, Ng HP, Liang M, Zheng W, May K, Bauman JG, Monahan S, Islam I, Wei GP, Ghannam A, Taub DD, Rosser M, Snider RM, Morrissey MM, Perez HD, Horuk R (1998) Identification and characterization of small molecule functional antagonists of the CCR1 chemokine receptor. J Biol Chem 273:15687-15692.

Hickman SE, El Khoury J (2014) TREM2 and the neuroimmunology of Alzheimer's disease. Biochem Pharmacol 88:495-498.

Ho RH, Tirona RG, Leake BF, Glaeser H, Lee W, Lemke CJ, Wang Y, Kim RB (2006) Drug and bile acid transporters in rosuvastatin hepatic uptake: function, expression, and pharmacogenetics. Gastroenterology 130(6):1793-806.

Hussain M, Javeed A, Ashraf M, Zhao Y, Mukhtar MM, Rehman MU (2012) Aspirin and immune system. Int. Immunopharmacol 12:10-20.

Jarvis GE, Bihan, Hamaia S, Pugh N, Ghevaert JG, Pearce C, Hughes CE, Watson SP, Ware J, Rudd E, Farndale RW (2011) A role for adhesion and degranulation-promoting adapter protein in collagen-induced platelet activation mediated via integrin $\alpha_{2} \beta_{1}$. J Thrombosis Haemostasis 10:268-277.

Jaturapatporn D, Isaac MG, McCleery J. \& Tabet N (2012) Aspirin, steroidal and nonsteroidal anti-inflammatory drugs for the treatment of Alzheimer's disease. Cochrane Database Syst Rev 2, CD006378.

Jick H, Zornberg GL, Jick SS, Seshadri S, Drachman DA (2000) Statins and the risk of dementia. Lancet 356(9242):1627-1631. 
Jones P, Kafonek S, Laurora I, Hunninghake D (1998) Comparative dose efficacy study of atorvastatin versus simvastatin, pravastatin, lovastatin, and fluvastatin in patients with hypercholesterolemia (the CURVES study). Am J Cardiol. 81:582-587.

Jung HW, Yoon CH, Park KM, Han HS, Park YK (2009) Hexane fraction of Zingiberis Rhizoma Crudus extract inhibits the production of nitric oxide and proinflammatory cytokines in LPS-stimulated BV2 microglial cells via the NF-kappaB pathway. Food Chem Toxicol 47:1190-1197.

Kata D, Földesi I, Feher LZ, Hackler LJr, Puskas LG, Gulya K (2016) Rosuvastatin enhances anti-inflammatory and inhibits pro-inflammatory functions in cultured microglial cells. Neuroscience 314:47-63.

Kettenmann H, Hanisch UK, Noda M, Verkhratsky A (2011) Physiology of microglia. Physiol Rev 91:461-553.

Kitamura S, Maeda K, Wang Y, Sugiyama Y (2008) Involvement of multiple transporters in the hepatobiliary transport of rosuvastatin. Drug Metab Dispos 36:2014-2023.

Korneev KV, Atretkhany KN, Drutskaya MS, Grivennikov SI, Kuprash DV, Nedospasov SA (2017) TLR-signaling and proinflammatory cytokines as drivers of tumorigenesis. Cytokine 89:127-135.

Kreutzberg GW (1996) Microglia: a sensor for pathological events in the CNS. Trends Neurosci 19:312-318.

Kroner A, Greenhalgh AD, Zarruk JG, Passos Dos Santos R, Gaestel M, David S (2014) TNF and increased intracellular iron alter macrophage polarization to a detrimental M1 phenotype in the injured spinal cord. Neuron 83:1098-1116.

Kurata T, Miyazaki K, Kozuki M, Morimoto N, Ohta Y, Ikeda Y, Abe K (2012) Atorvastatin and pitavastatin reduce senile plaques and inflammatory responses in a mouse model of Alzheimer's disease. Neurol Res 34:601-610.

Lee JK, Schuchman EH, Jin HK, Bae JS (2012) Soluble CCL5 derived from bone marrowderived mesenchymal stem cells and activated by amyloid $\beta$ ameliorates Alzheimer's disease in mice by recruiting bone marrow-induced microglia immune responses. Stem Cells 30:1544-1555. 
Li H, Yoon JH, Won HJ, Ji HS, Yuk HJ, Park KH, Park HY, Jeong TS (2017) Isotrifoliol inhibits pro-inflammatory mediators by suppression of TLR/NF- $\kappa \mathrm{B}$ and TLR/MAPK signaling in LPS-induced RAW264.7 cells. Int Immunopharmacol 45:110-119.

Lim ST, Mocchetti I (2015) Pharmacological induction of CCL5 in vivo prevents gp120mediated neuronal injury. Neuropharmacology 92:98-107.

Lindberg C, Crisby M, Winblad B, Schultzberg M (2005) Effects of statins on microglia. J Neurosci Res 82:10-19.

Liu H, Yu N, Lu S, Ito S, Zhang X, Prasad B, He E, Lu X, Li Y, Wang F, Xu H, An G, Unadkat JD, Kusuhara H, Sugiyama Y, Sahi J (2015) Solute Carrier Family of the Organic Anion-Transporting Polypeptides 1A2- Madin-Darby Canine Kidney II: A Promising In Vitro System to Understand the Role of Organic Anion-Transporting Polypeptide $1 \mathrm{~A} 2$ in Blood-Brain Barrier Drug Penetration. Drug Metab Dispos 43(7):1008-1018.

Loane DJ, Byrnes KR (2010) Role of microglia in neurotrauma. Neurother J Am Soc Exp Neurother 7:366-377.

Long-Smith CM, Sullivan AM, Nolan YM (2009) The influence of microglia on the pathogenesis of Parkinson's disease. Progr Neurobiol 89:277-287.

Lowry OH, Rosebrough NJ, Farr AL, Randall RJ (1951) Protein measurement with the Folin phenol reagent. J Biol Chem 193:265-275.

Lue LF, Schmitz C, Walker DG (2014) What happens to microglial TREM2 in Alzheimer's disease: Immunoregulatory turned into immunopathogenic? Neuroscience 302:138-50.

Lund S, Christensen KV, Hedtjärn M, Mortensen AL, Hagberg H, Falsig J, Hasseldam H, Schrattenholz A, Pörzgen P, Leis M (2006) The dynamics of the LPS triggered inflammatory response of murine microglia under different culture and in vivo conditions. J Neuroimmunol 180:71-87.

Marchini C, Angeletti M, Eleuteri AM, Fedeli A, Fioretti E (2005) Aspirin modulates LPSinduced nitric oxide release in rat glial cells. Neurosci Lett 381(1-2):86-91.

Martinez FO, Gordon S (2014) The M1 and M2 paradigm of macrophage activation: time for reassessment. F1000 Prime Rep. 6:13. 
McGeer PL, Kawamata T, Walker DG, Akiyama H, Tooyama I, McGeer EG (1993) Microglia in degenerative neurological disease. Glia 7:84-92.

McGeer PL, McGeer EG (1995) The inflammatory response system of brain: implications for therapy of Alzheimer and other neurodegenerative diseases. Brain Res Brain Res Rev. 21(2):195-218.

McGeer PL, Schulzer M, McGeer EG (1996) Arthritis and anti-inflammatory agents as possible protective factors for Alzheimer's disease: a review of 17 epidemiologic studies. Neurology 47:425-432.

McGeer EG, McGeer PL (2003) Inflammatory processes in Alzheimer's disease. Progr Neuropsychopharm Biol Psychiatry 27:741-749.

McGeer PL, McGeer EG (2004) Inflammation and neurodegeneration in Parkinson's disease. Parkinsonism Relat Disord 10, Suppl 1, S3-7.

McGeer EG, McGeer PL (2003) Inflammatory processes in Alzheimer's disease. Progr Neuropsychopharm Biol Psychiatry 27:741-749.

McGeer EG, McGeer PL (2010) Neuroinflammation in Alzheimer's disease and mild cognitive impairment: a field in its infancy. J Alzheimers Dis 19:355-361.

McTaggart F, Buckett L, Davidson R, Holdgate G, McCormick A, Schneck D, Smith G, Warwick M (2001) Preclinical and clinical pharmacology of Rosuvastatin, a new 3hydroxy-3-methylglutaryl coenzyme A reductase inhibitor. Am J Cardiol 87(5A):28B32B.

Minagar A. Shapshak P, Fujimura R, Ownby R, Heyes M, Eisdorfer C (2002) The role of macrophage/microglia and astrocytes in the pathogenesis of three neurologic disorders: HIV-associated dementia, Alzheimer disease, and multiple sclerosis. J Neurol Sci 202:13-23.

Moehle MS, West AB (2015) M1 and M2 immune activation in Parkinson's Disease: Foe and ally? Neuroscience 302:59-73.

Muzio L, Martino G, Furlan R (2007) Multifaceted aspects of inflammation in multiple sclerosis: the role of microglia. J Neuroimmunol 191:39-44. 
Nakamichi K, Saiki M, Kitani H, Kuboyama Y, Morimoto K, Takayama-Ito M, Kurane I (2006) Suppressive effect of simvastatin on interferon-beta-induced expression of CC chemokine ligand 5 in microglia. Neurosci Lett 407:205-210.

Nakamura Y (2002) Regulating factors for microglial activation. Biol Pharm Bull 25:945953.

Napoli I, Neumann H (2010) Protective effects of microglia in multiple sclerosis. Exp Neurol 225:24-28.

Neher JJ, Neniskyte U, Zhao JW, Bal-Price A, Tolkovsky AM, Brown GC (2011) Inhibition of microglial phagocytosis is sufficient to prevent inflammatory neuronal death. J Immunol 186:4973-4983.

Ohsawa K, Imai Y, Sasaki Y, Kohsaka S (2004) Microglia/macrophage-specific protein Iba1 binds to fimbrin and enhances its actin-bundling activity. J Neurochem 88:844856.

Omari KM, Lutz SE, Santambrogio L, Lira SA, Raine CS (2009) Neuroprotection and remyelination after autoimmune demyelination in mice that inducibly overexpress CXCL1. Am J Pathol 174:164-176.

Orihuela R, McPherson CA, Harry GJ (2016) Microglial M1/M2 polarization and metabolic states. Br J Pharmacol 173:649-665.

Orr CF, Rowe DB, Halliday GM (2002) An inflammatory review of Parkinson's disease. Prog Neurobiol 68:325-340.

Pettit LK, Varsanyi C, Tadros J, Vassiliou E (2013) Modulating the inflammatory properties of activated microglia with Docosahexaenoic acid and Aspirin. Lipids Health Dis 12:16.

Phani, S., Loike, J. D. \& Przedborski, S (2012) Neurodegeneration and inflammation in Parkinson's disease. Parkinsonism Relat Disord 18, Suppl 1, S207-209.

Phillis JW, Horrocks LA, Farooqui AA (2006) Cyclooxygenases, lipoxygenases, and epoxygenases in CNS: their role and involvement in neurological disorders. Brain Res Rev 52(2):201-243.

Prinz M, Priller J (2014) Microglia and brain macrophages in the molecular age: from origin to neuropsychiatric disease. Nat Rev Neurosci 15(5):300-312. 
Prokop S, Miller KR, Heppner FL (2013) Microglia actions in Alzheimer's disease. Acta Neuropathol 126:461-477.

Ransohoff RM (2016) A polarizing question: do M1 and M2 microglia exist? Nat Neurosci 19:987-991.

Rodriguez GA, Tai LM, LaDu MJ, Rebeck GW (2014) Human APOE4 increases microglia reactivity at $A \beta$ plaques in a mouse model of $A \beta$ deposition. J Neuroinflamm 11:111.

Rottman JB, Slavin AJ, Silva R, Weiner HL, Gerard CG, Hancock WW (2000) Leukocyte recruitment during onset of experimental allergic encephalomyelitis is CCR1 dependent. Eur J Immunol 30:2372-2377.

Sasaki Y, Ohsawa K, Kanazawa H, Kohsaka S, Imai Y (2001) Iba1 Is an actin-cross-linking protein in macrophages/microglia. Biochem Biophys Res Commun 286:292-297.

Schachter M (2005) Chemical, pharmacokinetic and pharmacodynamic properties of statins: an update. Fundam Clin Pharmacol 19:117-125.

Sharma JN, Yusof AP (1998) Pro-inflammatory properties of the kallikrein-kinin system: potential for new drug therapy. Inflammopharmacology 6:289-296.

Shimoyama M, De Pons J, Hayman GT, Laulederkind SJ, Liu W, Nigam R, Petri V, Smith JR, Tutaj M, Wang SJ, Worthey E, Dwinell M, Jacob H (2015) The Rat Genome Database 2015: genomic, phenotypic and environmental variations and disease. Nucleic Acids Res 43 Database Issue, D743-D750.

Schönbeck U, Libby P (2004) Inflammation, immunity, and HMG-CoA reductase Inhibitors: statins as antiinflammatory agents. Circulation 109 (S1) II18-26.

Schrijvers EM, Verhaaren BF, Koudstaal PJ, Hofman A, Ikram MA, Breteler MM (2012) Is dementia incidence declining?: Trends in dementia incidence since 1990 in the Rotterdam Study. Neurology 78:1456-1463.

Schrör K, Rauch BH (2015) Aspirin and lipid mediators in the cardiovascular system. Prostaglandins Other Lipid Mediat 17-23.

Schwab JM, Nguyen TD, Postler E, Meyermann R, Schluesener HJ (2000) Selective accumulation of cyclooxygenase-1-expressing microglial cells/macrophages in lesions of human focal cerebral ischemia. Acta Neuropathol 99(6):609-614. 
Simon MS, Rosenberg CA, Rodabough RJ, Greenland P, Ockene I, Roy HK, Lane DS, Cauley JA, Khandekar J (2012) Prospective analysis of association between use of statins or other lipid-lowering agents and colorectal cancer risk. Ann Epidemiol 22:1727.

Skuljec J, Sun H, Pul R, Bénardais K, Ragancokova D, Moharregh-Khiabani D, Kotsiari A, Trebst C, Stangel M (2011) CCL5 induces a pro-inflammatory profile in microglia in vitro. Cell Immunol 270:164-171.

Stewart WF, Kawas C, Corrada M, Metter EJ (1997) Risk of Alzheimer's disease and duration of NSAID use. Neurology 48:626-632.

Stuart LM, Takahashi K, Shi L, Savill J, Ezekowitz RA (2005) Mannose-binding lectindeficient mice display defective apoptotic cell clearance but no autoimmune phenotype. J Immunol174: 3220-3226. Erratum in: J Immunol 175:3447.

Sung S, Yang H, Uryu K, Lee EB, Zhao L, Shineman D, Trojanowski JQ, Lee VM, Praticò D (2004) Modulation of nuclear factor-kappa B activity by indomethacin influences A beta levels but not A beta precursor protein metabolism in a model of Alzheimer's disease. Am J Pathol 165(6):2197-206.

Stieger B, Gao B (2015) Drug transporters in the central nervous system. Clin Pharmacokinet 54(3):225-242.

Stoll G, Jander S (1999) The role of microglia and macrophages in the pathophysiology of the CNS. Prog Neurobiol 58(3):233-247.

Streit WJ (2002) Microglia as neuroprotective immunocompetent cells of the CNS. Glia 40:133-139.

Sun KY, Xu DH, Xie C, Plummer S, Tang J, Yang XF, Ji XH (2017) Lactobacillus paracasei modulates LPS-induced inflammatory cytokine release by monocytemacrophages via the up-regulation of negative regulators of NF-kappaB signaling in a TLR2-dependent manner. Cytokine 92:1-11.

Szabo M, Gulya K (2013) Development of the microglial phenotype in culture. Neuroscience 241:280-295.

Szabo M, Dulka K, Gulya K (2016) Calmodulin inhibition regulates morphological and functional changes related to the actin cytoskeleton in pure microglial cells. Brain Res Bull 120:41-57. 
Takai Y, Sasaki T, Matozaki T (2001) Small GTP-binding proteins. Physiol Rev 81(1):153208.

Taylor F, Huffman MD, Macedo AF, Moore TH, Burke M, Davey Smith G, Ward K, Ebrahim S (2013) Statins for the primary prevention of cardiovascular disease. Cochrane Database Syst Rev 2013 1:CD004816.

Ueno A, Oh-ishi S (2003) Roles for the kallikrein-kinin system in inflammatory exudation and pain: lessons from studies on kininogen-deficient rats. J Pharmacol Sci. 93:1-20.

van der Most PJ, Dolga AM, Nijholt IM, Luiten PGM, Eisel UL (2009) Statins: mechanisms of neuroprotection. Progr Neurobiol 88:64-75.

Vane JR, Botting RM (2003) The mechanism of action of aspirin. Thromb Res 110:255258.

Veillard NR, Braunersreuther V, Arnaud C, Burger F, Pelli G, Steffens S, Mach F (2006) Simvastatin modulates chemokine and chemokine receptor expression by geranylgeranyl isoprenoid pathway in human endothelial cells and macrophages. Atherosclerosis 188:51-58.

Watanabe K, Jose PJ, Rankin SM (2002) Eotaxin-2 generation is differentially regulated by lipopolysaccharide and IL-4 in monocytes and macrophages. J Immunol 168:19111918.

Weber C, Erl W, Weber KS, Weber PC (1997) HMG-CoA reductase inhibitors decrease CD11b expression and CD11b-dependent adhesion of monocytes to endothelium and reduce increased adhesiveness of monocytes isolated from patients with hypercholesterolemia. J Am Coll Cardiol 30:1212-1217.

Wierzbicki AS, Poston R, Ferro A (2003) The lipid and non-lipid effects of statins. Pharmacol Therap 99:95-112.

Wolozin B, Kellman W, Ruosseau P, Celesia GG, Siegel G (2000) Decreased prevalence of Alzheimer disease associated with 3-hydroxy-3-methyglutaryl coenzyme A reductase inhibitors. Arch Neurol 57(10):1439-43.

Worthley DL, Bardy PG, Mullighan CG (2005) Mannose-binding lectin: biology and clinical implications. Intern Med J 35:548-555. 
Yang YC, Huang WF, Chuan LM, Xiao DW, Zeng YL, Zhou DA, Xu GQ, Liu W, Huang B, Hu Q (2008) In vitro and in vivo study of cell growth inhibition of simvastatin on chronic myelogenous leukemia cells. Chemotherapy 54:438-446.

Yang JM, Rui BB, Chen C, Chen H, Xu TJ, Xu WP, Wei W (2014) Acetylsalicylic acid enhances the anti-inflammatory effect of fluoxetine through inhibition of NF- $\kappa \mathrm{B}$, p38-MAPK and ERK1/2 activation in lipopolysaccharide-induced BV-2 microglia cells. Neuroscience 275:296-304.

Zelcer N, Khanlou N, Clare R, Jiang Q, Reed-Geaghan EG, Landreth GE, Vinters HV, Tontonoz P (2007) Attenuation of neuroinflammation and Alzheimer's disease pathology by liver x receptors. Proc Natl Acad Sci USA 104:10601-10606.

Zipp F, Waiczies S, Aktas O, Neuhaus O, Hemmer B, Schraven B, Nitsch R, Hartung HP (2007) Impact of HMG-CoA reductase inhibition on brain pathology. Trends Pharmacol Sci 28:342-349. 
9. APPENDIX 
ARTICLE I. 


\section{ROSUVASTATIN ENHANCES ANTI-INFLAMMATORY AND INHIBITS PRO-INFLAMMATORY FUNCTIONS IN CULTURED MICROGLIAL CELLS}

\author{
D. KATA, ${ }^{a}$ I. FÖLDESI, ${ }^{b}$ L. Z. FEHER, ${ }^{c}$ L. HACKLER, Jr. \\ L. G. PUSKAS ${ }^{\circ}$ AND K. GULYA ${ }^{a *}$ \\ ${ }^{a}$ Department of Cell Biology and Molecular Medicine, University \\ of Szeged, Szeged, Hungary \\ ${ }^{\mathrm{b}}$ Department of Laboratory Medicine, University of Szeged, \\ Szeged, Hungary \\ ${ }^{\mathrm{c}}$ Avidin Ltd., Szeged, Hungary
}

\begin{abstract}
Microglial activation results in profound morphological, functional and gene expression changes that affect the pro- and anti-inflammatory mechanisms of these cells. Although statins have beneficial effects on inflammation, they have not been thoroughly investigated for their ability to affect microglial functions. Therefore the effects of rosuvastatin, one of the most commonly prescribed drugs in cardiovascular therapy, either alone or in combination with bacterial lipopolysaccharide (LPS), were profiled in pure microglial cultures derived from the forebrains of 18-dayold rat embryos. To reveal the effects of rosuvastatin on a number of pro- and anti-inflammatory mechanisms, we performed morphometric, functional and gene expression studies relating to cell adhesion and proliferation, phagocytosis, pro- and anti-inflammatory cytokine (IL-1ß, tumor necrosis factor $\alpha$ (TNF- $\alpha$ ) and IL-10, respectively) production, and the expression of various inflammation-related genes, including those related to the above morphological parameters and cellular functions. We found that microglia could be an important therapeutic target of rosuvastatin. In unchallenged (control) microglia, rosuvastatin inhibited proliferation and cell adhesion, but promoted microspike formation and elevated the expression of certain anti-inflammatory genes (Cxc/1, Cc/5, Mb/2), while phagocytosis or pro- and antiinflammatory cytokine production were unaffected. Moreover, rosuvastatin markedly inhibited microglial activation in LPS-challenged cells by affecting both their morphology and functions as it inhibited LPS-elicited phagocytosis and inhibited pro-inflammatory cytokine (IL-1 $\beta$, TNF- $\alpha$ ) production, concomitantly increasing the level of IL-10, an anti-
\end{abstract}

\footnotetext{
${ }^{*}$ Corresponding author. Address: Department of Cell Biology and Molecular Medicine, University of Szeged, 4 Somogyi u., Szeged H-6720, Hungary. Tel: +36-(62)-544-570; fax: +36-(62)-544-569. E-mail address: gulyak@bio.u-szeged.hu (K. Gulya).

Abbreviations: AD, Alzheimer's disease; Cd, cluster of differentiation; CNS, central nervous system; DIV, days in vitro; DMEM, Dulbecco's Modified Eagle's Medium; E18, embryonic day 18; EAE, experimental autoimmune encephalomyelitis; ELISA, enzyme-linked immunosorbent assay; FBS, fetal bovine serum; GAPDH, glyceraldehyde 3-phosphate dehydrogenase (EC 1.2.1.12); Iba1, ionized calcium-binding adaptor molecule 1; IL, interleukin; LPS, bacterial lipopolysaccharide; MS, multiple sclerosis; PBS, phosphate-buffered saline; RT, room temperature; S.D., standard deviation; subDIV, subcloned days in vitro; TBS, Tris-buffered saline; TI, transformation index; TNF- $\alpha$, tumor necrosis factor $\alpha$.
}

inflammatory cytokine. Finally, rosuvastatin beneficially and differentially affected the expression of a number of inflammation-related genes in LPS-challenged cells by inhibiting numerous pro-inflammatory and stimulating several anti-inflammatory genes. Since the microglia could elicit pro-inflammatory responses leading to neurodegeneration, it is important to attenuate such mechanisms and promote antiinflammatory properties, and develop prophylactic therapies. By beneficially regulating both pro- and anti-inflammatory microglial functions, rosuvastatin may be considered as a prophylactic agent in the prevention of inflammation-related neurological disorders. (C) 2015 The Authors. Published by Elsevier Ltd. on behalf of IBRO. This is an open access article under the CC BY-NC-ND license (http://creativecommons.org/ licenses/by-nc-nd/4.0/).

Key words: anti-inflammation, gene expression, lipopolysaccharide, phagocytosis, pro-inflammation, rosuvastatin.

\section{INTRODUCTION}

Microglia, the main immune cells in the central nervous system (CNS), are derived from the monocyte/macrophage lineage (Ginhoux et al., 2010). They play important roles in both physiological and pathophysiological conditions such as traumatic injury, stroke, ischemia or neurodegenerative diseases (Kreutzberg, 1996). In response to activation, the microglia transform from a resting state to an activated form, during which profound morphological and functional changes take place, such as process retraction, proliferation, phagocytosis and cytokine expression (Gehrmann et al., 1995; Kreutzberg, 1996; Hanisch, 2002; Luo and Chen, 2012). Although such anti-inflammatory mechanisms are essential in protecting the CNS, activated microglial cells can also be harmful to neurons by eliciting neuroinflammation that could lead to neurodegeneration (Banati et al., 1993; Gehrmann et al., 1995; GonzalezScarano and Baltuch, 1999; Streit, 2002; Graeber, 2010; Gresa-Arribas et al., 2012; Ghosh et al., 2013). In Alzheimer's disease $(A D)$, for example, the microglia produce proinflammatory factors such as interleukin-1 $\beta$ (IL-1 $1 \beta$ ) around the amyloid plaques, and these factors may themselves become important components of the AD pathology because of their ability to increase the expression of amyloid precursor protein (Cordle and Landreth, 2005; Ghosh et al., 2013).

Accumulating evidence indicates that a sequence of events contributes to the development and progression of $A D$, including oxidative stress, inflammation, and altered cholesterol metabolism (Gamba et al., 2015). Oxidative stress may be crucial in the development of 
neuroinflammation as oxidized cholesterol could act as a link connecting peripheral hypercholesterolemia to altered cholesterol metabolism in the brain (Gamba et al., 2015). Cholesterol modulates the processing of amyloid precursor protein and the production of $\beta$-amyloid peptides (Shobab et al., 2005), while removing cholesterol ameliorates the production these peptides in animal models (Bodovitz and Klein, 1996; Simons et al., 1998).

Statins (3-hydroxy-3-methylglutaryl coenzyme A reductase inhibitors) are the agents of first choice for the treatment of high cholesterol levels (Taylor et al., 2013). Although their main effects are related to the lipid metabolism (inhibition of cholesterol synthesis, reduction of the levels of low-density lipoproteins and triglycerides, and stimulation of the expression of high-density lipoproteins), they also strongly modulate inflammatory cells around atherosclerotic plaques (Wierzbicki et al., 2003; Burg and Espenshade, 2011). Apart from their therapeutic use in cardiovascular diseases, statins may also have beneficial effects in the CNS (Zipp et al., 2007; van der Most et al., 2009; Famer et al., 2010) as animal studies have demonstrated that statins attenuate neuroinflammation (Zelcer et al., 2007) and reduce senile plaques and inflammatory responses (Kurata et al., 2012).

Interestingly, in spite of being an obvious target for statins, microglial cells have not been at the focus of statin research. There have only been a few studies to demonstrate that under in vitro circumstances the microglia respond to statins such as atorvastatin and simvastatin (Lindberg et al., 2005; Nakamichi et al., 2006). In the present study, we investigated the effects of rosuvastatin, the most widely used and arguably the most effective statin (Nissen et al., 2006; Nicholls et al., 2011), on cultured pure microglia cells derived from mixed cultures of 18-day-old embryonic (E18) rat forebrains under control (unstimulated) and bacterial lipopolysaccharide (LPS)-stimulated conditions (Nakamura et al., 1999; Lund et al., 2006; Gresa-Arribas et al., 2012). To reveal the effects of rosuvastatin on a number of pro- and anti-inflammatory mechanisms, we performed morphometric, functional and gene expression studies relating to cell adhesion and proliferation, phagocytic capability, pro- and anti-inflammatory cytokine (IL-1 $\beta$, tumor necrosis factor $\alpha$ (TNF- $\alpha$ ) and IL-10, respectively) production, and the expression of various inflammationrelated genes, including those related to the above morphological parameters and cellular functions.

\section{EXPERIMENTAL PROCEDURES}

\section{Animals}

All animal experiments were carried out in strict compliance with the European Council Directive (86/609/EEC) and EC regulations (O.J. of EC No. L $358 / 1$, 18/12/1986) regarding the care and use of laboratory animals for experimental procedures, and followed the relevant Hungarian and local legislation requirements. The experimental protocols were approved by the Institutional Animal Welfare Committee of the University of Szeged (I-74-II/2009/MÁB). The pregnant Sprague-Dawley rats (45 rats, 170-190 g) were kept under standard housing conditions and fed ad libitum.

\section{Antibodies}

For a thorough characterization of different microglial phenotypes developed in vitro, an antibody against ionized calcium-binding adaptor molecule 1 (lba1), an intracellular actin- and $\mathrm{Ca}^{2+}$-binding protein expressed in the CNS specifically in macrophages and microglia (Ahmed et al., 2007), was used in our immunocytochemical and Western blot analyses. The anti-glyceraldehyde 3-phosphate dehydrogenase (GAPDH) antibody was used as an internal control in Western blot experiments (Wu et al., 2012). Dilutions of primary and secondary antibodies, and also incubation times and blocking conditions for each antibody used were carefully tested for both immunocytochemistry and Western blot analysis. To detect the specificities of the secondary antisera, omission control experiments (staining without the primary antibody) were performed. In such cases, no fluorescent or Western blot signals were detected.

\section{Cell cultures}

Pure microglial cells were isolated from mixed primary cortical cell cultures of rat embryos of either sex by the method we described earlier (Szabo and Gulya, 2013). Sibling embryos obtained from the same pregnancy were processed for culturing together; each pregnancy was considered as an independent experiment. Briefly, 10-12 fetal rats (E18) under anesthesia were decapitated and the frontal lobe of the cerebral cortex was removed, minced with scissors, incubated in $9 \mathrm{ml}$ Dulbecco's Modified Eagle's Medium (DMEM; Invitrogen, Carlsbad, USA) containing $1 \mathrm{~g} / \mathrm{l}$ D-glucose, $110 \mathrm{mg} / \mathrm{l} \mathrm{Na-pyruvate,} 4 \mathrm{mM}$ L-glutamine, $3.7 \mathrm{~g} / \mathrm{l} \mathrm{NaHCO}_{3}, 10,000 \mathrm{U} / \mathrm{ml}$ penicillin $\mathrm{G}$, $10 \mathrm{mg} / \mathrm{ml}$ streptomycin sulfate, $25 \mu \mathrm{g} / \mathrm{ml}$ amphotericin B and $0.25 \%$ trypsin for $10 \mathrm{~min}$ at $37^{\circ} \mathrm{C}$, and then centrifuged at $1000 \mathrm{~g}$ for $10 \mathrm{~min}$ at room temperature (RT). The pellet was resuspended and washed twice in $5 \mathrm{ml}$ DMEM containing 10\% heat-inactivated fetal bovine serum (FBS; Invitrogen) and centrifuged for $10 \mathrm{~min}$ at $1000 \mathrm{~g}$ at RT. The final pellet was resuspended in $2 \mathrm{ml}$ DMEM $/ 10 \%$ FBS, after which the cells were plated in the same medium on a poly-L-lysine-coated culture flask $\left(75 \mathrm{~cm}^{2}, 12 \times 10^{6} \mathrm{cell} /\right.$ flask) and cultured at $37^{\circ} \mathrm{C}$ in a humidified air atmosphere supplemented with $5 \% \mathrm{CO}_{2}$, in one or other of the following ways: (1) in poly-L-lysinecoated coverslips $\left(15 \times 15 \mathrm{~mm} ; 2 \times 10^{5}\right.$ cells/coverslip) for immunocytochemistry; (2) in poly-L-lysine-coated Petri dishes $\left(60 \mathrm{~mm} \times 15 \mathrm{~mm} ; 4 \times 10^{5}\right.$ cells/dish) for Western blot analyses and enzyme-linked immunosorbent assay (ELISA) studies; or (3) in a poly-L-lysine-coated culture flask $\left(75 \mathrm{~cm}^{2}, 12 \times 10^{6}\right.$ cells/flask) for the subsequent generation of pure microglial cell cultures.

Secondary microglial cells were subcloned from mixed primary cultures (DIV7) maintained in a poly-Llysine-coated culture flask $\left(75 \mathrm{~cm}^{2}, 12 \times 10^{6}\right.$ cells/flask) by shaking the cultures at $100 \mathrm{rpm}$ in a platform shaker for $30 \mathrm{~min}$ at $37^{\circ} \mathrm{C}$. Cultures from the same pregnancy were kept separate. Microglia from the supernatant 
were collected by centrifugation at $3000 \mathrm{~g}$ for $8 \mathrm{~min}$ at $\mathrm{RT}$ and resuspended in $2 \mathrm{ml}$ DMEM/10\% FBS. The cells were seeded at a density of $4 \times 10^{5}$ cells/Petri dish for Western blots or $2 \times 10^{5}$ cells/coverslip/Petri dish for immunocytochemistry, proliferation or phagocytosis assays, and cultured in DMEM in a humidified atmosphere supplemented with $5 \% \mathrm{CO}_{2}$ at $37^{\circ} \mathrm{C}$. The medium was changed on the first day after seeding (subDIV1). Immunocytochemistry routinely performed on the pure microglial cultures four days after seeding (subDIV4) consistently detected a $>99 \%$ incidence of the Iba1-immunopositive microglial cells for the Hoechst 33258 dye-labeled cell nuclei.

\section{Cell culture treatments}

On the fourth day of subcloning (subDIV4), DMEM was replaced and the expanded pure microglial cells were treated for $24 \mathrm{~h}$ with either LPS $(20 \mathrm{ng} / \mathrm{ml}$ final conc., dissolved in DMEM; Sigma, St. Louis, MO, USA) or rosuvastatin $(1 \mu \mathrm{M}$ final conc., dissolved in sterile, distilled water; Santa Cruz Biotechnology, Inc., Dallas, TX, USA) alone, or with a combination of LPS + rosuvastatin, and the effects were compared in a variety of morphological and functional tests. LPS treatment served as an immunochallenge. Four types of treatment regimens were used: (1) control (unchallenged and untreated) cultures; (2) LPSchallenged cultures received $20 \mathrm{ng} / \mathrm{ml}$ LPS; (3) rosuvastatin-treated cultures were stimulated with $1 \mu \mathrm{M}$ rosuvastatin; (4) LPS-challenged + rosuvastatin-treated cultures received both drugs in the indicated doses. Depending on the experiments, the treatments lasted for 6,24 or $72 \mathrm{~h}$ at $37^{\circ} \mathrm{C}$.

\section{Cell adhesion and proliferation}

To measure changes in cell adhesion and proliferation and cell viability, the ACEA Real-Time Cell Analysis (RTCA) system and 16-well E-Plates (Acea Biosciences, Inc., San Diego, CA, USA) were used. This system measured the electrical impedance of the cells expressed as cell index in real time. Briefly, $4 \times 10^{5}$ pure microglial cells in poly-L-lysine-coated Petri dishes were plated as described above. On the fourth day of culturing, the cells were trypsinized, centrifuged as above and seeded into gelatin-coated 16-well E-Plates at a density of 6000 cells per well. Test doses of LPS and rosuvastatin, either alone or in combination, were added to the wells before plating. After equilibration at RT for $10 \mathrm{~min}$, the E-plate was loaded into the RTCA machine and the cell index was measured continuously for $60 \mathrm{~h}$ using the cell microelectronic sensing technique with the XCELLigence real-time cell analysis system (RTCA DP; Acea Biosciences) as we published earlier (Ozsvári et al., 2010). Cell indices at $24 \mathrm{~h}$ were analyzed for comparison with cell proliferation data. Data analysis was carried out with the system's dedicated software (RTCA Software 1.2; Acea Biosciences) and Excel (Microsoft Corp., Redmond, WA, USA). To estimate the number of surviving/ proliferating microglial cells after treatments, the cultures were washed twice with $2 \mathrm{ml}$ phosphate-buffered saline (PBS) to remove cell debris, treated with $0.25 \%$ trypsin solution for $10 \mathrm{~min}$ at $37^{\circ} \mathrm{C}$, collected and counted in a Burker cell counting chamber. The number of viable cells was presented as mean \pm S.D.

\section{Immunocytochemistry}

Pure microglial cultures treated with different treatment regimens were fixed on coverslips with $4 \%$ formaldehyde for $5 \mathrm{~min}$ and rinsed with $0.05 \mathrm{M}$ PBS for $2 \times 5 \mathrm{~min}$. After permeabilization and blocking of the nonspecific sites in $0.05 \mathrm{M}$ PBS solution containing $5 \%$ normal goat serum (Sigma), 1\% heat-inactivated bovine serum albumin (Sigma) and $0.05 \%$ Triton $\mathrm{X}-100$ for $30 \mathrm{~min}$ at $37^{\circ} \mathrm{C}$, the cells on the coverslips were incubated overnight in a humidified chamber at $4{ }^{\circ} \mathrm{C}$ with rabbit anti-lba1 polyclonal antibody (1:500 final dilution; Wako, Japan), a microglia-specific actin-binding protein, in the above solution as we described previously (Szabo and Gulya, 2013). The cultured cells were washed for $4 \times 10 \mathrm{~min}$ at RT in $0.05 \mathrm{M} \mathrm{PBS}$, and then incubated with the Alexa Fluor 568 fluorochromeconjugated goat anti-rabbit antibody (1:1000 final dilution; Invitrogen) in the dark for $3 \mathrm{~h}$ at RT. The cells on the coverslip were washed for $4 \times 10 \mathrm{~min}$ in $0.05 \mathrm{M}$ PBS at RT, and the nuclei were stained in $0.05 \mathrm{M}$ PBS solution containing $1 \mathrm{mg} / \mathrm{ml}$ polyvinylpyrrolidone and $0.5 \mu \mathrm{l} / \mathrm{ml}$ Hoechst 33258 dye (Sigma). The coverslips were rinsed in distilled water for $5 \mathrm{~min}$, air-dried and mounted on microscope slides in Vectashield mounting medium (Vector Laboratories, Burlingame, CA, USA). Cells were viewed on a Nikon Microphot-FXA epifluorescent microscope (Nikon Corp., Tokyo, Japan) and photographed with a Spot RT Color CCD camera (SPOT RT/ke, Diagnostic Instruments, Inc., Sterling Heights, MI, USA).

\section{Western blot analysis}

Cultured microglial cells (subDIV4) were collected through use of a rubber policeman, homogenized in $50 \mathrm{mM}$ Tris- $\mathrm{HCl}(\mathrm{pH}$ 7.5) containing $150 \mathrm{mM} \mathrm{NaCl}$, $0.1 \%$ Nonidet P $40,0.1 \%$ cholic acid, $2 \mu \mathrm{g} / \mathrm{ml}$ leupeptin, $1 \mu \mathrm{g} / \mathrm{ml}$ pepstatin, $2 \mathrm{mM}$ phenylmethylsulfonyl fluoride and $2 \mathrm{mM}$ EDTA, and centrifuged at $10,000 \mathrm{~g}$ for $10 \mathrm{~min}$. The pellet was discarded and the protein concentration of the supernatant was determined (Lowry et al., 1951). For the Western blot analyses, 5-10 $\mu \mathrm{g}$ of protein was separated on an SDS polyacrylamide gel (4-10\% stacking gel/resolving gel), transferred onto Hybond-ECL nitrocellulose membrane (Amersham Biosciences, Little Chalfont, Buckinghamshire, England), blocked for $1 \mathrm{~h}$ in $5 \%$ nonfat dry milk in Tris-buffered saline (TBS) containing $0.1 \%$ Tween 20 , and incubated overnight with either a rabbit anti-lba1 polyclonal antibody (1:1000 final dilution; Wako) or a mouse anti-GAPDH monoclonal antibody (clone GAPDH-71.1; 1:20,000 final dilution; Sigma). After five rinses in $0.1 \%$ TBS-Tween 20 , the membranes were incubated for $1 \mathrm{~h}$ with the peroxidase-conjugated goat anti-rabbit secondary antibody (1:2000 final dilution; Invitrogen) for Iba1 or with the peroxidase-conjugated rabbit anti-mouse secondary antibody (1:2000 final dilution; 
Sigma) for GAPDH Western blots, and washed five times as before. The enhanced chemiluminescence method (ECL Plus Western blotting detection reagents; Amersham Biosciences) was used to reveal immunoreactive bands according to the manufacturer's protocol.

\section{In vitro phagocytosis}

The fluid-phase phagocytotic capabilities of the control and variously treated pure microglial cell cultures were determined via the uptake of fluorescent microspheres (carboxylate-modified polystyrene beads, fluorescent yellow-green ( $\lambda$ ex $\sim 470 \mathrm{~nm}$; $\lambda$ em $\sim 505 \mathrm{~nm}$ ), aqueous suspension, $2.0 \mu \mathrm{m}$ mean particle size; L4530, Sigma) as we described previously (Szabo and Gulya, 2013). Unstimulated (control) and LPS-stimulated pure microglial cell cultures (subDIV4) with or without rosuvastatin were tested for $24 \mathrm{~h}$. At the end of the treatment period, $1 \mu \mathrm{l}$ of a $2.5 \%$ aqueous suspension of fluorescent microspheres per $\mathrm{ml}$ was added to the culture, which was then incubated for $60 \mathrm{~min}$ at $37^{\circ} \mathrm{C}$. The cells were next washed five times with $2 \mathrm{ml}$ of PBS to remove dish- or cell surfacebound residual fluorescent microspheres, and fixed with $4 \%$ formaldehyde in PBS. In another setup, we also determined the number of microglial cell membrane-associated but not phagocytosed beads. Such negative controls were treated as above with the exception that microglial cultures with beads were incubated for $60 \mathrm{~min}$ at $4{ }^{\circ} \mathrm{C}$. At this temperature, the number of beads associated with cell surface averaged less than 1 bead per 100 lba1-labeled cells, thus the phagocytosis was not considered significant. For measurement of the phagocytotic activity, cells labeled with phagocytosed microbeads and processed for Iba1 immunocytochemistry were counted in 20 random fields in each treatment group (mean \pm S.D.) under a $20 \times$ or $40 \times$ objective. Statistically significant differences were determined by a two-way ANOVA.

\section{Determination of IL-1及, IL-10 and TNF- $\alpha$}

For ELISA assays, the supernatants were collected from each treatment and stored at $-20^{\circ} \mathrm{C}$. Concentrations of IL-1 $\beta$, IL-10 and TNF- $\alpha$ were measured with rat-specific ELISA kits (eBioscience, Vienna, Austria). The sensitivity of IL-1 $\beta$ (Cat\# BMS630), IL-10 (Cat\# BMS629) and TNF- $\alpha$ (Cat\#BMS622) assays was $4 \mathrm{pg} / \mathrm{ml}, 1.5 \mathrm{pg} / \mathrm{ml}$ and $11 \mathrm{pg} / \mathrm{ml}$, respectively. As stated by the manufacturer, the overall intra- and interassay coefficients of variation were $<10 \%$ in both cases for IL-1 $\beta$ and TNF- $\alpha$, and $<5 \%$ in both cases for IL- 10 .

\section{RNA isolation}

Total RNA from control and treated pure microglial cells was purified as described previously (Fabian et al., 2011); columns and wash buffer were from Bioneer (Viral RNA extraction kit; Daejon, South Korea). Briefly, cells were washed with PBS, incubated in lysis buffer (RA1; Macherey-Nagel, Düren, Germany), then collected and mixed with $70 \%$ ethanol in RNase-free water (Bioneer). The mixture was transferred through columns (Bioneer) and washed with $350 \mu \mathrm{l} 80 \%$ ethanol in diethyl pyrocarbonate-treated water, and then with $600 \mu \mathrm{l}$ and $300 \mu \mathrm{l} \mathrm{W} 2$ wash buffer (Bioneer). Total RNA was eluted in $50 \mu \mathrm{l}$ RNase free-water. One $\mu \mathrm{l}$ RNase inhibitor (Applied Biosystems, Foster City, CA, USA) was added to the samples. The quality and quantity of the isolated RNA were measured with NanoDrop1000 Version 3.8.1. (Thermo Scientific, Budapest, Hungary).

\section{RNA expression}

Reverse transcription from $3 \mu \mathrm{g}$ of total RNA in $30 \mu \mathrm{l}$ was performed with the High-Capacity cDNA Archive Kit (Applied Biosystems) according to the manufacturer's protocol. cDNA was diluted to $80 \mu \mathrm{l}$. The instrumentation included the Bravo automatic liquid handling system (Agilent Technologies, Inc., Santa Clara, CA, USA) for polymerase chain reaction (PCR) assay preparation and a LightCycler 1536 System (Roche Diagnostics Corp., Indianapolis, IN, USA) or a Light Cycler Nano Instrument (Roche) for cycling (Woudstra et al., 2013). The expression of 116 inflammation-related genes, together with that of six control genes (see below), was measured with Universal Probe Library assays using intron-spanning gene-specific primers (Rat Immune Panel; Avidin Ltd., Szeged, Hungary, www.avidinbiotech.com/services/gene-expression) and the LightCycler 1536 DNA Probe Master kit (Roche). Moreover, the expression of certain phagocytosis-related genes such as the integrin-associated protein or cluster of differentiation 47 (Cd47, NM_019195_2), the engulfment or cell motility protein (Elmō1, NM_001108415.1), the scavenger receptor class B member 1 (Scarb1, NM_031541_1), the plasminogen activator inhibitor-1 (Serpine1, NM_012620_1), the signal-regulatory protein $\alpha$ (Sirpa, NM_013016_2) and the vesicle-associated membrane protein 7 (Vamp7, NM_053531_1) were also analyzed, by the Light Cycler Nano Instrument. For the 1536 System, each $2 \mu \mathrm{l} \mathrm{PCR}$ reaction contained $8 \mathrm{ng}$ of cDNA, $0.4 \mu \mathrm{l}$ Lightcycler DNA Probes Master $(5 \times)$, the corresponding primer set and UPL probe and the Setup Control. The PCR cycling protocol was as follows: enzyme activation at $95^{\circ} \mathrm{C}$ for $60 \mathrm{~s}, 50$ cycles of denaturation at $95^{\circ} \mathrm{C}$ for $0 \mathrm{~s}$, and annealing and extension at $60^{\circ} \mathrm{C}$ for $30 \mathrm{~s}$. For the Nano Instrument, each $20 \mu \mathrm{l}$ PCR reaction contained $20 \mathrm{ng}$ cDNA, $10 \mu \mathrm{l}$ Lightcycler DNA Probes Master $(5 \times)$, the corresponding primer set and UPL probe and the Setup Control. The PCR protocol was as follows: enzyme activation at $95^{\circ} \mathrm{C}$ for $10 \mathrm{~min}, 50$ cycles of denaturation at $95^{\circ} \mathrm{C}$ for $15 \mathrm{~s}$, and annealing and extension at $60{ }^{\circ} \mathrm{C}$ for $30 \mathrm{~s}$. Gene expression was normalized to the average values of clathrin, heavy chain (Cltc, NM_019299.1), glyceraldehyde-3-phosphate-dehydrogen ase (Gapdh, M17701.1), glucuronidase, beta (Gusb, NM_017015.2), hypoxanthine phosphoribosyltransferase 1 (Hprt1, NM_012583.2), phosphoglycerate kinase 1 (Pgk1, NM_053291.3), and tubulin, beta 5 class I (Tubb5, NM_173102.2) expression as endogenous controls and expressed relative to the unstimulated controls by using the $2^{-\Delta \Delta C t}$ method. A total of 122 gene-specific assays were run on four independent samples from each condition. Student's $t$-test and a two-way ANOVA were applied for the analysis of significance where $p<0.05$ was 
considered significant. For hierarchical cluster analysis and visualization, the Hierarchical Clustering Explorer (v3.0) software was used (publicly available at http:// www.cs.umd.edu/hcil/multi-cluster/hce3.html). The complete linkage clustering method was applied with Euclidean distance metric.

\section{Image analysis and statistics}

Digital images were captured by a Nikon Microphot-FXA epifluorescent microscope (Nikon Corp., Tokyo, Japan), using a Spot RT Color CCD camera and the Spot RT software (Spot RT/ke Diagnostic Instruments, Sterling Heights, MI, USA). For the determination of microglial cell purity, Hoechst 33258-labeled cell nuclei that belonged to Iba1-immunopositive cells were counted on coverslip-cultured samples. For each culture, 50-100 randomly selected microscope fields were analyzed. In every case, the cultures had, on average, at least 99 Iba1-positive somata for 100 Hoechst 33258-labeled cell nuclei ( $>99 \%$ purity for microglial cells). Phagocytosed microspheres on 20 randomly sampled microscope fields from three coverslips for each treatment regimen were counted with the use of the computer program ImageJ (version 1.47; http://rsb.info. nih.gov/ij). For the measurement of area $\left(\mu \mathrm{m}^{2}\right)$, perimeter $(\mu \mathrm{m})$ and transformation index $(\mathrm{TI})$, Iba1immunoreactive microglial cell images were converted into binary replicas by using thresholding procedures implemented by ImageJ and Adobe Photoshop CS5.1 software (Adobe Systems, Inc., San Jose, CA, USA) as published by Szabo and Gulya (2013). TI was determined according to Fujita et al. (1996) by using the following formula: [perimeter of cell $(\mu \mathrm{m})]^{2} / 4 \pi$ [cell area $\left.\left(\mu \mathrm{m}^{2}\right)\right]$. Color correction and cropping of the light microscopic images were performed when photomicrographs were made for publication and assembled for a panel. Gray-scale digital images of the immunoblots were acquired by scanning the autoradiographic films with a desktop scanner (Epson Perfection V750 PRO; Seiko Epson Corp., Japan). The images were scanned and processed at identical settings to allow comparisons of the Western blots from different samples. The bands were analyzed through the use of ImageJ. The immunoreactive densities of equally loaded lanes were quantified, and all samples were normalized to the internal GAPDH load controls.

All statistical comparisons were made by using $R$ 3.1.0 for Windows (The R Foundation for Statistical Computing; Wirtschafts-Universität, Wien, Austria). Results were analyzed with a two-way ANOVA, and the Bonferroni correction was used to establish significance between groups. Values were presented as mean $\pm \mathrm{S}$. D.; $p<0.05$ was considered significant; *, ${ }^{* *}$ and ${ }^{* * *}$ denote $p<0.05, p<0.01$ and $p<0.001$, respectively.

\section{RESULTS}

\section{Rosuvastatin affects microglial morphology}

The morphological changes elicited by rosuvastatin in unchallenged (control) and LPS-challenged pure microglia cultures were documented through the use of Iba1 immunocytochemistry (Fig. 1A-D) and quantitatively analyzed on binary silhouettes of individual microglial cells (Fig. 2A-G). Iba1 protein expression was also monitored during treatments (Fig. 1E). Most of the unchallenged and untreated (control) microglia displayed ameboid morphology with $\mathrm{Tl}<3$; they had a predominantly ameboid shape, occasionally with small pseudopodia (Figs. $1 \mathrm{~A}$ and 2A). When administered alone for $24 \mathrm{~h}$, rosuvastatin induced the formation of numerous microspikes (Figs. $1 \mathrm{~B}$ and $2 B$ ); these slender cytoplasmic projections (filopodia) resulted in significantly increased perimeter and $\mathrm{TI}$ values of these cells (Fig. $2 \mathrm{~F}$, $\mathrm{G})$. Quantitative analysis showed that the average $\mathrm{TI}$ in this group increased about 10-fold, to above 19, as compared with the controls (Fig. 2G). The LPS challenge did not result in any significant morphometric change (Figs. 1C and 2C, E-G). However, rosuvastatin treatment in LPS-challenged cells resulted in a significantly enlarged and more ramified cell form $(\mathrm{TI}>7)$ with a much larger perimeter value as compared with their respective control values (Figs. $1 D$ and 2D, E-G), indicating that rosuvastatin profoundly antagonized the morphological changes characteristic of LPS-induced microglial activation. In relation to the substantially increased size of the LPS-challenged and rosuvastatintreated microglia (Figs. $1 \mathrm{D}$ and 2D, E), their Iba1 immunoreactivity was also significantly increased (Figs. 1E and 2E).

\section{Rosuvastatin inhibits proliferation and cell adhesion in both unchallenged and LPS-challenged microglia}

Rosuvastatin significantly inhibited cell proliferation in both unchallenged and LPS-challenged cultures, by $47.8 \%$ and $68.9 \%$, respectively, after a $24-\mathrm{h}$ treatment period (Fig. 3A). We used a 16-well E-Plate-based realtime analysis to determine whether rosuvastatin affects cell adhesion. Rosuvastatin inhibited cell adhesion in both unchallenged (control) and LPS-challenged microglia (Fig. 3B). The differences in levels of inhibition of cell adhesion between cultures with or without rosuvastatin (unchallenged and LPS-challenged microglia vs. rosuvastatin-treated and LPS-challenged + rosuvastatin-treated microglia) were significant by $20 \mathrm{~h}$ of culturing and thereafter, probably due to the significantly larger cell populations in the control and LSP-challenged microglial cultures as compared with those in the rosuvastatin or LPS + rosuvastatin-treated cultures (Fig. 3B), and to the ability of rosuvastatin to stimulate the formation of microspikes (Fig. 2B, D), i.e. the actin-based filamentous protrusions implicated in the cell motility, and consequently in the decreased adhesion of these cells.

\section{Rosuvastatin reduces phagocytotic activity in LPS-challenged cells}

The microglial function is inherently related to its phagocytotic activity. In pure microglial cultures (subDIV4), the control (unchallenged and untreated) microglia exhibited a low level of fluid-phase 

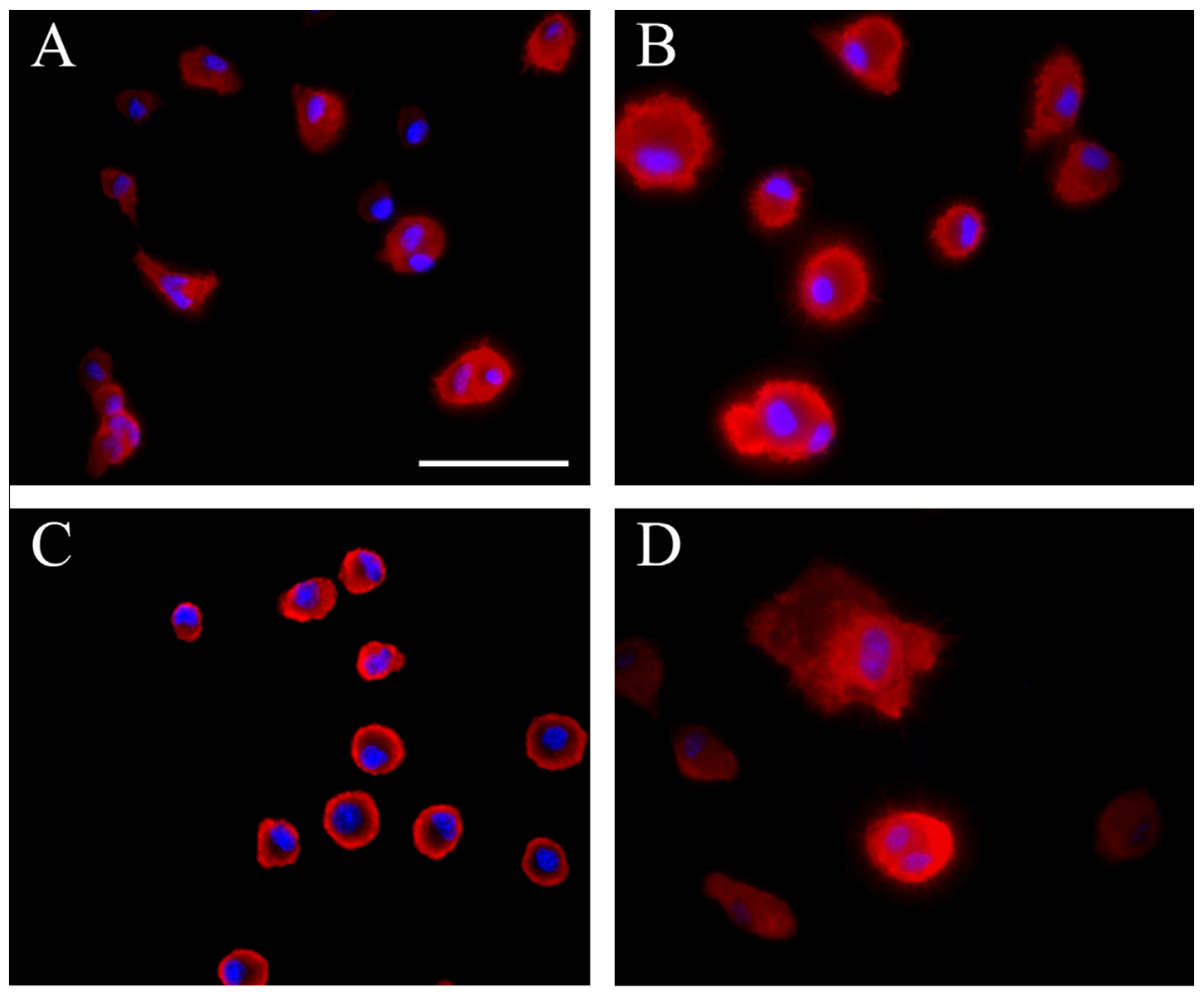

$\mathrm{E}$

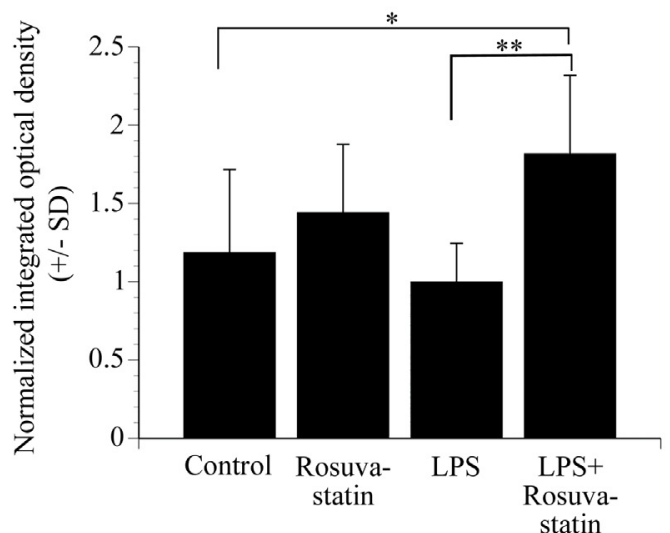

Ibal

$17 \mathrm{kDa}$

GAPDH

$36 \mathrm{kDa}$

Fig. 1. Rosuvastatin affects microglial cell morphology and Iba1 immunoreactivity in pure microglial cells after various treatments. Pure microglia cell cultures (subDIV4) were maintained as described in Experimental procedures. (A-D) Representative fluorescent immunocytochemical pictures demonstrate the typical cellular distribution of Iba1 immunoreactivity (red) in (A) control (unchallenged and untreated), (B) rosuvastatin-treated, (C) LPS-challenged and (D) LSP-challenged + rosuvastatin-treated microglial cells. The effects of rosuvastatin in unchallenged and LSP-challenged microglia were the most marked. Hoechst 33258-labeled cell nuclei are shown in blue. Scale bar in A (for all pictures): $50 \mu \mathrm{m}$. (E) Quantitative Western blot analysis of Iba1 and GAPDH immunoreactivities in pure microglial cell cultures. Protein samples from the cultures were separated by gel electrophoresis, transferred to nitrocellulose membranes and probed with either the lba1 or the GAPDH antibody. Gray-scale digital images of the immunoblots were acquired by scanning the autoradiographic films with a desktop scanner. The images were scanned and processed at identical settings to allow comparisons between the Western blots from different samples. Error bars indicate integrated optical density values (mean \pm SD) normalized to the internal standard GAPDH. Representative Western blot pictures are shown below the graphs. Data were analyzed with a two-way analysis of variance (ANOVA). ${ }^{*} p<0.05,{ }^{* *} p<0.01$. (For interpretation of the references to colour in this figure legend, the reader is referred to the web version of this article.) 
A

Control
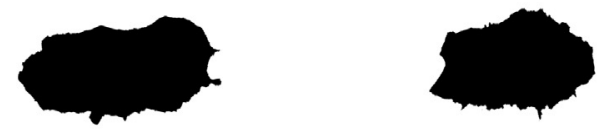
A: 693.48
P: 145.57

A: 550.58

P: 132.01

TI: 2.52

TI:2.43

B

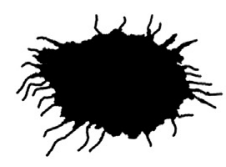

A:595.39

P: 388.23

TI: 20.25

C LPS
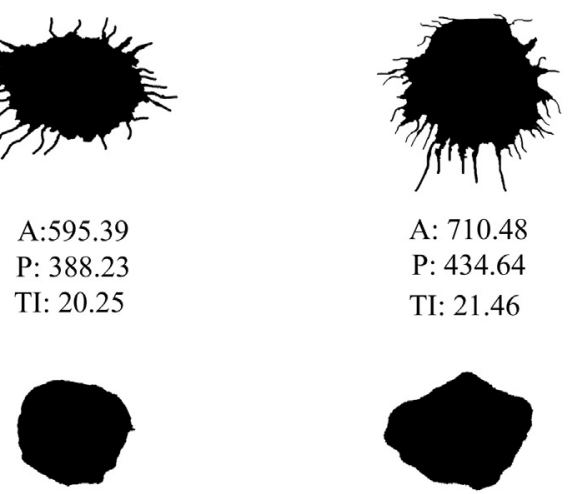

\title{
A: 710.48 \\ P: 434.64 \\ TI: 21.46
}

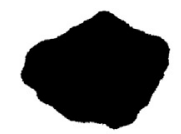

A: 415.15

P: 83.78

TI: 1.35

D ${ }_{\text {LPS }}+$ Rosuvastatin

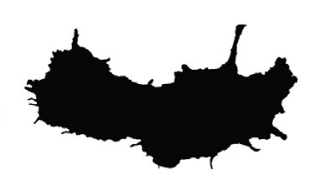
A: 1188.99
P: 329.15
TI: 7.25

\begin{abstract}
A: 522.02
P: 109.44

TI: 1.82
\end{abstract}

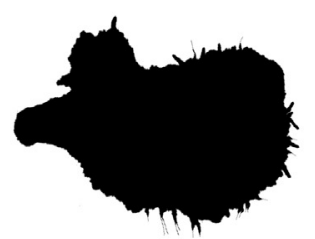
A: 2449.77
P: 490.51
TI: 7.81

F

E

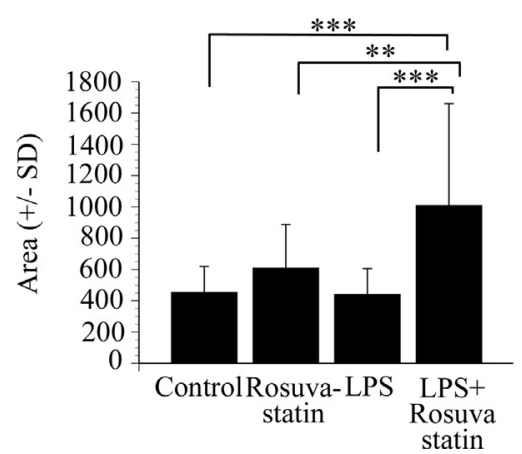

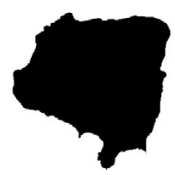

A: 685.19

P: 142.53

TI: 2.36

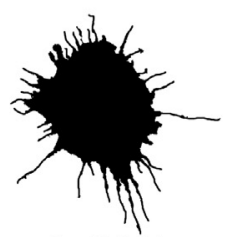
A: 608.74
P: 388.23
TI: 19.70

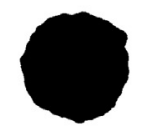
A: 420.32
P: 80.61
TI: 1.23

A: 155.40

P: 49.14

TI: 1.24

A: 757.04

P: 482.70

TI: 24.29
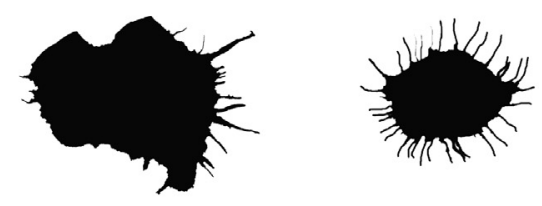

A: 1346.65
P: 391.95
TI: 9.08

A: 508.89

P: 219.43

TI: 5.540

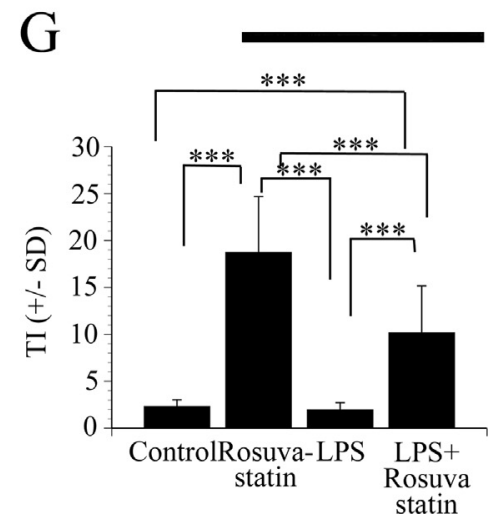

Fig. 2. Quantitative analysis of microglial morphology in pure microglial cell cultures after various treatments. Pure microglial cell cultures (subDIV4) were maintained as described in the Experimental procedure. (A-D) Iba1-positive microglial cells from pure microglial cultures (subDIV4) were photographed, the pictures were digitized and the morphological characteristics were quantitatively analyzed on binary silhouettes of unchallenged (A), rosuvastatin-treated (B), LPS-challenged (C) and LCS-challenged + rosuvastatin-treated (D) microglia. Four representative binary silhouettes are shown for each culturing protocol. Scale bar for all silhouettes: $50 \mu \mathrm{m}$. Area $(E)$ in $\mu \mathrm{m}^{2}$, perimeter $(\mathrm{F})$ in $\mu \mathrm{m}$, and $\mathrm{TI}$ values $(\mathrm{G})$, calculated as [perimeter of cell $(\mu \mathrm{m})]^{2} / 4 \pi\left[\right.$ cell area $\left.\left(\mu \mathrm{m}^{2}\right)\right]$, are indicated for each digitized cell. Unchallenged and untreated (control) cells, similarly to LPSchallenged cells, displayed a typical ameboid morphology with low TI values. Rosuvastatin affected the morphology of both the control and the LPSchallenged microglia $(B, D)$. In unchallenged cultures, it promoted microspike formation with a concurrent slight ramification of the cells (B). In the LPS-challenged + rosuvastatin-treated cultures (D), the microglia became larger and, while retaining microspikes, also developed thicker processes. Both the rosuvastatin treatment alone and the combined treatment with LPS resulted in larger perimeter (F) and higher TI values $(\mathrm{G})$ as compared with both the unchallenged and the LPS-challenged cultures. (E) Average area (in $\mu m^{2} \pm S$.D.) measurements for cultured pure microglial cells. ( $F$ ) Average perimeter (in $\mu \mathrm{m} \pm$ S.D.) measurements for cultured pure microglial cells. (G) Average TI values ( \pm S.D.) for cultured pure microglial cells. LPS: $20 \mathrm{ng} / \mathrm{ml}$; rosuvastatin: $1 \mu \mathrm{M}$. For $(E-G)$, error bars indicate mean \pm SD of six replicate measurements from three independent culturings. Data were analyzed with a two-way analysis of variance (ANOVA). ${ }^{* *} p<0.01 ;{ }^{* * *} p<0.001$. 

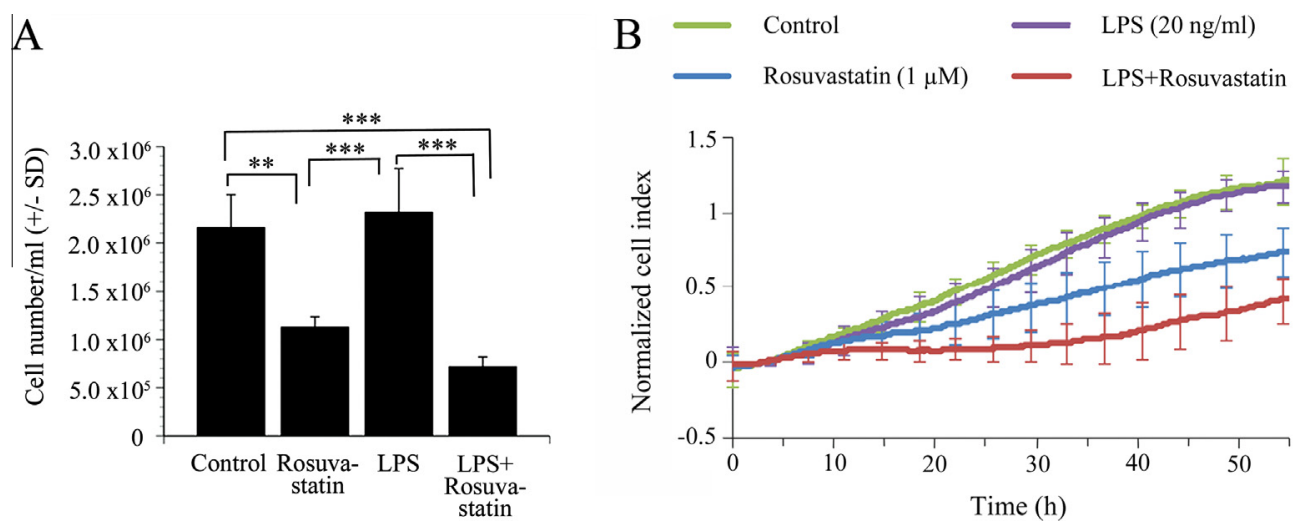

Fig. 3. Rosuvastatin inhibits cell proliferation and decreases cell adhesion. Pure microglial cultures (subDIV4) were maintained and treated as described in Experimental procedures section. (A) After culturing, the cells were collected and the number of surviving microglia was determined with a Bürker chamber. Rosuvastatin, in both unchallenged and LPS-challenged cultures, inhibited cell proliferation and displayed a strong antimitotic characteristic. LPS treatment did not affect cell proliferation. (B) Real-time monitoring of microglial cell adhesion after different treatment regimens. The ACEA Real-Time Cell Analysis (RTCA) system and 16-well E-Plates were used to determine cell indices as described in Experimental procedures section. Normalized cell index values are plotted as a function of time. In both unchallenged and LPS-challenged cells, rosuvastatin decreased cell adhesion (blue and red lines, respectively). Error bars indicate mean \pm SD of six replicate measurements from three independent culturings. Data were analyzed with a two-way analysis of variance (ANOVA). ${ }^{* *} p<0.01 ;{ }^{* * *} p=0.001$. (For interpretation of the references to colour in this figure legend, the reader is referred to the web version of this article.)

phagocytosis (Fig. 4A, E), engulfing only $2.62 \pm 1.7$ beads per cell $(n=91)$. Rosuvastatin did not affect the phagocytosis appreciably (Fig. 4B, E), the number of phagocytosed microbeads remaining low $(2.70 \pm 1.7$; $n=50$ ). As expected, the LPS challenge increased the phagocytotic activity of the microglial cells significantly (Fig. 4C, E). On average, the LPS-challenged cells accumulated $25.39 \pm 11.4$ beads per cell $(n=70)$, and some of the cells engulfed as many as 40 microbeads. In the LPS-challenged microglia, however, rosuvastatin inhibited the phagocytosis drastically, by nearly $80 \%$ (Fig. 4D, E) as the fluid-phase phagocytotic activity was returned close to the level of the control cells (4.67 \pm 3.9 microbeads per cell; $n=88$ ). As activated microglial cells often damage neuronal tissue, such a strong inhibition of a pro-inflammatory action by rosuvastatin could be beneficial in preventing or ameliorating neurodegeneration.

\section{Rosuvastatin concomitantly decreases pro-inflammatory and increases anti-inflammatory cytokine levels}

Activated microglia are known to express several pro- and anti-inflammatory cytokines, while statins are able to reduce the inflammatory effect in the vicinity of atherosclerotic plaques. We therefore expected rosuvastatin to regulate the amount of cytokines released by the microglia. Indeed, when the basal levels of the pro-inflammatory cytokines IL-1 $\beta$ and TNF- $\alpha$ and the anti-inflammatory cytokine IL-10 in unchallenged microglia were compared with the levels from rosuvastatin-treated LPS-challenged or unchallenged cells, a unique regulatory pattern emerged (Fig. 5). The basal level for IL-1 $\beta$ in unchallenged (control) microglia was $15.00 \pm 5.6 \mathrm{pg} / \mathrm{ml}$ (Fig. 5A). Rosuvastatin did not change this level significantly $(9.56 \pm 13.1 \mathrm{pg} / \mathrm{ml})$. As expected, a $24 \mathrm{~h}$-long LPS challenge significantly elevated the IL-1 $\beta$ level in the activated microglia, to $156.05 \pm 63.0 \mathrm{pg} / \mathrm{ml}$. However, when added together with LPS, rosuvastatin significantly inhibited the development of this elevated IL-1 $\beta$ level, by about $45 \%$, to $86.25 \pm 49.3 \mathrm{pg} / \mathrm{ml}$. A similarly strong effect of rosuvastatin was demonstrated on the level of TNF- $\alpha$, another pro-inflammatory cytokine, in LPS-challenged microglial cells (Fig. 5B). Two different treatment times $(6 \mathrm{~h}$ and $24 \mathrm{~h})$ were used as the TNF- $\alpha$ production responded quickly to the LPS challenge. The level of TNF- $\alpha$ in the unchallenged (control), rosuvastatintreated microglia could not be detected, but its level quickly rose, to $906.80 \pm 281.7 \mathrm{pg} / \mathrm{ml}$ in the LPSchallenged cells after $6 \mathrm{~h}$, and the level was still robust after $24 \mathrm{~h}(188.19 \pm 38.6 \mathrm{pg} / \mathrm{ml})$. When rosuvastatin was co-administered to LPS-challenged cells for either $6 \mathrm{~h}$ or $24 \mathrm{~h}$, it significantly inhibited the production of TNF- $\alpha$, by $39 \%$ and $40 \%$, respectively (Fig. $5 B$ ).

Moreover, rosuvastatin affected the production of IL-10, an anti-inflammatory cytokine (Fig. 5C). The basal and rosuvastatin-treated levels of IL-10 in the unchallenged microglia were not significantly different $(37.01 \pm 18.4 \mathrm{pg} / \mathrm{ml}$ vs. $75.32 \pm 35.4 \mathrm{pg} / \mathrm{ml})$, although elevated IL-10 production was noted after rosuvastatin treatment. Interestingly, LPS increased the IL-10 protein expression significantly to about $340 \%$ of the level of the unchallenged microglia $(125.3 \pm 25.3 \mathrm{pg} / \mathrm{ml} \quad \mathrm{pg} / \mathrm{ml})$. When rosuvastatin was co-administered with LPS, it boosted the IL-10 protein expression even higher, to about $750 \%$ of the basal level $(276.84 \pm 85.6 \mathrm{pg} / \mathrm{ml})$, indicating the very strong anti-inflammatory action of rosuvastatin.

\section{Rosuvastatin affects the expression of inflammation-related genes}

When the profound morphological and functional effects of rosuvastatin on the pro- and anti-inflammatory 

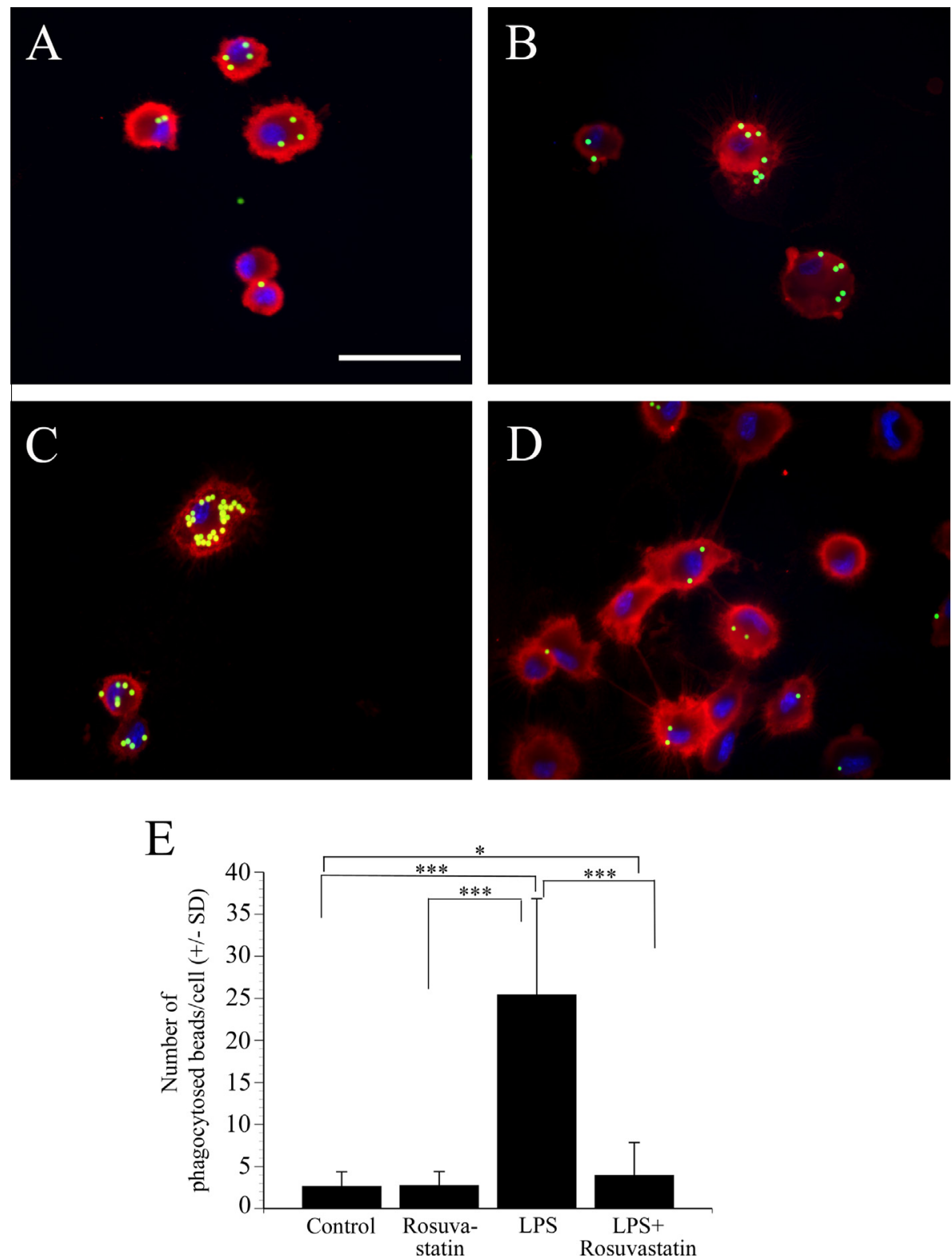

Fig. 4. Rosuvastatin is a potent inhibitor of phagocytosis. Pure microglial cultures (subDIV4) were maintained and treated with fluorescent microbeads ( $2 \mu \mathrm{m}$ in diameter) as described in Experimental procedures section. Iba1-specific fluorescent immunocytochemistry (red: microglia; blue: nucleus; green: microspheres) on unchallenged (A), rosuvastatin-treated unchallenged cells (B), LPS-challenged cells (C) and LPSchallenged + rosuvastatin-treated microglial cells (D) revealed that rosuvastatin inhibited phagocytosis in both naive, unchallenged (B) and LPSchallenged cells $(D)$. Scale bar in A (for all pictures) $=50 \mu \mathrm{m}$. (E) Quantitative analysis of the number of phagocytosed microbeads revealed that LPS dramatically activated phagocytosis, while rosuvastatin when present significantly decreased this microglial function. Error bars indicate mean $\pm \mathrm{SD}$ of six replicate measurements from three independent culturings. Data were analyzed with a two-way ANOVA. ${ }^{\star} p<0.05,{ }^{* \star * x} p<0.001$. (For interpretation of the references to colour in this figure legend, the reader is referred to the web version of this article.)

capabilities of the microglia had become apparent, we set out to analyze the effects of rosuvastatin on the expression of 122 inflammation-related genes in unchallenged and LPS-challenged pure microglial cells. The hierarchical cluster analysis of 75 such genes is summarized in Fig. 6, and the genes with 47 of the most noteworthy and significant expression changes in response to treatment are listed in Table 1. The results of the analysis indicated that treatment with $1 \mu \mathrm{M}$ rosuvastatin in unchallenged and LPS-challenged microglia could induce either the upregulation or the downregulation of a number of genes. Levels of expression of selected inflammation-related genes (for example, Ccl24, Ccr1, IL-11, Cxcl1, Ccl4, Ccl5, Hspb1, $T G F b-2$ and $M b / 2$ ) are highlighted in Fig. 7. Some of these genes responded to rosuvastatin in unchallenged or challenged cells, or were affected by the LPS challenge. The genes upregulated by the LPS challenge included those coding for chemokine ligands 1, 2, 4, 5, 9, 19 and 24 (Cxcl1 = 111.6-fold, $C c / 2=34.5$-fold, $C c / 4=17.6$-fold,$\quad C c / 5=147.0$-fold,$\quad C x c / 9=118.2-$ fold, $\quad C c / 19=5.2$-fold and $C$ cl24 $=24.6$-fold), IL-11 

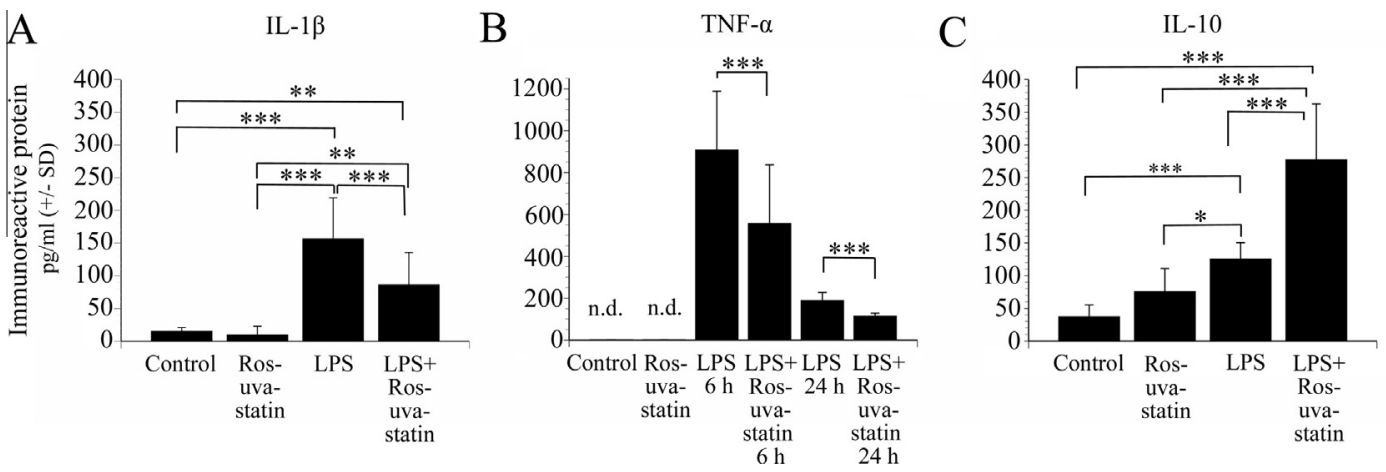

Fig. 5. Rosuvastatin reduces the pro-inflammatory cytokine IL-1 $\beta$ and TNF- $\alpha$ levels and increases the anti-inflammatory IL-10 production. Pure microglial cultures (subDIV4) were maintained and treated as described in Experimental procedures section. After treatments for 6 or $24 \mathrm{~h}$, immunoreactive protein levels ( $\mathrm{pg} / \mathrm{ml} \pm$ S.D.) for IL-1 $\beta$ (A), TNF- $\alpha$ (B) and IL-10 (C) were detected by ELISA. TNF- $\alpha$ production was measured after $6 \mathrm{~h}$ and $24 \mathrm{~h}(\mathrm{~B})$. As expected, pro-inflammatory cytokine production was significantly increased in the LPS-challenged cells (A, B). Rosuvastatin was a potent inhibitor of this effect for both IL-1 $\beta(A)$ and TNF- $\alpha(B)$. The level of the anti-inflammatory cytokine IL-10 was measured after $24 \mathrm{~h}(C)$. Rosuvastatin slightly increased the level of IL-10 both in unchallenged and in LPS-challenged microglia, to $750 \%$ of the control level in the latter case (C). Error bars indicate mean \pm S.D. of six replicate measurements from three independent culturings. Data were analyzed with a two-way ANOVA. n.d. $=$ not detected. ${ }^{*} p<0.05 ;{ }^{* *} p<0.01 ;{ }^{* * *} p<0.001$

$(/ / 11=19.3$-fold $), \quad$ IL-23 receptor $\quad(/ / 23 r=246.6$-fold $)$ and mannose-binding lectin (protein $\mathrm{C}$ ) two receptor $(M b / 2=33.2$-fold $)$. Only a few genes were downregulated by the LPS challenge, the most affected one being that of the myosin regulatory light chain 2 (Myl2 $=-4.4-$ fold).

Rosuvastatin treatment in unchallenged cells affected fewer, but similarly important microglial genes involved in pro- and anti-inflammatory processes. The genes upregulated by rosuvastatin included $\mathrm{Cxcl} 1$ (7.0-fold; Fig. 7D), the anti-inflammatory Cc/5 (6.6-fold; Fig. 7F), and, most importantly, Mb/2 (126.2-fold; Fig. 7I), a crucial factor in the development of innate immunity (Worthley et al., 2005). Rosuvastatin was in general a weak inhibitor of the expression of inflammatory genes as it downregulated only a few genes, notably the antiinflammatory interleukin-10 $(/ / 10=-4.0$-fold $)$ and the pro-inflammatory chemokine (C-C motif) receptor 1 (Ccr1 $=-2.9$-fold). When rosuvastatin was applied to LPS-challenged cultures (Table 1, Figs. 6 and 7), a more complex picture emerged. Some of the LPS-upregulated genes were inhibited by rosuvastatin, as seen in the case of $\mathrm{Ccl} 24$, where a substantial, $377 \%$ decrease in gene expression was observed, down from the 24.5-fold increase after LPS treatment to a 6.5 -fold increase (Fig. 7A), or in the case of Ccr1, where a $198 \%$ decrease in gene expression was detected (Fig. 7B). Interestingly, rosuvastatin alone did not exhibit a strong effect on these latter genes, but only when activated by LPS (Fig. 7C, D). Other genes were regulated synergistically by rosuvastatin when applied to LPS-challenged microglia. For example, $\mathrm{Cxcl} 1$ and $\mathrm{C}$ cl4 were both further upregulated by rosuvastatin in LPS-challenged cells (Fig. 7D, E). Some of the genes related to inflammation were not affected by the LPS challenge, but reacted weakly to rosuvastatin, as seen in Hspb1 gene expression (Fig. 7G, H), where a 2.8-fold increase was detected.

\section{DISCUSSION}

We carried out a quantitative investigation of the complex morphological, functional and gene expression characteristics of pure microglial cells of embryonic origin after rosuvastatin treatment in unstimulated and LPS-challenged cultures, and highlighted the complex beneficial effects of rosuvastatin that make it an excellent candidate for preventive neuroinflammatory therapy with well-balanced properties of enhanced antiinflammatory and subdued pro-inflammatory effects.

Although microglial cells prepared from embryonic nervous tissue may differ from those of the adult brain in certain characteristics (Floden and Combs, 2006), they are nevertheless similarly responsive to immunological (LPS) challenge and suitable for morphological, functional and gene expression studies. When activated, the microglia display both pro- and anti-inflammatory properties as they can be polarized along a continuum toward a detrimental (M1) or a beneficial (M2) state in the injured CNS (Kroner et al., 2014). Inflammation that is mediated, and perhaps enhanced, by the microglia has been implicated in a number of neuropathological conditions, ranging from acute injuries (Loane and Byrnes, 2010) and chronic inflammatory conditions (Gay, 2007; Napoli and Neumann, 2010) to neurodegenerative diseases (LongSmith et al., 2009; Prokop et al., 2013).

Statins are commonly used in the treatment of high blood cholesterol levels (Burg and Espenshade, 2011). They are classified on the basis of their lipid-lowering efficacy and their lipophilic/hydrophilic nature (Hamelin and Turgeon, 1998; Jones et al., 1998; Davidson, 2002; Schachter, 2005); while lipophilic statins penetrate the cell membrane, hydrophilic statins such as rosuvastatin (Crestor; AstraZeneca Pharmaceuticals, LP, Wilmington, DE, USA) are transported through the blood-brain barrier via multiple transporters (Kitamura et al., 2008; Abbott et al., 2010; Ellis et al., 2013) or ATP-binding cassette efflux transporters in microglia (Gibson et al., 2012). Rosuvastatin exhibits the greatest inhibitory effect on cholesterol biosynthesis (McTaggart et al., 2001) and most favorably alters the high-density lipoprotein profile among statins (Asztalos et al., 2007); it was the fourth highest-selling prescription drug in the USA in 2013 (http://www.drugs.com/stats/top100/2013/sales). 


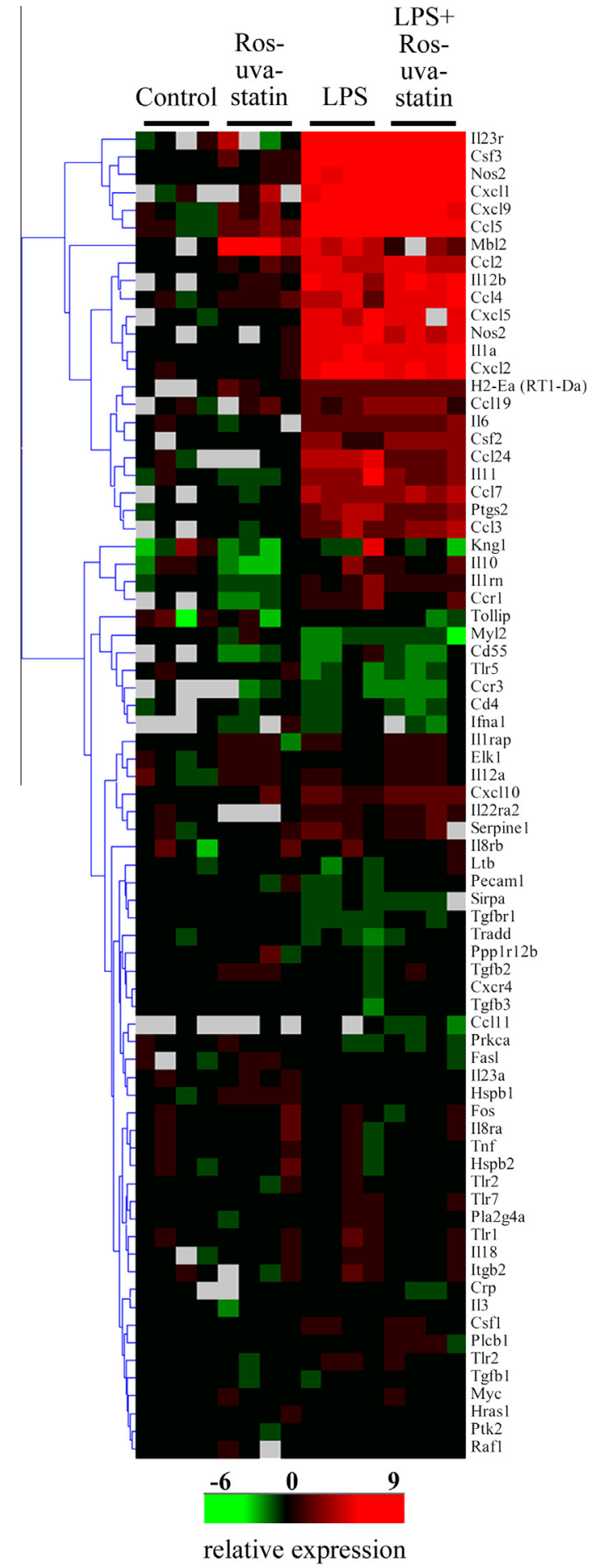

Fig. 6. Hierarchical cluster analysis of inflammation-related genes. Pure microglial cultures (subDIV4) were maintained and treated as described in Experimental procedures section. The cells (subDIV4) were cultured with or without LPS for $24 \mathrm{~h}$ in the presence or absence of rosuvastatin. Rosuvastatin: $1 \mu \mathrm{M}$; LPS: $20 \mathrm{ng} / \mathrm{ml}$; LPS + rosuvastatin: LPS $(20 \mathrm{ng} / \mathrm{ml})+$ rosuvastatin $(1 \mu \mathrm{M})$. For hierarchical cluster analysis and visualization, the Hierarchical Clustering Explorer (v3.0) software was used. The complete linkage clustering method was applied with Euclidean distance metric. The heat map depicts expression values relative to control samples on a $\log _{2}$ scale (overexpression: red, repression: green and no change: black). Missing values are indicated in gray. (For interpretation of the references to colour in this figure legend, the reader is referred to the web version of this article.)
Although their main action is to block cholesterol synthesis, other effects of statins, including those on the regression of atherosclerotic coronary lesions, are also important (Wierzbicki et al., 2003). Expecting similarly beneficial effects on the microglia, we determined how rosuvastatin modulates both pro- and anti-inflammatory actions by affecting numerous morphological, functional and gene expression parameters in pure microglial cultures. These cultures provide a unique opportunity to study these functional and expression parameters without the significant influence of any contaminating cell types. Our secondary microglial cultures were $>99 \%$ pure, a crucial factor when levels of secreted pro- and antiinflammatory peptides or gene expression levels are measured, as other cell types in the CNS are also capable of expressing such peptides (Gruol et al., 2014).

Our studies revealed the effects of rosuvastatin on various quantitative morphological properties of the microglia. Rosuvastatin affected the area, perimeter and TI profoundly in both unchallenged and LPS-challenged cells. It generally promoted microspike formation and increased the cell perimeter and TI through ramification. Concomitantly with the increase in cell area in both unchallenged and LPS-challenged cells, rosuvastatin affected the protein synthesis of Iba1, a protein that is implicated in actin cytoskeleton remodeling (Sasaki et al., 2001; Ohsawa et al., 2004). As expected, LPS treatment caused microglia activation that resulted in a low TI, but the combined treatment with LPS + rosuvastatin inhibited this activation through the development of microspikes and the cells becoming more ramified.

Rosuvastatin strongly inhibited microglia proliferation and adhesion as it significantly decreased the number of cells in both naïve and LPS-challenged cultures. Although the precise mechanisms are not known, statins are able to inhibit mitosis through cell cycle arrest in G1 (Yang et al., 2008) and G2/M (Gao et al., 2012). As rosuvastatin displays a weak anti-mitogenic effect, its regular use may prove helpful in lowering the risks of a number of cancer types (Simon et al., 2012). To quantify cell adhesion, we used the cell index value (Atienza et al., 2005; Jarvis et al., 2011). Our finding that rosuvastatin lowered cell adhesion in both unchallenged and LPS-challenged cells is in harmony with previous reports on the ability of statins to decrease the expression of cell adhesion molecules (Weber et al., 1997; Wierzbicki et al., 2003).

We also examined how rosuvastatin altered fluidphase phagocytosis. Phagocytosis is crucial in both the normal and the pathologic CNS as it efficiently eliminates foreign materials, apoptotic cells and cell debris (Kettenmann et al., 2011), and alteration of this clearance function could be harmful (Hickman and El Khoury, 2014; Lue et al., 2015). For example, proinflammatory phenotypes are linked to the phagocytic activity, and the blocking of phagocytosis may prevent some forms of inflammatory neurodegeneration, and might therefore be beneficial during infection, trauma, ischemia, neurodegeneration and aging (Neher et al., 2011; He et al., 2014). LPS is a strong activator of microglial phagocytosis (Nakamura, 2002; Lund et al., 2006; Szabo and Gulya, 2013). In our study, rosuvastatin 
Table 1. Differentially expressed transcripts in rosuvastatin-treated pure microglial cells with or without LPS challenge

\begin{tabular}{|c|c|c|c|c|}
\hline Gene & Name, NCBI reference sequence ID, RGD ID & Rosuvastatin & LPS & LPS + Rosuvastatin \\
\hline $\mathrm{Cxcl} 1$ & $\begin{array}{l}\text { Chemokine ligand } 1 \text { (melanoma growth-stimulating activity, alpha) } \\
\text { NM_030845.1, RGD ID } 619869\end{array}$ & +7.05 & +111.55 & +394.01 \\
\hline Csf3 & $\begin{array}{l}\text { Colony-stimulating factor } 3 \\
\text { NM_017104.1 (old), NM_017104.2, RGD ID } 2426\end{array}$ & +2.9 & +310.7 & +321.7 \\
\hline$\| 23 r$ & $\begin{array}{l}\text { Interleukin } 23 \text { receptor } \\
\text { XM_001072576.2, RGD ID } 1586368\end{array}$ & +2.12 & +246.56 & +268.81 \\
\hline $\mathrm{Ccl} 5$ & $\begin{array}{l}\text { Chemokine ligand } 5 \\
\text { NM_031116.3, RGD ID } 69069\end{array}$ & +6.56 & +146.97 & +241.56 \\
\hline Nos2 & $\begin{array}{l}\text { Nitric oxide synthase } \\
\text { U26686.1, RGD ID } 3185\end{array}$ & +1.82 & +169.95 & +135.48 \\
\hline Cxcl9 & $\begin{array}{l}\text { Chemokine ligand } 9 \\
\text { NM_145672.4, RGD ID } 628798\end{array}$ & +3.82 & +118.20 & +100.95 \\
\hline$\| 12 b$ & $\begin{array}{l}\text { Interleukin 12B } \\
\text { NM_022611.1, RGD ID } 628704\end{array}$ & +1.7 & +42.0 & +87.7 \\
\hline $\mathrm{Cxcl} 2$ & $\begin{array}{l}\text { Chemokine ligand } 2 \\
\text { NM_053647.1, RGD ID } 70069\end{array}$ & +1.2 & +75.4 & +67.3 \\
\hline II1a & $\begin{array}{l}\text { Interleukin } 1 \text { alpha } \\
\text { NM_017019.1, RGD ID } 2890\end{array}$ & +1.1 & +45.3 & +57.0 \\
\hline $\mathrm{Ccl} 4$ & $\begin{array}{l}\text { Chemokine ligand } 4 \\
\text { NM_053858.1, RGD ID } 620441\end{array}$ & +3.33 & +17.65 & +51.0 \\
\hline Cxcl5 & $\begin{array}{l}\text { Chemokine ligand } 5 \text { (also known as Cxcl6) } \\
\text { NM_022214.1, RGD ID } 708540\end{array}$ & +1.1 & +54.9 & +43.4 \\
\hline $\mathrm{Ccl} 2$ & $\begin{array}{l}\text { Chemokine ligand } 2 \\
\text { NM_031530.1, RGD ID } 3645\end{array}$ & +2.34 & +34.49 & +33.27 \\
\hline $\mathrm{Ccl} 7$ & $\begin{array}{l}\text { Chemokine ligand } 7 \\
\text { NM_001007612.1, RGD ID } 1359152\end{array}$ & -1.4 & +12.4 & +14.4 \\
\hline $\mathrm{Ccl} 3$ & $\begin{array}{l}\text { Chemokine ligand } 3 \\
\text { NM_013025.2, RGD ID } 3647\end{array}$ & -1.3 & +9.1 & +11.4 \\
\hline 116 & $\begin{array}{l}\text { Interleukin } 6 \\
\text { M26744.1, RGD ID } 2901\end{array}$ & -1.1 & +5.6 & +8.4 \\
\hline II11 & $\begin{array}{l}\text { Interleukin } 11 \\
\text { NM_133519.4, RGD ID } 621475\end{array}$ & -1.99 & +19.28 & +7.40 \\
\hline Ptgs 2 & $\begin{array}{l}\text { Prostaglandin endoperoxide synthase } 2 \\
\text { NM_017232.3, RGD ID } 620349\end{array}$ & -1.2 & +11.8 & +7.2 \\
\hline Ccl19 & $\begin{array}{l}\text { Chemokine ligand } 19 \\
\text { NM_001108661.1, RGD ID } 1310336\end{array}$ & +2.39 & +5.21 & +6.87 \\
\hline Mbl2 & $\begin{array}{l}\text { Mannose-binding lectin } 2 \\
\text { NM_022704.2, RGD ID } 67380\end{array}$ & +126.17 & +33.22 & +6.46 \\
\hline $\mathrm{Ccl} 24$ & $\begin{array}{l}\text { Chemokine ligand } 24 \\
\text { NM_001013045.1, RGD ID } 1310245\end{array}$ & +1.65 & +24.55 & +6.51 \\
\hline Cxcl10 & $\begin{array}{l}\text { Chemokine ligand } 10 \\
\text { NM_139089.1, RGD ID } 620209\end{array}$ & +1.8 & +4.5 & +5.5 \\
\hline II22ra2 & $\begin{array}{l}\text { Interleukin } 22 \text { receptor, alpha } 2 \\
\text { NM_001003404.1, RGD ID } 1303169\end{array}$ & +1.1 & +2.5 & +4.0 \\
\hline II10 & $\begin{array}{l}\text { Interleukin } 10 \\
\text { NM_012854.2, RGD ID } 2886\end{array}$ & -3.97 & +3.08 & +2.69 \\
\hline II1rn & $\begin{array}{l}\text { Interleukin } 1 \text { receptor antagonist } \\
\text { NM_022194.2, RGD ID } 621159\end{array}$ & -2.19 & +3.76 & +2.63 \\
\hline TIr2 & $\begin{array}{l}\text { Toll-like receptor } 2 \\
\text { NM_198769.2, RGD ID } 735138\end{array}$ & -1.5 & +1.8 & +2.1 \\
\hline Ccr1 & $\begin{array}{l}\text { Chemokine receptor } 1 \\
\text { NM_020542.2, RGD ID } 708446\end{array}$ & -2.89 & +3.88 & +1.96 \\
\hline Traf2 & $\begin{array}{l}\text { Tnf receptor-associated factor } 2 \\
\text { NM_001107815.2, RGD ID } 1310457\end{array}$ & +1.6 & +1.9 & +1.6 \\
\hline Mknk1 & $\begin{array}{l}\text { MAP kinase-interacting serine/threonine kinase } 1 \\
\text { NM_001044267.1, RGD ID } 1559603\end{array}$ & +1.4 & +1.6 & +1.5 \\
\hline CD47 & $\begin{array}{l}\text { Cluster of differentiation } 47 \\
\text { NM_019195.2, RGD ID } 2308\end{array}$ & -1.1 & +1.3 & +1.4 \\
\hline Pla2g4a & $\begin{array}{l}\text { Phospholipase A2, group IVA (cytosolic, Ca-dependent) } \\
\text { NM_133551.2, RGD ID } 67366\end{array}$ & -1.7 & +1.7 & +1.3 \\
\hline TIr7 & $\begin{array}{l}\text { Toll-like receptor } 7 \\
\text { EF032637.1, RGD ID } 1563357\end{array}$ & -1.2 & +1.8 & +1.3 \\
\hline
\end{tabular}


Table 1 (continued)

\begin{tabular}{|c|c|c|c|c|}
\hline Gene & Name, NCBI reference sequence ID, RGD ID & Rosuvastatin & LPS & LPS + Rosuvastatin \\
\hline Ddit3 & $\begin{array}{l}\text { DNA-damage-inducible transcript } 3 \\
\text { NM_001109986.1, RGD ID } 62391\end{array}$ & -1.3 & +1.7 & +1.3 \\
\hline II18rap & $\begin{array}{l}\text { Interleukin } 18 \text { receptor accessory protein } \\
\text { XM_003750691.2, RGD ID } 727867\end{array}$ & +1.2 & +1.7 & +1.2 \\
\hline Hmgn1 & $\begin{array}{l}\text { High-mobility group nucleosome-binding domain } 1 \\
\text { NM_001013184.1, RGD ID } 1307761\end{array}$ & +1.6 & +1.2 & +1.0 \\
\hline Scarb1 & $\begin{array}{l}\text { Scavenger receptor class B, member } 1 \\
\text { NM_031541.1, RGD ID } 2302\end{array}$ & +1.1 & -1.3 & +1.0 \\
\hline Jun & $\begin{array}{l}\text { Jun proto-oncogene } \\
\text { NM_021835.3, RGD ID } 2943\end{array}$ & +1.2 & -1.8 & -1.1 \\
\hline Hspb1 & $\begin{array}{l}\text { Heat shock protein } 1 \\
\text { NM_031970.3, RGD ID } 61306\end{array}$ & +2.79 & -1.04 & -1.19 \\
\hline $\mathrm{Hc}$ & $\begin{array}{l}\text { Clathrin, heavy chain } \\
\text { NM_019299.1, RGD ID } 2364\end{array}$ & +1.0 & +1.1 & -1.3 \\
\hline Tgfb3 & $\begin{array}{l}\text { Transforming growth factor, beta } 3 \\
\text { NM_013174.2, RGD ID } 3851\end{array}$ & +1.2 & -1.9 & -1.4 \\
\hline Elmo1 & $\begin{array}{l}\text { Engulfment and cell motility } 1 \\
\text { NM_001108415.1, RGD ID } 1308182\end{array}$ & -1.0 & -1.7 & -1.6 \\
\hline Prkca & $\begin{array}{l}\text { Protein kinase C, alpha } \\
\text { NM_001105713.1, RGD ID } 3395\end{array}$ & +1.3 & -2.1 & -1.7 \\
\hline Il10rb & $\begin{array}{l}\text { Interleukin } 10 \text { receptor, beta } \\
\text { NM_001107111.1, RGD ID } 1560373\end{array}$ & -1.4 & -1.1 & -1.9 \\
\hline Tgfbr1 & $\begin{array}{l}\text { Transforming growth factor, beta receptor } 1 \\
\text { NM_012775.2, RGD ID } 3852\end{array}$ & -1.2 & -2.5 & -2.0 \\
\hline Sirpa & $\begin{array}{l}\text { The signal-regulatory protein a } \\
\text { NM_013016.2, RGD ID } 3449\end{array}$ & -1.5 & -2.7 & -2.8 \\
\hline TIr5 & $\begin{array}{l}\text { Toll-like receptor } 5 \\
\text { FJ750588.1, RGD ID } 631351\end{array}$ & -1.2 & -3.0 & -2.9 \\
\hline Ccl11 & $\begin{array}{l}\text { Chemokine ligand } 11 \\
\text { NM_019205.1, RGD ID } 3644\end{array}$ & -1.2 & -1.4 & -3.0 \\
\hline Myl2 & $\begin{array}{l}\text { Myosin, light polypeptide } 2 \\
\text { NM_001035252.1 (old), NM_001035252.2, } \\
\text { RGD ID } 1564245\end{array}$ & -1.3 & -4.4 & -5.2 \\
\hline
\end{tabular}

The National Center for Biotechnology Information (NCBI) Reference Sequence Database can be retrieved at http://www.ncbi.nlm.nih.gov/refseq/. A description of a gene function (RGD ID) can be found in The Rat Genome Database 2015 (Shimoyama et al., 2015) at http://rgd.mcw.edu/. Data are expressed as fold-change over the expression of unchallenged and untreated (control) microglial cells. Treatments had different effects on inflammation-related genes. LPS mostly induced the upregulation of genes as compared with the untreated control microglia. Rosuvastatin alone also had some effects on these genes. Combined treatment demonstrated that rosuvastatin had different effects on LPS-activated microglia cells: inhibited the effect of LPS on certain genes (e.g. Cc/24, Ccr1, Kng1, Nos2, I/11), while it had a synergistic effect with LPS on others (e.g. Cxcl1, Cc/4, I/23r)

inhibited phagocytosis completely in the LPS-challenged microglia, while it was ineffective in inhibiting the basallevel phagocytosis in unchallenged cells, indicating that rosuvastatin is a potent inhibitor of this function only in pro-inflammatory situations and does not alter the normal clearance of cell debris in a healthy tissue. Thus, rosuvastatin could be helpful when excess microglial activity could harm the nervous tissue.

Cytokines, important immunomodulators in the normal functioning of the CNS, can be released, among others, by the microglial cells. Cytokines can also be harmful: previous studies have shown that neurodegeneration originating through neuroinflammation is often elicited by activated microglia (McGeer and McGeer, 2003, 2010) through the release of different pro-inflammatory cytokines and chemokines (Hanisch, 2002). High levels of IL-1 $\beta$ could be observed, for instance, in the vicinity of amyloid plaques of AD patients (McGeer et al., 1993; Lindberg et al., 2005; Ghosh et al., 2013), where activated microglia accumulate (Rodriguez et al., 2014). Previous studies also suggested that statins reduce levels of some of the pro-inflammatory cytokines (Lindberg et al., 2005;
Nakamichi et al., 2006; Veillard et al., 2006) and increase the anti-inflammatory cytokine IL-10 (Schönbeck and Libby, 2004). As expected, both pro- (IL-1 $\beta$, TNF- $\alpha$ ) and anti-inflammatory cytokines (IL-10) were increased in LPS-challenged cells as compared with the unchallenged (control) group. Rosuvastatin did not significantly affect the basal cytokine levels in unchallenged microglia, but strongly inhibited levels of the pro-inflammatory cytokines IL-1 $\beta$ and TNF- $\alpha$ when tested in LPS-challenged cells. Besides the inhibition of these pro-inflammatory agents, rosuvastatin exerted a direct anti-inflammatory effect by elevating the level of IL-10 in both unchallenged and LPS-challenged cells.

Effects of rosuvastatin on such diverse immune mechanisms of microglia as phagocytosis and cytokine production indicated a strong likelihood of its involvement in many other immune system-wide functions and possible effects on inflammation-related genes. We demonstrated that rosuvastatin, LPS and their combination had differential effects on the expression of inflammation-related genes. Several genes were upregulated after LPS challenge, confirming 
A
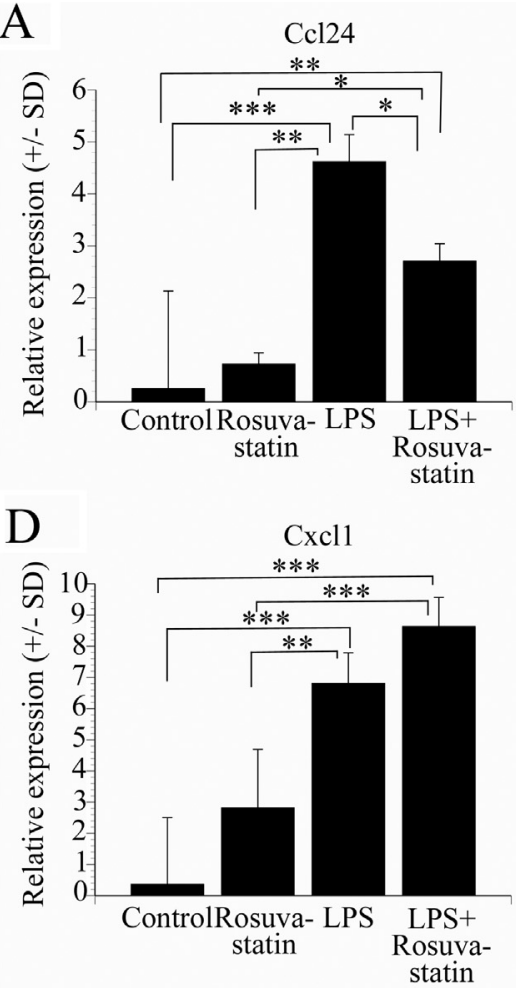

G

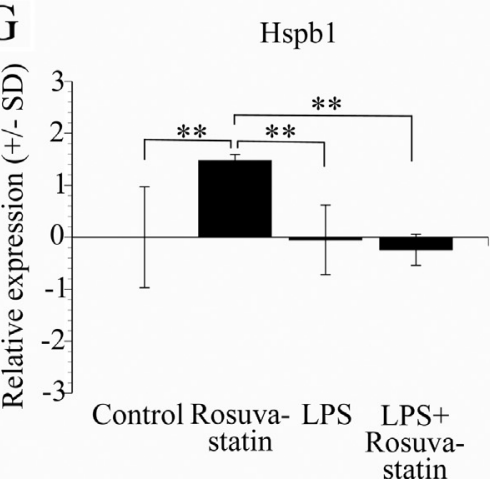

B

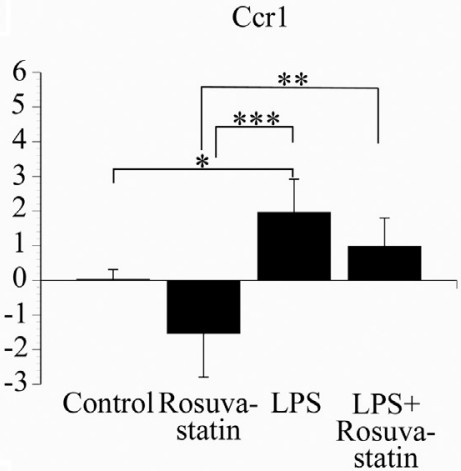

E

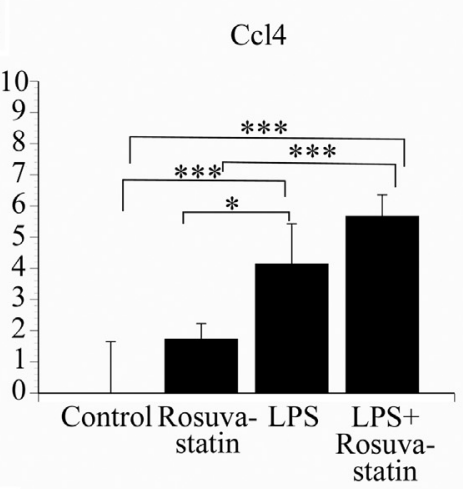

H

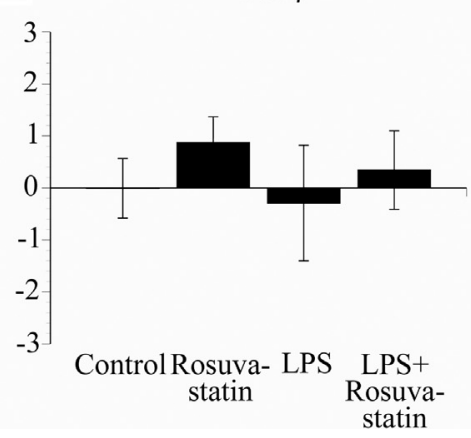

C

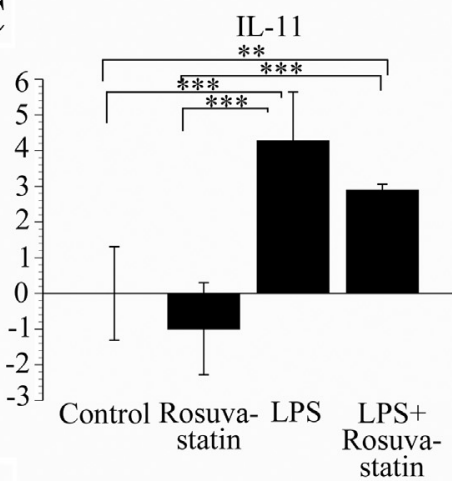

F

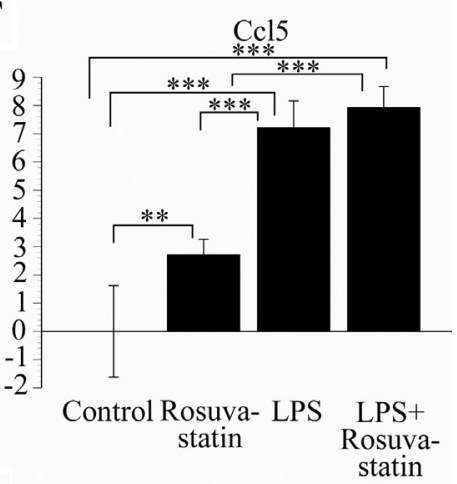

I

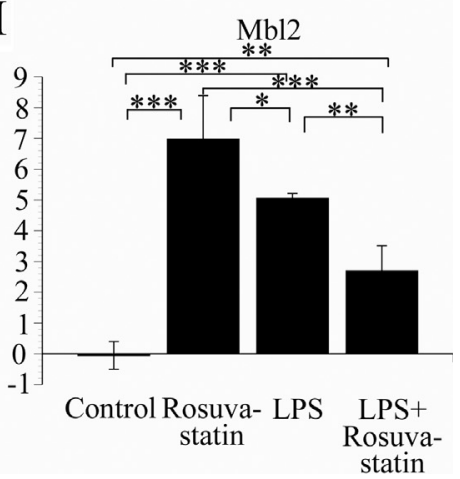

Fig. 7. Relative expression levels of various inflammation-related genes identified by real-time PCR in pure microglia cells. Pure microglial cultures (subDIV4) were maintained and treated as described in Experimental procedures section. The cells (subDIV4) were cultured with or without LPS for $24 \mathrm{~h}$ in the presence or absence of rosuvastatin. The extraction of total RNA and the real-time PCR are described in Experimental procedures section. The transcription levels of the chemokine ligand $24(\mathrm{Ccl} 24, \mathrm{~A})$, the chemokine receptor $1(\mathrm{Ccr} 1, \mathrm{~B}), \mathrm{L}-11(\mathrm{C})$, the chemokine $(\mathrm{CXC}$ motif) ligand 1 (or melanoma growth-stimulating activity, alpha), $(C x c / 1, \mathrm{D})$, the chemokine ligand $4(C \mathrm{Cl} 4, \mathrm{E})$, the chemokine ligand $5(C c / 5$, $\mathrm{F}$ ), the heat shock protein $1(H s p b 1, G)$, the transforming growth factor beta $(T G F / l-2, H)$ and the mannose-binding lectin (protein $\mathrm{C}) 2(M b / 2$, I) are shown in unstimulated (control), LPS-challenged and LPS-challenged + rosuvastatin-treated cells. For some pro-inflammatory genes, rosuvastatin inhibited their expression which was upregulated in LPS-challenged cells. In connection with $\mathrm{Cxcl1}, \mathrm{Cc} / 4$ and $\mathrm{Cc} / 5$, the combined treatment revealed synergistic effects between rosuvastatin and LPS for $\mathrm{Cxcl} 1, \mathrm{Ccl} 4$ and $\mathrm{Ccl} 5$. Rosuvastatin increased levels of expression of $H s p b 1, T G F-\beta$ and $M b / 2$. Relative expression levels (on a $\log _{2}$ scale) \pm SD from at least four separate experiments are shown for each condition. Data were analyzed with a two-way ANOVA. ${ }^{*} p<0.05 ;{ }^{* \star} p<0.01 ;{ }^{* \star *} p<0.001$.

its strong pro-inflammatory effects on the microglia. Rosuvastatin itself and in combination with LPS displayed different effects on gene expression. Although rosuvastatin was not able to decrease all the LPSupregulated genes, it suppressed the pro-inflammatory effects of LPS on some genes such as Ccl24 or Ccr1. $\mathrm{Ccl} 24$ is a chemokine that can readily be upregulated by pro-inflammatory cytokines or microbial stimulus such as LPS (Watanabe et al., 2002). Ccr1 is implicated in multiple sclerosis (MS) and experimental autoimmune encephalomyelitis (EAE). Previous studies suggested that Ccr1 could be upregulated in EAE (Rottman et al., 2000), and the microglia expressed Ccr1 around the demyelinating plaques, making Ccr1 antagonists or inhibitors possible targets for the development of MS-therapy (Hesselgesser et al., 1998; Eltayeb et al., 2007).

Rosuvastatin additionally increased the expression of certain genes. Its general effects on microglia were predominantly anti-inflammatory. The gene most upregulated by rosuvastatin was $\mathrm{Mb} / 2$, which is important in innate immunity (Worthley et al., 2005; Ip et al., 2009) and involved in the stimulation of phagocytosis (Stuart 
et al., 2005). Hspb1 was also upregulated by rosuvastatin. Hspb1 is a heat-shock protein with strong anti-apoptotic potential that regulates the cytoskeleton dynamics through $\mathrm{F}$-actin stabilization (Concannon et al., 2003). Cxcl1 has been reported to be an antiinflammatory protein with a neuroprotective role (Omari et al., 2009). Additional chemokine genes such as Cc/2 (El Khoury et al., 2007; El Khoury and Luster, 2008), Cxc/1 (Bosivert et al., 2006) and Cc/5 were all upregulated in our studies and implicated in microglia recruitment to areas of inflammation. Although $\mathrm{Ccl} 5$ has been demonstrated to induce pro-inflammatory mechanisms (Skuljec et al., 2011), it has also been shown to ameliorate AD-like pathology by recruiting microglia to $\beta$-amyloid deposits (Lee et al., 2012). The expression of a number of phagocytosis-related gene was also tested. For example, Mb/2 was upregulated in rosuvastatin-treated microglia in a seemingly contradictory action, while several other genes known to be involved in phagocytosis were inhibited, as expected from the phagocytosis essays, by rosuvastatin (for example Myl2 (-1.27), Sirpa $(-1.50)$, Elmo1 (-1.05), or CD47 (-1.07)). Although the overall downstream effect in the microglia is a strong inhibition of phagocytosis upon rosuvastatin treatment, it remains to be seen as to what intracellular signalization is activated to affect these genes or how these genes interact to elicit this particular cell response.

In summary, rosuvastatin elicits robust changes in the microglial functions in vitro as it potently inhibits the harmful pro-inflammatory signals and significantly enhances the beneficial anti-inflammatory actions of pure microglial cells after LPS challenge. Its effects include anti-mitogenic and anti-phagocytic action, strong inhibition of the synthesis of pro-inflammatory cytokines paralleled by a very strong stimulation of antiinflammatory cytokine production, and a beneficial differential expression of a number of inflammationrelated genes. As activated microglia often damage neuronal tissues by excessive cytokine and chemokine production and phagocytosis, the strong inhibition of such pro-inflammatory action by rosuvastatin illustrates an advantageous effect of this drug. Thus, rosuvastatin may be used prophylactically to inhibit pro-inflammatory and activate anti-inflammatory mechanisms of the microglia in order to reduce neuroinflammation and consequently neurodegeneration substantially. The microglia could therefore be a novel, specific therapeutic target in the fight against neurodegenerative disorders.

\section{COMPETING INTERESTS}

L.G.P. holds an equity position in Avidin Ltd. that produces a high-throughput QPCR product (Rat immune panel) and has a service using the same kit.

\section{AUTHORS' CONTRIBUTIONS}

This study is based on an original idea of K.G. L.H., L.G.P. and K.G. designed the experiments. D.K., I.F., L.Z.F. and L.H. performed research; L.G.P. contributed unpublished reagents/analytic tools; D.K., I.F. and L.H. analyzed data; D.K. and K.G. wrote the paper. All authors have read and approved the final manuscript.

Acknowledgments-This work was supported by program project grants to the University of Szeged from the Ministry of National Resources (TÁMOP-4.1.1.C-13/1/KONV-2014-0001, TÁMOP-4. 2.1.B-09/1/KONV-2010-0005 and TÁMOP-4.2.2.A-11/1/KONV-2 012-0052) through the European Union Cohesion Fund and from the National Development Agency of Hungary (KMR_12_1_2012_0072). The funders had no role in the study design, the data collection and analysis, the decision to publish, or the preparation of the manuscript. At the time of the experiments, D.K. was a Ph.D. student at the University of Szeged. We thank Mrs. Susan Ambrus for excellent technical help.

\section{REFERENCES}

Abbott NJ, Patabendige AA, Dolman DE, Yusof SR, Begley DJ (2010) Structure and function of the blood-brain barrier. Neurobiol Dis 37:13-25.

Ahmed Z, Shaw G, Sharma VP, Yang C, McGowan E, Dickson DW (2007) Actin-binding proteins coronin-1a and IBA-1 are effective microglial markers for immunohistochemistry. J Histochem Cytochem 55:687-700.

Asztalos BF, Le Maulf F, Dallal GE, Stein E, Jones PH, Horvath KV, McTaggart F, Schaefer EJ (2007) Comparison of the effects of high doses of rosuvastatin versus atorvastatin on the subpopulations of high-density lipoproteins. Am J Cardiol 99:681-685.

Atienza JM, Zhu J, Wang X, Xu X, Abassi Y (2005) Dynamic monitoring of cell adhesion and spreading on microelectronic sensor arrays. J Biomol Screen 10:795.

Banati RB, Gehrmann J, Schubert P, Kreutzberg GW (1993) Cytotoxicity of microglia. Glia 7:111-118.

Bodovitz S, Klein WL (1996) Cholesterol modulates alpha-secretase cleavage of amyloid precursor protein. J Biol Chem 271: 4436-4440.

Boisvert WA, Rose DM, Johnson KA, Fuentes ME, Lira SA, Curtiss LK, Terkeltaub RA (2006) Up-regulated expression of the CXCR2 ligand KC/GRO-alpha in atherosclerotic lesions plays a central role in macrophage accumulation and lesion progression. Am J Pathol 168:1385-1395.

Burg JS, Espenshade PJ (2011) Regulation of HMG-CoA reductase in mammals and yeast. Progr Lipid Res 50:403-410.

Concannon CG, Gorman AM, Samali A (2003) On the role of Hsp27 in regulating apoptosis. Apoptosis 8:61-70.

Cordle A, Landreth G (2005) 3-Hydroxy-3-methylglutaryl-coenzyme A reductase inhibitors attenuate $\beta$-amyloid-induced microglial inflammatory responses. J Neurosci 25:299-307.

Davidson MH (2002) Rosuvastatin: a highly efficacious statin for the treatment of dyslipidaemia. Exp Opin Invest Drugs 11:125-141.

El Khoury J, Luster AD (2008) Mechanisms of microglia accumulation in Alzheimer's disease: therapeutic implications. Trends Pharmacol Sci 29:626-632.

El Khoury J, Toft M, Hickman SE, Means TK, Terada K, Geula C, Luster AD (2007) Ccr2 deficiency impairs microglial accumulation and accelerates progression of Alzheimer-like disease. Nat Med 13:432-438.

Ellis LC, Hawksworth GM, Weaver RJ (2013) ATP-dependent transport of statins by human and rat MRP2/Mrp2. Toxicol Appl Pharmacol 269:187-194.

Eltayeb S, Berg AL, Lassmann H, Wallström E, Nilsson M, Olsson T, Ericsson-Dahlstrand A, Sunnemark D (2007) Temporal expression and cellular origin of CC chemokine receptors CCR1, CCR2 and CCR5 in the central nervous system: insight into mechanism of MOG-induced EAE. J Neuroinflamm 4:14.

Fabian G, Farago N, Feher LZ, Nagy LI, Kulin S, Kitajka K, Bito T, Tubak V, Katona RL, Tiszlavicz L, Puskas LG (2011) High-density 
real-time PCR-based in vivo toxicogenomic screen to predict organ-specific toxicity. Int J Mol Sci 12:6116-6134.

Famer D, Wahlund LO, Crisby M (2010) Rosuvastatin reduces microglia in the brain of wild type and ApoE knockout mice on a high cholesterol diet; implications for prevention of stroke and AD. Biochem Biophys Res Commun 402:367-372.

Floden AM, Combs CK (2006) Beta-amyloid stimulates murine postnatal and adult microglia cultures in a unique manner. $J$ Neurosci 26:4644-4648.

Fujita H, Tanaka J, Toin R, Tateishi N, Suzugl Y, Matsuda S, Sakanaka M, Maedap N (1996) Effects of GM-CSF and ordinary supplements on the ramification of microglia in culture: a morphometrical study. Glia 18:269-281.

Gamba P, Testa G, Gargiulo S, Staurenghi E, Poli G, Leonarduzzi G (2015) Oxidized cholesterol as the driving force behind the development of Alzheimer's disease. Front Aging Neurosci 7:119.

Gao Y, Lu XC, Yang HY, Liu XF, Cao J, Fan L (2012) The molecular mechanism of the anticancer effect of atorvastatin: DNA microarray and bioinformatic analyses. Int J Mol Med 30:765-774.

Gay F (2007) Activated microglia in primary MS lesions: defenders or aggressors? Int MS J MS Forum 14:78-83.

Gehrmann J, Matsumo Y, Kreutzberg G (1995) Microglia: intrinsic immunoeffector cell of the brain. Brain Res Rev 20:269-287.

Ghosh S, Wu MD, Shaftel SS, Kyrkanides S, LaFerla FM, Olschowka JA, O'Banion MK (2013) Sustained interleukin-1 $\beta$ overexpression exacerbates tau pathology despite reduced amyloid burden in an Alzheimer's mouse model. J Neurosci 33:5053-5064.

Gibson CJ, Hossain MM, Richardson JR, Aleksunes LM (2012) Inflammatory regulation of ATP binding cassette efflux transporter expression and function in microglia. J Pharmacol Exp Ther 343:650-660.

Ginhoux F, Greter M, Leboeuf M, Nandi S, See P, Gokhan S, Mehler MF, Conway SJ, Ng LG, Stanley ER, Samokhvalov IM, Merad M (2010) Fate mapping analysis reveals that adult microglia derive from primitive macrophages. Science 330:841-845.

Gonzalez-Scarano F, Baltuch G (1999) Microglia as mediators of inflammatory and degenerative diseases. Annu Rev Neurosci 22:219-240.

Graeber MB (2010) Changing face of microglia. Science 330: 783-788.

Gresa-Arribas N, Vieitez C, Dentesano G, Serratosa J, Saura J, Sola C (2012) Modelling neuroinflammation in vitro: a tool to test the potential neuroprotective effect of anti-inflammatory agents. Plos One 7:9.

Gruol DL, Vo K, Bray JG (2014) Increased astrocyte expression of IL-6 or CCL2 in transgenic mice alters levels of hippocampal and cerebellar proteins. Front Cell Neurosci 8:234.

Hamelin BA, Turgeon J (1998) Hydrophilicity/lipophilicity: relevance for the pharmacology and clinical effects of HMG-CoA reductase inhibitors. Trends Pharmacol Sci 19:26-37.

Hanisch UK (2002) Microglia as a source and target of cytokines. Glia 40:140-155.

He GL, Liu Y, Li M, Chen CH, Gao P, Yu ZP, Yang XS (2014) The amelioration of phagocytic ability in microglial cells by curcumin through the inhibition of EMF-induced pro-inflammatory responses. J Neuroinflamm 11:49.

Hesselgesser J, Ng HP, Liang M, Zheng W, May K, Bauman JG, Monahan S, Islam I, Wei GP, Ghannam A, Taub DD, Rosser M, Snider RM, Morrissey MM, Perez HD, Horuk R (1998) Identification and characterization of small molecule functional antagonists of the CCR1 chemokine receptor. J Biol Chem 273:15687-15692.

Hickman SE, El Khoury J (2014) TREM2 and the neuroimmunology of Alzheimer's disease. Biochem Pharmacol 88:495-498.

Ip WK, Takahashi K, Ezekowitz RA, Stuart LM (2009) Mannosebinding lectin and innate immunity. Immunol Rev 230:9-21.

Jarvis GE, Bihan Hamaia S, Pugh N, Ghevaert JG, Pearce C, Hughes CE, Watson SP, Ware J, Rudd E, Farndale RW (2011) A role for adhesion and degranulation-promoting adapter protein in collagen-induced platelet activation mediated via integrin $\alpha_{2} \beta_{1}$. J Thromb Haemost 10:268-277.
Jones P, Kafonek S, Laurora I, Hunninghake D (1998) Comparative dose efficacy study of atorvastatin versus simvastatin, pravastatin, lovastatin, and fluvastatin in patients with hypercholesterolemia (the CURVES study). Am J Cardiol 81: 582-587.

Kettenmann H, Hanischuk Noda M, Verkhratsky A (2011) Physiology of microglia. Physiol Rev 91:461-553.

Kitamura S, Maeda K, Wang Y, Sugiyama Y (2008) Involvement of multiple transporters in the hepatobiliary transport of rosuvastatin. Drug Metab Dispos 36:2014-2023.

Kreutzberg GW (1996) Microglia: a sensor for pathological events in the CNS. Trends Neurosci 19:312-318.

Kroner A, Greenhalgh AD, Zarruk JG, Passos Dos Santos R, Gaestel M, David S (2014) TNF and increased intracellular iron alter macrophage polarization to a detrimental M1 phenotype in the injured spinal cord. Neuron 83:1098-1116.

Kurata T, Miyazaki K, Kozuki M, Morimoto N, Ohta Y, Ikeda Y, Abe K (2012) Atorvastatin and pitavastatin reduce senile plaques and inflammatory responses in a mouse model of Alzheimer's disease. Neurol Res 34:601-610.

Lee JK, Schuchman EH, Jin HK, Bae JS (2012) Soluble CCL5 derived from bone marrow-derived mesenchymal stem cells and activated by amyloid $\beta$ ameliorates Alzheimer's disease in mice by recruiting bone marrow-induced microglia immune responses. Stem cells 30:1544-1555.

Lindberg C, Crisby M, Winblad B, Schultzberg M (2005) Effects of statins on microglia. J Neurosci Res 82:10-19.

Loane DJ, Byrnes KR (2010) Role of microglia in neurotrauma. Neurother J Am Soc Exp Neurother 7:366-377.

Long-Smith CM, Sullivan AM, Nolan YM (2009) The influence of microglia on the pathogenesis of Parkinson's disease. Progr Neurobiol 89:277-287.

Lowry OH, Rosebrough NJ, Farr AL, Randall RJ (1951) Protein measurement with the folin phenol reagent. J Biol Chem 193: 265-275.

Lue LF, Schmitz C, Walker DG (2015) What happens to microglial TREM2 in Alzheimer's disease: immunoregulatory turned into immunopathogenic? Neuroscience 302:138-150.

Lund S, Christensen KV, Hedtjärn M, Mortensen AL, Hagberg $H$, Falsig J, Hasseldam H, Schrattenholz A, Pörzgen P, Leis M (2006) The dynamics of the LPS triggered inflammatory response of murine microglia under different culture and in vivo conditions. $J$ Neuroimmunol 180:71-87.

Luo XG, Chen SD (2012) The changing phenotype of microglia from homeostasis to disease. Translat Neurodegener 1:9.

McGeer EG, McGeer PL (2003) Inflammatory processes in Alzheimer's disease. Progr Neuropsychopharm Biol Psychiatry 27:741-749.

McGeer EG, McGeer PL (2010) Neuroinflammation in Alzheimer's disease and mild cognitive impairment: a field in its infancy. J Alzheimers Dis 19:355-361.

McGeer PL, Kawamata T, Walker DG, Akiyama H, Tooyama I, McGeer EG (1993) Microglia in degenerative neurological disease. Glia 7:84-92.

McTaggart F, Buckett L, Davidson R, Holdgate G, McCormick A, Schneck D, Smith G, Warwick M (2001) Preclinical and clinical pharmacology of Rosuvastatin, a new 3-hydroxy-3methylglutaryl coenzyme A reductase inhibitor. Am J Cardiol 87(5A):28B-32B.

Nakamichi K, Saiki M, Kitani H, Kuboyama Y, Morimoto K, Takayama-Ito M, Kurane I (2006) Suppressive effect of simvastatin on interferon-beta-induced expression of CC chemokine ligand 5 in microglia. Neurosci Lett 407:205-210.

Nakamura Y (2002) Regulating factors for microglial activation. Biol Pharm Bull 25:945-953.

Nakamura Y, Si QS, Kataoka K (1999) Lipopolysaccharide-induced microglial activation in culture: temporal profiles of morphological change and release of cytokines and nitric oxide. Neurosci Res 35:95-100.

Napoli I, Neumann H (2010) Protective effects of microglia in multiple sclerosis. Exp Neurol 225:24-28. 
Neher JJ, Neniskyte U, Zhao JW, Bal-Price A, Tolkovsky AM, Brown GC (2011) Inhibition of microglial phagocytosis is sufficient to prevent inflammatory neuronal death. J Immunol 186:4973-4983.

Nicholls SJ, Ballantyne CM, Barter PJ, Chapman MJ, Erbel RM, Libby P, Raichlen JS, Uno K, Borgman M, Wolski K, Nissen SE (2011) Effect of two intensive statin regimens on progression of coronary disease. N Engl J Med 365:2078-2087.

Nissen SE, Nicholls SJ, Sipahi I, Libby P, Raichlen JS, Ballantyne $\mathrm{CM}$, Davignon J, Erbel R, Fruchart JC, Tardif JC, Schoenhagen P, Crowe T, Cain V, Wolski K, Goormastic M, Tuzcu EM, ASTEROID Investigators (2006) Effect of very high-intensity statin therapy on regression of coronary atherosclerosis: the ASTEROID trial. JAMA 295:1556-1565.

Ohsawa K, Imai Y, Sasaki Y, Kohsaka S (2004) Microglia/macrophage-specific protein Iba1 binds to fimbrin and enhances its actin-bundling activity. J Neurochem 88:844-856.

Omari KM, Lutz SE, Santambrogio L, Lira SA, Raine CS (2009) Neuroprotection and remyelination after autoimmune demyelination in mice that inducibly overexpress CXCL1. Am J Pathol 174:164-176.

Ozsvári B, Puskás LG, Nagy LI, Kanizsai I, Gyuris M, Madácsi R, Fehér LZ, Gerö D, Szabó C (2010) A cell-microelectronic sensing technique for the screening of cytoprotective compounds. Int $\mathrm{J}$ Mol Med 25:525-530.

Prokop S, Miller KR, Heppner FL (2013) Microglia actions in Alzheimer's disease. Acta Neuropathol 126:461-477.

Rodriguez GA, Tai LM, LaDu MJ, Rebeck GW (2014) Human APOE4 increases microglia reactivity at $A \beta$ plaques in a mouse model of $A \beta$ deposition. J Neuroinflammation 11:111.

Rottman JB, Slavin AJ, Silva R, Weiner HL, Gerard CG, Hancock WW (2000) Leukocyte recruitment during onset of experimental allergic encephalomyelitis is CCR1 dependent. Eur J Immunol 30:2372-2377.

Sasaki Y, Ohsawa K, Kanazawa H, Kohsaka S, Imai Y (2001) Iba1 Is an actin-cross-linking protein in macrophages/microglia. Biochem Biophys Res Commun 286:292-297.

Schachter M (2005) Chemical, pharmacokinetic and pharmacodynamic properties of statins: an update. Fundam Clin Pharmacol 19:117-125.

Schönbeck U, Libby P (2004) Inflammation, immunity, and HMG-CoA reductase Inhibitors: statins as antiinflammatory agents. Circulation 109(S1):II18-II26.

Shimoyama M, De Pons J, Hayman GT, Laulederkind SJ, Liu W, Nigam R, Petri V, Smith JR, Tutaj M, Wang SJ, Worthey E, Dwinell M, Jacob H (2015) The Rat Genome Database 2015: genomic, phenotypic and environmental variations and disease. Nucleic Acids Res 43(Database issue):D743-D750.

Shobab LA, Hsuing GY, Feldman HH (2005) Cholesterol in Alzheimer's disease. Lancet Neurol 4:841-852.

Simon MS, Rosenberg CA, Rodabough RJ, Greenland P, Ockene I, Roy HK, Lane DS, Cauley JA, Khandekar J (2012) Prospective analysis of association between use of statins or other lipid-lowering agents and colorectal cancer risk. Ann Epidemiol 22:17-27.

Simons M, Keller P, De Strooper B, Beyreuther K, Dotti CG, Simons K (1998) Cholesterol depletion inhibits the generation in hippocampal neurons. Proc Natl Acad Sci USA 95:6460-6464.
Skuljec J, Sun H, Pul R, Bénardais K, Ragancokova D, MoharreghKhiabani D, Kotsiari A, Trebst C, Stangel M (2011) CCL5 induces a pro-inflammatory profile in microglia in vitro. Cell Immunol 270:164-171.

Streit WJ (2002) Microglia as neuroprotective immunocompetent cells of the CNS. Glia 40:133-139.

Stuart LM, Takahashi K, Shi L, Savill J, Ezekowitz RA (2005) Mannose-binding lectin-deficient mice display defective apoptotic cell clearance but no autoimmune phenotype. J Immunol 174:3220-3226. Erratum in: J Immunol 175:3447.

Szabo M, Gulya K (2013) Development of the microglial phenotype in culture. Neuroscience 241:280-295.

Taylor F, Huffman MD, Macedo AF, Moore TH, Burke M, Davey Smith G, Ward K, Ebrahim S (2013) Statins for the primary prevention of cardiovascular disease. Cochrane Database Syst Rev 1:CD004816. 2013.

van der Most PJ, Dolga AM, Nijholt IM, Luiten PGM, Eisel UL (2009) Statins: mechanisms of neuroprotection. Progr Neurobiol 88:64-75.

Veillard NR, Braunersreuther V, Arnaud C, Burger F, Pelli G, Steffens S, Mach F (2006) Simvastatin modulates chemokine and chemokine receptor expression by geranylgeranyl isoprenoid pathway in human endothelial cells and macrophages. Atherosclerosis 188:51-58.

Watanabe K, Jose PJ, Rankin SM (2002) Eotaxin-2 generation is differentially regulated by lipopolysaccharide and IL-4 in monocytes and macrophages. J Immunol 168:1911-1918.

Weber C, Erl W, Weber KS, Weber PC (1997) HMG-CoA reductase inhibitors decrease CD11b expression and CD11b-dependent adhesion of monocytes to endothelium and reduce increased adhesiveness of monocytes isolated from patients with hypercholesterolemia. J Am Coll Cardiol 30:1212-1217.

Wierzbicki AS, Poston R, Ferro A (2003) The lipid and non-lipid effects of statins. Pharmacol Therap 99:95-112.

Worthley DL, Bardy PG, Mullighan CG (2005) Mannose-binding lectin: biology and clinical implications. Intern Med J 35: 548-555.

Woudstra C, Lambert D, Anniballi F, De Medici D, Austin J, Fach P (2013) Genetic diversity of the flagellin genes of Clostridium botulinum groups I and II. Appl Environ Microbiol 79:3926-3932.

Wu Y, Wu M, He G, Zhang X, Li W, Gao Y, Li Z, Wang Z, Zhang C (2012) Glyceraldehyde-3-phosphate dehydrogenase: a universal internal control for Western blots in prokaryotic and eukaryotic cells. Anal Biochem 423:15-22.

Yang YC, Huang WF, Chuan LM, Xiao DW, Zeng YL, Zhou DA, Xu $\mathrm{GQ}$, Liu W, Huang B, Hu Q (2008) In vitro and in vivo study of cell growth inhibition of simvastatin on chronic myelogenous leukemia cells. Chemotherapy 54:438-446.

Zelcer N, Khanlou N, Clare R, Jiang Q, Reed-Geaghan EG, Landreth GE, Vinters HV, Tontonoz P (2007) Attenuation of neuroinflammation and Alzheimer's disease pathology by liver $x$ receptors. Proc Natl Acad Sci USA 104:10601-10606.

Zipp F, Waiczies S, Aktas O, Neuhaus O, Hemmer B, Schraven B, Nitsch R, Hartung HP (2007) Impact of HMG-CoA reductase inhibition on brain pathology. Trends Pharmacol Sci 28:342-349. 
ARTICLE II. 


\title{
A novel pleiotropic effect of aspirin: Beneficial regulation of pro- and anti-inflammatory mechanisms in microglial cells
}

\author{
Diana Kata ${ }^{\mathrm{a}}$, Imre Földesi ${ }^{\mathrm{b}}$, Liliana Z. Feher ${ }^{\mathrm{c}}$, Laszlo Hackler Jr. ${ }^{\text {c, Laszlo G. Puskas }}{ }^{\mathrm{c}}$, Karoly Gulya ${ }^{\mathrm{a}, *}$ \\ a Department of Cell Biology and Molecular Medicine, University of Szeged, Szeged, Hungary \\ ${ }^{\mathrm{b}}$ Department of Laboratory Medicine, University of Szeged, Szeged, Hungary \\ ${ }^{c}$ Avidin Ltd., Szeged, Hungary
}

\section{A R T I C L E I N F O}

\section{Keywords:}

Aspirin

Anti-inflammation

Gene expression

Lipopolysaccharide

Phagocytosis

Pro-inflammation

\begin{abstract}
A B S T R A C T
Aspirin, one of the most widely used non-steroidal anti-inflammatory drugs, has extensively studied effects on the cardiovascular system. To reveal further pleiotropic, beneficial effects of aspirin on a number of pro- and anti-inflammatory microglial mechanisms, we performed morphometric and functional studies relating to phagocytosis, pro- and anti-inflammatory cytokine production (IL-1 $1 \beta$, tumor necrosis factor- $\alpha$ (TNF- $\alpha$ ) and IL-10, respectively) and analyzed the expression of a number of inflammation-related genes, including those related to the above functions, in pure microglial cells. We examined the effects of aspirin $(0.1 \mathrm{mM}$ and $1 \mathrm{mM})$ in unchallenged (control) and bacterial lipopolysaccharide (LPS)-challenged secondary microglial cultures. Aspirin affected microglial morphology and functions in a dose-dependent manner as it inhibited LPS-elicited microglial activation by promoting ramification and the inhibition of phagocytosis in both concentrations. Remarkably, aspirin strongly reduced the pro-inflammatory IL- $1 \beta$ and TNF- $\alpha$ production, while it increased the anti-inflammatory IL-10 level in LPS-challenged cells. Moreover, aspirin differentially regulated the expression of a number of inflammation-related genes as it downregulated such pro-inflammatory genes as Nos2, Kng1, IL1ß, Ptgs2 or Ccr1, while it upregulated some anti-inflammatory genes such as IL10, Csf2, Cxcl1, Ccl5 or Tgfb1. Thus, the use of aspirin could be beneficial for the prophylaxis of certain neurodegenerative disorders as it effectively ameliorates inflammation in the brain.
\end{abstract}

\section{Introduction}

Microglia is the principal immune cell in the central nervous system (CNS). Under pathophysiological conditions such as injury, infection or neurodegeneration (Kettenmann et al., 2011; Kreutzberg, 1996) microglia become activated that proliferate, phagocytose and release pro- and anti-inflammatory cytokines, growth factors or reactive species (Gehrmann et al., 1995; Hanisch, 2002; Kreutzberg, 1996; Luo and Chen, 2012; Smith et al., 2012). Neuroinflammatory processes are strongly associated with the development of Alzheimer's disease (AD; Akiyama et al., 2000; McGeer and McGeer, 2004), Parkinson's disease (PD; Phani et al., 2012; Shin et al., 2015) and multiple sclerosis (MS; Minagar et al., 2002; Muzio et al., 2007). In AD, for example, $\beta$-amyloid accumulation leads to the production of cytokines (IL-1 $\beta$, IL- 6 , TNF- $\alpha$ ) and the activation of nitric oxide synthase (Nos) gene through the nuclear transcription factor kappa B (NF- $\mathrm{kB}$ ) signaling pathway (Medeiros et al., 2007). IL-1 $\beta$ in turn increases the expression of amyloid precursor protein (Ge and Lahiri, 2002), while increased expression of TNF- $\alpha$ is reported for both MS

\footnotetext{
Abbreviations: AD, Alzheimer's disease; Cd, cluster of differentiation; CNS, central nervous system; COX, cyclooxygenase (prostaglandin-endoperoxide synthase, EC 1.14.99.1); DIV,

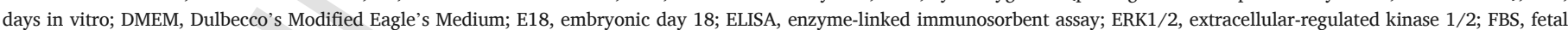

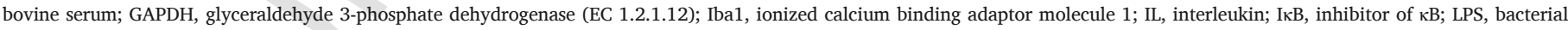

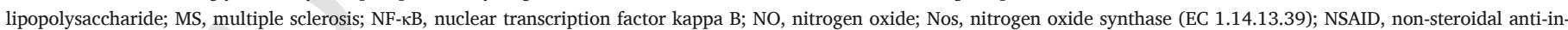

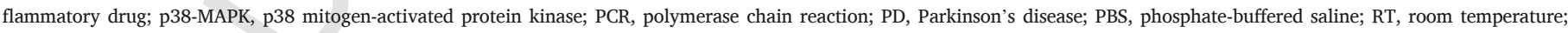

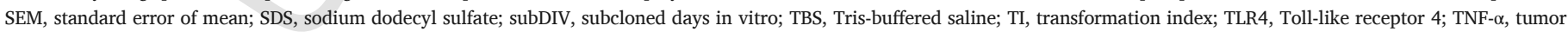
necrosis factor $\alpha$.

* Corresponding author at: Department of Cell Biology and Molecular Medicine, University of Szeged, Somogyi u. 4, Szeged, H-6720, Hungary.

Email addresses: kata.diana@med.u-szeged.hu (D. Kata); foldesi.imre@med.u-szeged.hu (I. Földesi); l.feher@avidinbiotech.com (L.Z. Feher); hackler@avidinbiotech.com (L. Hackler); laszlo@avidinbiotech.com (L.G. Puskas); gulyak@bio.u-szeged.hu (K. Gulya)
} 
and PD (Minagar et al., 2002). Strong anti-inflammatory mechanisms can also lead to the development of neurodegenerative diseases (Gehrmann et al., 1995; Ghosh et al., 2013; Gonzalez-Scarano and Baltuch, 1999; Graeber, 2010; Streit, 2002).

Aspirin (acetylsalicylic acid) is one of the most commonly used non-steroidal anti-inflammatory drugs (NSAIDs). By inhibiting the enzyme cyclooxygenase (COX; prostaglandin-endoperoxide synthase, EC 1.14.99.1) it blocks the conversion of arachidonic acid to prostanoids (Vane and Botting, 2003). Apart from its well known beneficial anti-inflammatory effects in the cardiovascular system (Amann and Peskar, 2002) and its role in anti-cancer therapy (Cuzick et al., 2014), it also has widespread effects on immune cell functions such as NO production, cytokine (e.g. IL-1 $\beta$, IL- 6 , IL-8, TNF- $\alpha$ ) and adhesion molecule expression (Hussain et al., 2012). Its anti-inflammatory function is based on the inhibition of the NF-kB signaling pathway (Amann and Peskar, 2002), while its neuroprotective effect in the injured brain is linked to COX-2 inhibition; overexpression of COX-2 is indicative of neuronal damage (Berk et al., 2013; Strauss, 2008). Although aspirin has not been extensively studied in microglia, its anti-inflammatory actions are recently reported (Medeiros et al., 2013; Wang et al., 2011; Yang et al., 2014).

In the present study we investigated the pleiotropic effects of aspirin on secondary, pure microglial cultures derived from mixed primary cultures of 18-day-old embryonic (E18) rat forebrains under control (unchallenged) and bacterial lipopolysaccharide (LPS)-challenged conditions (Gresa-Arribas et al., 2012; Kata et al., 2016; Lund et al., 2006). To reveal the effects of aspirin on pro- and anti-inflammatory mechanisms, we performed quantitative morphometric, functional and gene expression studies relating to phagocytic capability, pro- and anti-inflammatory cytokine production (IL- $1 \beta, \mathrm{TNF}-\alpha$, and IL-10, respectively) and the expression of various genes related to inflammation. A preliminary report on the effects of aspirin on pure microglial cultures was presented in poster form (Kata and Gulya, 2014).

\section{Material and methods}

\subsection{Animals}

All animal experiments were carried out in strict compliance with the European Council Directive (86/609/EEC) and EC regulations (O.J. of EC No. L 358/1, 18/12/1986) regarding the care and use of laboratory animals for experimental procedures, and followed the relevant Hungarian and local legislation requirements. The experimental protocols were approved by the Institutional Animal Welfare Committee of the University of Szeged (I-74-II/2009/MÁB). The pregnant Sprague-Dawley rats (170-190 g) were kept under standard housing conditions and fed ad libitum.

\subsection{Antibodies}

For a thorough characterization of different microglial phenotypes developed in vitro, an antibody against the ionized calcium binding adaptor molecule 1 (Iba1), an intracellular actin- and $\mathrm{Ca}^{2+}$-binding protein expressed in the CNS specifically in macrophages and microglia (Ahmed et al., 2007), was used in our immunocytochemical and Western blot analyses. The anti-glyceraldehyde 3-phosphate dehydrogenase (GAPDH) antibody was used as an internal control in Western blot experiments (Wu et al., 2012). Antibody dilutions, incubation times and blocking conditions were tested for both immunocytochemistry and Western blot analysis. To detect the specificities of the secondary antisera, staining without the primary antibody was performed. In such cases, no fluorescent or Western blot signals were detected.

\subsection{Cell cultures}

Pure microglial cells were isolated from mixed primary cortical cell cultures of rat embryos of either sex by the method we described earlier (Kata et al., 2016; Szabo and Gulya, 2013). Sibling embryos obtained from the same pregnancy were processed for culturing together; each pregnancy was considered as an independent experiment. Briefly, 10-12 fetal rats (E18) under anesthesia were decapitated and the frontal lobe of the cerebral cortex was removed, minced with scissors, incubated in $9 \mathrm{ml}$ Dulbecco's Modified Eagle's Medium (DMEM; Invitrogen, Carlsbad, USA) containing $1 \mathrm{~g} / \mathrm{l}$ D-glucose, $110 \mathrm{mg} / \mathrm{l}$ Na-pyruvate, $4 \mathrm{mM}$ L-glutamine, $3.7 \mathrm{~g} / 1 \mathrm{NaHCO}_{3}, 10,000 \mathrm{U} / \mathrm{ml}$ penicillin $\mathrm{G}, 10 \mathrm{mg} /$ $\mathrm{ml}$ streptomycin sulfate, $25 \mu \mathrm{g} / \mathrm{ml}$ amphotericin B and $0.25 \%$ trypsin for $10 \mathrm{~min}$ at $37{ }^{\circ} \mathrm{C}$, and then centrifuged at $1000 \mathrm{~g}$ for $10 \mathrm{~min}$ at room temperature (RT). The pellet was resuspended, washed twice in $5 \mathrm{ml}$ DMEM containing 10\% heat-inactivated fetal bovine serum (FBS; Invitrogen) and centrifuged for $10 \mathrm{~min}$ at $1000 \mathrm{~g}$ at RT. The final pellet was resuspended in $2 \mathrm{ml} \mathrm{DMEM} / 10 \% \mathrm{FBS}$, after which the cells were plated in the same medium on a poly-L-lysine-coated culture flask $\left(75 \mathrm{~cm}^{2}\right.$, $12 \times 10^{6}$ cell/flask) and cultured for a number of days in vitro (DIV) at $37{ }^{\circ} \mathrm{C}$ in a humidified air atmosphere supplemented with $5 \% \mathrm{CO}_{2}$, in one or other of the following ways: 1 ) in poly-L-lysine-coated coverslips (15 $\times 15 \mathrm{~mm} ; 2 \times 10^{5}$ cells/coverslip) for immunocytochemistry; 2) in poly-L-lysine-coated Petri dishes ( $60 \mathrm{~mm}$ x $15 \mathrm{~mm} ; 4 \times 10^{5}$ cells/dish) for Western blot and enzyme-linked immunosorbent assays (ELISA); or 3 ) in a poly-L-lysine-coated culture flask $\left(75 \mathrm{~cm}^{2}, 12 \times 10^{6}\right.$ cells/flask) for the subsequent generation of pure microglial cell cultures.

Secondary microglial cells were subcloned from mixed primary cultures (DIV7) maintained in a poly-L-lysine-coated culture flask $\left(75 \mathrm{~cm}^{2}\right.$, $12 \times 10^{6}$ cells/flask) by shaking the cultures at $100 \mathrm{rpm}$ in a platform shaker for $30 \mathrm{~min}$ at $37^{\circ} \mathrm{C}$. Microglia from the supernatant were collected by centrifugation at $3000 \mathrm{~g}$ for $8 \mathrm{~min}$ at RT and resuspended in $2 \mathrm{ml} \mathrm{DMEM} / 10 \% \mathrm{FBS}$. The cells were seeded at a density of $4 \times 10^{5}$ cells/Petri dish for Western blots or $2 \times 10^{5}$ cells/coverslip/Petri dish for immunocytochemistry or phagocytosis assays, and cultured in DMEM in a humidified atmosphere supplemented with $5 \% \mathrm{CO}_{2}$ at $37{ }^{\circ} \mathrm{C}$. The medium was changed on the first day after seeding (subDIV1).

\subsection{Cell culture treatments}

The aspirin concentrations used in our study are comparable to the therapeutic plasma salicylate levels for pain relief, inhibition of platelet aggregation or anti-inflammation (Higgs et al., 1987). On the fourth day of subcloning (subDIV4), DMEM was replaced and the expanded pure microglial cells were treated with either bacterial lipopolysaccharide (LPS; $20 \mathrm{ng} / \mathrm{ml}$ final conc., dissolved in DMEM; Sigma, St. Louis, MO, USA) or aspirin ( $0.1 \mathrm{mM}$ (low) and $1 \mathrm{mM}$ (high) final conc., from $\geq 99 \%$ acetylsalicylic acid dissolved in sterile, distilled water; Sigma) alone, or with a combination of LPS + aspirin, and the effects were compared in a variety of morphological and functional tests. LPS treatment served as an immunochallenge. Six types of treatment regimens were used: 1) control (unchallenged and untreated) cultures; 2) LPS-challenged cultures received $20 \mathrm{ng} / \mathrm{ml}$ LPS; 3) aspirin-treated cultures received $0.1 \mathrm{mM}$ aspirin; 4) aspirin-treated cultures received $1 \mathrm{mM}$ aspirin; 5) LPS-challenged + aspirin-treated cultures were challenged with $20 \mathrm{ng} /$ $\mathrm{ml}$ LPS and treated with $0.1 \mathrm{mM}$ aspirin; 6) LPS-challenged + aspirin-treated cultures were challenged with $20 \mathrm{ng} / \mathrm{ml} \mathrm{LPS}$ and received 
$1 \mathrm{mM}$ aspirin. Depending on the experiments, the treatments lasted for 6 or $24 \mathrm{~h}$ at $37^{\circ} \mathrm{C}$.

\subsection{Immunocytochemistry}

Pure secondary microglial cultures treated with different treatment regimens were fixed on coverslips with $4 \%$ formaldehyde for $5 \mathrm{~min}$ and rinsed with $0.05 \mathrm{M}$ phosphate-buffered saline (PBS) for $2 \times 5 \mathrm{~min}$. After permeabilization and blocking of the nonspecific sites in 0.05 M PBS solution containing 5\% normal goat serum (Sigma), 1\% heat-inactivated bovine serum albumin (Sigma) and $0.05 \%$ Triton X-100 for $30 \mathrm{~min}$ at $37^{\circ} \mathrm{C}$, the cells on the coverslips were incubated overnight in a humidified chamber at $4{ }^{\circ} \mathrm{C}$ with rabbit anti-Iba1 polyclonal antibody (1:500 final dilution; Wako, Japan) in the above solution (Kata et al., 2016). The cultured cells were washed for $4 \times 10 \mathrm{~min}$ at RT in $0.05 \mathrm{M} \mathrm{PBS}$, and then incubated with the Alexa Fluor 568 fluorochrome-conjugated goat anti-rabbit antibody (1:1000 final dilution; Invitrogen) in the dark for $3 \mathrm{~h}$ at RT. The cells on the coverslip were washed for $4 \times 10 \mathrm{~min}$ in $0.05 \mathrm{M}$ PBS at RT, and the nuclei were stained in $0.05 \mathrm{M}$ PBS solution containing $1 \mathrm{mg} / \mathrm{ml}$ polyvinylpyrrolidone and $0.5 \mu \mathrm{l} / \mathrm{ml}$ Hoechst 33258 dye (Sigma). The coverslips were rinsed in distilled water for $5 \mathrm{~min}$, air-dried and mounted on microscope slides in Vectashield mounting medium (Vector Laboratories, Burlingame, CA, USA).

\subsection{Western blot analysis}

Cultured microglial cells (subDIV4) were collected through use of a rubber policeman, homogenized in $50 \mathrm{mM}$ Tris- $\mathrm{HCl}$ ( $\mathrm{pH}$ 7.5) containing $150 \mathrm{mM} \mathrm{NaCl}, 0.1 \%$ Nonidet P40, $0.1 \%$ cholic acid, $2 \mu \mathrm{g} / \mathrm{ml}$ leupeptin, $1 \mu \mathrm{g} / \mathrm{ml}$ pepstatin, $2 \mathrm{mM}$ phenylmethylsulfonyl fluoride and $2 \mathrm{mM}$ EDTA, and centrifuged at 10,000g for $10 \mathrm{~min}$ (Kata et al., 2016; Szabo and Gulya, 2013). The pellet was discarded and the protein concentration of the supernatant was determined (Lowry et al., 1951). For the Western blot analyses, 5-10 $\mu \mathrm{g}$ of protein was separated on a sodium dodecyl sulfate/polyacrylamide gel (4\%/10\% stacking gel/ resolving gel), transferred onto Hybond-ECL nitrocellulose membrane (Amersham Biosciences, Little Chalfont, Buckinghamshire, England), blocked for $1 \mathrm{~h}$ in $5 \%$ nonfat dry milk in Tris-buffered saline (TBS) containing $0.1 \%$ Tween 20 , and incubated overnight with either a rabbit anti-Iba1 polyclonal antibody (1:1000 final dilution; Wako) or a mouse anti-GAPDH monoclonal antibody (clone GAPDH-71.1; 1:20,000 final dilution; Sigma). The membranes were rinsed 5 times in $0.1 \%$ TBS-Tween 20 and incubated for $1 \mathrm{~h}$ with the peroxidase-conjugated goat anti-rabbit secondary antibody (1:2000 final dilution; Invitrogen) for Iba1 or with the peroxidase-conjugated rabbit anti-mouse secondary antibody (1:2000 final dilution; Sigma) for GAPDH Western blots, then washed 5 times as before. The enhanced chemiluminescence method (ECL Plus Western blotting detection reagents; Amersham Biosciences) was used to reveal immunoreactive bands according to the manufacturer's protocol.

\subsection{In vitro phagocytosis}

The fluid-phase phagocytic capabilities of the control and variously treated pure microglial cell cultures were determined via the uptake of fluorescent microspheres (carboxylate-modified polystyrene beads, fluorescent yellow-green ( $\lambda$ ex $\sim 470 \mathrm{~nm}$; $\lambda$ em $\sim 505 \mathrm{~nm}$ ), aqueous suspension, $2.0 \mu \mathrm{m}$ mean particle size; L4530, Sigma) as we described previously (Szabo and Gulya, 2013; Szabo et al., 2016). Unchallenged (control) and LPS-challenged pure microglial cell cultures (subDIV4) with or without aspirin treatments were tested for $24 \mathrm{~h}$. At the end of the treatment period, $1 \mu \mathrm{l}$ of a $2.5 \%$ aqueous suspension of fluorescent microspheres per $\mathrm{ml}$ was added to the culture, which was then incubated for $60 \mathrm{~min}$ at $37^{\circ} \mathrm{C}$. The cells were next washed 5 times with $2 \mathrm{ml}$ of PBS to remove dish- or cell surface-bound residual fluorescent microspheres, and fixed with $4 \%$ formaldehyde in PBS. In another setup, we also determined the number of cell membrane-associated but not phagocytosed beads. Such negative controls were treated as above with the exception that microglial cultures with beads were incubated for $60 \mathrm{~min}$ at $4{ }^{\circ} \mathrm{C}$. At this temperature, the number of beads associated with cell surface averaged less than 1 bead/100 Iba1-labeled cells, thus the phagocytosis was not considered significant. For measurement of the phagocytotic activity, cells labelled with phagocytosed microbeads and processed for Iba1 immunocytochemistry were counted in 20 random fields in each treatment group (mean \pm SEM) under a $20 \times$ or $40 \times$ objective. Statistically significant differences were determined by two-way ANOVA.

\subsection{Determination of $I L-1 \beta, I L-10$ and $T N F-\alpha$}

Our protocols for ELISA assays were described previously (Kata et al., 2016). Briefly, the supernatants were collected from each treatment and stored at $-20^{\circ} \mathrm{C}$. Concentrations of IL- $1 \beta$, IL-10 and TNF- $\alpha$ were measured with rat-specific ELISA kits (eBioscience, Vienna, Austria). The sensitivity of IL-1 $\beta$ (Cat\# BMS630), IL-10 (Cat\# BMS629) and TNF- $\alpha$ (Cat\#BMS622) assays was 4 pg/ml, 1.5 pg/ml and 11 pg/ml, respectively. As stated by the manufacturer, the overall intra- and interassay coefficients of variation were $<10 \%$ in both cases for IL- $1 \beta$ and TNF- $\alpha$, and $<5 \%$ in both cases for IL- 10 .

\subsection{RNA isolation}

Total RNA from control and treated pure microglial cells was purified as described previously (Fabian et al., 2011); columns and wash buffer were from Bioneer (Viral RNA extraction kit; Daejon, South Korea). Briefly, cells were washed with PBS, incubated in lysis buffer (RA1; Macherey-Nagel, Düren, Germany), then collected and mixed with 70\% ethanol in RNase-free water (Bioneer). The mixture was transferred through columns (Bioneer) and washed with $350 \mu \mathrm{l} 80 \%$ ethanol in diethylpyrocarbonate-treated water, and then with $600 \mu \mathrm{l}$ and $300 \mu \mathrm{l}$ W2 wash buffer (Bioneer). Total RNA was eluted in $50 \mu \mathrm{l}$ RNase free-water. One $\mu \mathrm{l}$ RNase inhibitor (Applied Biosystems, Foster City, CA, USA) was added to the samples. The quality and quantity of the isolated RNA was measured with NanoDrop1000 Version 3.8.1. (Thermo Scientific, Budapest, Hungary).

\subsection{RNA expression}

Reverse transcription from $3 \mu \mathrm{g}$ total RNA in $30 \mu \mathrm{l}$ was performed with the High Capacity cDNA Archive Kit (Applied Biosystems) according to the manufacturer's protocol as described previously (Kata et al., 2016). cDNA was diluted to $80 \mu \mathrm{l}$ with nuclease-free water. The instrumentation included the Bravo automatic liquid handling system (Agilent Technologies, Inc., Santa Clara, CA, USA) for polymerase chain reaction (PCR) assay preparation and a LightCycler 1536 System (Roche Diagnostics Corp., Indianapolis, IN, USA) or a Light Cycler Nano Instrument (Roche) for cycling (Woudstra et al., 2013). The expression of 116 inflammation-related genes, together with that of 6 control genes (see below), was measured with Universal Probe Library assays using intron-spanning gene-specific primers (Rat Immune Panel; Avidin Ltd., Szeged, Hungary, www.avidinbiotech.com/custom-pathways/) and the LightCycler 1536 DNA Probe Master kit (Roche). Moreover, the expression of certain 
phagocytosis-related genes such as the integrin associated protein or cluster of differentiation 47 (Cd47, NM_019195_2), the engulfment or cell motility protein (Elmo1, NM_001108415.1), the scavenger receptor class B member 1 (Scarb1, NM_031541_1), the plasminogen activator inhibitor-1 (Serpine1, NM_012620_1), the signal-regulatory protein $\alpha$ (Sirpa, NM_013016_2) and the vesicle-associated membrane protein 7 (Vamp7, NM_053531_1) were also analyzed by the Light Cycler Nano Instrument. For the 1536 System, each $2 \mu \mathrm{l}$ PCR reaction contained $8 \mathrm{ng}$ cDNA, $0.4 \mu \mathrm{l}$ LightCycler DNA Probes Master (5x), the corresponding primer set and UPL probe and the Setup Control (Kata et al., 2016). The PCR cycling protocol was as follows: enzyme activation at $95{ }^{\circ} \mathrm{C}$ for $60 \mathrm{~s}, 50$ cycles of denaturation at $95{ }^{\circ} \mathrm{C}$ for $0 \mathrm{~s}$, and annealing and extension at $60{ }^{\circ} \mathrm{C}$ for $30 \mathrm{~s}$. For the Nano Instrument, each $20 \mu \mathrm{l}$ PCR reaction contained $20 \mathrm{ng}$ cDNA, $10 \mu \mathrm{l}$ Lightcycler DNA Probes Master (5x), the corresponding primer set and UPL probe and the Setup Control. The PCR protocol was as follows: enzyme activation at $95{ }^{\circ} \mathrm{C}$ for $10 \mathrm{~min}, 50$ cycles of denaturation at $95{ }^{\circ} \mathrm{C}$ for $15 \mathrm{~s}$, and annealing and extension at $60{ }^{\circ} \mathrm{C}$ for $30 \mathrm{~s}$. Gene expression was normalized to the average values of clathrin, heavy chain (Cltc, NM_019299.1), Gapdh (M17701.1), glucuronidase, beta (Gusb, NM_017015.2), hypoxanthine phosphoribosyltransferase 1 (Hprt1, NM_012583.2), phosphoglycerate kinase 1(Pgk1, NM_053291.3), and tubulin, beta 5 class I (Tubb5, NM_173102.2) expression as endogenous controls and expressed relative to the unchallenged controls by using the $2^{-\Delta \Delta \mathrm{Ct}}$ method.

A total of 122 gene-specific assays were run on 3 independent samples from each condition. Student's $t$-test and two-way ANOVA were applied for the analysis of significance where $p<0.05$ was considered significant. Gene expression was analyzed by GraphPad Prism 6 (GraphPad Software, Inc., La Jolla, CA, USA). For hierarchical cluster analysis and visualization, the Hierarchical Clustering Explorer (v3.0) software was used (Human-Computer Interaction Lab., University of Maryland, MD, USA; publicly available at http://www.cs.umd.edu/hcil/multi-cluster/ hce3.html). The complete linkage clustering method was applied with Euclidean distance metric.

\subsection{Image analysis and statistics}

Digital images were captured by a Nikon Microphot-FXA epifluorescent microscope (Nikon Corp., Tokyo, Japan), using a Spot RT Color CCD camera and the Spot RT software (Spot RT/ke Diagnostic Instruments, Sterling Heights, MI, USA). For the determination of microglial cell purity, Hoechst 33258-labelled cell nuclei that belonged to Iba1-immunopositive cells were counted on coverslip-cultured samples. For each culture, 50-100 randomly selected microscope fields were analyzed. In every case, the cultures had, on average, at least 99 Iba1-positive somata for 100 Hoechst 33258-labelled cell nuclei ( $>99 \%$ purity for microglial cells). Phagocytosed microspheres on 20 randomly sampled microscope fields from 3 coverslips for each treatment regimen were counted with the use of the computer program ImageJ (version 1.47; http://rsb.info.nih.gov/ij). For the measurement of area $\left(\mu \mathrm{m}^{2}\right)$, perimeter $(\mu \mathrm{m})$ and transformation index (TI), Iba1-immunoreactive microglial cell images were converted into binary replicas by using thresholding procedures implemented by ImageJ and Adobe Photoshop CS5.1 software (Adobe Systems, Inc., San Jose, CA, USA) as we published earlier (Kata et al., 2016; Szabo and Gulya, 2013; Szabó et al., 2016). TI was determined (Fujita et al., 1996) according to the following formula: [perimeter of cell $(\mu \mathrm{m})]^{2} / 4 \pi$ [cell area $\left.\left(\mu \mathrm{m}^{2}\right)\right]$. Color correction and cropping of the light microscopic images were performed when photomicrographs were made for publication and assembled for a panel. Gray-scale digital images of the immunoblots were acquired by scanning the autoradiographic films with a desktop scanner and processed at identi- cal settings to allow comparisons of the Western blots from different samples. The bands were analyzed through the use of ImageJ. The immunoreactive densities of equally loaded lanes were quantified, and all samples were normalized to the internal GAPDH load controls.

All statistical comparisons were made by using R 3.1.0 for Windows (The R Foundation for Statistical Computing; Vienna University of Economics and Business, Vienna, Austria). Results were analyzed with two-way ANOVA, and the Bonferroni correction was used to establish significance between groups. Values were presented as means \pm SEM; $\mathrm{p}<0.05$ was considered significant; *** and $* * *$ denote $\mathrm{p}<0.05$, $\mathrm{p}<0.01$ and $\mathrm{p}<0.001$, respectively.

\section{Results}

\subsection{Aspirin regulates microglial morphology in vitro}

Microglial morphology was analyzed on pure microglial cultures 4 days after seeding (subDIV4). Immunocytochemistry routinely performed on these secondary cultures consistently detected a $>99 \%$ incidence of the Iba1 immunopositive microglial cells for the Hoechst 33258 dye-labeled cell nuclei (Fig. 1). The morphological changes elicited by aspirin treatments in unchallenged and LPS-challenged pure microglia cultures (Fig. $2 A-F$ ) were quantitatively analyzed on binary silhouettes of individual microglial cells (Fig. $3 A-I$ ). Iba1 protein expression was also monitored during treatments (Fig. $2 G$ ). The amount of Iba1 immunoreactivity was significantly increased in the aspirin-treated (low: $2.09 \pm 0.17$; high: $2.22 \pm 0.26$ ) and the LPS-challenged + aspirin-treated groups (low: $2.30 \pm 0.29$; high: $2.49 \pm 0.32$ ) as compared to LPS-challenged values $(1.35 \pm 0.14$; Fig. $2 G)$. Most of the unchallenged and untreated (control) microglia displayed slightly amoeboid/ ramified morphology with $\mathrm{TI}=6.44 \pm 1.33$; they typically had only a few short processes (Figs. $2 A, 3 A$ ). LPS challenge resulted in a significant change in morphology (Figs. $2 B, 3 B, G-I$ ) as amoeboid morphologies with low TI values $(1.37 \pm 0.03)$ were more typical; LPS challenge decreased area, perimeter and TI values (by $48 \%, 65 \%$ and $78 \%$, respectively) as compared to the controls. When LPS-challenged cells were treated with aspirin, significantly enlarged and more ramified cells were seen as compared to the values of the LPS-challenged cells (Figs. $2 B$, $E, F, 3 B, E-I)$ indicating that aspirin was able to reverse the morpho-

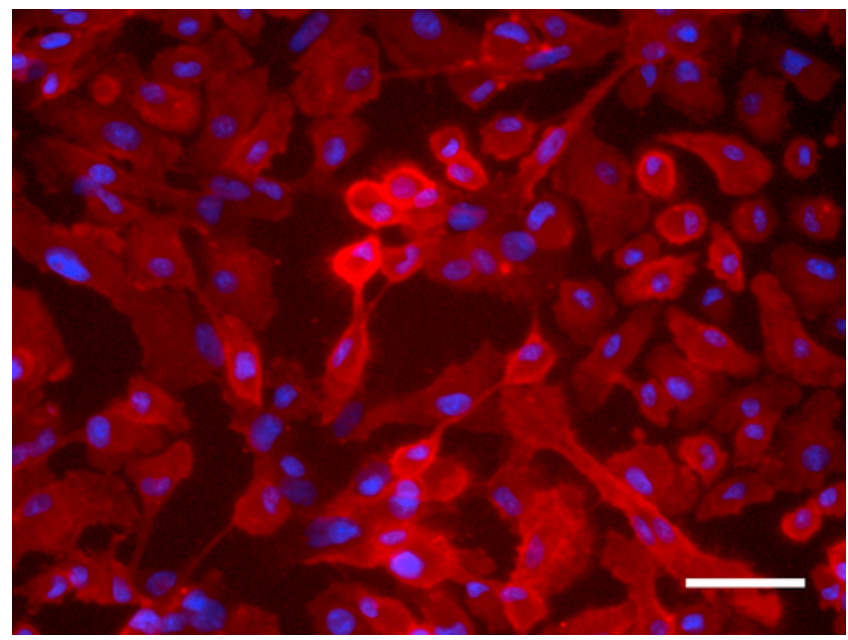

Fig. 1. Localization of Iba1 immunoreactive microglial cells in a pure secondary microglial culture (subDIV4).The typical purity of the culture is $>99 \%$; in this representative photomicrograph of a field of view the purity is $100 \%$ since every Hoechst 33258 -labeled cell nuclei (blue) is surrounded by Iba1 immunopositive cytoplasm (red). Scale bar: $50 \mu \mathrm{m}$. 

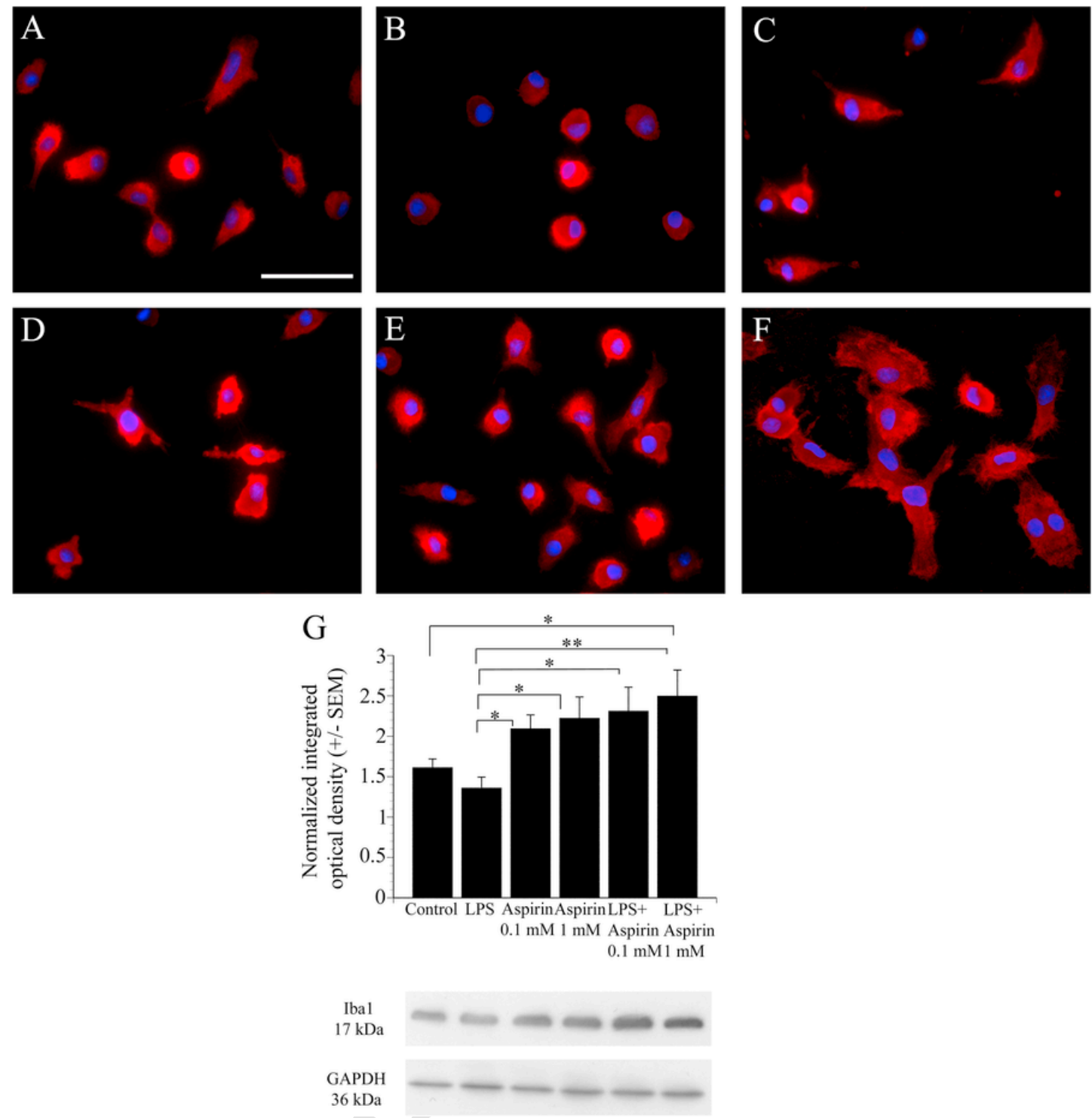

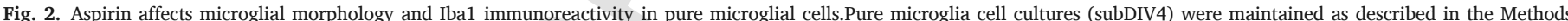

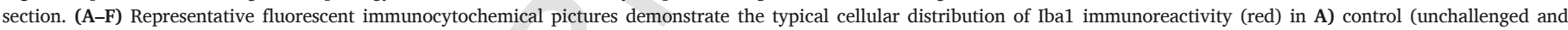

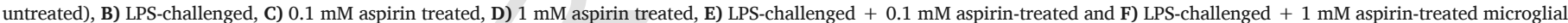

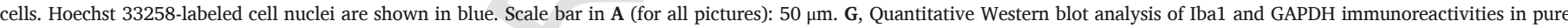

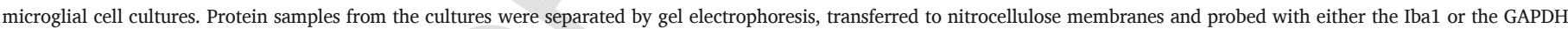

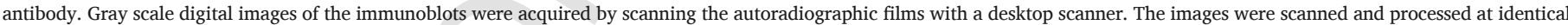

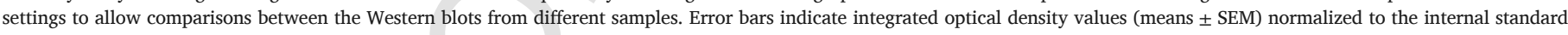
GAPDH. Representative Western blot pictures are shown beside the graph. Data were analyzed with two-way analysis of variance (ANOVA). *p $<0.05$, **p $<0.01$.

logical changes induced by LPS-challenge. Both aspirin doses increased the TI values to the control level (low: $5.73 \pm 0.56$; high: $7.36 \pm 0.61$ ) and induced ramified morphology with thick processes and microspikes (Figs. 2E, $F ; 3 E, F)$.

\subsection{Aspirin inhibits increases in LPS-induced phagocytosis by microglia}

Unchallenged and untreated microglia exhibited a low level of fluid-phase phagocytosis engulfing only $3.63 \pm 0.21$ beads per cell ( $\mathrm{n}=60$; Fig. $4 A, G$ ). As expected, microglial activation was associated with robust phagocytic activity as LPS challenge increased phagocytosis significantly to about $350 \%$ of the control level $(12.87 \pm 0.65$; $\mathrm{n}=58$; Fig. $4 A, B, G$ ). Aspirin alone did not affect the phagocytosis appreciably (Fig. 4C, D, G), as the number of phagocytosed microbeads remained low in both cases (low: $2.72 \pm 1.19$, high: $3.30 \pm 0.22 ; n=60$ ). However, aspirin inhibited phagocytosis significantly in LPS-challenged microglia (Fig. 4E, F, G). Aspirin ( $0.1 \mathrm{mM}$ or $1 \mathrm{mM}$ ) decreased phagocytosis dose-dependently by about $30 \%(9.20 \pm 0.59 ; \mathrm{n}=55 ;$ Fig. $4 E, G)$ and $70 \%(3.86 \pm 0.23 \mathrm{mi}-$ crobeads per cell; $\mathrm{n}=67$; Fig. $4 F, G$ ), respectively, as compared to LPS treatment.

\subsection{Aspirin strongly influences both pro- and anti-inflammatory cytokine levels}

Activated microglia express several inflammatory cytokines. When the basal levels of the pro-inflammatory cytokines IL- $1 \beta$ and TNF- $\alpha$ and the anti-inflammatory cytokine IL-10 in unchallenged mi- 
A

Control

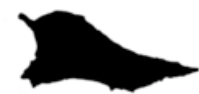

A: 546.26

P: 221.57

B

TI: 7.15

LPS

$\mathrm{C}$

Aspirin

$0.1 \mathrm{mM}$

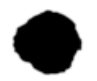

A: 244.17

P: 67.27

TI: 1.47

D

A: 580.16
P: 173.08
TI: 4.11

Aspirin

$1 \mathrm{mM}$

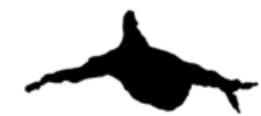

E

LPS+

Aspirin

$0.1 \mathrm{mM}$

\section{A: 536.95}

P: 200.61

TI: 5.96

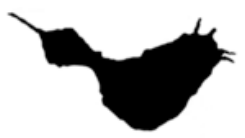

A: 771.82

P: 233.75

F

LPS+

Aspirin

$1 \mathrm{mM}$

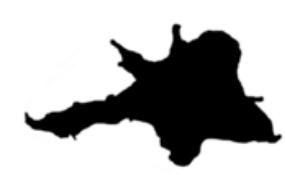

A: 1188.18

P: 354.65

TI: 8.42

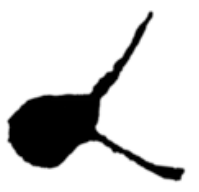

A: 796.12

P: 280.22

TI: 7.85

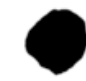

A: 228.37

P: 62.08

TI: 1.34

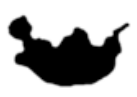

A: 352.52

P: 120.96

TI: 3.30

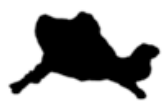

A: 482.57

P: 147.30

TI: 3.58

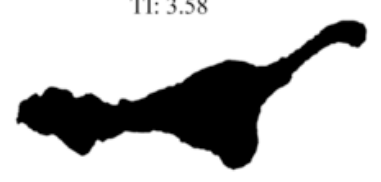

A: 1305.92

P: 273.17

TI: 4.55

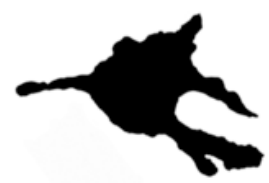

A: 1022.96
P: 292.92
TI: 6.67

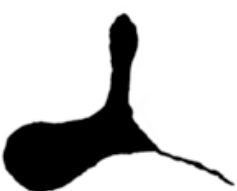

A: 381.97

P: 183.81

TI: 7.04

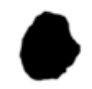

A: 234.69

P: 60.98

TI: 1.26

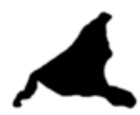

\section{A: 352.21}

P: 124.95

TI: 3.52

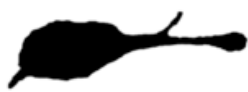

A: 531.26

P: 185.25

TI: 5.14

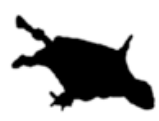

A: 466.76

P: 171.57

TI: 5.02

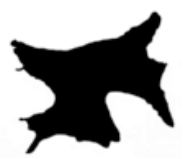

A: 884.66

P: 270.35

TI: 6.57

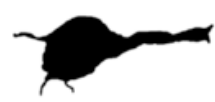

A: 585.08

P: 179.55

TI: 4.39

A: 241.23

P: 62.24

TI: 1.28

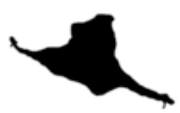

A: 377.66

P: 150.72

TI: 4.79

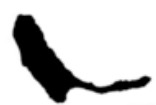

A: 265.40

P: 118.59

TI: 4.22

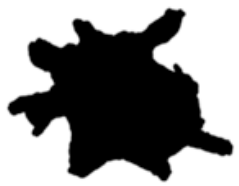

A: 1596.80

P: 285.93

TI: 4.07

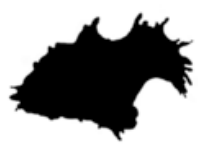

A:948.96

P: 283.64

TI: 6.74

G

$\mathrm{H}$

I
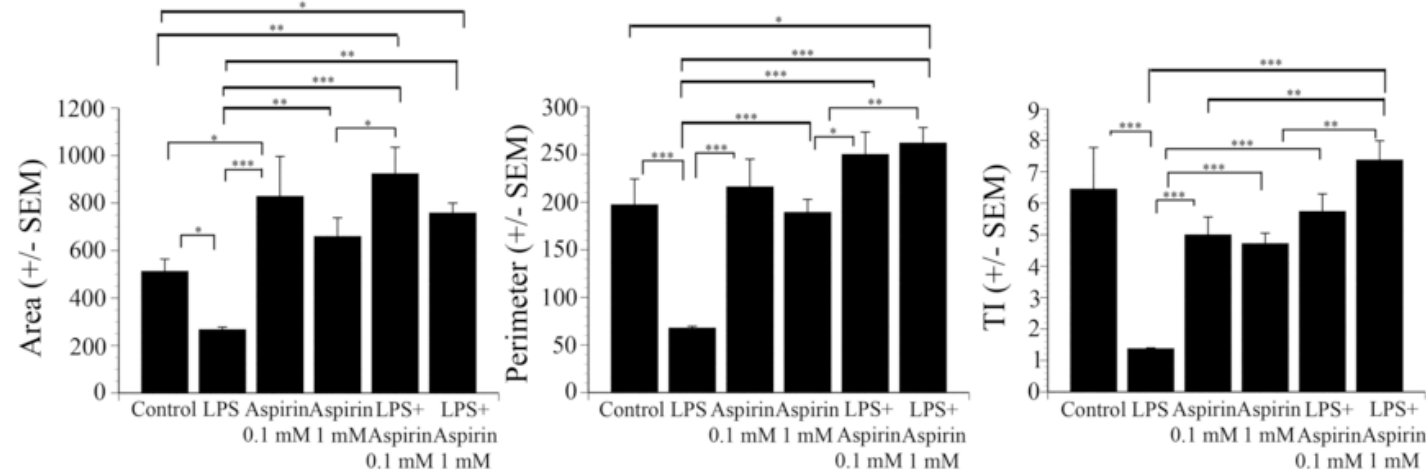

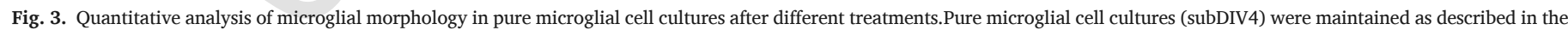

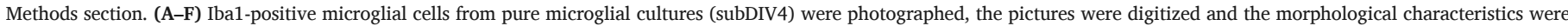

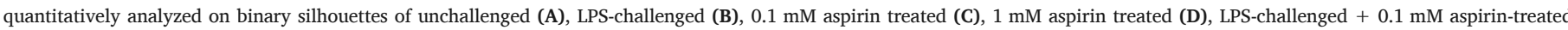

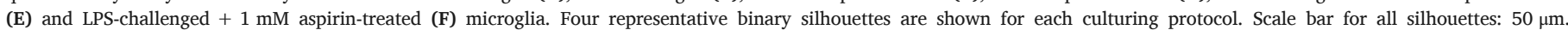

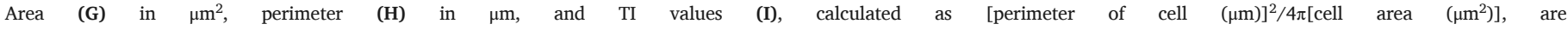




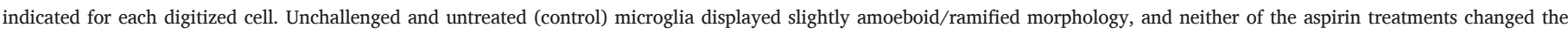

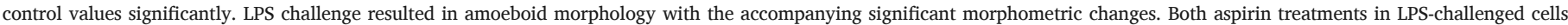

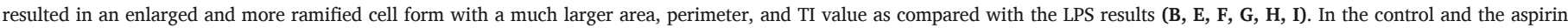

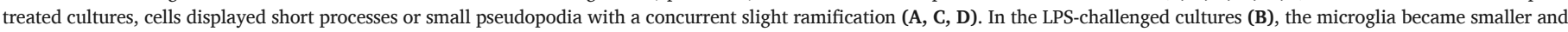

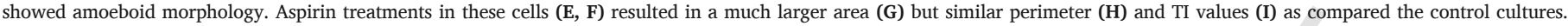

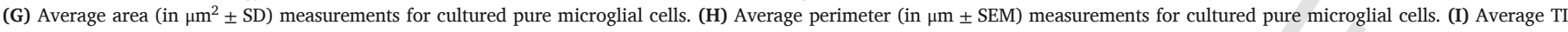

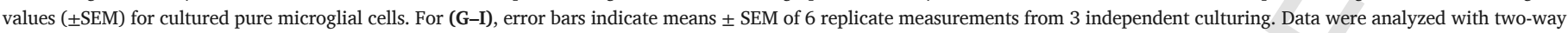
analysis of variance (ANOVA). *p $<0.05, * * \mathrm{p}<0.01$, ***p $<0.001$.
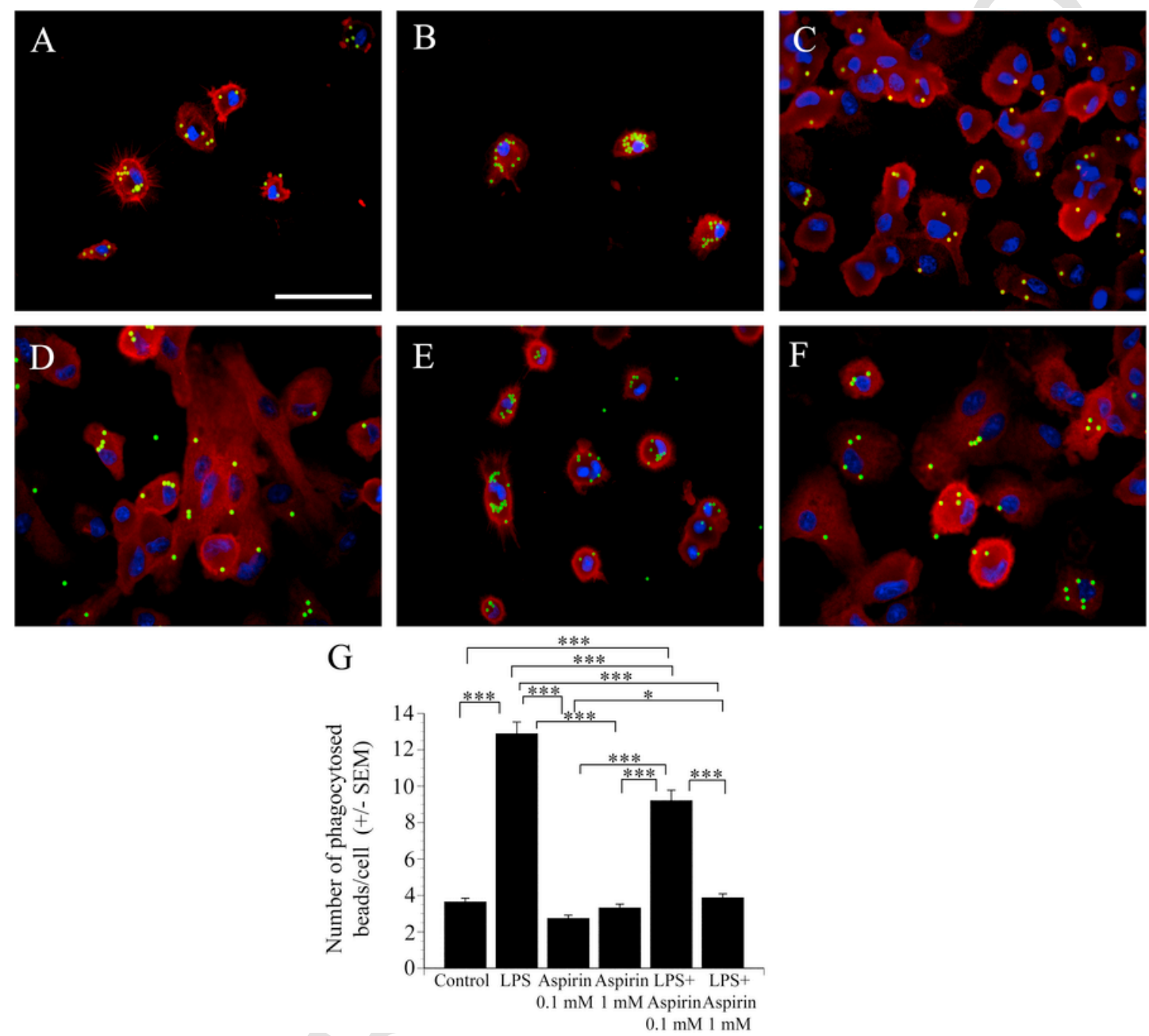

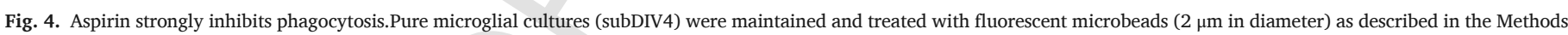

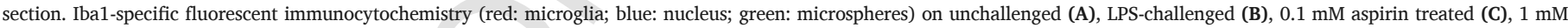

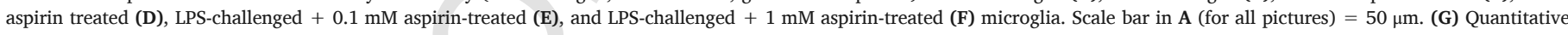

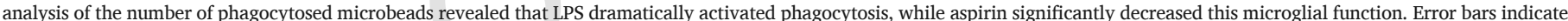
means \pm SEM of 6 replicate measurements from 3 independent culturing. Data were analyzed with two-way ANOVA. *p $<0.05$, ***p $<0.001$.

croglia were compared with the levels from aspirin-treated LPS-challenged cells, a unique regulatory pattern emerged (Fig. 5). In the case of IL-1 $\beta$ the basal level in unchallenged (control) microglia was $22.45 \pm 2.87 \mathrm{pg} / \mathrm{ml}$ (Fig. $5 A$ ). Both aspirin treatments were able to change this level (low: $10.26 \pm 2.62 \mathrm{pg} / \mathrm{ml}$; high: $10.19 \pm 2.23 \mathrm{pg} / \mathrm{ml}$ ). As expected, LPS challenge significantly elevated the IL- $1 \beta$ level to $336.15 \pm 51.72 \mathrm{pg} / \mathrm{ml}$. However, co-incubation of LPS and $1 \mathrm{mM}$ aspirin significantly inhibited IL-1 $\beta$ level by about $50 \%$, to $169.6 \pm 19.42 \mathrm{pg} / \mathrm{ml}$, while $0.1 \mathrm{mM}$ aspirin decreased it by about $16.5 \%$, to $280.05 \pm 25.0 \mathrm{pg} / \mathrm{ml}$ (Fig. $5 A$ ).

A similarly strong effect of aspirin was demonstrated on the level of TNF- $\alpha$, another pro-inflammatory cytokine, in LPS-challenged microglial cells (Fig. 5C, D). Two different treatment periods $(6 \mathrm{~h}$ and $24 \mathrm{~h}$ ) were used as the TNF- $\alpha$ production responded quickly to the
LPS challenge. The level of TNF- $\alpha$ in the control group could not be detected, but its level quickly rose, to $1187 \pm 94.12 \mathrm{pg} / \mathrm{ml}$ in the LPS-challenged cells after $6 \mathrm{~h}$, and the level was still elevated after $24 \mathrm{~h}$ $(189.92 \pm 27.4 \mathrm{pg} / \mathrm{ml})$. Aspirin treatments $(0.1 \mathrm{mM}$ and $1 \mathrm{mM})$ resulted in small, detectable TNF- $\alpha$ levels for both doses $(27.69 \pm 2.89 \mathrm{pg} / \mathrm{ml}$ and $29.23 \pm 1.73 \mathrm{pg} / \mathrm{ml}$ after $6 \mathrm{~h}$, while $8.24 \pm 1.81 \mathrm{pg} / \mathrm{ml}$ and $9.09 \pm 0.6 \mathrm{pg} / \mathrm{ml}$ after $24 \mathrm{~h}$ ). When aspirin was co-administered to LPS-challenged cells for either $6 \mathrm{~h}$ or $24 \mathrm{~h}$, it inhibited the production of TNF- $\alpha$ in both cases, but only the high aspirin concentration decreased the TNF- $\alpha$ level significantly by about $25 \%$ (to $844.76 \pm 67.11 \mathrm{pg} / \mathrm{ml}$ after $6 \mathrm{~h})$ and $50 \%(96.79 \pm 6.02 \mathrm{pg} / \mathrm{ml}$ after $24 \mathrm{~h})($ Fig. $5 C, D)$.

Aspirin also affected the production of IL-10 (Fig. 5B). LPS challenge increased the basal IL-10 level $(24.98 \pm 3.47 \mathrm{pg} / \mathrm{ml})$ signifi- 

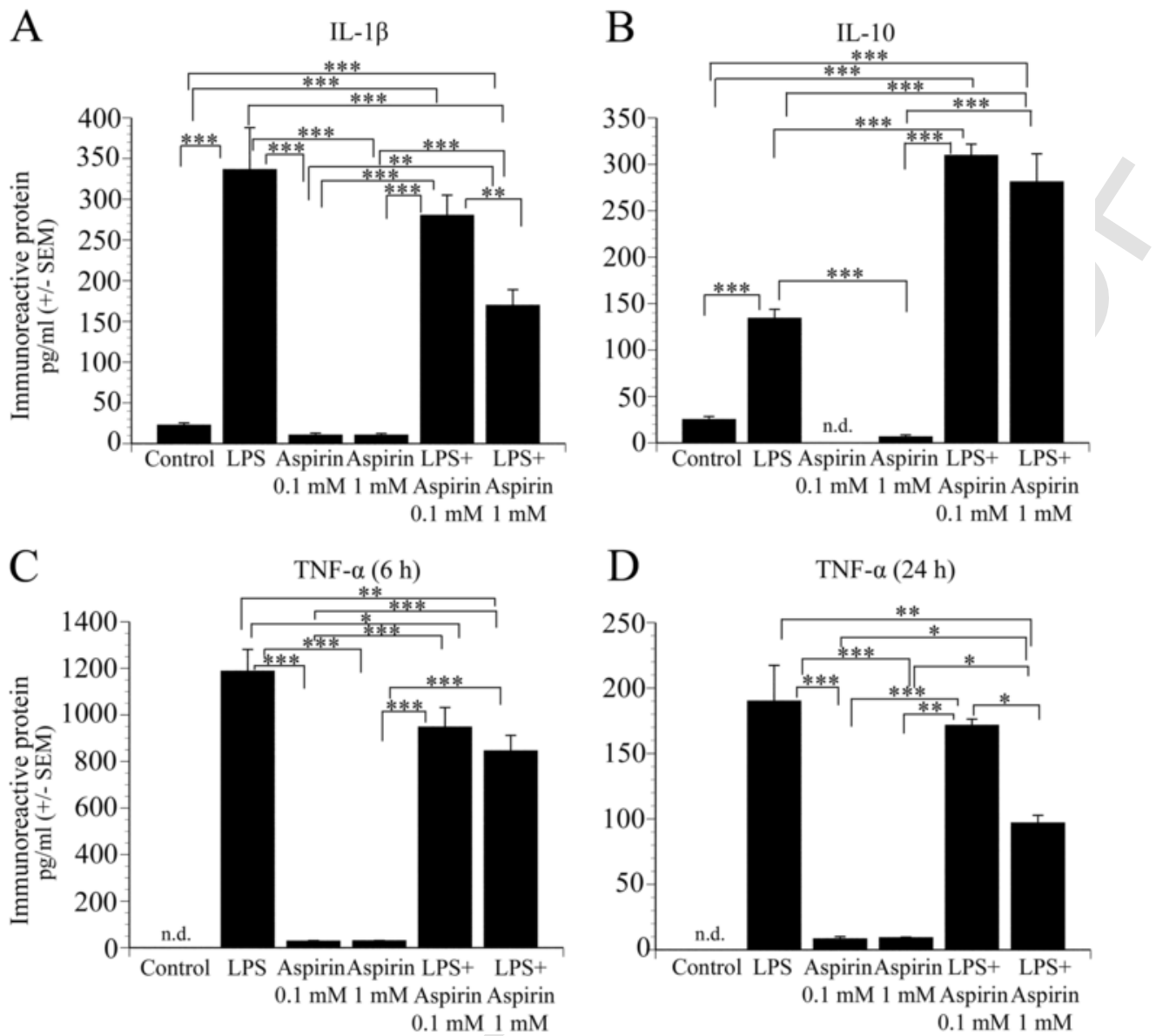

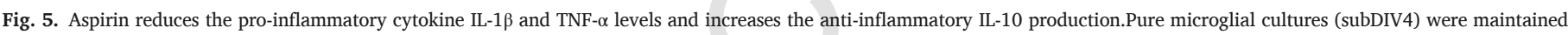

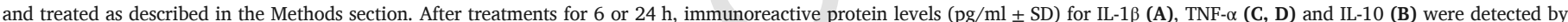

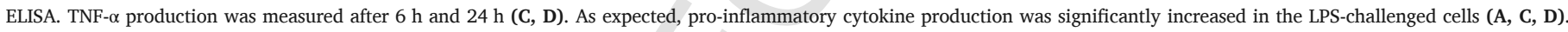

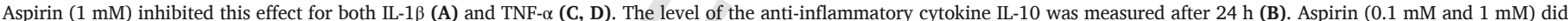

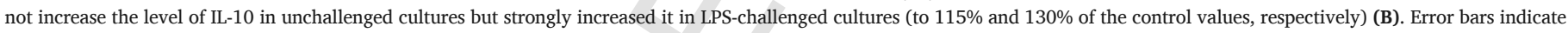
means \pm SEM of 6 replicate measurements from 3 independent culturing. Data were analyzed with two-way ANOVA. n.d. $=$ not detected. *p $<0.05 ; * * p<0.01, * * * p<0.001$.

cantly $(134.0 \pm 9.9 \mathrm{pg} / \mathrm{ml})$. When aspirin was co-administered with LPS, the IL-10 protein expression was further increased as compared to the LPS challenged value (low: $309.47 \pm 12.29 \mathrm{pg} / \mathrm{ml}$, high: $280.95 \pm 30.3 \mathrm{pg} / \mathrm{ml}$ ). Aspirin administered alone to unchallenged cells had no significant effects on the microglial IL-10 levels.

\subsection{Aspirin affects the expression of inflammation-related genes}

We analyzed the effects of aspirin on the expression of 116 inflammation-related genes in unchallenged and LPS-challenged pure microglial cells with or without aspirin treatment. The hierarchical cluster analysis of 46 such genes is summarized in Fig. 6, and those with the most noteworthy and significant expression changes in response to the treatments are listed in Table 1. The genes upregulated by the LPS challenge included those coding for chemokine ligands 1,2 , 4, 5, 7, 9 (Cxcl1 = 84.30-fold, $C c l 2=16.95$-fold, $C c l 4=9.80$-fold, Ccl5 $=38.26$-fold,$\quad$ Cxcl5 $=33.19, \quad$ Cxcl9 $=73.44$-fold, $) \quad$ IL-1 $\beta$ (Il1 $\beta=24.70$-fold), IL-6 receptor (Il6 = 7.57-fold) and nitric oxide synthase (Nos2 $=369.22$-fold). Only a few genes were downregulated by the LPS challenge, including Tgfb2 (-1.73-fold), Sirpa ( -2.42 -fold), Tlr5 ( -3.42 -fold) and Myl2 ( -4.46 -fold).

The levels of expression of some inflammation-related genes strongly downregulated by aspirin are highlighted in Fig. 7. Aspirin treatment in unchallenged cells affected fewer, but similarly impor- tant microglial genes involved in pro- and anti-inflammatory processes. In unchallenged cells the genes downregulated by aspirin $(0.1 \mathrm{mM}$ or $1 \mathrm{mM}$ ) included the interleukin 1 receptor antagonist (Il1 $r n=-1.37$-fold; -1.44 -fold), the anti-inflammatory DNA damage inducible transcript 3 (Ddit $=-1.43$-fold, and -1.79 -fold), the pro-inflammatory IL6 (Il6 $=-1.23$-fold; -1.55 -fold) and the pro-inflammatory chemokine (C-C motif) receptor 1 (Ccr $1=-1.42$-fold, -1.44-fold). When aspirin was co-administered to LPS-challenged cultures (Table 1), a more complex picture emerged. Some of the LPS-upregulated genes were inhibited by aspirin, as seen in the case of $\mathrm{Ccr} 1$ (Fig. 7A), IL1rn (Fig. 7B) or Nos2 (Fig. 7D). Kng1 (Fig. 7C), a pro-inflammatory gene was downregulated by both aspirin treatments following LPS challenge. Other genes were further upregulated by aspirin when applied to LPS-challenged microglia such as Ccl5 or Csf2, or the pro-inflammatory Ccl4 (Table 1).

\section{Discussion}

Microglial activation results in profound morphological, functional and gene expression changes that activate both pro- and anti-inflammatory mechanisms (Kroner et al., 2014) that in turn not only protect the nervous tissue but can elicit chronic inflammation that could lead to the development of neuropathological conditions (Jones and Thomsen, 2013; Long-Smith et al., 2009). Aspirin, one of 


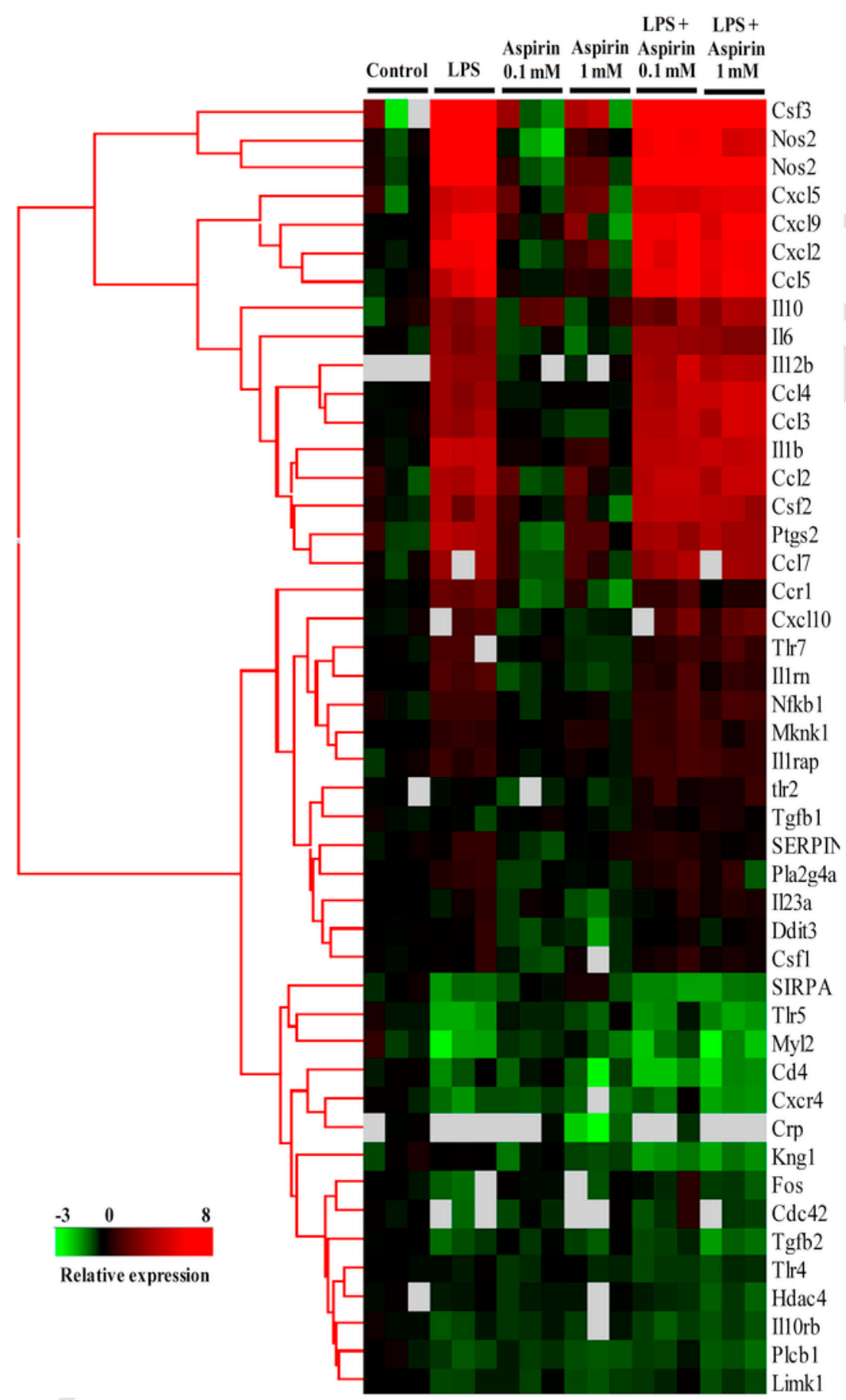

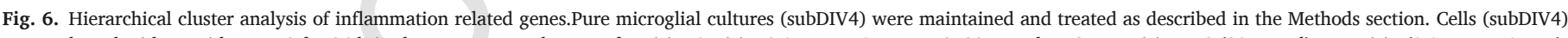

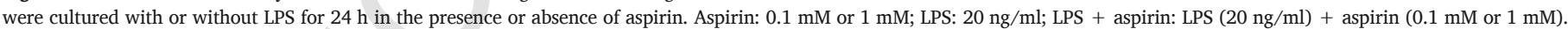

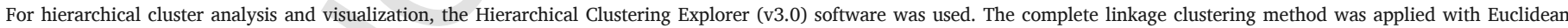

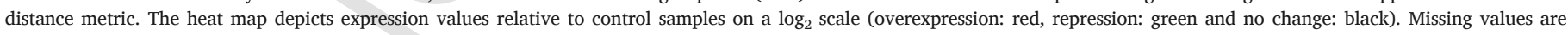
indicated in grey.

the most commonly used drugs, is noted for its strong anti-inflammatory actions. It acetylates the active site of the enzyme COX, and irreversibly blocks the conversion of arachidonic acid to prostanoid (Vane and Botting, 2003). Apart from its classical beneficial role in cardiovascular diseases, however, aspirin may be beneficial in neuroinflammation-related disorders given that appropriate target cells, the microglia, are present in the nervous tissue.

In the present study we investigated the complex pleiotropic, beneficial effects of aspirin on the modulation of inflammation by quan- titatively analyzing numerous morphological, functional (phagocytosis, cytokine release) and gene expression parameters in pure, secondary microglial cultures. As our cultures were $>99 \%$ pure, they provided a unique opportunity to study these functional and expression parameters without the significant influence of any contaminating cell types. This is a crucial factor when, for example, the levels of secreted pro- and anti-inflammatory peptides or gene expression levels are measured, as other cell types in the CNS are also capable of expressing such genes (Gruol et al., 2014). 
Table 1

Differentially expressed transcripts in aspirin-treated pure microglial cells with or without LPS challenge.

\begin{tabular}{|c|c|c|c|c|c|c|}
\hline Gene & $\begin{array}{l}\text { Name } \\
\text { NCBI Reference Sequence ID } \\
\text { RGD ID }\end{array}$ & LPS & $\begin{array}{l}\text { Aspirin } \\
0.1 \mathrm{mM}\end{array}$ & $\begin{array}{l}\text { Aspirin } \\
1 \mathrm{mM}\end{array}$ & $\begin{array}{l}\text { LPS + Aspirin } \\
0.1 \mathrm{mM}\end{array}$ & $\begin{array}{l}\text { LPS + Aspirin } \\
1 \mathrm{mM}\end{array}$ \\
\hline $\mathrm{Ccl} 2$ & $\begin{array}{l}\text { Chemokine ligand } 2 \\
\text { NM_031530.1 } \\
\text { RGD ID } 3645\end{array}$ & +16.95 & +1.14 & +1.70 & +20.92 & +21.35 \\
\hline $\mathrm{Ccl} 3$ & $\begin{array}{l}\text { Chemokine ligand } 3 \\
\text { NM_013025.2 } \\
\text { RGD ID } 3647\end{array}$ & +11.33 & -1.01 & -1.31 & +18.41 & +24.79 \\
\hline Ccl4 & $\begin{array}{l}\text { Chemokine ligand } 4 \\
\text { NM_053858.1 } \\
\text { RGD ID } 620441\end{array}$ & +9.80 & -1.05 & +1.06 & +17.68 & +29.80 \\
\hline Ccl5 & $\begin{array}{l}\text { Chemokine ligand } 5 \\
\text { NM_031116.3 } \\
\text { RGD ID } 69069\end{array}$ & +38.26 & +1.02 & +1.35 & +84.12 & +62.69 \\
\hline Ccl7 & $\begin{array}{l}\text { Chemokine ligand } 7 \\
\text { NM_001007612.1 } \\
\text { RGD ID } 1359152\end{array}$ & +11.48 & -1.14 & +1.50 & +10.82 & +11.82 \\
\hline Ccr1 & $\begin{array}{l}\text { Chemokine receptor } 1 \\
\text { NM_020542.2 } \\
\text { RGD ID } 708446\end{array}$ & +4.51 & -1.42 & -1.44 & +2.16 & +1.29 \\
\hline Cxcl1 & $\begin{array}{l}\text { Chemokine ligand } 1 \text { (melanoma growth-stimulating } \\
\text { activity, alpha) } \\
\text { NM_030845.1 } \\
\text { RGD ID } 619869\end{array}$ & +84.30 & -1.51 & +4.11 & +43.46 & +246.78 \\
\hline Cxcl2 & $\begin{array}{l}\text { Chemokine ligand } 2 \\
\text { NM_053647.1 } \\
\text { RGD ID } 70069\end{array}$ & +69.02 & -1.37 & +1.73 & +63.70 & +60.07 \\
\hline Cxcl5 & $\begin{array}{l}\text { Chemokine ligand } 5 \text { (Cxcl6) } \\
\text { NM_022214.1 } \\
\text { RGD ID } 708540\end{array}$ & +33.19 & +1.41 & +2.11 & +34.89 & +46.37 \\
\hline Cxcl9 & $\begin{array}{l}\text { Chemokine ligand } 9 \\
\text { NM_145672.4 } \\
\text { RGD ID } 628798\end{array}$ & +73.44 & +1.40 & +1.22 & +86.22 & +68.51 \\
\hline Cxcl10 & $\begin{array}{l}\text { Chemokine ligand } 10 \\
\text { NM_139089.1 } \\
\text { RGD ID } 620209\end{array}$ & +2.83 & -1.30 & -1.24 & +3.93 & +3.21 \\
\hline Csf1 & $\begin{array}{l}\text { Colony stimulating factor-1 } \\
\text { AF515736.1 } \\
\text { RGD ID621063 }\end{array}$ & +1.31 & -1.49 & -1.03 & +1.48 & +1.30 \\
\hline Csf2 & $\begin{array}{l}\text { Colony stimulating factor-2 } \\
\text { XM_001074265.1(old) } \\
\text { NM_053852.1 } \\
\text { RGD ID621065 }\end{array}$ & +10.01 & +1.20 & -1.00 & +20.66 & +14.84 \\
\hline Csf3 & $\begin{array}{l}\text { Colony stimulating factor } 3 \\
\text { NM_017104.1 (old), NM_017104.2 } \\
\text { RGD ID } 2426\end{array}$ & +305.58 & +1.23 & +4.96 & +282.90 & +278.46 \\
\hline Ddit3 & $\begin{array}{l}\text { DNA-damage inducible transcript } 3 \\
\text { NM_001109986.1 } \\
\text { RGD ID } 62391\end{array}$ & +1.25 & -1.43 & -1.79 & +1.14 & +1.04 \\
\hline Ill $\beta$ & $\begin{array}{l}\text { Interleukin } 1 \text { beta } \\
\text { NM_031512.2 } \\
\text { RGD ID } 2891\end{array}$ & +24.70 & +1.18 & +1.62 & +19.88 & +22.98 \\
\hline Illrap & $\begin{array}{l}\text { Interleukin } 1 \text { receptor accessory protein } \\
\text { NM_012968.1 } \\
\text { RGD ID2893 }\end{array}$ & +1.97 & -1.02 & +1.06 & +2.30 & +2.08 \\
\hline Il1rn & $\begin{array}{l}\text { Interleukin } 1 \text { receptor antagonist } \\
\text { NM_022194.2 } \\
\text { RGD ID } 621159\end{array}$ & +2.83 & -1.37 & -1.44 & +2.02 & +1.64 \\
\hline Il6 & $\begin{array}{l}\text { Interleukin } 6 \\
\text { M26744.1 } \\
\text { RGD ID } 2901\end{array}$ & +7.57 & -1.23 & -1.55 & +10.82 & +7.22 \\
\hline Il10 & $\begin{array}{l}\text { Interleukin } 10 \\
\text { NM_012854.2 } \\
\text { RGD ID } 2886\end{array}$ & +8.47 & +2.01 & +1.04 & +6.28 & +11.87 \\
\hline Il18 & $\begin{array}{l}\text { IFN-gamma-inducing factor IL-18 } \\
\text { AY077842.1 } \\
\text { RGD ID } 2889\end{array}$ & +2.24 & +1.63 & -1.29 & +1.90 & +2.03 \\
\hline Kng1 & $\begin{array}{l}\text { Kininogen } 1 \\
\text { NM_012696.2 } \\
\text { RGD ID } 2980\end{array}$ & +1.04 & -1.36 & -1.55 & -2.75 & -2.82 \\
\hline Nos2 & $\begin{array}{l}\text { Nitric oxide synthase } \\
\text { U26686.1 } \\
\text { RGD ID } 3185\end{array}$ & +369.22 & -1.28 & +1.78 & +73.06 & +51.21 \\
\hline
\end{tabular}


Table 1 (Continued)

\begin{tabular}{|c|c|c|c|c|c|c|}
\hline Gene & $\begin{array}{l}\text { Name } \\
\text { NCBI Reference Sequence ID } \\
\text { RGD ID }\end{array}$ & LPS & $\begin{array}{l}\text { Aspirin } \\
0.1 \mathrm{mM}\end{array}$ & $\begin{array}{l}\text { Aspirin } \\
1 \mathrm{mM}\end{array}$ & $\begin{array}{l}\text { LPS + Aspirin } \\
0.1 \mathrm{mM}\end{array}$ & $\begin{array}{l}\text { LPS + Aspirin } \\
1 \mathrm{mM}\end{array}$ \\
\hline Pla2g4a & $\begin{array}{l}\text { Phospholipase A2, group IVA (cytosolic, calcium- } \\
\text { dependent) } \\
\text { NM_133551.2 } \\
\text { RGD ID } 67366\end{array}$ & +1.73 & -1.33 & -1.16 & +1.66 & +1.07 \\
\hline Ptgs2 & $\begin{array}{l}\text { Prostaglandin endoperoxide synthase } 2 \\
\text { NM_017232.3 } \\
\text { RGD ID } 620349\end{array}$ & +16.83 & -1.33 & +2.14 & +11.76 & +12.55 \\
\hline Sirpa & $\begin{array}{l}\text { The signal-regulatory protein a } \\
\text { NM_013016.2 } \\
\text { RGD ID } 3449\end{array}$ & -2.42 & -1.22 & +1.04 & -2.84 & -2.63 \\
\hline Tgfb1 & $\begin{array}{l}\text { Transforming growth factor, beta } 1 \\
\text { NM_021578.2 } \\
\text { RGD ID } 69051\end{array}$ & -1.21 & +1.05 & -1.10 & +1.25 & +1.34 \\
\hline Tgfb2 & $\begin{array}{l}\text { Transforming growth factor, beta } 2 \\
\text { NM_031131.1 } \\
\text { RGD ID } 70491\end{array}$ & -1.73 & -1.15 & -1.43 & -1.47 & -2.41 \\
\hline Tlr2 & $\begin{array}{l}\text { Toll-like receptor } 2 \\
\text { NM_198769.2 } \\
\text { RGD ID } 735138\end{array}$ & -1.03 & -1.49 & -1.22 & +1.63 & +1.63 \\
\hline Tlr7 & $\begin{array}{l}\text { Toll-like receptor } 7 \\
\text { EF032637.1 } \\
\text { RGD ID } 1563357\end{array}$ & +2.71 & +1.05 & -1.36 & +1.79 & +2.21 \\
\hline
\end{tabular}

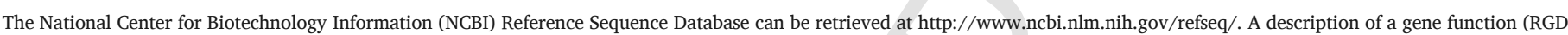

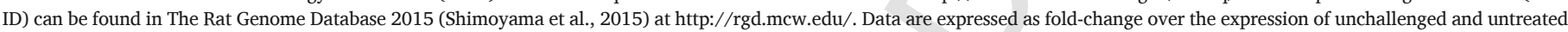

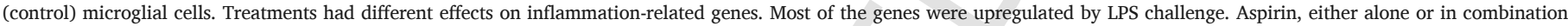

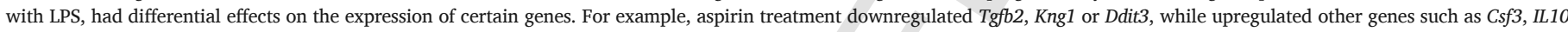
and CxCl1 in unchallenged cells. In LPS-challenged microglia, aspirin inhibited IL1rn, Ccr1, Kng1, Nos2, while it had a synergistic effect with LPS on others (e.g. Cxcl5, Ccl4, Csf2).

Aspirin reversed the morphological effects of LPS-induced microglia activation through the increase of the area, perimeter and TI values; the combined treatment with LPS also inhibited this activation through the development of microspikes and inducing the cells to become more ramified. Aspirin also affected the protein synthesis of Iba1, a Ca ${ }^{2+}$-binding protein that is implicated in actin cytoskeleton remodeling (Ohsawa et al., 2004; Szabo et al., 2016).

LPS is a potent activator of microglial phagocytosis (Kata et al., 2016; Lund et al., 2006; Szabo and Gulya, 2013; Szabo et al., 2016), a crucial factor both in normal and pathologic functions of the CNS (Kettenmann et al., 2011). Alteration of this function could be harmful (Hickman and El Khoury, 2014; Lue et al., 2015). Pro-inflammatory phenotypes are associated with increased phagocytic activity, and blocking of phagocytosis may prevent some forms of inflammatory neurodegeneration; this may be beneficial under different neuropathological conditions (He et al., 2014; Neher et al., 2011). Aspirin inhibited phagocytosis in the LPS-challenged microglia only, while it did not inhibit the basal phagocytotic activity in unchallenged cells, a physiological microglial function crucial for the healthy CNS.

LPS is the main ligad for Toll-like receptor 4 (TLR4). TLR4-induced signalling activates the NF- $\mathrm{kB}$ and MAPK pathways leading to the production of pro-inflammatory cytokines (Fuentes et al., 2016; Korneev et al., 2017). Aspirin inhibits the production of pro-inflammatory cytokines through the suppression of LPS-induced NF- $\kappa \mathrm{B}$ and MAPK pathways in microglial cells (Cianciulli et al., 2016; Sun et al., 2017; Yang et al., 2014). NF-кB activity is suppressed in the cytoplasm with an inhibitory IкB protein. The phosphorylation and degra-

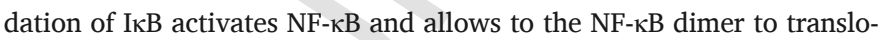
cate to the nucleus and activate target genes such as IL1 $\beta$ and TNF- $\alpha$ (Sun et al., 2017; Yang et al., 2014). LPS-stimutated degradation of I $\mathrm{KB}$ could be strongly inhibited by aspirin (Yang et al., 2014). Anti-inflammatory property is mediated by inhibition of several members of MAPK family, e.g., p38 MAPK and ERK1/2 (Jung et al., 2009; $\mathrm{Li}$ et al., 2017); according to recent data, aspirin enhances the inhibition of p38-MAPK and ERK phosphorylation in a microglial cell line (Yang et al., 2014).

Cytokines are important to the normal and pathologic immunomodulatory functions of the microglia. Previous studies demonstrated a strong relationship between cytokines and neurodegenerative diseases (McGeer and McGeer, 2010; Smith et al., 2012). Microglial cells activated by $\beta$-amyloid deposits produce toxic mediators and pro-inflammatory cytokines such as IL-1 $\beta$, IL- 6 , TNF- $\alpha$ and iNos that could result in chronic inflammation (Benveniste et al., 2001). High level of IL-1 $\beta$ could be observed in the vicinity of amyloid plaques of AD patients (McGeer et al., 1993) that could be responsible for plaque accumulation (Akiyama et al., 2000). COX-2 is also increased in $\mathrm{AD}$ patients (Akiyama et al., 2000). Recent attempts have been made to ameliorate neuroinflammation through the suppression of microglial activation both in vivo and in vitro (Lim et al., 2015; Wang et al., 2011; Yang et al., 2016). Similarly to the findings for $\mathrm{AD}$, previous studies also suggested that activated microglia could be associated with neuronal loss during PD due to the activation of cytokines, COX-2 and iNos expression (Orr et al., 2002; Phani et al., 2012) or increased levels of TNF- $\alpha$ and nitrogen oxide could cause demyelination in MS (Minagar et al., 2002).

As expected, both pro- (IL-1 $\beta$, TNF- $\alpha$ ) and anti-inflammatory (IL-10) cytokines were increased in LPS-challenged microglia as compared with the unchallenged cells. Aspirin did not significantly affect the basal cytokine levels in unchallenged cells, but strongly reduced the levels of the pro-inflammatory cytokines IL- $1 \beta$ and TNF- $\alpha$ when tested in LPS-challenged microglia. Besides the inhibition of these pro-inflammatory agents, aspirin was also able to elevate the anti-inflammatory IL-10 in LPS-challenged cells. Thus, aspirin is remarkably beneficial as it concomitantly decreased pro-inflammation-related cytokines but increased anti-inflammation-related cytokine peptides in immunochallenged cells.

We also demonstrated that aspirin, LPS and their combination had differential effects on the expression of several inflammation-related genes in pure microglial cells. Some of these genes encode 
A

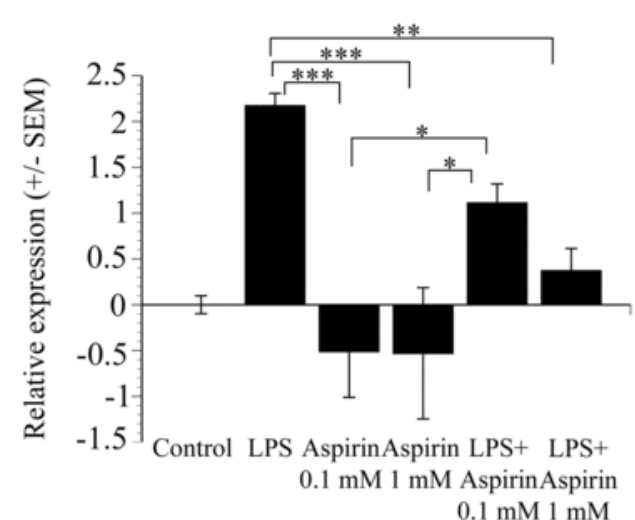

C

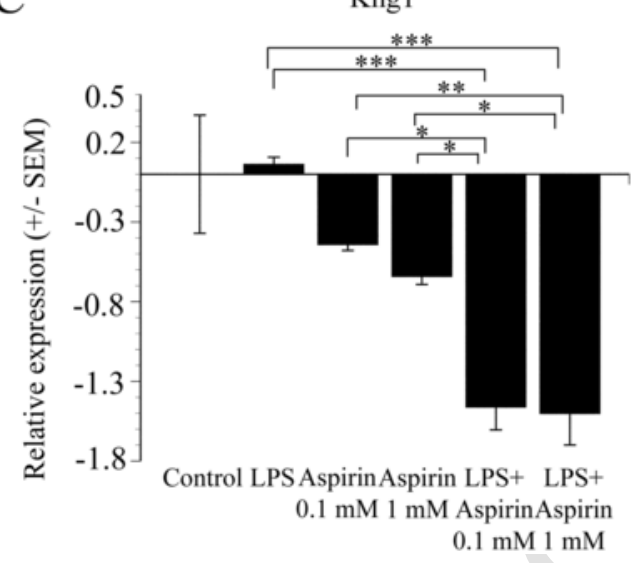

B ILlrn

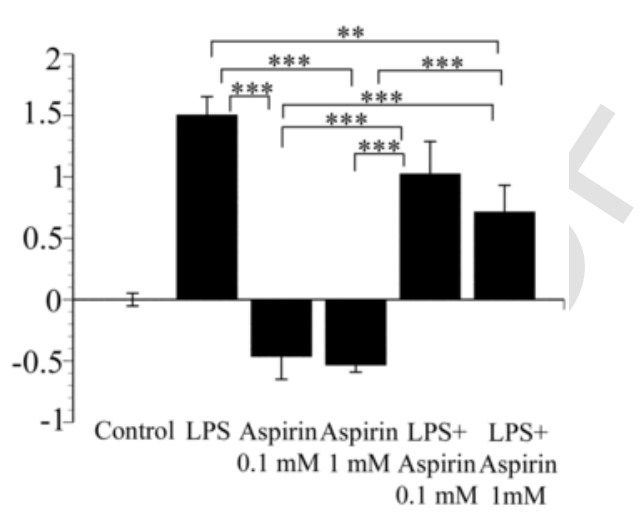

D Nos2

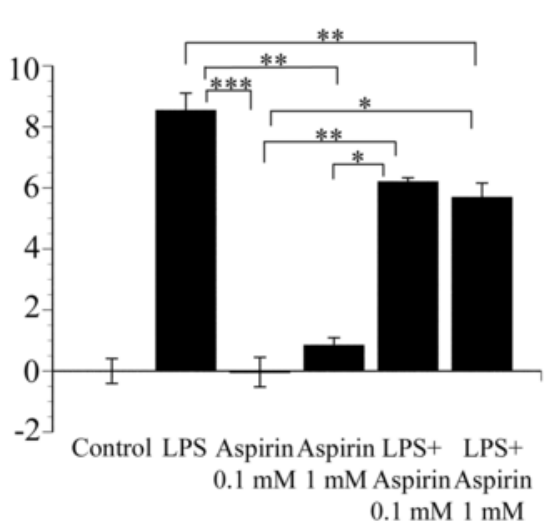

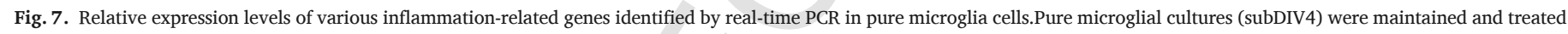

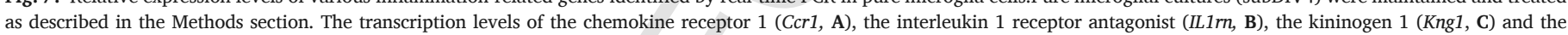

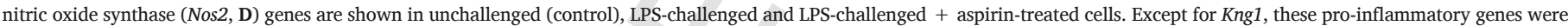

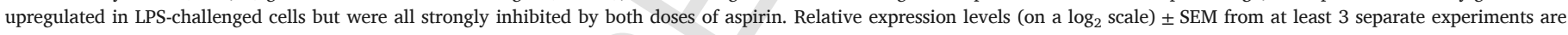
shown for each condition. Data were analyzed with two-way ANOVA. ${ }^{*}<<0.05,{ }^{* *} \mathrm{p}<0.01,{ }^{* * *} \mathrm{p}<0.001$.

markers that can be related to different microglia subtypes proposed as M1 or M2 phenotypes (Moehle and West, 2015; Orihuela et al., 2016). In this context, for example, the pro-inflammatory $I L 1 \beta, I L 6$, IL18, Cxcl9, TNF- $\alpha, C x c l 10$, and the chemokine Ccl5, genes encode M1 markers, while the anti-inflammatory $I L 10$ and the pro-inflammatory Tgfb2 genes are M2 markers (Franco and Fernández-Suárez, 2015). In an LPS-based animal model for Parkinson's disease, a Rho kinase inhibitor reversed the inflammatory M1 to anti-inflammatory M2 microglia, decreased NF- $\mathrm{KB}$ activation, and inhibited IL-12 and TNF- $\alpha$ generation (He et al., 2016), demonstrating a protective effect against LPS-mediated dopaminergic degeneration. It must be noted, however, that the concept of M1/M2 polarization of microglia cells is not universally accepted and needs reassessment (Martinez and Gordon, 2014; Ransohoff, 2016).

Our study demonstrated that several genes were upregulated after LPS challenge, confirming its strong pro-inflammatory effects on microglia. Aspirin, both alone and in combination with LPS, displayed different effects on microglial gene expression. It suppressed the pro-inflammatory effects of LPS on some genes such as Ccr1 and Nos2. It may be of importance that Ccr1 was previously associated with both MS and experimental autoimmune encephalomyelitis (Rottman et al., 2000) and Ccr1 protein was localized around the demyelinating plaques (Eltayeb et al., 2007). In our experiment (Fig. 7A) both aspirin doses decreased Cor1 expression. Multiple studies suggested that Nos2 has a central role in inflammatory reactions and pathogenesis of certain neurodegenerative diseases (Akiyama et al., 2000; Block and Hong, 2005; Galea and Feinstein, 1999). Thus, downregulating Nos2 expression could be crucial for possible future therapies. We showed that aspirin inhibited Nos2 expression significantly in LPS-challenged microglia. Kininogen (Kng1) is well known for its pro-inflammatory properties (Sharma and Yusof, 1998; Stewart et al., 1997) as it increases the release of inflammatory cytokines and affects the formation of inflammatory exudate and pain (Ueno and Oh-ishi, 2003).

Aspirin also increased the expression of genes that were predominantly anti-inflammatory e.g. $I L 10, T g f b 1$ or Ccl5. IL-10 is a well known anti-inflammatory cytokine that limits the production of pro-inflammatory cytokines including IL- $1 \alpha$ and $-\beta$, IL-6, IL-12, IL-18, and TNF- $\alpha$ (Couper et al., 2008). Previous studies showed that Tgfb1 had a protective effect against excitotoxicity and the loss of this protein resulted in neurodegeneration (Brionne et al., 2003). Ccl5 was also upregulated in our studies. Although Ccl5 was demonstrated to induce pro-inflammatory mechanisms (Skuljec et al., 2011), it was also shown to ameliorate AD-like pathology by recruiting microglia to $\beta$-amyloid deposits (Lee et al., 2012) and to protect against neuronal injury (Campbell et al., 2013; Lim and Mocchetti, 2015). Upregulation of such anti-inflammatory genes in neurodegenerative disorders could be beneficial. 
As activated microglia often damage neuronal tissues (Hong et al., 2016; Lui et al., 2016) or cause chronic inflammation by excessive cytokine production combined with high level of phagocytosis, effective inhibition of pro-inflammatory actions by aspirin could be an important prophylactic therapy in preventing neuroinflammation and thus neurodegeneration. Our data indicate that aspirin beneficially regulates microglia, cells that could be targets in treating or preventing neurodegenerative disorders. With respect to the large population who receives aspirin for pain medication or prevention of a number of pathologic conditions, to study the interactions of this drug with the nervous system is even more important. Early observations revealed that NSAIDs could reduce the risk of AD (McGeer et al., 1996; Stewart et al., 1997), a notion that has not been proven in randomised controlled trials assessing the efficacies of aspirin, steroidal and non-steroidal anti-inflammatory drugs in $\mathrm{AD}$ (Jaturapatporn et al., 2012). However, we recently demonstrated that rosuvastatin, a new generation 3-hydroxy-3-methylglutaryl coenzyme A reductase inhibitor regulated microglial pro- and anti-inflammatory functions very favorably (Kata et al., 2016). As the effects of aspirin on selected morphological, functional and gene expression characteristics of microglia are very similar to that of rosuvastatin, and these drugs are frequently prescribed together for a number of cardiovascular illnesses, their extended use may have contributed to the lower than expected incidence of AD (Schrijvers et al., 2012). Thus, the individual and combined effects of aspirin and rosuvastatin on microglial functions should be further analyzed for a prophylactic therapeutic approach in neurodegenerative disorders.

\section{Conclusion}

Aspirin elicits strong responses to microglial functions in LPS-challenged pure microglial cells. The most important pleiotropic beneficial effects of aspirin are 1) the robust inhibition of phagocytosis in activated microglia, 2) the inhibition of synthesis of pro-inflammatory cytokines combined with a very strong stimulation of anti-inflammatory cytokine production, and 3 ) the beneficial differential expression of a number of inflammation-related genes. Such beneficial regulation of microglial functions could point to the possible benefits of aspirin therapy in certain neuroinflammatory and neurodegenerative diseases.

\section{Author contributions}

This study is based on an original idea of KG. Designed the experiments: LH, LGP and KG. Performed the experiments: DK, IF, LZF and LH. Contributed unpublished reagents/analytic tools: LGP. Analyzed the data: DK, IF and LH. Wrote the paper: DK and KG. All authors have read and approved the final manuscript.

\section{Conflict of interests}

LGP holds an equity position in Avidin Ltd. that produces a high-throughput QPCR product (Rat immune panel) and has a service using the same kit (http://avidinbiotech.com/custom-pathways/).

\section{Acknowledgements}

This work was supported by grants to the University of Szeged from the Ministry of National Resources (GINOP_2.3.2-15-2016-00034 and GINOP_2.3.2-15-2016-00039) through the European Union Cohesion Fund and from the National Development Agency of Hungary (KMR_12_1_2012_0072). The funders had no role in the study design, the data collection and analysis, the decision to pub- lish, or the preparation of the manuscript. At the time of the experiments, D.K. was a Ph.D. student at the University of Szeged.

\section{References}

Ahmed, Z., Shaw, G., Sharma, V.P., Yang, C., McGowan, E., Dickson, D.W., 2007. Actin-binding proteins coronin-1a and IBA-1 are effective microglial markers for immunohistochemistry. J. Histochem. Cytochem. 55, 687-700.

Akiyama, H., Barger, S., Barnum, S., Bradt, B., Bauer, J., Cole, G.M., Cooper, N.R., Eikelenboom, P., Emmerling, M., Fiebich, B.L., et al., 2000. Inflammation and Alzheimer's disease. Neurobiol. Aging 21, 383-421.

Amann, R., Peskar, B.A., 2002. Anti-inflammatory effects of aspirin and sodium salicylate. Eur. J. Pharmacol. 447, 1-9.

Benveniste, E.N., Nguyen, V.T., O’Keefe, G.M., 2001. Immunological aspects of microglia: relevance to Alzheimer's disease. Neurochem. Int. 39, 381-391.

Berk, M., Dean, O., Drexhage, H., McNeil, J.J., Moylan, S., O'Neil, A., Davey, C.G., Sanna, L., Maes, M., 2013. Aspirin: a review of its neurobiological properties and therapeutic potential for mental illness. BMC Med. 11, 74

Block, M.L., Hong, J.S., 2005. Microglia and inflammation-mediated neurodegeneration: multiple triggers with a common mechanism. Prog. Neurobiol. 76, 77-98.

Brionne, T.C., Tesseur, I., Masliah, E., Wyss-Coray, T., 2003. Loss of TGF-beta 1 leads to increased neuronal cell death and microgliosis in mouse brain. Neuron 40, 1133-1145.

Campbell, L.A., Avdoshina, V., Rozzi, S., Mocchetti, I., 2013. CCL5 and cytokine expression in the rat brain: differential modulation by chronic morphine and morphine withdrawal. Brain Behav. Immun. 34, 130-140.

Cianciulli, A., Calvello, R., Porro, C., Trotta, T., Salvatore, R., Panaro, M.A., 2016. PI3k/ Akt signalling pathway plays a crucial role in the anti-inflammatory effects of curcumin in LPS-activated microglia. Int. Immunopharmacol. 36, 282-290.

Couper, K.N., Blount, D.G., Riley, E.M., 2008. IL-10: the master regulator of immunity to infection. J. Immunol. 180, 5771-5777.

Cuzick, J., Thorat, M.A., Andriole, G., Brawley, O.W., Brown, P.H., Culig, Z., Eeles, R.A., Ford, L.G., Hamdy, F.C., Holmberg, L., et al., 2014. Prevention and early detection of prostate cancer. Lancet Oncol. 15, e484-e492.

Eltayeb, S., Berg, A.L., Lassmann, H., Wallström, E., Nilsson, M., Olsson, T., Ericsson-Dahlstrand, A., Sunnemark, D., 2007. Temporal expression and cellular origin of CC chemokine receptors CCR1, CCR2 and CCR5 in the central nervous system: insight into mechanism of MOG-induced EAE. J. Neuroinflammation 4, 14.

Fabian, G., Farago, N., Feher, L.Z., Nagy, L.I., Kulin, S., Kitajka, K., Bito, T., Tubak, V., Katona, R.L., Tiszlavicz, L., Puskas, L.G., 2011. High-density real-time PCR-based in vivo toxicogenomic screen to predict organ-specific toxicity. Int. J. Mol. Sci. 12, 6116-6134

Franco, R., Fernández-Suárez, D., 2015. Alternatively activated microglia and macrophages in the central nervous system. Prog. Neurobiol. 131, 65-86.

Fuentes, E., Rojas, A., Palomo, I., 2016. NF-кB signaling pathway as target for antiplatelet activity. Blood Rev. 30, 309-315.

Fujita, H., Tanaka, J., Toku, R., Tateishi, N., Suzuki, Y., Matsuda, S., Sakanaka, M., Maeda, N., 1996. Effects of GM-CSF and ordinary supplements on the ramification of microglia in culture: a morphometrical study. Glia 18, 269-281.

Galea, E., Feinstein, D.L., 1999. Regulation of the expression of the inflammatory nitric oxide synthase (NOS2) by cyclic AMP. FASEB J. 13, 2125-2137.

Ge, Y.W., Lahiri, D.K., 2002. Regulation of promoter activity of the APP gene by cytokines and growth factors: implications in Alzheimer's disease. Ann. N. Y. Acad. Sci. 973, 463-467.

Gehrmann, J., Matsumo, Y., Kreutzberg, G., 1995. Microglia: intrinsic immunoeffector cell of the brain. Brain Res. Rev. 20, 269-287.

Ghosh, S., Wu, M.D., Shaftel, S.S., Kyrkanides, S., LaFerla, F.M., Olschowka, J.A., O’Banion, M.K., 2013. Sustained interleukin-1 $\beta$ overexpression exacerbates tau pathology despite reduced amyloid burden in an Alzheimer's mouse model. J. Neurosci. $33,5053-5064$

Gonzalez-Scarano, F., Baltuch, G., 1999. Microglia as mediators of inflammatory and degenerative diseases. Annu. Rev. Neurosci. 22, 219-240.

Graeber, M.B., 2010. Changing face of microglia. Science 330, 783-788.

Gresa-Arribas, N., Vieitez, C., Dentesano, G., Serratosa, J., Saura, J., Sola, C., 2012. Modelling neuroinflammation in vitro: a tool to test the potential neuroprotective effect of anti-inflammatory agents. PLoS One 7, e45227.

Gruol, D.L., Vo, K., Bray, J.G., 2014. Increased astrocyte expression of IL-6 or CCL2 in transgenic mice alters levels of hippocampal and cerebellar proteins. Front. Cell. Neurosci. 8, 234.

Hanisch, U.K., 2002. Microglia as a source and target of cytokines. Glia 40, 140-155.

He, G.L., Liu, Y., Li, M., Chen, C.H., Gao, P., Yu, Z.P., Yang, X.S., 2014. The amelioration of phagocytic ability in microglial cells by curcumin through the inhibition of EMF-induced pro-inflammatory responses. J. Neuroinflammation 11, 49.

He, Q., Li, Y.H., Guo, S.S., Wang, Y., Lin, W., Zhang, Q., Wang, J., Ma, C.G., Xiao, B.G., 2016. Inhibition of Rho-kinase by Fasudil protects dopamine neurons and attenuates inflammatory response in an intranasal lipopolysaccharide-mediated Parkinson's model. Eur. J. Neurosci. 43, 41-52.

Hickman, S.E., El Khoury, J., 2014. TREM2 and the neuroimmunology of Alzheimer's disease. Biochem. Pharmacol. 88, 495-498.

Higgs, G.A., Salmon, J.A., Henderson, B., Vane, J.R., 1987. Pharmacokinetics of aspirin and salicylate in relation to inhibition of arachidonate cyclooxygenase and antiinflammatory activity. Proc. Natl. Acad. Sci. U. S. A. 84, 1417-1420.

Hong, S., Beja-Glasser, V.F., Nfonoyim, B.M., Frouin, A., Li, S., Ramakrishnan, S., Merry, K.M., Shi, Q., Rosenthal, A., Barres, B.A., Lemere, C.A., Selkoe, D.J., Stevens, B., 2016. Complement and microglia mediate early synapse loss in Alzheimer mouse models. Science 352, 712-716. 
Hussain, M., Javeed, A., Ashraf, M., Zhao, Y., Mukhtar, M.M., Rehman, M.U., 2012. Aspirin and immune system. Int. Immunopharmacol. 12, 10-20.

Jaturapatporn, D., Isaac, M.G., McCleery, J., Tabet, N., 2012. Aspirin, steroidal and non-steroidal anti-inflammatory drugs for the treatment of Alzheimer's disease. Cochrane Database Syst. Rev. 2, CD006378.

Jones, K.A., Thomsen, C., 2013. The role of the innate immune system in psychiatric disorders. Mol. Cell. Neurosci. 53, 52-62.

Jung, H.W., Yoon, C.H., Park, K.M., Han, H.S., Park, Y.K., 2009. Hexane fraction of Zingiberis Rhizoma Crudus extract inhibits the production of nitric oxide and proinflammatory cytokines in LPS-stimulated BV2 microglial cells via the NF-kappaB pathway. Food Chem. Toxicol. 47, 1190-1197.

Kata, D., Gulya, K., 2014. Aspirin regulates the inflammatory responses of activated microglia. Poster No. C112. In: FENS Forum of Neuroscience. July 5-9, 2014, Milan, Italy. p. 219.

Kata, D., Földesi, I., Feher, L.Z., Hackler Jr., L., Puskas, L.G., Gulya, K., 2016. Rosuvastatin enhances anti-inflammatory and inhibits pro-inflammatory functions in cultured microglial cells. Neuroscience 314, 47-63.

Kettenmann, H., Hanisch, U.K., Noda, M., Verkhratsky, A., 2011. Physiology of microglia. Physiol. Rev. 91, 461-553.

Korneev, K.V., Atretkhany, K.N., Drutskaya, M.S., Grivennikov, S.I., Kuprash, D.V., Nedospasov, S.A., 2017. TLR-signaling and proinflammatory cytokines as drivers of tumorigenesis. Cytokine 89, 127-135.

Kreutzberg, G.W., 1996. Microglia: a sensor for pathological events in the CNS. Trends Neurosci. 19, 312-318.

Kroner, A., Greenhalgh, A.D., Zarruk, J.G., Passos Dos Santos, R., Gaestel, M., David, S., 2014. TNF and increased intracellular iron alter macrophage polarization to a detrimental M1 phenotype in the injured spinal cord. Neuron 83, 1098-1116.

Lee, J.K., Schuchman, E.H., Jin, H.K., Bae, J.S., 2012. Soluble CCL5 derived from bone marrow-derived mesenchymal stem cells and activated by amyloid $\beta$ ameliorates Alzheimer's disease in mice by recruiting bone marrow-induced microglia immune responses. Stem Cells 30, 1544-1555.

Li, H., Yoon, J.H., Won, H.J., Ji, H.S., Yuk, H.J., Park, K.H., Park, H.Y., Jeong, T.S., 2017. Isotrifoliol inhibits pro-inflammatory mediators by suppression of TLR/NF-kB and TLR/MAPK signaling in LPS-induced RAW264.7 cells. Int. Immunopharmacol. 45, 110-119.

Lim, S.T., Mocchetti, I., 2015. Pharmacological induction of CCL5 in vivo prevents gp120-mediated neuronal injury. Neuropharmacology 92, 98-107.

Lim, H.W., Park, J.I., More, S.V., Park, J.Y., Kim, B.W., Jeon, S.B., Yun, Y.S., Park, E.J., Yoon, S.H., Choi, D.K., 2015. Anti-neuroinflammatory effects of DPTP, a novel synthetic clovamide derivative in in vitro and in vivo model of neuroinflammation. Brain Res. Bull. 112, 25-34.

Long-Smith, C.M., Sullivan, A.M., Nolan, Y.M., 2009. The influence of microglia on the pathogenesis of Parkinson's disease. Prog. Neurobiol. 89, 277-287.

Lowry, O.H., Rosebrough, N.J., Farr, A.L., Randall, R.J., 1951. Protein measurement with the Folin phenol reagent. J. Biol. Chem. 193, 265-275.

Lue, L.F., Schmitz, C., Walker, D.G., 2015. What happens to microglial TREM2 in Alzheimer's disease: immunoregulatory turned into immunopathogenic?. Neuroscience $302,138-150$.

Lui, H., Zhang, J., Makinson, S.R., Cahill, M.K., Kelley, K.W., Huang, H.Y., Shang, Y., Oldham, M.C., Martens, L.H., Gao, F., Coppola, G., et al., 2016. Progranulin deficiency promotes circuit-specific synaptic pruning by microglia via complement activation. Cell 165, 921-935.

Lund, S., Christensen, K.V., Hedtjärn, M., Mortensen, A.L., Hagberg, H., Falsig, J., Hasseldam, H., Schrattenholz, A., Pörzgen, P., Leis, M., 2006. The dynamics of the LPS triggered inflammatory response of murine microglia under different culture and in vivo conditions. J. Neuroimmunol. 180, 71-87.

Luo, X.G., Chen, S.D., 2012. The changing phenotype of microglia from homeostasis to disease. Transl. Neurodegener. 1, 9 .

Martinez, F.O., Gordon, S., 2014. The M1 and M2 paradigm of macrophage activation: time for reassessment. F1000Prime Rep. 6, 13.

McGeer, P.L., McGeer, E.G., 2004. Inflammation and neurodegeneration in Parkinson's disease. Parkinsonism Relat. Disord. 10 (Suppl. 1), S3-S7.

McGeer, E.G., McGeer, P.L., 2010. Neuroinflammation in Alzheimer's disease and mild cognitive impairment: a field in its infancy. J. Alzheimers Dis. 19, 355-361.

McGeer, P.L., Kawamata, T., Walker, D.G., Akiyama, H., Tooyama, I., McGeer, E.G., 1993. Microglia in degenerative neurological disease. Glia 7, 84-92.

McGeer, P.L., Schulzer, M., McGeer, E.G., 1996. Arthritis and anti-inflammatory agents as possible protective factors for Alzheimer's disease: a review of 17 epidemiologic studies. Neurology 47, 425-432.

Medeiros, R., Prediger, R.D., Passos, G.F., Pandolfo, P., Duarte, F.S., Franco, J.L., Dafre, A.L., Di Giunta, G., Figueiredo, C.P., Takahashi, R.N., et al., 2007. Connecting TNF-alpha signaling pathways to iNOS expression in a mouse model of Alzheimer's disease: relevance for the behavioral and synaptic deficits induced by amyloid beta protein. J. Neurosci. 27, 5394-5404.

Medeiros, R., Kitazawa, M., Passos, G.F., Baglietto-Vargas, D., Cheng, D., Cribbs, D.H., LaFerla, F.M., 2013. Aspirin-triggered lipoxin A4 stimulates alternative activation of microglia and reduces Alzheimer disease-like pathology in mice. Am. J. Pathol. 182, 1780-1789.
Minagar, A., Shapshak, P., Fujimura, R., Ownby, R., Heyes, M., Eisdorfer, C., 2002. The role of macrophage/microglia and astrocytes in the pathogenesis of three neurologic disorders: HIV-associated dementia, Alzheimer disease, and multiple sclerosis. J. Neurol. Sci. 202, 13-23.

Moehle, M.S., West, A.B., 2015. M1 and M2 immune activation in Parkinson's Disease: foe and ally?. Neuroscience 302, 59-73.

Muzio, L., Martino, G., Furlan, R., 2007. Multifaceted aspects of inflammation in multiple sclerosis: the role of microglia. J. Neuroimmunol. 191, 39-44.

Neher, J.J., Neniskyte, U., Zhao, J.W., Bal-Price, A., Tolkovsky, A.M., Brown, G.C., 2011 Inhibition of microglial phagocytosis is sufficient to prevent inflammatory neuronal death. J. Immunol. 186, 4973-4983.

Ohsawa, K., Imai, Y., Sasaki, Y., Kohsaka, S., 2004. Microglia/macrophage-specific protein Iba1 binds to fimbrin and enhances its actin-bundling activity. J. Neurochem. 88, 844-856.

Orihuela, R., McPherson, C.A., Harry, G.J., 2016. Microglial M1/M2 polarization and metabolic states. Br. J. Pharmacol. 173, 649-665.

Phani, S., Loike, J.D., Przedborski, S., 2012. Neurodegeneration and inflammation in Parkinson's disease. Parkinsonism Relat. Disord. 18 (Suppl. 1), S207-S209.

Ransohoff, R.M., 2016. A polarizing question: do M1 and M2 microglia exist?. Nat. Neurosci. 19, 987-991.

Rottman, J.B., Slavin, A.J., Silva, R., Weiner, H.L., Gerard, C.G., Hancock, W.W., 2000 Leukocyte recruitment during onset of experimental allergic encephalomyelitis is CCR1 dependent. Eur. J. Immunol. 30, 2372-2377.

Schrijvers, E.M., Verhaaren, B.F., Koudstaal, P.J., Hofman, A., Ikram, M.A., Breteler, M.M., 2012. Is dementia incidence declining?: Trends in dementia incidence since 1990 in the Rotterdam Study. Neurology 78, 1456-1463.

Sharma, J.N., Yusof, A.P., 1998. Pro-inflammatory properties of the kallikrein-kinin system: potential for new drug therapy. Inflammopharmacology 6, 289-296.

Shimoyama, M., De Pons, J., Hayman, G.T., Laulederkind, S.J., Liu, W., Nigam, R., Petri, V., Smith, J.R., Tutaj, M., Wang, S.J., et al., 2015. The Rat Genome Database 2015: genomic, phenotypic and environmental variations and disease. Nucleic Acids Res. 43 (Database Issue), D743-D750.

Shin, W.H., Jeon, M.T., Leem, E., Won, S.Y., Jeong, K.H., Park, S.J., McLean, C., Lee, S.J., Jin, B.K., Jung, U.J., Kim, S.R., 2015. Induction of microglial toll-like receptor 4 by prothrombin kringle-2: a potential pathogenic mechanism in Parkinson's disease. Sci. Rep. 5, 14764.

Skuljec, J., Sun, H., Pul, R., Bénardais, K., Ragancokova, D., Moharregh-Khiabani, D., Kotsiari, A., Trebst, C., Stangel, M., 2011. CCL5 induces a pro-inflammatory profile in microglia in vitro. Cell. Immunol. 270, 164-171.

Smith, J.A., Das, A., Ray, S.K., Banik, N.L., 2012. Role of pro-inflammatory cytokines released from microglia in neurodegenerative diseases. Brain Res. Bull. 87, 10-20.

Stewart, W.F., Kawas, C., Corrada, M., Metter, E.J., 1997. Risk of Alzheimer's disease and duration of NSAID use. Neurology 48, 626-632.

Strauss, K.I., 2008. Antiinflammatory and neuroprotective actions of COX2 inhibitors in the injured brain. Brain Behav. Immun. 22, 285-298.

Streit, W.J., 2002. Microglia as neuroprotective immunocompetent cells of the CNS Glia 40, 133-139.

Sun, K.Y., Xu, D.H., Xie, C., Plummer, S., Tang, J., Yang, X.F., Ji, X.H., 2017. Lactobacillus paracasei modulates LPS-induced inflammatory cytokine release by monocyte-macrophages via the up-regulation of negative regulators of NF-kappaB signaling in a TLR2-dependent manner. Cytokine 92, 1-11.

Szabo, M., Gulya, K., 2013. Development of the microglial phenotype in culture. Neuroscience 241, 280-295.

Szabo, M., Dulka, K., Gulya, K., 2016. Calmodulin inhibition regulates morphological and functional changes related to the actin cytoskeleton in pure microglial cells. Brain Res. Bull. 120, 41-57.

Ueno, A., Oh-ishi, S., 2003. Roles for the kallikrein-kinin system in inflammatory exudation and pain: lessons from studies on kininogen-deficient rats. J. Pharmacol. Sci. 93, 1-20.

Vane, J.R., Botting, R.M., 2003. The mechanism of action of aspirin. Thromb. Res. 110, 255-258.

Wang, Y.P., Wu, Y., Li, L.Y., Zheng, J., Liu, R.G., Zhou, J.P., Yuan, S.Y., Shang, Y., Yao S.L., 2011. Aspirin-triggered lipoxin A4 attenuates LPS-induced pro-inflammatory responses by inhibiting activation of NF-kB and MAPKs in BV-2 microglial cells. J. Neuroinflammation 8,95

Woudstra, C., Lambert, D., Anniballi, F., De Medici, D., Austin, J., Fach, P., 2013. Genetic diversity of the flagellin genes of Clostridium botulinum groups I and II. Appl. Environ. Microbiol. 79, 3926-3932

Wu, Y., Wu, M., He, G., Zhang, X., Li, W., Gao, Y., Li, Z., Wang, Z., Zhang, C., 2012. Glyceraldehyde-3-phosphate dehydrogenase: a universal internal control for Western blots in prokaryotic and eukaryotic cells. Anal. Biochem. 423, 15-22.

Yang, J.M., Rui, B.B., Chen, C., Chen, H., Xu, T.J., Xu, W.P., Wei, W., 2014. Acetylsalicylic acid enhances the anti-inflammatory effect of fluoxetine through inhibition of NF- $\mathrm{kB}$, p38-MAPK and ERK1/2 activation in lipopolysaccharide-induced BV-2 microglia cells. Neuroscience 275, 296-304. 